\title{
Perspectives of High School Students in a Spanish Immersion Program
}

\author{
A Dissertation \\ Presented to \\ The Faculty of the Curry School of Education \\ University of Virginia \\ In Partial Fulfillment \\ of the Requirements for the Degree \\ Doctor of Philosophy \\ by \\ Lucy Welbourn Johnson, B.S., M.A.T.
}

May 2014 
(C) Copyright by

Lucy Welbourn Johnson

All Rights Reserved

May 2014 


\begin{abstract}
To function today amidst the societal, economic, and national security challenges of our interconnected world, American students need the ability to speak one or more languages other than English and to perform effectively in the respective cultures (Trilling \& Fadel, 2009). Foreign language educators have achieved more progress in the former than the latter, however; their insightful analysis of culture learning, along with that of interculturalists, has proved hard to "operationalize" (Klein, 2004).
\end{abstract}

This descriptive, qualitative study shows a way. Interview and focus-group data were collected from 27 native English-speaking, native Spanish-speaking, and heritage language students in a one-way, foreign-language immersion program at a large public high school in Virginia. A major finding of the study is that social interaction, as the determinant of comfort level and emotional support as well as the vehicle for linguistic and cultural interchange, played an essential role in the language and culture learning of the ethnically diverse study participants; vis-à-vis culture, they progressed from knowledge, to ever-wider experience and reflection on that experience, to a deeper level of culture learning.

Research has shown that students have the potential to develop advanced levels of target language proficiency in the formal classroom setting in high school foreign language immersion programs (Forrest, 2011); nonetheless, an authoritative study has yet 
to be conducted to support this claim. Similarly, while educators and interculturalists have identified the goals of culture learning — awareness of other cultures, greater crosscultural understanding, an ability to view one's culture of origin from an outsider's perspective — only a limited amount of educational research, of a general nature, has explored students' perspectives on their culture learning experiences (Paige, R. M., Jorstad, H. L., Siaya, L., Klein, F.M., \& Colby, J., 2003). This study breaks ground in the research literature by examining immersion students' beliefs about the experience of learning two languages and cultures. It contributes to what we know about culture teaching and learning in the fields of immersion education, bilingual education, and foreign / second language education, and thanks to the students' input, it offers a way to make culture learning "operational." 


\section{DEDICATION}

This dissertation is dedicated to my late husband, Charles McCoy Johnson, III, MD, who served as my initial inspiration for the pursuit of

this degree and my constant supporter

until his death. 


\section{ACKNOWLEDGEMENTS}

As this dissertation draws to a close, I owe a debt of gratitude to all those who walked with me on this journey, for without you this would not have been possible. I thank God Almighty for life and health, and for sustaining me throughout this voyage. The first steps along this path started in high school when I discovered a love for the French language and culture and included studying in a number of institutions of higher education, as well as experiencing languages and cultures in the field, both at home and abroad.

I offer my heartfelt thanks to the members of my dissertation committee for their time, unfailing support, and patience. Hal Burbach was my advisor when I started this degree in Social Foundations of Education and served as the Chair of my dissertation committee until his retirement. I thank him for opening the doors of the program to me, for supporting me during my studies. I am grateful to Hal for his ability to see the big picture when examining issues in education. It was also he, who advised me to ask the methodologist on my committee, Bob Covert, to be his successor. As my advisor, Bob consistently encouraged and supported me, keeping me focused by setting short-term and long-term goals, which on several occasions seemed unattainable. His voice of experience prepared me mentally to believe that I would finish, reminding me that a dissertation is written one word at a time. 
I express gratitude to the members of my committee: Diane Hoffman, Ruth Ferree, and Karen Ford, all of whom share with me an academic and professional background in languages and cultures as well as a passion for them. My thanks are extended to Diane for offering brilliant insights into the central themes in my study and for urging me to delve more deeply into the data analysis process. Ruth contributed her experience as a foreign language educator and helped me at every step of the study, starting with the design phase. I am grateful to her for questioning my findings, challenging me to support them sufficiently with evidence from the study participants. I also want to express my appreciation to Karen Ford, who joined the committee prior to my defense. Her careful attention to the manuscript was greatly appreciated as it yielded the discovery of previously overlooked problems in grammar, from missing punctuation to incomplete sentences! Additionally, her knowledge of the literature related to English Language Learners, more specifically to Generation 1.5 students, provided a noteworthy dimension to my analysis of the native Spanish-speakers and heritage language learners in my study.

My professors in Social Foundations of Education, Hal Burbach, Eric Bredo, Diane Hoffman, and Jennings Wagoner, contributed greatly to my intellectual formation as they introduced me to the world outside the classroom and to the bigger picture in education that I had not considered previously. To them, I express my gratitude. Their breadth of knowledge and passion for their respective fields of expertise sparked my intellectual curiosity and gave me a strong foundation on which to build my research. The Social Foundations community, to which professors and students belonged, was indeed 
very special. I am saddened by the death of Jennings Wagoner, who was the consummate scholar of the History of American Education. His spirit lives on in all those of us who were his students.

To the Curry School of Education faculty members who were my professors outside of the program, I express my thanks and appreciation for their contribution to my intellectual formation. My gratitude also goes out to the professors for whom I conducted research and to other faculty members who helped me along the way. I am especially grateful for the assistance of Dr. Sandra Lopez-Baez, a former faculty member at the Curry School of Education, whose knowledge of the field of immersion education and cultural, ethnic, and linguistic background as a native Spanish-speaker formed the basis of the interview protocol for my study. I express my gratitude to the administrators and staff at the Curry School for their support along this journey. I thank my peers in Social Foundations and other fellow classmates for the storms we have weathered and the times we shared together both intellectually and personally.

Great appreciation is expressed as well to the study participants for sharing with me their time and insights into the Immersion experience in their program, to the center director and faculty members, to the school principal, and to the members of the school division team that reviewed and approved my study and allowed me access to the research site. 
I have reserved this final section of acknowledgements for the members of my family, who have been with me throughout this journey. The saying "Life happens" holds meaning for our family during my doctoral studies as we celebrated events such as college, masters' degrees, and law school graduations, 3 weddings, the catastrophic illnesses of my husband and my father, the deaths of my husband, my dad, and my uncle, and the birth of 6 grandchildren. To my late husband, Charlie, I express my deep gratitude for his unfailing love, support, and patience. He read the drafts of papers, cooked gourmet meals, and quietly, consistently urged me to finish my dissertation. To my parents, Edward Hambleton Welbourn and Nancy Parker Welbourn, I owe my deep appreciation for their support throughout my life, but most especially in high school and college, when others doubted my intellectual abilities. I express thanks for the support of my late parents-in-law, Charles McCoy Johnson and Jane Ingling Johnson, EdD, whose doctoral degree from Columbia University served as an inspiration to me. I also recognize the other members of our families for their contributions along the way on this journey.

I offer my utmost gratitude to my children, Marie, Charles, and Andrew, my son-inlaw, Matt, my daughters'-in-law Kate and Keller for their support and love and for their precious gifts of new life: our five grandsons and one granddaughter. To my grandsons, Parker, Grayson, Cole, Caleb, and Jonah, and to my granddaughter, Caroline, who have brought immeasurable joy to the family; I offer a challenge to follow the paths of their 
great grandmother, their grandfather, and their grandmother in pursuit of a doctoral degree. 
TABLE OF CONTENTS

Page

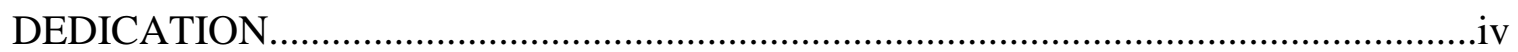

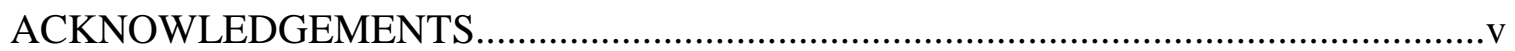

\section{CHAPTERS}

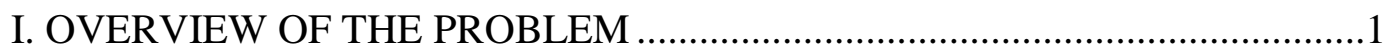

Rationale for Studying Languages Other Than English .......................................1

Rationale for the Immersion Context: Why Immersion Education? ......................3

Rationale for the Role of Social Interaction in Language and Culture Learning .7

Statement of the Problem.................................................................................

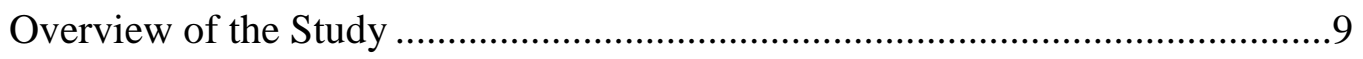

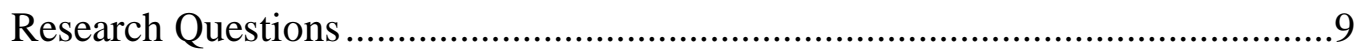

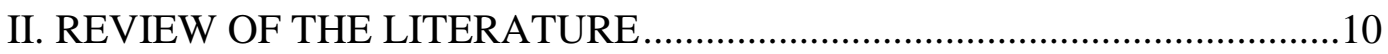

Second Language Acquisition Studies.........................................................................

The Developing System ..............................................................................11

The Nature of the Experience of Acquiring a Second Language .......................12

Immersion Education Programs.................................................................................

Two-way Immersion Programs.....................................................................16

Foreign Language (One-way) Immersion Programs ………...............................17

Social Interaction in Two-way and Foreign Language Immersion Programs 
Social Status and Language Status .........................................................19

Two-way Immersion Studies ................................................................22

Foreign Language (One-way) Immersion Studies .....................................28

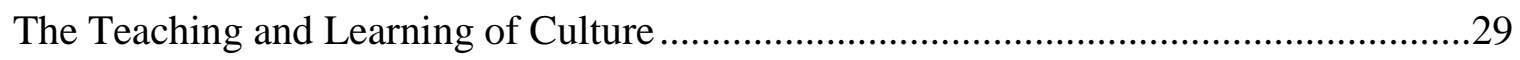

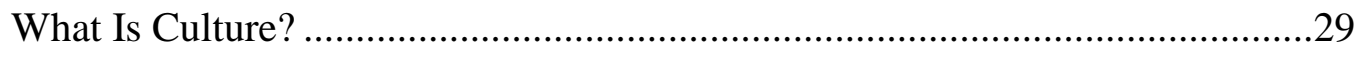

Defining Cross-cultural Awareness and Cross-cultural Understanding .............32

Culture Teaching and Learning in Foreign Language Education ....................................35

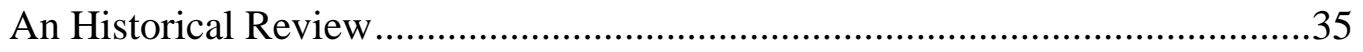

Culture Goals in Immersion Education......................................................44

Studies on Culture Teaching and Learning in Immersion Education ................43

Culture Teaching: What Limits?..........................................................47

What Approach to Culture Teaching? ......................................................52

Implications for Research Questions ..................................................56

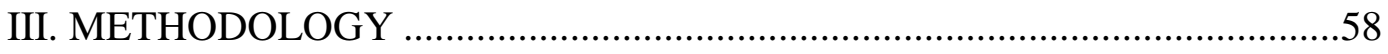

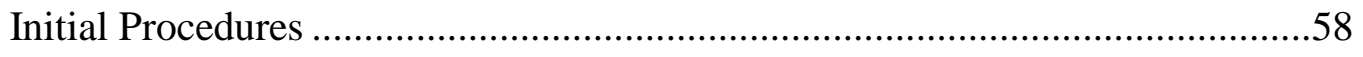

Data Collection Methods ......................................................................60

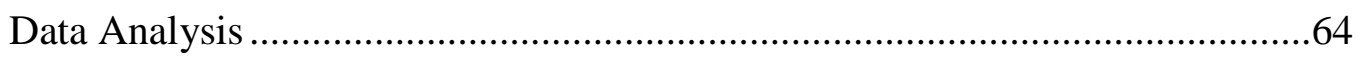

The Validity of the Data …....................................................................66

Researcher-as-Instrument Statement ..................................................68 
IV. FINDINGS (PART I): PERSPECTIVES OF SPANISH IMMERSION HIGH SCHOOL STUDENTS ON LANGUAGE DEVELOPMENTAND ON

SOCIAL INTERACTION WITHIN THE IMMERSION FAMILY.

Students' Backgrounds .73

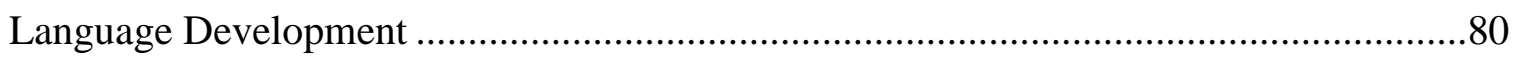

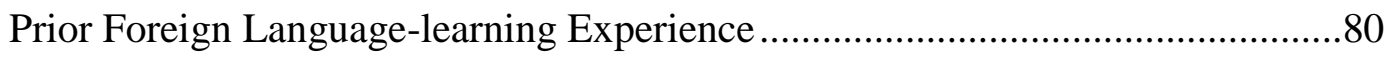

The Communicative Aspect: The Initial Immersion Experience ........................81

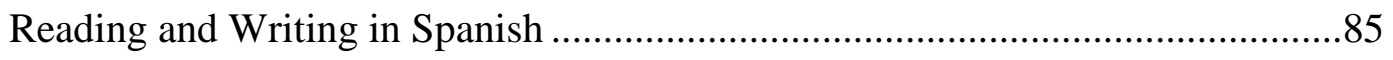

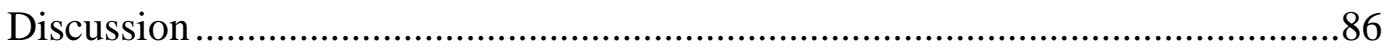

Mastering Academic Content in Spanish.....................................................8

Becoming Proficient in Spanish............................................................97

Communicating in Spanish in the Local Community ....................................100

Communicating with People in a Spanish-speaking Country ............................114

Social Interaction: The Immersion Family ......................................................119

The Immersion Community "Family" at Dover High School: Group Cohesion /

Support Network of Immersion Peers and Teachers

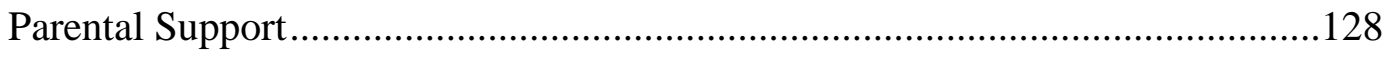

Evidence of Academic Engagement ....................................................... 129

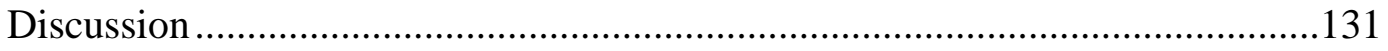

V. FINDINGS (PART II): PERSPECTIVES OF SPANISH IMMERSION HIGH SCHOOL STUDENTS LEARNING ABOUT AMERICAN CULTURE AND THE CULTURES OF THE SPANISH-SPEAKING WORLD .........................134

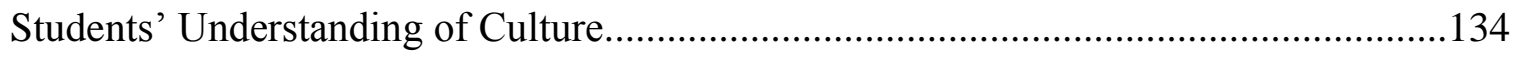

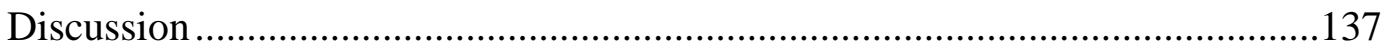


Students' Perspectives on American Culture.

Learning about the Cultures of the Spanish-speaking World within the Immersion Program.

Knowledge

Experience.

Learning about Aspects of Cultures through Experiences in the Local Community

Experience

Experiencing the Cultures of the Spanish-speaking World While Abroad

Themes

Transformation: Changing Cultural Perspectives

Discussion and Conclusion

Immersion Students' Plans after High School

VI. CONCLUSIONS AND IMPLICATIONS FOR FURTHER RESEARCH ..223

Second Language Acquisition Studies..... .224

The Developing System .224

The Nature of the Experience of Acquiring a Second Language ..... .226

Foreign-language (One-way) Immersion

Social Interaction in Two-way Immersion and Foreign Language Immersion Programs

Language Status .229

The Role of Social Interaction in L2 Acquisition and Culture Learning. .235 
Student Friendships .237

The Teaching and Learning of Culture 238

Culture Terms Revisited .240

Students' Awareness of Basic Culture Notions

What Culture is "Taught" at Dover?

The Extracurricular Experiences in Culture Learning in the Local Community and Abroad.

The Role of Service Learning .246

The Culture Learning Process: Culture-general and Culture-specific Content ...247

Review of Research Questions .248

Question One: Are There Benefits of the Immersion Program and the Immersion Experience for Students? .248

Question Two: Does the Setting Enhance Culture Learning? .255

Question Three: What Has Been Learned from the Students That Has Not Been Addressed in the Research Literature? .259

Implications for Further Research .261

Implications for Teachers, for School Districts, and for the Foreign Language Curriculum.

Conclusion: The Dover Spanish Immersion Program and the 5 Cs of the ACTFL National Standards .268

The Dover Curriculum and the $9^{\text {th }}$ and $10^{\text {th }}$-Grade Experience .269

The Dover Curriculum and the $11^{\text {th }}$ and $12^{\text {th }}$-Grade Experience .270

BIBLIOGRAPHY .273

APPENDICES .292 
Appendix A: IRB Documents.

Appendix B: Interview and Focus Group Questions .

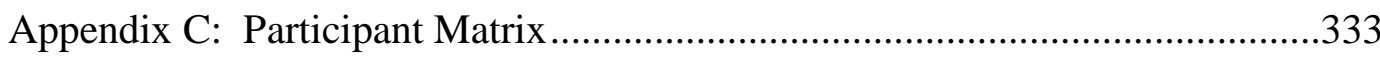

Appendix D: Dover High School Spanish Immersion Program Goals and Content.. 


\section{OVERVIEW OF THE PROBLEM}

\section{Rationale for Studying Languages Other Than English}

In American education today, students need to develop the essential skills and knowledge that will enable them to be successful, both personally and professionally, during their adult lives in the present-day world. Essential skills for $21^{\text {st }}$-century citizenship include the ability to speak one or more languages other than English and to perform appropriately and effectively in the respective cultures (Trilling \& Fadel, 2009). Some language educators argue that the global nature of business and the linguistic exigencies of national security and international diplomacy have created the context that has made proficiency in one or more languages other than English, with concomitant cross-cultural understanding, an urgent priority for American education (Rhodes \& Pufahl, 2009). Another leader in education extends this argument further, saying that "understanding cultures other than our own has become necessary not only for personal enrichment and good citizenship but for our survival as a nation" (Duderstadt, as cited in Bok, 2009, p. ix). Additionally, electronic media have greatly facilitated communication with people throughout the world, making linguistic and cultural skills in other languages even more valuable assets to possess (Christian, 2008). On a governmental level, the Department of Education identified the importance of proficiency in other languages for "personal, educational, economic, and national security" when 
it launched the President's National Security Language Initiative (Lenker \& Rhodes, 2007, p. 3).

Traditional K-12 foreign language education in the United States has not been structured to achieve this objective, however. At the high school level, for example, students typically take one course per year for two or three years. This amount of instruction time and the length of the course of study are inadequate to becoming proficient in a second language (L2); second-language skills take time to develop, and a great deal of meaning-based input in the target language (TL) is required (VanPatten, 2003). Consequently, students tend not develop high levels of proficiency in the TL (Forrest, 2011). The result is a mismatch between the goals of L2 proficiency and the means to reach them, based on evidence from second language acquisition (SLA) research (VanPatten, 2003).

The same is true of culture. In classroom learning, the target language is the focus of - and constitutes the content of--instruction as students develop their rudimentary second-language skills. Research has shown that the cultural content of these classes tends to be superficial and factually based (Paige, R.M., Jorstad, H.L., Siaya, L., Klein, F., and Colby, J., 2003), giving students shallow academic knowledge about the culture, rather than deeper awareness and understanding. Overall, students do not acquire linguistic and cultural skills that they could apply as adults in the workplace or in their personal lives, even though these skills would serve them well throughout their lives. American schools have the responsibility to equip youth with all the skills necessary to be successful and productive citizens (Met, 2001). Schools are shirking their responsibility to this generation of youth by failing to offer them the opportunity to study other 
languages and cultures beginning at an early age and to develop an in-depth understanding of the target cultures. The status of L2 learning and culture learning in the U.S. suggests the need to further explore approaches that are potentially more effective.

\section{Rationale for the Immersion Context: Why Immersion Education?}

The concept of the immersion context in the field of second language acquisition refers to an intensive exposure to the target language (TL). One common context is the study abroad model, where students live in a country where the TL is spoken and where they use their L2 exclusively for all communication, both formal and informal. This is an example of a total immersion context. In a variation of this total immersion model, L2 learners participate in an intensive course in the TL in an academic setting, such as a college or high school, in their home country. Although they are expected to speak the language exclusively, the cultural context is not authentic.

The concept of immersion in the formal settings of elementary and secondary education offers intensive instruction in the target language, when compared to traditional foreign language instruction, is more accurately called partial-immersion because a portion of the instructional day is spent in English. Immersion education, or dual language education, is a promising alternative instructional approach (Howard, Sugarman, \& Christian, 2003) in which students are educated in two languages: the majority language, such as English in the U.S., and a minority language, such as Spanish in the U.S. (Fortune \& Tedick, 2008). Immersion programs have established the dual goals of academic achievement and a high level of proficiency in both languages (Fortune \& Tedick, 2008, Tedick, Christian, \& Fortune, 2011). In these programs, 
language and content are integrated because the minority language is the medium of instruction for academic content. Evidence from research on academic performance and second language acquisition in immersion programs has shown that the most effective way to learn a language is by communicating in it in (Genesee \& Lindholm-Leary, 2013) "purposeful social and academic contexts" (Snow, Met, \& Genesee, 1989, p. 20). Immersion students do excel academically and reach high levels of L1 and L2 proficiency on the elementary school level (Fortune \& Tedick, 2008; Genesee \& Lindholm-Leary, 2013). It must be noted that the L2 proficiency research data apply to elementary school students and there are no known authoritative studies on L2 proficiency for students in high school level programs. Nonetheless, the conditions (see discussion under VanPatten, 2003 in the Literature Review) are present in foreign language immersion high school programs for students to have the potential to reach high levels of proficiency in their L2.

Immersion education distinguishes itself from the traditional approach to foreign language instruction in the amount of time (sometimes called time on task) (Genesee, 2008, p. 36) that students spend in instruction in the TL. This additional exposure over a protracted period of time (four to twelve years, depending upon the type and duration of the program) has produced positive linguistic outcomes (Lindholm-Leary, 2001; Genesee, 2008). Although the research literature has documented students' L2 proficiency through standardized tests (Fortune \& Tedick, 2008), no known studies examine the process of acquiring a second language from the students' own perspective. This study begins to address this gap. 
The culture goal for students in immersion programs, "increased cultural awareness" (Fortune \& Tedick, 2003, retrieved from http://www.cal.org/resources/digest/0304Fortune.html ), has proven much more difficult to attain than the linguistic goal; incorporating culture goals is an important issue which remains unrealized in immersion education in the United States (Lyster, 2007; Met \& Lorenz, 1997). The question of how students make sense of the cultures in which they are schooled is absent from the empirical literature. This study begins to fill in this gap as well.

In the United States, $75 \%$ of the immersion programs are located in elementary and middle schools (Center for Applied Linguistics, 2011, retrieved from http://www.cal.org/resources/immersion/ ). A total of 448 are foreign language immersion programs and 422 are known two-way immersion programs in the U.S. On the secondary level, there are far fewer TWI programs for various reasons including the organization of the school, curricular issues, the articulation of programs from one level to the next, and the existence of qualified teachers, among others (de Jong \& Bearse, 2011, p. 105). For the foreign language immersion programs on the secondary level, some of the same reasons may explain the smaller number of programs. The success of this model for SLA stems from the amount of instructional time that students spend in their second language (L2). In elementary school immersion programs, including grades $\mathrm{K}-5 / 6$, students receive instruction in the minority language for at least $50 \%$ of their instructional day, up to a maximum of $90 \%$ (Lindholm-Leary, 2001). Rather than being the focus of instruction, the minority (target) language is the language of instruction for content-area subjects such as math, science, world history, or physical education, while 
English is the language of instruction for the other content areas (Fortune \& Tedick, 2008). By the end of elementary school, students have established a firm base of linguistic proficiency in both their native language (L1) and their L2.

Immersion programs on the high school level have been defined by Fortune and Tedick (2008) as those that offer two or more content area subjects taught in the minority language. The immersion approach remains a strong model for SLA on the secondary school level, as research has documented, although the percentage of instruction in English increases incrementally through middle school and high school, while the percentage of instructional time in the minority language decreases.

Each of these programs offers students a unique opportunity to achieve advanced levels of L2 proficiency and cultural awareness (Fortune \& Tedick, 2008; Tedick, Christian, \& Fortune, 2011). Although the cultural aspect may be marginalized (Lange \& Paige, 2003; Wesely, 2009), many programs feature a cultural component (Carr, 2003; Johnson, 2003; Lake County website (pseudonym); Henrico County website accessed 3/28/2014, (http://teachers.henrico.k12.va.us/specialist/WLweb/ImmCenter/curriculum.htm ). Immersion students do develop some cross-cultural knowledge about the target culture through academic content and through an experiential component that involves interactions with members of the TL speech community (personal communication with the director of the Spanish Immersion Center at Dover High School (pseudonym), 6/18/2010). The literature review in chapter II summarizing the relevant empirical research from two-way immersion and foreign language immersion programs shows that the research on students' experiences with culture is almost non-existent. The present 
study responds to this gap, focusing on a high school foreign language immersion program.

\section{Rationale for the Role of Social Interaction in Language and Culture Learning}

The language and culture learning process involves cognitive, affective, and behavioral components (Paige et al., 2003). Language is socially constructed within a particular cultural context, and the meaning of words is therefore also constructed within a specific cultural context (Holme, 2002). Social interaction thus plays an integral role in the second language and culture learning process. Research shows that successful SLA involves social interaction (see VanPatten, 2003) in which L2 learners interact with each other, with their teacher, and with members of the TL speech community.

The culture learning process necessarily involves the same social interactions. Feedback is essential to it; students test out their understanding of effective and appropriate communication and behavior in the TL with these same interlocutors (conversation with Eric Bredo, 4/10/2010). In addition, the immersion education context tends to afford students greater opportunities to use their L2 for authentic communication in multiple contexts outside of the classroom. This study examines, among others, immersion students' experiences with the cultures of the local Spanish-speaking community as they interact with its members. 


\section{Statement of the Problem}

Little is known about high school foreign language immersion students' experiences with learning about the target culture. Instead, scholars in the field of second language acquisition have theorized about the cultural goals and benefits of learning a second or other language. Students have the potential to gain insights into their home culture and the target culture (Kramsch, 1993; Galloway, 1999; Byram, 1988). They may also develop cross-cultural awareness and understanding, and open-mindedness vis-à-vis other cultures (http://www.kwintessential.co.uk/cultural-services/articles/cross-culturalunderstanding.html , accessed 3/3/2014). Immersion programs themselves (both foreign language immersion and two-way immersion) have stated goals which include crosscultural understanding and respect for and appreciation of other cultures (Genesee, 2007, Retrieved from http://harvest.alpineschools.org/wpcontent/uploads/2013/01/TopTenFindingsUtahspanishdualimmersion.pdf\%E2\%80\%9D.p

df ), but no empirical studies focus on how student participants conceive of cross-cultural awareness or cross-cultural understanding, creating a gap between the theoretical goals proposed by scholars and educators and evidence from actual classrooms. The present one, a descriptive, qualitative study of students' perspectives on culture learning in immersion education opens a new thread in the field of immersion education, giving immersion researchers and teachers a new perspective on their programs and an additional way to improve them.

Although this study seeks to understand how students participating in an immersion program make sense of another culture, it also suggests an alternative for the traditional model of culture teaching within foreign language (FL) education. The insight 
gained may also have implications for a wider audience in American education in general in an era when many classrooms are culturally and racially diverse.

\section{Overview of the Study}

Chapter II reviews four related areas of the literature: second language acquisition (because of its integral relationship with culture teaching and learning); immersion education; the role of social interaction; and culture learning and teaching itself. The third chapter begins with a discussion of the qualitative research design and its suitability as a research method for this exploratory study. The study procedures, from site selection to sample population selection, are then discussed, along with data collection and data analysis. Chapter IV and V analyze and discuss the findings of the study, while chapter VI proposes an interpretation of the findings and their relationship to the previously existing literature. Finally, it discusses the implications of the research, some recommendations for future studies, and the conclusions.

\section{Research Questions}

The following research questions will be explored in Chapter VI:

Research Question 1: Are there benefits of the Immersion Program and the Immersion Experience for Students?

Research Question 2: Does the setting enhance culture learning?

Research Question 3: What has been learned from the students that has not been addressed in the research literature? 


\section{REVIEW OF THE LITERATURE}

This study seeks to understand a phenomenon that is largely unknown in the empirical literature, namely students' perspectives on their language development and on American culture and the cultures of the Spanish-speaking world. It combines four areas of the research: second language acquisition, immersion education, social interaction, and culture learning and teaching. The research literature on second language acquisition (SLA) is robust, and scholars generally agree about some of the factors that promote the process of acquiring a second or other language in the formal classroom setting and in the naturalistic setting. Immersion education is a relatively young but growing field whose two main branches are two-way immersion education and foreign language immersion education (also called one-way immersion). Although the two-way immersion literature is the more developed of the two, its cultural aspect is in its infancy (see Bearse \& de Jong, 2008, for two-way immersion; Wesely, 2009, for one-way immersion), while there is no known foreign language immersion literature on the topic of culture on the high school level. Social interaction has a well-developed literature, and various theories exist within educational theory and educational psychology, but few studies have explored the role of social interaction in language and culture learning and acquiring skills in a second or other culture. Culture teaching and learning have generated abundant theoretical literature for over fifty years, but the empirical literature is much less robust. Research has focused on the culture teaching side and has virtually ignored the culture-learning side, most especially students' experience. Moreover, in the realm of culture, although 
scholars (Paige et al., 2003; Lange \& Paige, 2003) have argued that the cultural component of a language is central to SLA, the empirical literature shows that culture teaching and learning have been marginalized in the classroom.

\section{Second Language Acquisition Studies}

To gain an understanding of the effectiveness of immersion education as a model for second language acquisition, it is first necessary to examine what the theoretical literature, based on empirical research, says about the processes that contribute to reaching advanced levels of proficiency in a second language.

\section{The Developing System}

Research supports the notion that acquiring proficiency in another language involves the gradual development of an implicit linguistic system that evolves over time as the L2 learner processes the language (VanPatten, 2003). The developing system's parts, including "comprehension, speech production, learning, and social interaction" (p. 44), combine to serve the shared goal of communication. In contemporary SLA circles (VanPatten, 2003), the concept of input is widely accepted to be at the heart of the development of this linguistic system. This term is defined as "the language that a learner hears (or reads) that has some kind of communicative intent" (p. 25). Input is both conversational and non-conversational. In the former, two or more L2 speakers interact for the purpose of conveying a message. Examples of the latter are lectures or radio and television programs, where the $\mathrm{L} 2$ learner may not actively interact with the speaker(s). The research literature provides evidence for the vital role of input in the 
language acquisition process; all proficient speakers of an L2 have been exposed to large amounts of linguistic input (VanPatten, 2003). In the immersion setting, evidence from L2 learners in elementary schools confirms that they too successfully reach advanced levels of proficiency in their L2, making immersion the most effective instructional approach for language learning (Fortune \& Tedick, 2008; Genesee, 1987; Lyster, 2007). Therefore the more input the better, provided that it is in the form of meaning-based, spoken interactions of an L2 learner with a teacher, L2 peers, or native speakers. The input that L2 learners receive must be comprehensible in terms of their linguistic development and be contextualized to foster comprehension. L2 learners also need as many interactions as possible over a long period of time to reach advanced levels of proficiency. The research literature also provides evidence of the role of output, defined as "the language that the learner produces" (VanPatten, 2003, p. 62). All output needs to be meaning-based, unlike phrases repeated verbatim from a teacher's model, as in a repetition drill.

\section{The Nature of the Experience of Acquiring a Second Language}

This study assumes that acquiring proficiency in a second language is about more than acquiring linguistic skills. As L2 learners become familiar with the similarities and differences between their native language (L1) and their L2, they "develop insight into the nature of language and the concept of culture and realize that there are multiple ways of viewing the world" they realize that they cannot truly master the language until they have also mastered the cultural contexts in which the language occurs" (ACTFL, 1999). Many language educators and scholars share this belief in the link between SLA and the 
acquisition of a second culture, while others focus on SLA in isolation (FL Listserv entries over 2-3 years; personal communication with Ruth Ferree, 11/8/2010). In fact the main theories of SLA see the cultural aspect of a language as "irrelevant" to the process of acquiring another language (Andrawiss, 2004, p. 67). VanPatten (2003) does not even mention culture as being part of the language acquisition process.

When students acquire L2 proficiency, however, they learn that there are different ways of communicating a message that are specific to the TL. Expressions, grammatical structures, and vocabulary differ from one language to another. Students learn that language and culture have an effect on each other and that "meanings are not fully shared between languages" (Holme, 2002, p. 222). Students therefore learn that speaking another language involves more than "plugging" new vocabulary into their "existing syntactic structures" (Mantle-Bromley, 1992, p. 117). When they gain insight into the nature of language learning, they are learning to rise above their "linguistic naïveté." Another distinction between languages, as Holme (2002) suggests, is that "language(s) divide(s) up the territory of meaning" (p. 209). Holme's example from an adult English as a second language class illustrates this concept and shows the engrained cultural assumptions and biases that are embedded in each language. Students were asked to think of and describe an early childhood memory and to say what sounds they heard and what they smelled. Here is one student response: "I was walking with my mother. There was a path. The path was very long and I was tired. I wanted to go into my mother's back (219)." The native English-speaking professor interpreted the into as a grammatical error, which indicated that the student had confused the meanings of into with onto. The student, however, explained a cultural practice: mothers carried their 
children "in the back." This example illustrates that it is important for L2 students to grasp the significance and culturally accurate meanings of words in the TL (Trompenaars, 1994) in order to reach advanced levels of proficiency. In sum, one of the most important aspects of acquiring a second or other language is the integral link that exists between a language and its culture. Nonetheless, the main SLA theories do not consider culture to play a role in the acquisition of a language.

\section{Immersion Education Programs}

An overview of immersion education was provided in chapter I: what it is, its preponderant location in elementary and middle schools, and the varying use of the minority language as the language of instruction during the school day. As previously noted, the percentage of instruction in English increases, while the percentage of the minority language decreases, in the secondary school-level programs in grades 6/7-8. Immersion programs on the high school level are characterized by a minimum of two content area subjects taught in the minority language. Fortune \& Tedick (2008) have identified their goals to be: academic achievement and bi- or multilingualism, in addition to "literacy in at least two languages and enhanced levels of intercultural sensitivity" (p. 10). They represent an effective model for SLA, bearing out the SLA theory previously discussed (VanPatten, 2003; Ellis, 2008). Since immersion students learn their L2 through academic content, the input that they receive has a communicative intent. For this reason, it is also contextualized and comprehensible. They also receive a great deal of input over a protracted period of time because of their extended time on task —all 
factors that have been shown in the research literature to promote advanced levels of proficiency in an L2 (VanPatten, 2003; Ellis, 2008).

In the field of immersion education, students are partially or totally immersed in the language learning process, yet that characteristic alone does not constitute an immersion program in this study. For example, programs for English language learners (ELL), where the sole language of instruction is English, have been called "structured English immersion" or "English immersion" (Fortune and Tedick, 2008), and technically, they could fall into that category. Scholars in immersion education, however, caution that these programs should not be compared to one-way or two-way immersion programs because of their subtractive nature, where English replaces the L1 of minority language students, who receive little or no support in their L1 (Fortune and Tedick, 2008). As a result, their L1 literacy development is negatively affected, and in turn so is their L2 literacy (Amato, 2012; Roth, 2006; Minami \& Ovando, 2004). Other factors that negatively affect ELL students are related to their socio-economic status (Bray, 2007), their minority language status (Bray; also the section in this chapter), and socio-cultural isolation from majority language students and teachers (Amato, 2012; Roth, 2006; Bray, 2007). In addition, the findings from studies by Bray and Roth showed that ELL programs for low SES Hispanic students did not stress academic achievement. In contrast to those findings, other studies of students from similar backgrounds showed that adequate support from teachers, parents, and administrators, in collaboration with each other, was a very important factor for ELLs in terms of their "linguistic, academic, cognitive, and socio-cultural development" (Roth, 2006; Amato, 2012). 


\section{Two-way Immersion Programs}

TWI programs offer a unique experience in American education, since their students are educated in two languages and two cultures within the same classroom for the elementary school years and throughout the secondary school years as well, for those programs that include the secondary school option. The first TWI program was started at Coral Way Bilingual Elementary School in Miami, Florida, in 1963 (Christian, 1996; Bearse \& de Jong, 2008). In the United States, two-way immersion programs are overwhelmingly located in elementary schools, comprising $79 \%$ of the 300 plus existing programs (Center for Applied Linguistics, 2011.

http://www.cal.org/resources/immersion/). There are 13 programs that continue through K-8 or K-12 and only 11 public high school programs.

The main benefits of elementary TWI programs have been documented in the empirical literature. Language majority and language minority students alike are successful academically across all subjects and reach high levels of proficiency and literacy in both languages (Christian, 1996; Lindholm-Leary, 2001; Thomas \& Collier, 1997, 2002; Howard, Sugarman, \& Christian, 2003; Genesee \& Lindholm-Leary, 2013). Students also develop "positive cross cultural attitudes and self-esteem" (Christian, 1996, p. 73).

Although these programs offer many advantages to both native English speakers (Lindholm-Leary, 2001; Howard, Sugarman, \& Christian, 2003) and non-native English speakers, some researchers have raised questions about various issues related to program design and implementation (Mora, Wink, \& Wink, 2001; Bearse \& de Jong, 2008; de 
Jong \& Howard, 2009; Montone and Loeb, 2000; Howard et al., 2003), socioeconomic status (SES) (see Valdés, 1997; Delgado-Larocco, 1998), the status of the minority language and its culture (Amrein \& Peña, 2000; Freeman, 1996; Howard et al.; de Jong \& Howard, 2009; Delgado-Larocco, 1998; Carrigo, 2000; Hadi-Tabassum, 2002), the status of the majority language and culture (Amrein \& Peña, 2000; Delgado-Larocco, 1998; Carrigo, 2000; Hadi-Tabassum, 2002; Alanís, 2000; McCollum, 1994), and equality of educational opportunity (Valdés, 1997; Bearse \& de Jong, 2008; de Jong \& Howard, 2009; Lindholm-Leary, 2001). Findings from several studies about language status issues in TWI programs will be discussed in the section on social interaction.

\section{Foreign Language (One-way) Immersion Programs}

The earliest foreign language immersion programs in this country were Spanish immersion programs in California (Wesely, 2009). Currently, there are 448 known foreign language immersion programs in public schools in the United States, with approximately $75 \%$ of them residing in elementary schools (Lenker \& Rhodes, 2007; Center for Applied Linguistics, 2011, Retrieved from http://www.cal.org/resources/immersion/ ). Foreign language immersion programs on the high school level are rare in the United States, with approximately 41 programs listed in the Center for Applied Linguistics directory (2011). Some high school level programs are continuations from elementary and middle school, while others begin in the $9^{\text {th }}$ grade for students with no prior immersion experience (Barr-Harrison, 1999, 2003). These programs offer language majority students linguistic benefits similar to those two-way immersion programs (Fortune \& Tedick, 2008). 


\section{Social Interaction in Two-Way and Foreign Language Immersion Programs}

The conceptual framework of this study traces the connection between a language and its culture, so inextricably linked in the second language acquisition process, to the need to integrate the two facets of a language and culture in immersion education. As L2 students learn a language and its culture in immersion education, it is a developmental process that involves the interaction of students with their peers, their teachers, and members of a TL speech community, whence this closer look at the literature of social interaction.

Social interaction is an essential and integral component of both SLA and the teaching and learning of culture because L2 students need feedback from members of the target language as to whether they are acting in linguistically and culturally appropriate ways. When L2 learners interact with members of a "TL community" (Dewaele, 2008, p. 252), communication involves not only "what to say" but also "what to say to whom in what circumstances and how to say it," as Hymes (1972, p. 277) has pointed out. Communication, therefore, involves the melding of the linguistic component and the cultural component if one is to achieve competence in the language. The particular context (the "to whom" and the "how") in which an interaction takes place is therefore another factor that the L2 speaker must consider, as appropriate interactions are contextdependent (Dewaele, 2008). L2 teachers convey the basic rules of appropriate behavior to their students, but when the latter actually talk with members of the TL community, they confirm or disconfirm the level of appropriateness of their interactions. The degree to which interactions are appropriate also varies by TL community, so the L2 speaker will find judging appropriateness to be a challenging task that some L2 users will handle 
with more facility than others. Social interaction with members of the TL community plays an indispensable role in the acquisition of a second language and culture, suggesting that an experiential component needs to be built into foreign language instruction.

\section{Social Status and Language Status}

The corpus of social interaction literature provides background for the present study of a high school foreign language immersion program, but the majority of the research is only indirectly relevant, in part because the research in the immersion context focuses principally on elementary school programs, and on two-way programs in particular. Nonetheless, two recurring research themes, social and language status, are worth summarizing briefly, since they highlight specific potential problems and therefore helped to shape the research questions of this study.

The primary purpose of public education is to prepare children to be active, contributing members of society. Education itself is a social process: children learn through interaction with others. Does status influence student performance? Cohen \& Lotan (1997) have shown that interaction precedes learning. They present evidence from research on classroom group work that status influences the level of participation and learning of students, showing that the amount of knowledge acquired is greater for highstatus students than for low-status students (Cohen, 1984).

"Expectation states theory" dovetails with the notion of status. It was developed by Berger, Cohen, \& Zelditch $(1966,1972)$ to explain the role that race plays on interactions between people from diverse races in primary and secondary school settings 
and serves as a predictor of the degree to which students of different races contribute to a group assignment, whether they work hard on it and are actively involved, based on their status in the classroom (Cohen, 1982). It posits that students with high status tend to control interactions in the classroom, regardless of whether the difference in status is related to a specific group assignment. The status of a student is linked to the perception of his or her academic ability (low to high) and to the level of academic achievement actually achieved, in a process that is a self-fulfilling prophecy whereby there are low expectations for low-status students in terms of the degree to which they are actively involved and participate in group work in the classroom. Low expectations in one area lead to a generalized expectation of poor performance on classroom tasks. Cohen's theory suggests that status treatments have the potential to positively affect the attitudes and academic performance of students. The treatments break the pattern of failure in school and turn it into success, giving the students the confidence and motivation needed to succeed.

Language status is also at issue. A global problem that many countries confront, it is rooted in history and is related to a group's social, economic, and political status within a particular country. In the United States, English is the majority language, and its dominant status in society at large and in schools is documented widely by researchers (Amrein \& Peña, 2000; Delgado-Larocco, 1998; Carrigo, 2000; Hadi-Tabassum, 2002; Alanís, 2000; McCollum, 1994). Within this context, proficiency in English for immigrants is an indispensable prerequisite to gaining equal status and access to opportunities in the U.S. (Amrein \& Peña, 2000). Historically, the United States has been a melting pot where newcomers have been assimilated into American culture and 
traded their home language for English. Although this country is a nation of immigrants, many of whom came from non-English-speaking backgrounds, however, proficiency in another language has been considered a low priority for the nation and for the American public school curriculum (Amrein \& Peña, 2000) because so much of the world speaks English. As a nation, we have only recently begun to recognize the value of the linguistic and cultural skills of our immigrant population as a resource in international relations, global commerce, and national security. It is unclear, however, how widespread this sentiment is, despite studies and government programs that encourage it (Goals 2000 (Omaggio Hadley, 2001); the National Defense Education Act (1958); The National Security Education Act (1991); the National Security Language Initiative (2006). Evidence from the most recent foreign language survey showed that high school FL enrollments have remained stable during the time period 1997-2008.

This study suggests that foreign languages continue to be a low priority in American education and in the country. Perceptions do seem to be changing about the relative importance of certain languages vis-à-vis others as students choose to take a less commonly taught languages (i.e. Chinese or Arabic) instead of a more traditional language, such as French (Draper \& Hicks, 2002) (Rhodes \& Pufahl, 2009).

Despite the lack of urgency that many Americans feel about the need for proficiency in foreign languages, America's school-aged population is increasingly diverse in terms of language, culture, ethnicity, and educational background - a trend that is expected to continue (Cohen \& Lotan, 2004) . Moreover, this diversity is reflected in the population as a whole (Hobbs \& Stoops, 2002), reinforcing the obligation of our schools to promote the mastery of languages in addition to English and the development 
of cultural competence in the cultures of the peoples with whom Americans interact, as some scholars have suggested (Met, 2001; Rhodes \& Pufahl, 2010; Christian, Pufahl \& Rhodes, 2005; Christian, 2008; National Research Council, Center for Education, 2007). A failure to understand the cultural context of the messages from other countries and cultures renders Americans ineffective and potentially offensive.

Immersion programs are the principal response of American school systems to this imperative, with the particular support of Americans who recognize the importance of learning another language, as well as the growing Spanish-speaking population that wants its children to preserve their native language. In the majority of two-way immersion programs in the United States, Spanish is the minority language. The issue of language status does arise in a number of programs; although these programs seek to promote both languages equally, the task remains challenging, as research studies have documented (Amrein \& Peña, 2000; Freeman, 1996; Howard et al., 2003; de Jong \& Howard, 2009). Language status is an extraordinarily complex issue, to which a number of factors contribute: external, societal factors; state, district, and school level goals and policies; and factors related to each individual classroom. Many are factors over which a TWI classroom or program have little or no control.

\section{Two-Way Immersion Studies}

The most relevant immersion education literature on language status and social interaction consists of a relatively small number of studies, many of which involved a limited number of students. In two-way immersion programs, where language minority and language majority students are educated side by side, a few studies have shown 
evidence of unequal patterns of social interaction between these two groups of students and between minority language students and majority language teachers (Palmer, 2004, 2008; Amrein \& Peña, 2000; Freeman, 1996; Howard et al. 2003; de Jong \& Howard, 2009; Delgado-Larocco, 1998; Carrigo, 2000; Hadi-Tabassum, 2002). Cohen's status treatments are relevant to this study in the two-way immersion context, as Palmer's (2004, 2008) study has suggested.

The minority language status of Spanish, as an issue, has affected a number of aspects of the two-way immersion experience and has been documented in the TWI empirical literature. NES (native English-speaking) students have tended to receive more positive benefits, while for the NSS (native Spanish-speaking) students the research seems to suggest that the lower status of their L1 more negatively affected their experience in TWI programs. Most research studies of elementary TWI programs have focused on the outcomes for minority language students, who are primarily native Spanish speakers; few studies have explored the perspective of the native English speakers. Those that have included both NES and NSS students have examined L1 and L2 language use and language preference, teacher expectations for their use of their L1 and L2 in class, literacy in L1 and L2, academic achievement in L1 and L2 as measured by standardized tests in each language, equality of educational opportunity, and social interactions between the two groups of students.

In this research, language use and language preference are shown to be affected by the language status issue. In a research review article on elementary school TWI programs, Howard et al. (2003) found that NES students preferred English over Spanish and were English dominant, while the NSS students were more "balanced bilinguals." 
These particular studies did not examine students' perspectives on their choice of language. Amrein and Peña (2000) correlated this finding on the use of Spanish with the differential treatment of NES vs. NSS students that is related to the status of the respective languages in the classroom. NES students were not always required to use their L2 during instruction in that language, yet listened to instruction in that language. The researchers also found that the TWI teachers had dissimilar expectations for their NSS peers, who were expected to use their L2 during instruction in that language. The result of this differential treatment created a double standard in teacher expectations and sent a message to students about the status of each language in the classroom. Additionally, the NSS students could only communicate with their monolingual English teachers in their L2, which meant that they could not express themselves as well. The authors were concerned that this situation created an unequal educational opportunity for this group of students. Other studies about minority vs. majority language use, reviewed by de Jong and Howard (2009) confirm a greater use of English for NSS and NES students alike, even when Spanish was the language of instruction, because the NES students were often weaker in their L2 and could not perform academic tasks exclusively in that language. Other studies of Spanish use have shown a similar pattern (McCollum, 1999; Delgado-Larocco, 1998; Bikle, Billings \& Hakuta, 2004; Howard et al., 2003; Palmer, 2004, 2008).

For both groups of students, the choice of which language to use is affected by the status of each language in the TWI program, in the school at large and within society. As de Jong and Howard (2009) have said, "English dominant socio-political context" (p. 86) makes it difficult to place the majority and the minority languages on equal footing in 
terms of use. A related study that represented years of research in California and Nevada schools (Valdés, 1997) found that NES students had a sense of the prestigious status of English and were aware of their higher social standing compared to their NSS peers. These studies that have been referenced, where NSS students chose to use their L2 over their L1, even during "Spanish time," when it was the language of instruction, provide evidence that students were aware of, and were choosing to use, the higher-status language. As previously mentioned, all of these studies looked at issues concerning NES and NSS students in elementary school level TWI programs.

As students move on to secondary school (for the K-12 programs), the design of the program changes and there are shifts in the instructional time spent in each language. Bearse and de Jong (2008) report that during the elementary school years, students spend $50 \%$ of their day in each language, while in middle school the percentage drops to $30 \%$ for Spanish and increases to $70 \%$ for English. In their high school study, students actually took only one course per semester in Spanish. The decreasing amount of instruction in Spanish resulted in the diminishing status of this language and the rising status of English in that particular school district. The dominance of English at all levels of TWI reinforces the message about the lower status of Spanish and, by extension the status of the culture is also lower, according to the researchers. English dominance also sends a message about its value and about the importance of other languages in school and in society.

One of the major concerns related to language status and language equity in the TWI literature is the issue of the access that students have to "learning opportunities" (de Jong \& Howard, 2009, p. 86) in each language when it is the language of instruction. 
Students need "equal access in both languages" and "equal use of both languages." They need developmentally appropriate input in their native language to develop their academic language, and this skill may then be accessed for use in an L2. On the elementary school level, a simplified version of the L1 that is appropriate for L2 learners is not advanced enough for the L1 speakers. On the high school level, for students to have access to these learning opportunities, the course work must be offered by the school, and students need access to native language models (L1 speakers) for the L2 learners to acquire proficiency (de Jong \& Howard, 2009). The assumption is that each group of students will serve as the native language model for their L2 peers. For students to acquire high levels of proficiency in a second language, according to one major theory of SLA, they require a great deal of meaning-based interaction (input) with native language models (VanPatten, 2003). In TWI classrooms, some research has shown that the NES and NSS students may not be able to serve this function for their L2 peers (de Jong \& Howard, 2009). Some elementary school studies provide evidence of the problem of "watered down" (Freeman, 1998) input in Spanish that served the needs of the $\mathrm{L} 2$ learners but failed to meet the instructional needs of the L1 speakers for rich and developmentally appropriate language input (Lindholm-Leary, 2001; McCollum, 1999; Mora, Wink \& Wink, 2001; Valdés, 1997; Palmer, 2004, 2008). In the high school study, since students only took one course in Spanish per semester, each language group had less access to the language, and it affected them differently (Bearse \& de Jong, 2008). The NES students reported that they had less access to spoken Spanish, and this affected their fluency in their L2. The NSS students also had less access to Spanish, and this affected their academic language development. The NES students gained the 
advantage in educational opportunity because overall, the most courses were in English, leading to the development of their academic language.

These two articles (Bearse \& de Jong, 2008; de Jong \& Howard, 2009) highlight the educational challenges that TWI programs face when the needs of the native speakers conflict with those of the L2 learners (de Jong \& Howard, 2009). They believe that issues of language status affect students' language choice and language preference, often resulting in unequally distributed educational opportunities that frequently disadvantage the NSS students, and conclude that these issues need to be addressed methodically on the program level. On an optimistic note, in one elementary school study, Howard and Sugarman (2007) found that the goal of assuring linguistic benefits to both groups is achievable: teachers separated the L1 and L2 speakers for Spanish language arts and offered grammar instruction to the L2 speakers and enrichment and literacy to the L1 speakers.

TWI programs operate within the context of the American system of education and are constrained by its requirements. The secondary school curriculum, especially on the high school level, has many content area requirements with end-of-course exams, resulting in reduced opportunities to take more courses in Spanish, the suggestion of Bearse and de Jong (2008) and de Jong and Howard (2009). They note that TWI high school programs may also lack bilingual and Spanish-speaking staff with the proper content-area certification to teach the variety of courses to serve the needs of NES and NSS students alike.

With regard to social interaction in two-way immersion programs, researchers have explored its effects on the language use and language preference of NSS and NES 
students with their respective peers at each level, and their findings are conflicting. Howard et al.'s research review article of elementary school programs (2003) reported that students spoke of positive interactions between their peers from both language groups. In focus group interviews with NES and NSS students in the high school study (Bearse \& de Jong, 2008), students talked about the friendships that they had formed over the length of the program (since kindergarten) with their peers from both language groups, evidence of positive social interactions between these two groups. In another research review from elementary school programs, however, Mora, Wink, \& Wink (2001) found evidence from ethnographic studies that the unequal social and linguistic status of Spanish led teachers to marginalize the NSS students. These differences in social interaction patterns are similar to those identified by Cohen and Lotan (1997) for low-status students. Researchers have concluded that teachers need to be conscious of the way that they interact with all students (Palmer, 2004, 2008). Evidence from Palmer's research suggests that Cohen and Lotan's status treatments may help to improve this type of student-teacher interaction. More research on social interaction in TWI classrooms would contribute to a better understanding of the dynamics in these classrooms, especially on the elementary and middle school levels where most of the programs are concentrated.

\section{Foreign Language (One-Way) Immersion Studies}

In foreign language immersion education, the socioeconomic and cultural characteristics of the students may not be a salient factor depending upon the ethnic, racial, and socioeconomic characteristics of students in a particular program. No known 
research exists about social interaction amongst students in this context to confirm or disconfirm the significance of this factor.

Foreign language immersion programs generally serve language majority students, yet students from a variety of linguistic and cultural backgrounds are enrolled in a significant number of these programs (Genesee, 2008). The Spanish immersion program investigated in this study had some native Spanish-speaking students and the issue of language status was anticipated, in principle. Research questions therefore needed to include how these students view the status of the language that they are studying. This researcher is not aware of any empirical literature on the issue of majority/minority language status for foreign language immersion programs. The findings of this present study, which will be discussed in chapters IV and V, did not show minority language to be a factor for the participants.

\section{The Teaching and Learning of Culture}

This section introduces basic concepts of culture and examines the theoretical and empirical literature on culture learning and culture teaching in two-way immersion and foreign language immersion education-the last piece of the conceptual framework puzzle and one most relevant to the present study.

\section{What is Culture?}

A broad description of the concept refers to that of a nation and comes from the field of anthropology: historically, "culture" refers to a civilization of the ancient or modern world, such as ancient Roman culture. A more basic, commonly accepted, 
definition is a "set of shared beliefs, values, and behaviors of a social group" (Byram, 2003, p. 50). The concept of culture may therefore also refer to a narrower group of people, such as a race of people or an ethnic group, the employees of a company, or even a group of friends. A culture is shared, which means that the members of the cultural group jointly construct the meanings that they assign to their common beliefs, values, and behaviors. This joint effort to construct meaning involves the interaction of members with each other and with members of other cultures or cultural groups with whom they come in contact. An individual's native culture forms the backdrop for interpreting other cultures (Trompenaars, 1994). It is also a lens through which one looks at the world and interprets the meaning of what one sees. Learning another language and culture and developing cross-cultural skills thus involves at least two languages and cultures—one's native language and culture (L1 and $\mathrm{C} 1)$ and the second language and culture (L2 and C2) — and implies a relationship between the two.

Variation is characteristic of culture, and teaching culture as belonging to an entire language group or country, such as "the Spanish in the United States" or "the French," ignores this variation (Damen, 2003) and proposes a stereotypical culture that may really belong to no one. Further, cultural variation exists from one individual to the next and is affected by such individual characteristics as "age, experience, social class, resources, [and] personal attributes" (Damen, 2003, p. 88). In addition, culture is never static but changes and evolves over time, much as individuals do (Damen, 2003). The ever-evolving nature of culture is a characteristic that will have implications for the discussion of culture teaching and learning that follows: Culture in the foreign language 
classroom has often been taught as a set of discreet "food, festivals, folklore, statistical facts" (Kramsch, 1991, p. 218) that ignore its dynamic nature.

An iceberg metaphor is often adduced to illustrate the fact that the preponderant part of a culture is not visible. The multilayered aspect of culture is vividly captured by Trompenaars (1994). "Culture comes in layers, like an onion: to understand it you have to unpeel it layer by layer" (p. 8). He identifies these layers as the surface layer, including works of art (music, literature, etc.) and products, the "middle layer", comprising "norms and values," and the inner layer that consists of the "basic assumptions" (p. 25) of a culture. Norms are defined as the way that a culture judges "right and wrong" (p. 24), while "values" represent the concepts of "good" versus "bad" that are shared by a culture. Finally, "assumptions about existence" (p. 25) are defined as the beliefs about the "way in which a group of people solves problems" (p. 7). It is the products and the behaviors of a culture that change and evolve over time, even as the norms and values that represent its cultural traditions tend to retain their stability and importance.

The American Council on the Teaching of Foreign Languages developed a practical, complementary definition for its Standards for Foreign Language Learning: Preparing for the 21 st Century (1999), slicing the "onion" somewhat differently, as it were. Culture is conceived of as having two components, traditionally called "Big C" and "little c" culture. Big C refers to "formal culture," including information and awareness of the target society and its political and economic institutions, its history, and its most famous citizens, in addition to the "products of literature, fine arts, and the sciences that were traditionally assigned to the category of elite culture" (Standards, p. 48). "Little c" culture comprises the sociological and anthropological aspects of the daily 
lives of the people in the target culture (TC) and the behavioral patterns characteristic of its members. Standards also identifies different aspects of "little c" culture: "products," such as food, festivals, ceremonies, and sports; "practices," that is, ways of doing things in a particular culture, such as eating the main meal of the day at noontime; and "perspectives," such as one’s outlook, frame of reference, attitude, viewpoint, or cultural lens.

\section{Defining Cross-Cultural Awareness and Cross-Cultural Understanding}

The foreign language immersion and non-immersion literature describes the goals of culture learning using a variety of terms: cross-cultural understanding, cross-cultural competence, cross-cultural appreciation or awareness, cross-cultural sensitivity, intercultural competence, and intercultural sensitivity. These terms, however, are not well defined in the theoretical and empirical literature (Klein, 2004; Sugarman, personal communication 9/29/2009). For the purposes of this study, "cross-cultural awareness" and "cross-cultural understanding" have been chosen as the most appropriate, understandable, and functional because they appear to be the most descriptive of what students are developing.

What do these two terms mean? One useful study places them in a hierarchical order, yielding a clearer understanding of the nuances between them: cross-cultural knowledge, cross-cultural awareness, cross-cultural sensitivity, cross-cultural understanding, and cross-cultural competence (http://www.kwintessential.co.uk/culturalservices/articles/cross-cultural-understanding.html, accessed 3/3/2014). These distinctions were intended for the international business community but are relevant to 
the field of education as well. Moving from possessing cross-cultural knowledge to possessing cross-cultural competence is a gradual process propelled by academic coursework and experience in the workplace — or the target culture.

The first term in the kwintessential (2013) list, cross-cultural knowledge, is knowledge gained about aspects of the culture, including values, beliefs, and behaviors. Gaining this "surface level" knowledge of a culture represents the crucial first step to "cross-cultural understanding. Without it, cross-cultural appreciation cannot take place." Imagine the hapless student who ventures unprepared into a culture with a different understanding of time, truth, or individualism (Condon, 1986)! In the academic world, students can develop cross-cultural knowledge through courses about the target country, but they can gain the experiential knowledge only through interactions with members of the TL community in school, in the community outside school, or in the foreign country whose culture it is.

The second term, cross-cultural awareness, involves the perception and valuing of cultural differences from the perspective of a member (an insider) of that culture. At this stage, there may be "changes within the learner's behaviour and attitudes such as a greater flexibility and openness." This type of awareness goes beyond surface-level knowledge and involves a consciousness that other cultural perspectives exist, an understanding of one's native culture (C1) and of the target culture (C2), the ability to value both cultures, and the ability to adopt the cultural lens of the $\mathrm{C} 1$ and $\mathrm{C} 2$. Cross-cultural awareness is acquired gradually through training and interaction with members of the TL community.

Scholars do not agree about whether the third term, cross-cultural sensitivity, is a personality trait that cannot be acquired (Klein, 2004; Fantini, 2000) or the normal 
consequence of cross cultural awareness (kwintessential, 2013). The latter source defines it as the ability to interpret a situation in terms of the context, circumstances, and embedded actions and to interact with people in a culturally and linguistically appropriate, inoffensive way. Interaction with members of the TL community may be an important element of cross-cultural sensitivity.

The same source defines the next term, cross-cultural understanding, as dealing with cultural difference. It denotes the ability to perceive and analyze circumstances, events, and people and to respond in culturally appropriate ways in terms of language and culture. This term thus goes a step beyond the previous ones, as it involves an analytical component, yet it still does not address the ability to work effectively in other cultures. Finally, cross-cultural competence combines all of the other abilities and includes a further element: the ability to "create cultural synergy in the workplace," that is, the ability to work effectively across cultures.

The discussion of these terms was destined for individuals who interact with people from different cultures and are therefore experiencing and dealing with cultural differences first hand. They may well have acquired specialized cultural knowledge in a classroom setting, but their interaction with members of a TL speech community is what leads them to a deeper level of cross- cultural understanding and awareness. In the present study, students participate in a service learning program, affording them the chance to interact with members of the TL community, and they have opportunities to travel to, and in some cases to live in, the target culture. Their cross-cultural awareness and cross-cultural understanding in these settings will be explored in this study. 


\section{Culture Teaching and Learning in Foreign Language Education}

\section{An Historical Review}

A brief look at the history of culture teaching and learning in foreign language education provides the contextual background in which immersion education programs developed and allows us to understand its current status in foreign language (one-way) immersion programs as well as the approaches used there and in foreign language education as a whole.

In the first half of the 20th century in American public secondary education, the study of a foreign language and its culture contributed to what it meant to be an "educated" person in the Western European tradition of a liberal education. The primary goal of foreign language education was exposure to another language and to its "high" or "Big C" culture, which focused on important features of geography, history, literature, and the arts (Seelye, 1993), otherwise put, its civilization (Grittner, 1990). This approach conceived of culture as academic content; students gained insights into the target culture through the study of literature. Language classes were conducted primarily in English and included a study of grammar and the translation of literary texts. Students experienced neither communicating in the TL nor interacting with members of the TL community.

Research from textbooks published prior to the 1940s (Kramsch \& McConnellGinet, 1992) establishes that culture was often presented as a fixed set of facts to learn by heart. The texts were frequently written through the American cultural lens and included the author's perspective and innate biases. Features of the foreign culture $(\mathrm{C} 2)$ were selected based on a comparison with the native (American) culture (C1). Neither a culture's ever-changing nature and nor its internal variability was taken into account, 
leading to a shallow, narrow approach to culture teaching that looked at cultural distinctions as an academic exercise devoid of any intellectual value (Klein, 2004). One learned about culture rather than understanding culture on a deeper level.

It is now accepted that for L2 learners, the acquisition of a second culture involves discovering aspects of the $\mathrm{C} 2$, gaining insight into their native culture, and examining cultural beliefs, values, and behaviors from $\mathrm{C} 1$ and $\mathrm{C} 2$ through dialogue with others and with themselves alone (Kramsch, 1993a) in a process called "cross-cultural reflection" (Kramsch, 2003, p. 205). As Kramsch (1993a) has suggested, the FL classroom is an anthropological site, "the site of cross-cultural fieldwork" (p. vi) where the teacher is the "cultural mediator."

The next important step in FL education was the introduction of the Audiolingual Method (ALM), originally developed by the U.S. Army in the 1960s (Hancock \& Scebold, 2000) to respond to the need for its personnel stationed across the globe to communicate in other languages. ALM dramatically changed the approach to the teaching of language and introduced a new philosophical approach to culture teaching: Students now had greater opportunities to develop their aural and oral skills, which provided them with the novel cultural experience of actually speaking the target language (TL). The approach involved listening to stylized conversations by native speakers of the FL and memorizing dialogues about "authentic", stereotypical aspects of the daily lives of people in the TC (Hancock \& Scebold, 2000). ALM provided a practical approach to learning a language that emphasized memorized phrases, a potentially useful tool for tourists abroad. On a very basic survival level, the tourist or business traveler was able to ask directions to the train station or to order an espresso coffee in an Italian café. 
These dialogues may have conveyed a message to the L2 learner about the basic concept of speaking in another language, but it did not teach them about authentic communication. A brief digression concerning the difference between an L2 speech act and a conversation in an L2 is therefore necessary because, as Galloway (1999) has argued, communication in an L2 is a cultural experience. The author makes an important distinction between "talk" and "conversation" (Galloway, 1999, p. 177). Talk is defined as what is necessary for conversation but may be simply a linguistic accomplishment that remains on the surface level. A conversation, on the other hand, is a "shared experience of engagement, connection, relationship, revelation of uniqueness" that involves substance and an emotional involvement. Conversation is an "art" that must be explicitly taught on the linguistic and cultural levels, making it a cognitive as well as an affective experience. Cultural variations on the value of the conversation also need to be learned: "[T]he decision of what to say is not merely one of vocabulary, and...the decisions of when and to whom have tangled cultural roots and broad cultural consequences" (Galloway, 1999, p. 178, italics in the original). This leads the author to conclude that teaching the "art of conversation is the most profound of all cross-cultural learning experiences" (p. 180).

The ALM dialogues remained on the level of talk because students tended to be unable to improvise them to take the speech act to the level of a conversation. Students could not acquire proficiency in the target language with the ALM method since there was no meaning-based interaction with members of the TL community, which is crucial to developing proficiency in the TL (VanPatten, 2003). 
A recurring theme of this study is the role that social interaction plays in the acquisition of a second language and culture. L2 learners may learn some basics of speech in interaction with their teacher and their peers; however they learn the art of conversation - the "what, when, and to whom" (Galloway, 1999, p. 178) —in interaction with members of the TL community. This type of interaction provides them with the necessary feedback on how effectively they have communicated their message and how culturally appropriate it is. ALM, as a method, involved more speech production than previous ones, but the canned phrases were not authentic, spontaneous interactions because they did not involve the element of feedback. Nevertheless, it may have set the stage for the more communicative approaches that were to follow.

The ALM method also represented a transformation in the approach to the teaching of culture. The "high" or "Big C" culture of the humanities was replaced by the more functional, practical, "little c" culture of the social sciences (Kramsch, 1993a; Hancock \& Scebold, 2000; Omaggio Hadley, 2001). The ALM textbooks included "cultural notes" about aspects of daily life in the TC to guide teachers at each level in each chapter (Grittner, 1990), and the goal of FL education switched from the development of well-educated individuals to exposure to the L2 and awareness of the every-day world in another culture.

At the classroom level, however, the study of other cultures kept the characteristics of the past: the lessons were shallow and fact-based (Paige et al., 2003). Cultural lessons were learned from the perspective of the dominant American culture, which neither encouraged students to look critically at their native and target cultures to gain insights into cultural differences nor to look at their world from the perspective of 
another culture (Paige et al., 2003). In addition, teaching the culture of a nation exclusively as the culture of the predominant cultural group—-for example the French as white Catholics from France-at the expense of other ethnic groups within France or of the French-speaking peoples of Africa, Southeast Asia, or the Caribbean, gives a shallow understanding of cultural diversity within a living culture (Lafayette, 1988).

The contemporary era in culture teaching within FL education was marked by the introduction of two foreign language frameworks, National Standards for Foreign Language Learning (ACTFL, 1996) and Acquiring Cross-Cultural Competence: Four Stages for Students of French (Singerman, 1996). National Standards (1999) establishes linguistic and cultural goals for all K-12 students: "The U.S. must educate students who are equipped linguistically and culturally to communicate successfully in a pluralistic American society and abroad" (Standards, 2006, p.7). Goals are divided into five areas: communication, cultures, connections, comparisons, communities. The second language acquisition process is situated in the first standard; all of the others relate in whole or in part to culture. The National Standards framework has had a significant influence on FL education since it was launched (Bateman, 2002): in principal, it places culture at the center of FL instruction (Lange, 1999), establishing a firm link between culture teaching and language teaching (Lange \& Paige, 2003).

ACTFL's framework for the teaching of culture guides classroom teachers and gives direction to the foreign language profession in American education (Andrawiss, 2004). The Standards are the basis of 33 state standards documents and have influenced the cultural content of many foreign language textbooks (Andrawiss, 2004; Lange 1999). The document also guides teachers in the approach to culture teaching, with examples of 
products, practices, and perspectives to teach and suggestions for comparison with American culture.

Within its five goals, the Standards (1999) framework establishes benchmarks at various levels in the curriculum for specific cultural and linguistic knowledge and skills to be attained. The language-learning goals emphasize three aspects of communication: interacting amongst individuals, expressing oneself in the TL, and reading content from across the centuries. The approach to language teaching places an emphasis on interaction and on meaning-based input and output (VanPatten, 2003). Students learn to exchange information and opinions and to share their feelings and emotions in culturally appropriate ways (National Standards, 1999). This is a radical change from the ALM approach that involved repeating mindless, meaningless dialogues!

Under the overarching goal for culture, to "gain knowledge and understanding of other cultures," there are two standards: 1) "Students demonstrate an understanding of the relationship between the practices and perspectives of the culture studied" and 2) "Students demonstrate an understanding of the relationship between the products and perspectives of the culture studied." In sum, the Standards provide classroom teachers, curriculum planners, and other FL professionals with a framework to be used in developing state standards, curricula, teaching methods, and lesson plans.

The second framework was created by the AATF National Commission on Cultural Competence and was entitled Acquiring Cross-Cultural Competence: Four Stages for Students of French (Singerman, 1996). Its goal was to provide guidance to French teachers in teaching cultural competence in the cognitive, behavioral and affective domains. These two frameworks and the state standards documents have resulted in 
more agreement about the makeup of culture and the content of culture teaching than has previously existed in the FL classroom. The National Standards framework puts culture at the core of foreign language instruction (Paige, et al., 2003) and scholars have emphasized the intrinsic relationship that exists between a foreign language and its culture (Agar, 1994; Byram, 1989; Hall, 2002; Kramsch, 1993a).

But clarity of goals and objectives has not sufficed. An extensive review of the research has shown that culture teaching, both now and in the past, has played a minor or insignificant role in foreign language instruction for 50 years (Paige et al., 2003; Lange \& Paige, 2003). The classroom teaching of culture, including components such as "attitudes, beliefs, ideologies, ways of behaving and thinking, and values" (Paige et al., 2003, p. x), is a complex task (Paige, et al., 2003; Lange, 1999). Teachers have consequently resorted to focusing on the surface-level aspect-"food, fairs, folklore, and statistical facts" (Kramsch, 1991, p. 218). In practitioners' defense, a significant number of textbooks, among them Allez, viens! (1996) and its equivalent in Spanish, have departed from presenting the culture of country as that of the cultural majority. Students in the French textbook learn about the francophone world and the customs and lives of young people from cities in France, Canada, the Ivory Coast, and Haiti. Nonetheless, we are back where we started, and Wesely's (2009) assertion that reaching cultural objectives in immersion education remains a challenge, appears to be true of foreign language instruction in general. 


\section{Culture Goals in Immersion Education}

Fortune and Tedick (2003) have identified the primary goals of immersion education as "high levels of academic achievement" literacy in two or more languages, and "increased cultural awareness" and are straightforward in terms of how they might be achieved. Met \& Lorenz (1997) identify a rather nebulous goal for the cultural content of immersion programs: to "learn about and understand the culture(s) of the people who speak the immersion language" (p. 259). Their first culture objective is an academic goal, perhaps similar to cross-cultural knowledge (Kwintessential, 2013), that involves finding out about the culture by integrating a culture learning goal, such as the 24 hour clock, with a content goal for mathematics (Met \& Lorenz, 1997). The two stated culture goals, "increased cultural awareness" and "understand the culture," seem to be similar, but the two pairs of immersion scholars do not define what they mean by these goals or how students are to achieve them.

Although Fortune and Tedick (2008), Met and Lorenz (1997), and numerous others concur about the culture goals for immersion education, we already know that that these objectives "have been difficult to meet" (Wesely, 2009, p. 204). Further, we do not know how students define the cultural aspect of their program, since only Wesely's study has examined cross-cultural understanding from the students' perspective. The present study has foreign language immersion high school students' perspectives as its main focus, examining students' awareness and understanding of the cultures in which they are schooled in the formal classroom and in other contexts outside of the classroom. 


\section{Studies on Culture Teaching and Learning in Immersion Education}

Research on culture teaching in traditional FL instruction has focused on learning objective content: the products, practices, and perspectives of the target culture, as defined in the ACTFL National Standards (1999). In the immersion setting as well, researchers have found that this aspect of a language has been marginalized (Lyster, 2007; Met \& Lorenz, 1997), as discussed earlier in this chapter. Only Wesely's empirical study of language learning motivation from the foreign language immersion literature examines students' perspectives on culture. In individual interviews, $6^{\text {th }}$-grade students, who had completed French or Spanish elementary school immersion programs, were asked about their understanding of the target culture. She found that the academic curriculum alone was not sufficient for developing cross-cultural understanding. In describing the target culture, some students, for example, identified the target language while others discussed holidays. Those students who did develop some level of crosscultural understanding had had exposure to the target culture through extra-curricular experiences that were not directly related to what they had learned in the academic curriculum. These students had gained insights into the cultures through their relationships with members of the local speech community and through exposure to aspects of the cultures during homestays abroad or other in-depth non-tourist experiences (Wesely, 2009, p. 278).

The research literature on two-way immersion programs, much of it from the last ten years, focuses almost exclusively on the elementary school level. TWI literature on secondary school programs (middle school or high school) is very sparse (de Jong \& 
Bearse, 2011; Bearse \& de Jong, 2008); a search of the empirical literature on TWI for studies related to culture or cross-cultural understanding yielded no results. The existing studies look at students' attitudes towards their second language or culture or intercultural friendships with peers from the program. In their review of multiple studies, from small and larger-scale programs, Howard, Sugarman, and Christian (2003) reported that students acquired positive attitudes about their peers from the other culture. In three studies (Lambert \& Cazabon, 1994; Bearse \& de Jong, 2008; de Jong \& Bearse, 2011), students reported that they had developed friendships with peers from both language groups.

The present study investigates a one-way, foreign language immersion setting. In the relevant literature, scholars have mainly explored practical programmatic issues (see, for example, Met \& Lorenz, 1997) and student achievement (Wesely, 2009). There is no known empirical literature on high school-aged students in foreign language immersion programs in this country and only one study at this level in two-way immersion programs (Bearse \& de Jong, 2008). Further, few studies exist to provide evidence of what happens in culture teaching and learning in any type of foreign or second language classroom (Paige et al., 2003, p. 222).

In the empirical literature, though immersion programs in general have been shown to offer students the most effective means to learn a second or other language (Genesee, 1987; Lyster, 2007), certain researchers found that overall the target culture is not presented systematically and comprehensively in the curriculum and that the same content tends to be repeated from year to year (Genesee, 2007; Met \& Lorenz, 1997). In her literature review, Wesely's corroboration and expansion of the previous findings that 
the teaching of culture may be marginalized or excluded from curriculum altogether led her to conclude that the development of cross-cultural understanding is not an automatic or inevitable by-product of participation in a foreign language immersion program. It appears that culture teaching and learning in foreign language immersion research has not been, nor is it currently a priority in foreign language immersion research because of its status in these programs (Paige et al., 2003).

What does evidence from course offerings in foreign language immersion high school programs say about the cultural content in the curriculum? Is this cultural content aligned with the goals of the programs? No current survey of course offerings from these programs exists, although it is possible to search the Center for Applied Linguistics (2011) directory, Retrieved from (http://www.cal.org/resources/immersion/), for information on individual schools. In a national survey of immersion programs, Fortune and Jorstad (1996) found that the high school-level programs offered primarily language arts and TL literature courses. The only other survey of this level and type of immersion program from that era was conducted by Barr-Harrison (1999). It suggests that the course offerings in the target language may be somewhat broader than those presented in the other survey, based on evidence from one school in Virginia from their 1997-1998 school year. Information on course offerings from this same school's current website (Retrieved from, http://teachers.henrico.k12.va.us/specialist/WLweb/ImmCenter/curriculum.htm) shows that students generally take math, physical education/health, and social studies in addition to language arts and TL literature courses. This program also offers a studyabroad component in the 11th grade and an immersion field experience (community service) in the 12th grade. 
Information on course offerings from two other schools is also available. One program offers similar courses in language arts, social studies, and math (Johnson, 2003), while the second offers courses in language Arts, social studies, TL literature, a studyabroad component, an elective student-teaching experience, and an independent study course (Carr, 2003). The course offerings for the research site in the present study resemble those of these other programs. They include language arts, math, physical education, and social studies. In addition, they also earn credits for immersion service learning, immersion field experience, and the study-abroad component, which is optional.

A review of the course offerings from these programs shows that students are acquiring cultural knowledge and an awareness of the cultures of the countries where their TL is spoken through social studies courses: cultural anthropology, global studies, or political science and humanities. Through these courses, students gain a cognitive level of knowledge about the target culture(s), yet this knowledge may represent a surface level understanding. It is not known, however, what "received messages" about the target culture (Wesely, 2009) students gain from these courses, as no known studies exist.

In the realm of affective culture learning, most of the programs also offer a service learning component and a study abroad experience, where students have the opportunity to interact with members of the TL speech community. This experience provides another level of awareness and understanding that develops only through crosscultural interaction and has the potential to give students deeper insights into the target culture. However, yet again, no known studies exist of students' level of cross-cultural awareness, which has been gained through this experience. A study analyzing the cultural content of these courses in greater depth and students' "received messages" 
would give a better understanding of their cross cultural awareness and make a contribution to the FL immersion literature.

\section{Culture Teaching: What Limits?}

Thus far in this lengthy section, we have considered the nature and the teaching of culture: with regard to the latter, its history, its aspirations, its implementation in various settings, and the relative shortcomings of these applications. It is time now to narrow the focus of the theoretical part of this inquiry, to look more closely at the shortcomings and to ascertain if researchers believe the gap between the goals and achievements of culture teaching can be bridged. While scholars in the field of second language acquisition have theorized about the cultural goals and benefits of learning a second or other language, at the same time they have inquired whether there are limits to the level of culture objectives that are attainable within the context of American public education and in the formal classroom setting.

In that context, the inherent focus in all subjects is the objective learning and evaluation of students (Paige et. al., 2003). This approach is reflected in FL education, where research shows that, as previously noted, most content on culture teaching is factbased—food, festivals, fairs, and statistical facts (Paige et al., 2003; Andrawiss, 2004); much of the cultural content of FL instruction is on the cognitive level and involves the memorization of discreet facts (Damen, 1987). When culture is presented in this manner, students understand neither that a culture changes and evolves over time, nor that there are affective and behavioral components. Rather, they see culture as made up of objective academic content, devoid of its human element (Andrawiss, 2004) and natural 
characteristics. In other words, although the teaching of language and culture in the formal classroom setting affords students the opportunity to discover a new world and a new way of expressing themselves, the realities of the setting often interfere with the realization of the goal of gaining new insights into their native culture and into themselves as cultural beings.

Even so, certain scholars argue in the theoretical literature about the positive aspect of this setting (Damen, 1987; Kramsch, 1993a; Mitchell, 1988). They posit that this milieu protects novice L2 learners when they make linguistic errors and cultural blunders and provides them with feedback from their teacher, allowing them to learn from these cultural mistakes as preparation for interactions in a real-world setting of a TL community. Although interaction is possible with native speakers in the naturalistic setting and is restricted to that between fellow beginning students and the teacher in the formal setting, novice FL students might not benefit from the in situ interactional advantage, given their limited speaking skills (Van Lier, 1988).

Other scholars criticize the formal classroom environment, arguing that is by nature a contrived setting. The first theoretical limitation deals with the previously mentioned emphasis on objective knowledge acquisition and assessment (Paige et al., 2003) in American education in general and, in FL instruction, the focus on a cognitive and deductive learning process (Damen, 1987): Students memorize facts and take discreet item tests that are de-contextualized (Paige et al., 2003), developing a narrow view of the TC. They are gaining an academic proficiency in the culture of a country, rather than experiencing that grappling with their own beliefs, cultural outlook, and assumptions that represent a step in the process of acquiring competence in another culture. Robinson- 
Stuart \& Nocon (1996) aptly refer to this type of culture learning as "cognitive boundary crossing" (p. 434); the element of real-world experience is not present.

A second theoretical criticism of this setting involves the dynamics of the classroom and classroom control. In a compilation of SLA research studies, Ellis (1992) found that overall the teacher strictly controlled communication, deciding who speaks, how long they speak, and when they start and stop. In this type of environment, some have argued that students do not have the chance to learn how to go about initiating and stopping conversations (Sacks, Schegloff, \& Jefferson, 1974). L2 students require these types of communication skills to interact with members of a TL community.

In their extensive review of the theoretical and empirical literature on the limitations of the formal classroom setting as an appropriate venue for culture learning, Paige et al. (2003) aggregate the thoughts of a number of scholars around the oppositional stance between the theoretical advantages and disadvantages of that context (where there may or may not be members of a TL community nearby) and the naturalistic setting, where culture is learned in "the field", i.e. in a TL speech community or a country where the TL is spoken. In principle, L2 students learn about another culture in the naturalistic setting when they go to another country to the study and live and are thus provided with the "real-life context" that some scholars posit is necessary for acquiring another culture (Fetzer, 1997). Several other scholars agree with Fetzer about the importance of the real-world experience to which students have access in the field (Robinson-Stuart \& Nocon, 1996; Jurasek, 1995).

Research findings from the study abroad literature, however, have shown that the benefits of first-hand experience are not always positive (Paige et al., 2003). While 
clearly positive outcomes have been frequently documented-greater self-confidence, an increase in global awareness, enhanced cultural self-awareness and positive attitudes toward other culture groups (Barnlund, 1988) — an unfavorable experience in a target country can negatively impact students' attitudes toward the target culture and their language- and culture-learning progress.

In one major theoretical argument in favor of the naturalistic setting, Krashen (1982) posits that L2 learners acquire a second language and culture through an implicit process in this setting, while they learn the language and learn about the culture in an explicit process in the formal classroom setting (Krashen, 1982). For this reason, he, like Fetzer, (1997) favors the former. So do Robinson-Stuart and Nocon (1996), who feel that culture acquisition — culture is, after all, socially constructed — can only take place through interaction between L2 learners and native speakers of the target language. Culture, they write, is "a process, that is, ... a way of perceiving, interpreting, feeling, being in the world...Culture is not only located in cultural products and forms, but in the active lives of those who share those forms" (p. 432).

The question therefore arises: Is it possible to teach cross-cultural skills in the formal FL or FL immersion setting? Is the development of competence in another culture an unrealistic goal for the formal FL classroom setting?

Some scholars suggest that there may be limits to what can be taught there. Kramsch (1993a) and Baumgratz-Gangl (1991) caution that there is a limit to the amount of foreign culture that can be integrated into the FL classroom and that it is difficult for teachers to make it real. Paulston (1992) believes that it is only possible to teach culture at the cognitive level because the deeper levels of culture are acquired in interaction with 
members of the TL speech community. Paige, et al. (2003) and Saville-Troike (2003) suggest that the natural limitations of the setting should be acknowledged and accepted for what they are.

To summarize, on the one hand developing cross-cultural awareness and understanding is an affective process that entails interaction with members of the TL community in a real-world context. L2 learners' cross-cultural understanding develops through this interaction and through the feedback about the cultural appropriateness and effectiveness of their communication with L1 speakers (Fantini, 2000; Paige et al., 2003). When students interact with their FL teacher, they may gain a certain level of understanding of this aspect of culture, but it is limited (Kramsch, 1993a; BaumgratzGangl, 1991): There is undeniably no substitute for authentic interaction with members of the TL community if one wishes to acquire skills in another culture.

Cross-cultural understanding also develops through self-reflection and reflection with others about all aspects of the native culture and the target culture, at every stage of the process (Kramsch, 1993a; Fantini, 2000). It is through reflection that one develops the ability to see the world from two perspectives (Fantini, 2000), and this "ability to shift cultural perspectives" (Bennett, Bennett, \& Allen, 2003, p. 252) is at the heart of culture learning for L2 students.

On the other hand, in spite of its limitations, the classroom setting plays an important role as a starting point for second language and culture acquisition; it is indeed a nurturing environment for the development of early speaking skills and of a basic awareness of the unfamiliar culture, as some scholars have suggested (Damen, 1987; Kramsch, 1993a; Mitchell, 1988). Are there approaches to a more in-depth exploration 
of other cultures that address some of the major limitations of the formal classroom setting and yet are also realistically achievable?

\section{What Approach to Culture Teaching?}

In the post-National Standards era, culture is seen as an evolving process to be learned rather than a phenomenon to be explained (Crawford-Lange \& Lange, 1984; Kramsch, 2003; Byram, 1997; Bateman, 2002). Students develop the tools to critically examine, interact with, analyze, evaluate, and judge their own language (L1) and culture (C1) along with the second language (L2) and culture (C2) (Crawford-Lange \& Lange, 1984). Teachers serve as facilitators of culture learning, giving students the tools to become skilled "cultural detectives" (Trifonovitch, 1977, p. 554). The core of culture learning is not the cultural knowledge that is learned but the skill of changing from one cultural lens to another (Bennett et al., 2003). What skill does one need to accomplish this? No one has really posited how L2 learners might acquire such a skill nor what it might look like in students, though the term "mental flexibility" proposed by researchers in this field may be appropriate (Fantini, 2000; Ferree, 2010, personal communication). Robinson (1991) has proposed the term "cultural versatility," along with a color-wheel analogy whereby a (purple) synthesis is achieved between the L2 learner's background culture (blue) and the cultural objective from the (red) target culture without either the student or the interlocutor giving up his or her native culture; purple is the area where the two cultures “overlap” (Robinson-Stuart \& Nocon, 1996, p. 432).

Kramsch's (2003) approach resembles that of Crawford-Lange \& Lange (1984); as previously mentioned, she posits that culture learning is an on-going process of 
discovery, analogous to a dig at an anthropological site. The teacher serves as a crosscultural "mediator" and a vehicle for educational change as she engages students in a dialogue about $\mathrm{C} 1$ and $\mathrm{C} 2$ with the goal of bringing students to an understanding of "why speakers of two different languages act and react the way they do" (Kramsch, 2003, p. $32)$.

This ideal process is essential, yet hard to implement because it is complex. The definition of culture learning from Paige et al. (2003) captures this complexity and allows us to revisit the definitions of culture given at the beginning of this section-and to envision some solutions:

Culture learning is the process of acquiring the culture-specific and culturegeneral knowledge, skills, and attitudes required for effective communication and interaction with individuals from other cultures. It is a dynamic, developmental, and ongoing process which engages the learner cognitively, behaviorally, and affectively (p. 177).

What do they mean by culture-general and culture-specific? Culture- general content is comprised of the knowledge and skills the learner acquires about how to learn about and acquire a second culture (Paige et al., 2003). Once the L2 student has acquired these, they may be applied to learning an actual culture. Culture-specific content is the knowledge and skills acquired about a particular target culture.

Kleinjans (1975), Bennett et al. (2003) and others support Paige et al.'s identification of the cognitive, behavioral, and affective domains of culture learning, domains of that trace their origins to learning theory in the field of psychology (Bloom, 1964) and to "interculturalists," as discussed in Damen (1987).

In the realm of cognition, or knowledge, an example of culture-general content would be the stages of cultural adjustment and culture shock (Paige et al., 2003). 
Culture-specific knowledge includes all aspects of "little c" culture and "Big C" culturelearning about existentialist writers in France, for example.

In the domain of behavior, strategies for recognizing and coping with culture shock while living or visiting an unfamiliar culture constitute a culture-general example. A culture-specific example is learning to perform formal and informal French greetings, i.e. to shake hands for a formal greeting and to kiss on both cheeks when greeting friends or family members.

In the affective domain, an example of culture-general content involves the recognition that cultures are socially constructed. An example of culture-specific content would be to develop an appreciation for the Japanese tea ceremony. Kinesics—“the study of all bodily motions that are communicative" (Morain, 1986, p. 66)—would appear to be both behavioral and affective. They can in principle be spoken about in the classroom: "Insight into posture, movement, facial expression, eye management, gestures and distancing as they affect communication not only increase sensitivity to other human beings but inevitably students' understanding of their own kinetic systems" (Morain, 1986, pp. 75-76). But the experiences that allow L2 learners to incorporate these bodily motions into their skill set can only be gained through social interaction with members of the L2 speech community.

Some researchers have suggested that the behavioral and affective domains of culture learning may often be overlooked in L2 instruction because of their complexity and their experiential nature, and the fact that they do not lend themselves to objective testing (Paige et al., 2003; Kramsch, 2003; Bennett et al., 2003). Learning new behaviors 
or gaining an appreciation of a new cultural value develops over time and must be experienced (Paige et al, 2003; Bennett et al., 2003; Fantini, 2000).

Paige et al.'s ultimate goal for culture learning, "effective communication and interaction with individuals from other cultures" (Paige et al., 2003, p. 177), with the aspects that have been defined above, suggests that culture learners need a more comprehensive approach to culture teaching and learning. Each learner needs to develop a framework and tools to become "an effective language and culture learner," to help him or her understand and appropriately interact and perform while a resident in an unfamiliar culture.

What does this process involve? As students prepare to be culture learners (Paige et al., 2003; Mantle-Bromley, 1992), they need culture-general content, that is, they need to develop a conscious awareness of themselves as cultural beings (Paige et al., 2003; Bennett et al., 2003; Mantle-Bromley, 1992), which involves becoming cognizant of their own "culture-bound behaviors" (Mantle- Bromley, 1992, p. 119). This dovetails with other researchers' promotion of "cross-cultural reflection" (Kramsch, 1993a, p. 205), which means critically studying and analyzing one's native culture (C1) (Kramsch, 1993a; Galloway, 1999) and the second culture through dialogue with others and in a written dialogue with oneself. Through the process of "cross-cultural reflection," culture learners gain an awareness and recognition that there are other cultural perspectives in the world (Galloway, 1999), meaning that culture is not innate, but rather is learned (Kleinjans, 1975). Through "cross-cultural dialogue," students develop the ability to understand the viewpoint of an individual from another culture (Kramsch, 1993a, p. 232). Interestingly, Kramsch's approach is designed for college- and university-level students 
and does not necessarily involve interaction with native speakers. She uses cultural conflict and difference as her point of departure, in a process that tests students' sense of the world.

Culture learning that focuses on a mix of culture-specific and culture-general knowledge, skills, and attitudes gives students the cultural framework (Mantle-Bromley, 1992, p. 117) and the tools for interacting with people from unfamiliar cultures and for analyzing novel cultural situations and adapting to them. As culture learners develop cross-cultural skills, they may develop the ability to step out of their own cultural frame of reference to examine an issue from the perspective of their C2 (Bennett et al., 2003). These skills that they will take with them for their entire lives equip them to be educated citizens of the 21 st century.

\section{Implications for Research Questions}

This chapter has reviewed the literature related to second language acquisition and its relationship to culture learning and teaching in one-way and two-way immersion education as a process in which social interaction plays a leading role. Each of these sections raises unanswered questions, many of which are answered in the dissertation or merit further exploration. In the FL immersion setting: What roles do the majority and minority cultures (C1 and $\mathrm{C} 2$ ) play? What do students say about their experience with these cultures? In the social interaction section: How do students talk about their crosscultural experiences and interactions with members of the TL community? The language status literature points to the need to understand more thoroughly the dynamic between majority language speaker and minority language speakers at all grade levels, especially 
on the high school level, where no known studies exist. This suggests two related questions: What is the status of the minority and majority languages in the FL immersion program? In what ways are students' perceptions of the minority and majority cultures affected by the status of their language? The culture section of the literature review suggests a major question: What processes are involved in developing students' awareness and understanding of the cultures in which they are schooled?

What impact do field experiences have on students' cultural evolution? One of the unique features of the FL immersion setting, especially within the context of traditional foreign language education, is the possibility of interacting with members of the TL speech community in various courses that are an integral part of their curriculum. Students may develop cross- cultural knowledge, awareness, and understanding in these authentic interactions with local members of the TL community, for example as translators for parents of county students or student teachers on the elementary school level. (At the study site, students have an "Immersion Field Experience" and the chance to study abroad in Mexico or Spain).

In order to understand students' experience with culture learning in the foreign language immersion setting, one needs direct access to their own perspective in their own words. Individual interviews and focus groups provide just such an entrée. Herein lies the uniqueness of this study, whose methodology is presented in the following chapter. 


\section{METHODOLOGY}

A qualitative design was chosen for this descriptive study of the experience of Spanish immersion high school students with Hispanic and American cultures because it is the most appropriate one for an exploratory study of the perspectives of the program participants in their own words. It is also the appropriate choice for a problem that has not been studied previously (Creswell, 2005), and this study seeks to explore and understand a phenomenon on which little empirical research has been conducted to date.

\section{Initial Procedures}

Site selection was based on purposeful sampling of possible locations that are "information rich" (Patton, 1990) and therefore provide the best opportunity to understand the phenomenon. The site selected was the Lake County (pseudonym) Spanish Immersion Center at Dover High School (pseudonym), a large suburban school located in Virginia.

In terms of ethnicity, Lake County School District is 55\% White, 26\% Black, 11 $\%$ Hispanic, . $5 \%$ American Indian and Alaskan Native, $4 \%$ two or more races, and 2\% Asian, Hawaiian, and Pacific Islander. In Lake County, $33 \%$ of the students are eligible for free or reduced lunch (county website 1/27/2014). In 2011 Dover High School was 60\% White, 32\% Black, $6 \%$ Hispanic, and 2\% American Indian, Asian, and Hawaiian. In Lake County, $25 \%$ of the students were eligible for free or reduced lunch (county website, 2011). For cohorts graduating between 2013 and 2016, students in the Dover 
High School Spanish Immersion Program are 40\% White, 25.26\% Black, $27.37 \%$ Hispanic, .5\% American Indian and Alaskan Native, $6.32 \%$ two or more races, $0 \%$ Asian, and $1.05 \%$ Hawaiian.

Participants were selected through purposeful sampling of all $10^{\text {th }}, 11^{\text {th }}$, and $12^{\text {th }}$. grade Spanish Immersion students (approximately 75 in all). At the beginning of the spring 2011 semester, the researcher delivered packets containing information and consent forms to the director of the Dover High School Spanish Immersion Program, for distribution to prospective students and their parents. A cover letter described the study and all the consent forms required for participation. The packet also included an invitation to meet with this researcher and the Immersion Program director at the school to discuss the research project and to answer any questions and address concerns. This meeting had been suggested by members of the school division's study selection committee, including the principal of the school and the Lake County Director of School Improvement, because they felt that parents would be more comfortable granting permission for their child to participate in the study if they had met the researcher in person and heard about the study directly from her. Unfortunately, no one came. A few students and one parent expressed an interest in the study via email. Those who chose to participate returned the required parent consent/ child assent forms directly to the researcher through a box at the school. The director continued to remind students to complete the forms if they were interested in participating.

The following documents were part of the proposal packet (Appendix A):

1. Parent / Student Cover Letter

2. Parent consent 

a. Interview
b. Focus group

3. Child Assent

a. Interview

b. Focus group

4. Student Cover Letter-18+yrs

5. General Consent
a. Interview
b. Focus group

\section{Data Collection Methods}

The question-writing process took place over a period of eight months and included input from an expert in the field, Dr. Sandra Lopez-Baez, as well as from my dissertation committee chair, Dr. Robert Covert; a member of my committee, Dr. Ruth Ferree; and fellow doctoral students in the dissertation group. The researcher created one set of questions for the interviews and conducted one interview with a graduate of the Dover Immersion Program as a pilot test, a strategy used to check the questions for clarity (Kvale, 1996). The subject was a teacher of Spanish at the high school level and had also taught in a Spanish immersion summer program. Several questions were rewritten, following his suggestions.

The individual interview is a data collection strategy whose primary goal is to understand the interviewee's perspective on the significance of a particular phenomenon (Kvale, 1996). Since an interview is private in nature, the data remain confidential, and 
some individuals may be more comfortable discussing emotions or sensitive topics in this setting. Given the topic of the study, individual interviews were considered to be an appropriate data collection method (Kvale, 1996). They started at the beginning of data collection and continued until all volunteers had been interviewed. All meetings took place at the school, in the Immersion wing of the building, and were scheduled during a half-hour, early-morning study hall or immediately after school to avoid conflicts with students' academic schedules. The interviews varied in length from thirty minutes to over an hour, depending on students' schedules and their individual responses. All interviews and focus groups were taped with an audio recorder. The director of the program helped to coordinate these sessions by asking students to fill out a signup sheet noting the times they were available.

The focus group is another appropriate data collection method for studies that seek to understand different points of view on a phenomenon (Krueger \& Casey, 2009). Focus groups are indicated when the phenomenon to be studied is complex, and they were also suitable for the goals of this study according to Krueger and Casey's (2009) criteria for suitability. The researcher followed these authors' guidelines while planning and conducting the focus group sessions. When focus groups as a data collection strategy are added to interviews, they serve to expand upon themes from previous interviews, to suggest aspects of the phenomenon that have not yet been raised, and to test the data's truthfulness.

The focus groups followed the interviews and were held during the last month of school. In a discussion about the best time to schedule these sessions, the program director proposed to send students as an entire class for part of an extended Immersion 
class period. This proposal was approved by the principal of the school and by the respective Immersion teachers. The program director also communicated with students to coordinate these sessions.

The $10^{\text {th }}$-grade students were grouped separately from the $11^{\text {th }}$ and $12^{\text {th }}$ graders. The rationale for this decision, made by the researcher in consultation with members of the Lake County committee, was to examine possible differences between the experiences of the younger and older students, which might show some long-term effects of participation in the program. The two $10^{\text {th }}$-grade sessions lasted approximately one hour, while the two $11^{\text {th }}$ and $12^{\text {th }}$-grade focus groups lasted approximately ninety minutes. A snack and drinks were offered to the focus group participants. The findings, discussed in chapters IV and V, show that the responses of the two groups revealed definite differences in their level of understanding.

The original interview questions were used as the basis for the focus group questions, to which the researcher added summaries of the most common responses. This was a strategy suggested by Dr. Ruth Ferree, the foreign language and teacher training coordinator at the University of Virginia and, as previously noted, a member of the researcher's committee. Students were asked to reflect upon these responses and to give additional reactions, if any. (For the interview and focus group questions, see Appendix B.) The researcher read the original interview question and the student responses. When the list was long, it was divided into sections read in several stages, to allow students to respond in a more focused manner. No written notes were provided to the students. The reaction strategy proved very effective, as students responded to what their peers had said and explored some of the questions in more depth. Each focus group evolved depending 
upon students' responses to the questions. Some students volunteered their answers, and the researcher asked the others to contribute their thoughts, insuring that everyone had an opportunity to participate. As the discussions unfolded, student interest in a particular question guided the researcher's decisions on moving from one question to the next. When time permitted, the researcher added a few spontaneous questions that were not part of the original set from the individual interviews. They focused on students' posthigh school plans and on their plans five years after graduation. There was time in the last three focus groups (the exception was $11^{\text {th }}$ and $12^{\text {th }}$-grade group 1) for students to answer questions about these plans.

In reflecting on the methodological choices that were made for data collection strategies, the researcher concluded that the use of focus groups as well as interviews yielded a much deeper level of analysis of the themes than the interviews would have done by themselves. Further, the most valuable aspect of the focus groups was that the researcher was able to observe students' interactions with each other and the personal relationships that existed between them. The focus groups also documented the types of exchanges that existed between students and that are possible in this setting. They provided evidence of the existence of multiple cultural perspectives and of differences in the levels of students' cross-cultural awareness and understanding. The juniors and seniors had talked about the value of frequent conversations and debates for their personal relationships and for the level of cross-cultural understanding on issues related to the cultures of the Spanish-speaking world; the focus groups were supportive evidence of the quality of these exchanges. 


\section{Data Analysis}

This study used the approach of Miles and Huberman (1994) for the majority of the data analysis. The researcher listened to the tapes and transcribed them (Maxwell, 2005). Data analysis involved data reduction and began as the researcher developed a hypothesis about the meaning of a given phenomenon, identified a conceptual framework, and chose the initial codes. All of the transcripts were coded. Data segments were then summarized, and these summaries were further grouped into themes (Miles \& Huberman, 1994). Student sketches were created from the individual interviews and the field notes, followed by a cross-case analysis that was displayed in a matrix. These data displays facilitated drawing conclusions. Holistic analysis of interview data occurred concurrently with each one: during and after each interview the researcher took notes on her impressions of the student and his or her comfort level and level of interest in the discussion, as well as of his or her answers to the questions.

During the focus groups, the researcher took notes on which student answered a question first, noted a word or two of what he or she said, and continued this procedure for each subsequent participant. During some of the discussions, it was not always possible to record this information when the conversation was animated and when students spoke simultaneously. Nevertheless, in retrospect, this strategy was an essential tool during the transcription phase for identifying the speakers, the beginning and end of a question, and certain key words in a discussion. This technique was suggested by Dr. Ruth Ferree.

The transcripts were hand coded with the approval of the researcher's professor of Qualitative Analysis with Computers, Dr. Nancy Deutsch. A computer program such as 
NVivo might have been used to structure the interview and focus group data and to help with the coding, but manual coding was more consistent with the researcher's learning style, and it was agreed that twenty-six interviews and four focus groups were a manageable number to code by hand. The initial coding process started with common themes from students' interviews.

In the coding process, the $11^{\text {th }}$ and $12^{\text {th }}$ graders were divided into three groups. The researcher started with the group of students who had been abroad to Spain or Mexico as individuals or with the Lake County program, on the premise that they might have broader types of experiences and greater insight into Spanish language and culture. These interviews yielded a rich array of initial codes to analyze. The remaining interviews were divided in two randomly to ease the coding process.

Early assistance with the coding scheme was offered by a fellow doctoral student, a former teacher of English as a Second Language familiar with student experiences with language and culture, who, like the researcher, was familiar with the ACTFL Five Cs of Foreign Language Teaching and had thought independently about these codes as the appropriate conceptual framework for the study. Dr. Ruth Ferree was also consulted.

The process for analyzing focus group data followed the same procedures as for the interviews. When each transcript was completed, answers from individual students were added to the respective student sketch, forming a complete picture of each individual. Each total profile was then analyzed. The initial focus group received special scrutiny. After the tape was transcribed, a synopsis of the answers to each question from that session was created. This additional step permitted the researcher to verify the completeness of the answers to the questions, to gain insight into the quality of each 
question, and to edit ambiguous questions prior to the subsequent sessions, a technique suggested by Krueger \& Casey (2009). The decision was made to use the same questions for the final three focus groups as for the first because they gave students the opportunity to contribute additional insights into issues related to their experiences in the program.

\section{The Validity of the Data}

In qualitative analysis, a researcher considering the validity of study data takes steps to confirm its trustworthiness and accuracy, a process which runs concurrently with the entire course of the study (Krueger \& Casey, 2009). Vetted strategies that contribute to the validity of the data include member checking, triangulation, and auditing (Creswell, 2005; Lincoln \& Guba, 1985).

Member checking is the process of communicating with one or more participants to verify the accuracy of interview and focus group data that are of particular relevance to preliminary findings and conclusions (Creswell, 2005; Lincoln \& Guba, 1985). The researcher sent the interview transcripts to all participants via the email address provided on the consents (and verified during the interview), asking them to check for truthfulness. Only two of the 26 interview participants replied. No changes were made to the documents (Creswell, 2005). This researcher does not know why so few responded to this request.

Triangulation is an integral part of any qualitative study. It occurs during the design, data collection, and data analysis phases and increases the study's validity (Miles \& Huberman, 1994). Triangulation during study design involves choosing different data sources and types, methods, and investigators; its goal is checking, comparing, and 
replicating findings at different events. The present study uses different sources for the data (the perspectives of multiple people) and two data types (interviews and focus groups). For each student profile, the focus group and interview responses serve to confirm the data for that person individually. The objective was to create a balanced study, to reduce bias, and to create a plausible and truthful narrative.

The concept of an audit comes from the field of accounting and generally involves an independent review of a company's finances from an outside firm (Lincoln \& Guba, 1985). In qualitative research, the audit represents a further step in confirming the findings of a study by evaluating it from the inside and from the outside.

One type of audit, peer debriefing, involves an outside review of the study by colleagues in order to increase the validity of the data (Lincoln \& Guba, 1985). Miles and Huberman (1994) maintain that peer debriefing is important to the quality of data analysis and suggest that peers code selected passages from transcripts to give input into the viability of the codes, a process they call "check-coding" (p. 64). This researcher asked a fellow graduate student to review three coded interviews. Prior to coding them independently, she was trained on the coding schema. The researcher subsequently compared these two sets of coding results. The peer reviewer had added several general codes to the coding schema, whereas the researcher's codes for those chunks of data identified them on a more detailed level. In the peer evaluator's results for the three interviews, the codes "program evaluation", "consequences of being in the program", and "challenges" (of the program) recurred 46 times, out of total of 93 chunks in all to be coded in those interviews. A comparison of the chunks that were coded "challenges" showed that they had been coded "communication," "teacher expectations," and "teacher 
relationships" by the researcher. In each of these chunks, the student had described an aspect of the Immersion Program that pushed her beyond her comfort level at that particular time. This researcher agreed with the code choices of the peer reviewer approximately $95 \%$ of the time; when taking into consideration the more detailed codes, we were in agreement 85 to $90 \%$ of the time.

The audit trail also includes the dependability audit and the confirmability audit (Lincoln \& Guba, 1985). The former consists of an outside examination of the research process and the end results, including researcher bias, the thoroughness of the inquiry, and the findings, analysis, and recommendations. The latter involves an inspection of the study documents, including the proposal, the interview protocol, the data analysis, the findings, and the conclusions. The documents created in this study are available for inspection by the researcher's dissertation committee and others.

\section{Researcher-as-Instrument Statement}

In qualitative research, it has been widely recognized that the "researcher is the instrument of the research," and that "separating your research from other aspects of your life cuts you off from a major source of insights, hypotheses, and validity checks" (Maxwell, 2005, p. 38). On the philosophical and theoretical levels, scholars recognize the value of experience and identity to doing research (Berg \& Smith, 1988; Denzin \& Lincoln, 2000; Jansen \& Peshkin, 1992). In this section, I will discuss in the first person the aspects of my educational, professional, and experiential background that are relevant to my research. 
I started my college career at Pine Manor Junior College, where I took general education requirements and liberal arts courses. I was immersed in French much of the time, as I lived in the French House and took my meals in the French-speaking dining room. While a student at Pine Manor, I spent three semesters in Paris, one at foreign language institutes and two at French universities: 1'Université de Paris 3 (Censier, now Sorbonne Nouvelle) and l'Institut d'Etudes Politiques de Paris.

I trained as a foreign language teacher, earning a B.S. in French from Georgetown University and an M.A.T. in French from the University of California at Berkeley. In addition to pedagogical courses, I studied linguistics, French language and literature, and French politics, civilization, and history. My graduate studies at U.C. Berkeley were a continuation of my pedagogical training and course work in French. In the early 2000s, I resumed my graduate work, spending two summer sessions abroad in Valencia, Spain, with the Longwood College program. While there, I studied Spanish history, pedagogy, and grammar, and I lived with a family. At the University of Virginia, I have completed the course work requisite for a doctorate in Social Foundations of Education, where relevant courses included three in qualitative analysis methods and one in quantitative analysis methods. My other courses pertinent to this study include anthropology of education, comparative education, ethnography and education, and sociology of education. Although much of my academic apprenticeship was spent studying French and Spanish, both the languages and the cultures, it was through my Social Foundations course work and my independent research for comprehensive exams that I gained a more conscious awareness of my own experience as a student and teacher and of the processes involved in acquiring another language and culture. My independent research for my 
comprehensive exams included extensive reading in the field of intercultural communication and competence—a field with which I had previously been familiar experientially. My interest in languages and cultures has spanned over forty years, starting with my first French class in middle school.

Professionally, I have been involved in foreign language and culture education in formal classroom settings at all levels from elementary to first-year college. I also taught in one summer immersion high school program. I have also led groups of high school students to France and other countries in Europe over several summers. My experiences as a French and Spanish teacher have given me an empirical understanding of the approaches to teaching another language and culture in both formal classroom and total immersion settings. In addition, I have gained an appreciation of some of the challenges and the limits of teaching in these settings.

Outside the classroom, I was the founding vice-president of the Charlottesville branch of the Alliance Française, an international French cultural organization made up of Francophones and Francophiles of many different nationalities who share an interest in languages and cultures, especially those of the French-speaking world. This experience has contributed to my understanding of cultures and to my experience working in a multicultural environment.

Experientially, my years in the field of languages and cultures and my identity as a speaker of three languages contribute to my credibility as a researcher in this field. My experiences abroad have included multiple home stays with families while I was a student in France and Spain, starting in high school and continuing for thirty years. By learning to speak another language in the formal classroom setting, in the United States, 
France, and Spain, I gained insight into this process from a student perspective. I also played the role of participant and observer as I learned French and Spanish in the naturalistic setting in France and Spain and watched my peers participating in the same programs. I have reflected on my, and their, experience.

My understanding of other cultures and of culture learning has been particularly influenced by one organization, The Experiment in International Living, in Brattleboro, Vermont (http://www.experimentinternational.org/, accessed 1/31/2014), now administered by World Learning (http://www.worldlearning.org). I have been a threetime participant and a one-time leader for this organization. The pre-departure orientation program for the students included discussions about weathering culture shock, developing cross-cultural sensitivity and cross-cultural understanding, and developing the ability to look at the world from another cultural perspective. As a participant, it prepared me to live in my host culture rather than play the role of critical tourist. In sum, my academic and life experiences have converged naturally and substantively in the present investigation of student perspectives on other cultures. 


\section{FINDINGS (PART I)}

\section{PERSPECTIVES OF SPANISH IMMERSION HIGH SCHOOL STUDENTS ON THEIR LANGUAGE DEVELOPMENT AND ON SOCIAL INTERACTION WITHIN THE IMMERSION FAMILY}

The next two chapters divide the major findings of the study into those related to language and social interaction and those related to culture, recognizing first, that the language and social interaction findings are significant and should be set out in detail, and second, that they are separable from culture learning only in theory - in reality, language acquisition and social interaction infuse and mediate culture learning and cannot be neglected in any discussion of the latter.

The present chapter starts with a brief discussion of students' backgrounds. They are divided into three language groups: native English speakers (NES), heritage Spanish speakers (HSS), and native Spanish speakers (NSS). These distinctions will be further defined in the next section. Then, the findings that are related to students' language development are discussed starting with their initial experiences during the first semester of $9^{\text {th }}$ grade and continuing with the process of mastering academic content in the target language (TL). There is a discussion of their use of Spanish to interact with native Spanish-speakers in a variety of settings, both local and international, outside of the Immersion classroom. The second half of the chapter presents the findings related to the role of the Immersion family in students' experiences. 


\section{Students' Backgrounds}

A total of 27 students participated in the study. There were $1410^{\text {th }}$ graders and 13 $11^{\text {th }}$ and $12^{\text {th }}$ graders. Nine $10^{\text {th }}$ graders were native English speakers (NES), 4 were native Spanish speakers (NSS), and 1 was a heritage language speaker (HSS). In the $11^{\text {th }}$ and $12^{\text {th }}$ grade group, there were 11 NES, 1 NSS, and 1 HSS. There were $712^{\text {th }}$ graders and $611^{\text {th }}$ graders. All of the NSS and the 2 heritage language speakers were girls. In the NES group, there were $310^{\text {th }}$-grade boys and $211^{\text {th }}$-grade boys. There were also 16 girls. It is important to note that of the 27 study participants, 2 did not participate in both an interview and a focus group. As one NES $10^{\text {th }}$ grader, Bella Swan (note: all names are pseudonyms), only participated in a focus group, the total number of interview participants was 26 . In the $10^{\text {th }}$ grade, there were only 8 NES interview participants. For the focus groups, one NSS $10^{\text {th }}$ grader, Mary Scott, did not participate, leaving only 3 NSS $10^{\text {th }}$ graders and a total of only 26 focus group participants overall. (See Appendix C for a matrix of participants.)

Students' experiences were varied, depending upon their status as native English speakers, native Spanish speakers, or heritage Spanish speakers, as well as upon their experiences in life, and individual differences that existed amongst students across all three groups. There were no speakers of languages other than Spanish and English. Defining the language status of a student was not a straightforward process for students with at least one native Spanish-speaking parent, but it was a continuum or a matter of degree. For each student in this category, their status was determined based on this factor, on how the student defined him or herself, and on the language that he or she had 
spoken throughout their lives. The notes on each individual student include the rationale that was used.

Native English speakers. The NES study participants were those who had been raised speaking mostly or exclusively English at home. Two of the students in this group were also heritage language students who had at least one Spanish-speaking parent yet had limited exposure to the language. They will be described in the next paragraph. Several different ethnicities and races were represented within the NES study participants, resulting in somewhat different cultural backgrounds. There were 3 African Americans (AM, JA, and RB) and 1 student of mixed race (MW) (African American and possibly Caucasian). Only 3 NES specifically identified the ethnic origin of their families. RT ( $10^{\text {th }}$ grader) said her family was of Italian origin. EM told me that her family is of Irish and Jewish descent, but said she had been raised in mainstream American culture. Finally, SW mentioned that she was of Asian descent. Six of these 7 students were juniors or seniors. Within this group, only AM had no experience abroad in a Spanish-speaking country. The racial or ethnic backgrounds of these represented salient characteristics of their individual identities that clearly influenced their cultural experiences within the Immersion community, in their local community, and in the Spanish-speaking communities abroad. Those students who were not Caucasian, including the three African-Americans (JA, RB, MW) and the student of Asian descent $(\mathrm{SW})$, attracted some attention in the communities that they visited in Spain and Mexico, where the population was mostly white-skinned. In one example, people in Mexico assumed that RB was from Africa because the only blacks that they had ever seen 
appeared on television during the World Cup (Soccer) in South Africa several years earlier. The experiences of these students will be discussed in more detail in chapter V.

Heritage Spanish speakers. The widely accepted definition of heritage Spanish speaker is that proposed by renowned Stanford University scholar G. Valdés (2001). It "refer[s] to a language student who is raised in a home where a non-English language is spoken, who speaks or at least understands the language, and who is to some degree bilingual in that language and in English" (p. 38). This scholar places the emphasis on the linguistic aspect of a heritage speaker. Another scholar has included the cultural aspect as well. 'In general, the term 'heritage language learner' is used to describe a person studying a language who has proficiency in or a cultural connection to that language” (Kelleher, 2010) (Retrieved from, http://www.cal.org/heritage/pdfs/briefs/Who-is-a-Heritage-Language-Learner.pdf ). These two definitions combined constitute the definition of the heritage Spanish speaker for the purpose of this study. Descriptions of these students follow in this next paragraph.

Two HSS were identified because they had had some exposure to Spanish at home. Both of the students in this study shared the commonality of language but were quite different in terms of their individual backgrounds in addition to variations in the breadth and depth of their experiences. The first student, senior FF, was raised in a primarily English-speaking home by her English-speaking mother and Spanish-speaking father. She reported that, as a child, she spoke some Spanish with her father but did not feel comfortable speaking it with anyone else. The second student, $10^{\text {th }}$ grader LG, was 
born in Puerto Rico and spoke Spanish until she came to the U.S. after $1^{\text {st }}$ grade; she considered herself to be native English speaking. A third student, BS, was a native English speaker, yet could also be considered to be a heritage language learner because of her exposure to Spanish and to Hispanic culture through her father and his family, who were native Spanish speakers, and who lived in Texas, near the Mexican border. She had traveled there to visit them several times, but did not identify herself as a HSS.

Native Spanish-speakers. Five students could be considered NSS participants. Within this group, one student (NS) was born in Mexico of Spanish-speaking parents, came to the U.S. at the age of five, and had been raised speaking only Spanish at home. The second student (PG) was born in the Dominican Republic of a Spanish-speaking mother and came to the U.S. at a young age. She also spent a year in the D.R. during elementary school. She and her family also spoke Spanish at home. The third student (NJ) was born in Peru of a Spanish- speaking mother and spoke Spanish until the age of five, when she came to this country. She stated that she could speak Spanish but had lost her reading and writing abilities in elementary school; she has been classified as a NSS student. The fourth (MM) was raised in a bilingual household consisting of one Englishspeaking and one Spanish-speaking parent. The language status of the fifth student (MS) was unclear because of her statements about her language background. "I live in a house where my mom is Puerto Rican. When I was younger, I lived in New York in a Puerto Rican community. I didn't start speaking Spanish out loud 'till I was around 7th grade and I started taking Spanish class. Like, 'cause I understood the language, I just didn't speak it. (Note: She and her mother had been in the South since her middle school years.) She continued: “A lot of it was Spanish. At home, I don't speak English. Actually, I don't 
unless somebody comes over and they don't know Spanish well, so we'd all just speak Spanish. In another part of the interview she said, "Since I'm a native speaker, I knew how to speak the language. It's just I couldn't read it, and I couldn't write it that well yet." She has been classified as a native Spanish speaker primarily because she identified herself in that way.

A recurring theme for all four $10^{\text {th }}$-grade students is represented by MS's assessment of the deficiencies in her reading and writing skills in her L1. Although all five of these students had identified themselves as native Spanish-speakers, it is not possible to assume that they possessed strong language skills in their L1 prior to starting the Immersion Program. Overall they had not been educated for any significant period of time (or not at all) in school in their L1 in their home country. They had learned colloquial Spanish from their parent(s) at home and several acknowledged that their reading and writing (including their understanding of Spanish grammar) skills were weak, but believed that their L1 oral/ aural skills were strong.

A brief examination of the empirical research on the first and second language development of immigrant students in the United States and Canada may serve to clarify why it is important to pay attention to students' level of proficiency in their L1 and L2. The issue is important for the immigrant student population overall and is relevant for the native Spanish speaking students in the Spanish Immersion Program at Dover High School. In the K-12 setting, proficiency in the language of instruction goes beyond conversational skills and requires the use of academic language, which Cummins and Man Yee-Fun (2007) have called the language of school. Academic language matters because it is associated with school achievement. Within academic language, academic 
writing is the component in which immigrant students may be deficient (Harklau, 2003) and which Harklau has defined as "complex linguistic structures and rhetorical styles that are not typically used in everyday social interactions" (p. 2). Research on immigrant and ELL students has documented the challenges faced by these students (Asher, 2011; Forrest, 2006; Harklau, 2003), especially in high school and college. It is relevant, at least to some extent, to the NSS participants in this study, who had not had the opportunity to develop their academic language in their L1 since virtually all of their schooling had been in English. Additionally, they may have been deficient in their academic language in their L2. In contrast to this group of students, research has shown that a sub-group of immigrant students, who are educated for a longer period of time in their L1 prior to starting their schooling in another language, have the opportunity to develop their language and literacy skills (including their academic language), and their content area knowledge. A strong foundation in these skills is established and upon which students may build in their L2. The research literature on the first and second language development needs of these immigrant and ELL students further clarifies the issues involved.

Research has identified immigrant and ELL students in the United States and Canada by the term Generation 1.5, which means that they share characteristics of the first generation (their parents) and of the second generation (those who are born in the U.S.) in terms of language development in their L1 and their L2. They lack the L1 language skills of their parents, who were educated in their home country, yet are not fluent in the English of their peers (Asher, 2011). As a result, deficiencies existed in their academic language skills in their L1 and their L2 (Asher, 2011; Forrest, 2006; Harklau, 
2003). These deficiencies may not be immediately apparent to educators in the schools because these students demonstrate a familiarity with American culture and have been educated in the U.S. (Forrest, 2006). A study by Garnett (2012) of the K-16 trajectories of immigrant students from 17 empirical studies in Canada documented the ethnic and cultural diversity of their backgrounds as well as widespread variations in academic achievement. The researcher examined K-16 data on academic enrollment, dropout rates, high school graduation rates, and college GPAs. His findings showed that even immigrant students who had been successful academically in high school struggled in their university level coursework because of deficiencies in their academic language skills; particularly in writing in the language of instruction (p. 15). In consideration of these research findings and to the fact that their number continues to increase in American schools, researchers urge educators to recognize the academic needs of this population and to prepare them in high school with the academic language requirements of university level coursework (Forrest, 2006; Harklau, 2003; Garnett, 2012; Crossman \& Pinchbeck, 2012).

This next section marks the beginning of the discussion of the experiences of each group of students with language development. The discussion will include the perspectives of the native Spanish speakers on developing their writing skills in their L1. It is important to note that when students started the program, all had been educated in English previously and therefore shared the common experience of transitioning from an English-speaking classroom to the exclusively Spanish-speaking Immersion classroom. 


\section{Language Development}

\section{Prior Foreign Language-learning Experience}

It is important to discuss NES students' previous experience with language learning because it had an effect on their initial experience in Immersion. For the native English-speaking students as a whole, their prior experience with Spanish consisted of completing Spanish I, which meant that they had studied it for one or two years in middle school. A number of students volunteered information about their experiences with learning a second language in the traditional foreign language setting.

Only three (of 20) NES students, RT, TC, and DM, identified themselves as strong language students. DM said, "I didn't think of it as something difficult. I found it fun. It just depends if that's your thing. And that was my thing, just languages, so it wasn't difficult." RT said, "I do really enjoy the language. It's always been my best subject in school and it comes easy for me." Although TC did not describe her background in the same words as the other two, she said of her level of proficiency in Spanish, "I was at the Immersion level that they needed."

A fourth student, senior SW, undoubtedly typified the extent to which the Immersion experience represented a major change in approach and emphasis from traditional Spanish I classes, which emphasized studying grammar and vocabulary. "I am more of a passive learner, so when I took Spanish I, I did terrible at speaking, but I would be awesome at, like, the grammar tests. So I would learn all that. I think one of my fears of Spanish before was just standing up before a class and having everybody say, 'Oh, wow, she's a terrible speaker of this.' I don't really think the traditional Spanish class 
works for me. (In the Immersion Program), I don't really feel like I'm being judged as much," a recurring theme amongst study participants that will be discussed in greater detail. SW's description of her approach to learning a language and of her level of proficiency in her L2 is important, as it establishes a baseline for her at the start of the program. She credited the Immersion setting with an important role in her developing proficiency in Spanish, reporting significant increases over her four years in the program, as well as a change in her approach to language learning (another recurring theme to be discussed later in this chapter). The rest of the NES students (16) did not directly discuss their prior language-learning experiences.

\section{The Communicative Aspect: The Initial Immersion Experience}

Native English speakers and heritage Spanish speakers. The experience of the Spanish Immersion students at Dover High School began with an entirely Spanishspeaking environment from the very first day. Students were expected to use Spanish to communicate anything and everything they wished to say in each of their Immersion classes, a novel experience for most of them, who may never have said anything of significance in their L2. Teachers continued to enforce this requirement. This was especially important in the initial stages, as students adjusted to the new experience, because it forced them to go beyond their comfort level and to find strategies to convey their message. The native Spanish speaker MM spoke of this stringency and many students also confirmed it in their interviews (RT, LG): "They really do immerse you into it. They don't allow you to speak English in class. They hear you speak English in class, 
they tell you like 'Look, stop speaking English or you have to leave the classroom' ". Two $10^{\text {th }}$-grade NES students, TC and AG, and $12^{\text {th }}$ grader DM believed that the transition to speaking Spanish exclusively was easy. Only one of them, TC, said that she had studied it for three years before high school. As previously noted, she stated, "I was at the Immersion level that they needed." The other two students did not say how long they had studied it before starting the Immersion Program.

Most students, across both languages, felt that their level of Spanish was not adequate for expressing themselves in the target language. Altogether, 13 students, including NSS NJ and heritage speakers LG and FF, characterized the transition as “difficult.” Seven students (RB, JM, ES, JS, ES, AM, LG), including heritage speaker LG, shared concerns about expressing themselves in the target language. For example, NES junior RB said of her initial experience, "That was scary. The first day, I was like 'Oh my gosh!' I didn't even know how to say 'Can I go to the bathroom?' But after a couple of weeks when you hear it all the time, it just automatically comes to you out of nowhere." Additionally, one NES junior, CL, said she and her peers felt like "scared church mice." This sentiment was articulated by SW: "[When I was walking to class, I'd think] 'Oh, no. I have to speak Spanish in here.' It was like some kind of a dread going to class, because you were like 'How am I going to express myself if I don't know how to say this in Spanish?" " SW also indicated the length of time that she felt this way: "I think I was just like any other freshman in the program. I didn't really talk much for the first semester."

Only one student, NES senior EM, expressed a very emotionally charged experience of adjusting to the IP. "At first, it was hard.... the whole entire first month of 
my freshman year, I cried. When I was doing my homework, I would cry because it was frustrating. I didn't understand. When my teachers talked to me, I didn't understand." No other student in the study spoke of a similar adjustment process, yet some might have experienced it without expressing their reaction. In addition, several study participants said that they had considered leaving the program in its initial stage. It is not known how common these feelings were amongst Immersion students who left the program during the initial or subsequent stages; no details about this group were forthcoming, including how many leave each year. For all of the students who persevered, their comments about their initial experiences in the program are important, as they establish a baseline by which to measure and evaluate any progress in the later years. (One senior, NSS MM, did not mention anything about her transition to the Immersion Program.)

Although the two heritage speakers had communicated with family members in Spanish prior to starting the program, they still commented on how uncomfortable they were with the language and with the transition to communicating exclusively in Spanish in the Immersion classes. Senior FF said, "When we were transitioning into the $9^{\text {th }}$ grade, I understood Spanish but definitely was not comfortable speaking it with my family members, besides my dad. I wanted to practice." For $10^{\text {th }}$ grader LG, the transition involved learning to speak academic Spanish: "It's kinda hard because at home I speak English, but I speak Spenglish to my dad, so my Spanish skills aren't that up to date.”

Native Spanish speakers. Native Spanish-speaking students also underwent an adjustment process in taking three of their academic courses in Spanish, but it was different in nature from that of the NES students since it involved their native language. The issue was not feeling competent communicating with the oral language, but rather 
speaking it appropriately and reading and writing it. This group of students had to learn Spanish for the academic setting because it was different from the language for nonacademic settings that they spoke with their family and friends outside of school. In addition, the Spanish that is spoken in various countries of the world differs in terms of vocabulary and pronunciation.

Two NSS students spoke of the adjustment to learning academic Spanish in their Immersion classrooms. MS said, "The Spanish I know is a little bit different from the Spanish that we learn in school, because my Spanish is a slang version from New York. So it's different. So I came over to Immersion and I started learning things, and it was hard to comprehend it at first because I was sitting there trying to catch up with people 'cause there were some words I use for some things that we learn a different word for them. I got confused from it, but then I started getting it and now I'm OK with it." NS also had a similar experience with her slang from Mexico.

MS also talked about differences in pronunciation: "The one thing I had trouble with, though, was when I speak Spanish, my accent's a little weird because I don't pronounce my s's fully. I don't know why I don't, but I don't, but my accent's not really thick, but it's really strong, so I have to tone it down a bit so people can understand me. And there are some words that I use; the teachers don't, so they get confused a bit. And then you have people who can't speak it like I do and so we have a little bit of communication problems."

MS was the only native Spanish speaker who talked about the effect of communicating in the Spanish of the academic Immersion setting in the non-academic 
setting of her Latino family: "It's a little different because in a Spanish-speaking community, I'm always trying to speak properly and make it come out right. So, they sit there and they laugh, 'cause they think it's cute that I'm trying to learn Spanish the proper way. 'Cause they think the Spanish I'm taking is proper Spanish, like from like the original Spanish from Spain. So they're always like 'Wow, you're using big words.' I'm like 'I know,' but I'm trying to apply vocabulary I've learned in Immersion to real life."

\section{Reading and Writing in Spanish}

The main difficulty that the four NSS $10^{\text {th }}$ graders had was reading (MS, NS, and $\mathrm{NJ})$ and writing their native language (MS, PG, NS, NJ) — their skills in English were stronger since they had all been educated in their L2. Three of them spoke about their initial experiences with Immersion. MS said, for example, "Since I'm a native speaker, I knew how to speak the language_-it's just that I couldn't read it, and I couldn't write it that well yet." PG also said, "Other students might have trouble with the spoken. I don't. They're really good at the written, but I'm not, 'cause it's all those accents and stuff. When you speak it, you don't notice it. It's a challenge." MS and NJ also said that they had to learn the written accents.

One of the $10^{\text {th }}$ graders, NS, felt that she had to learn to express herself in more detail in Spanish writing: "Whenever you want to write something, you are given a story and you need to write about it. In your head it sounds more specific, but in Spanish it doesn't come out the same. We have to go into more detail about it - a lot of detail, rather than English. It's really to describe it. I don't know how to explain it. 
A recurring theme common to NES and NSS students alike was that they sometimes found it difficult to keep the languages separate and to refrain from speaking Spanish in one of their English-speaking classes. Three of the NSS students (NJ, PG, NS) and a number of the NES students discussed this issue. PG explained, "Sometimes I catch myself. It's like my brain wants to speak Spanish in English class. I am so used to speaking Spanish in the morning in most of my classes, so it's...sometimes I'm in English class and I start off in mid-conversation and I shoot off, but I'm in Spanish and everybody looks at me like 'What?' And then I have to rewind and be like 'OK, what I said was...." (Note: she did not complete this sentence.).

\section{Discussion}

During this initial experience in the Spanish Immersion program, the adjustment process for students varied from a few weeks to the entire first semester. For some NES and heritage Spanish speakers, it was a more difficult experience than for others. Nine of the 21 felt that the transition was "easy" or unremarkable or did not mention it as a difficult aspect of the program. For another ten students, the transition was not as smooth; they reported that they did not feel comfortable communicating in the target language (TL) because they believed that their speaking skills were inadequate at that time. In the case of EM, who cried out of frustration at not understanding the language, the transition was very difficult. For these eleven students, the adjustment process resembled the initial experience of communicating in Spanish while visiting a Spanishspeaking country. Overall, most NES and HSS language students said that they had 
become more comfortable with understanding and speaking Spanish in their Immersion classes within a relatively short period of time. There were no noted differences between these two groups of students in the amount of time that it took them to adjust to speaking Spanish all the time.

A study of the percentage of students who remained in the Dover SI Program through graduation was conducted by the Lake County central office (11/2013). [See attached chart on the next page.] It revealed significant variations for the cohorts 20112014: $41 \%$ for the 2011 cohort, $62 \%$ for the 2012 cohort, $78 \%$ for the 2013 cohort, and $43 \%$ for the 2014 cohort. The term cohort year has been defined as the year in which students graduated from high school. As a specialty center, this program recruits students across the district, but only those who live within Dover's geographic territory have transportation available to them. In addition, non-academic factors were the primary reason that students left the program for a significant number of them during the two highest years of attrition. For example, in the 2011 cohort, 5of the10 students who left during the first year had transportation problems. In the 2014 cohort, 5 of the 11 students who left during their freshman year or early in their sophomore year had medical problems. An analysis of the other reasons that students left the Immersion Program showed that there were academic and non-academic factors (conversation with the director spring 2011). Among the reasons given were scheduling conflicts with other required courses, student failure, and student workload. Students also commented on the reasons that they had considered leaving and on the reasons why some of their peers had left, confirming the directors reasons. Two $10^{\text {th }}$ graders gave two reasons: student workload and scheduling conflicts. In addition, two seniors also stated that they had 
considered leaving due to the heavy workload. One senior listed the fact that as Immersion students, they had fewer electives (during $11^{\text {th }}$ and $12^{\text {th }}$ grades) than their nonimmersion peers as a disadvantage in the program. Student comments, discussed earlier in the chapter, were evidence that many students felt that they were beyond their comfort zone in terms of their Spanish-speaking abilities during the initial period of adjustment. They had to be willing to take the risk that their skills would improve, to live with this adverse situation, and to persist until they started to feel more comfortable in communicating in the target language. It was imperative that they adjust quickly in order to understand the content in their core subjects and to pass these courses. One of the $10^{\text {th }}$ -grade students, BS, gave her perspective: “In $7^{\text {th }}$ and $8^{\text {th }}$ grades, I didn't care about it [learning to speak Spanish]. Now I do, 'cause I have so much of it. I have to know it to be able to communicate and learn history in Spanish." By the end of the initial period, study participants had crossed this first hurdle on the way to surviving the SIP.

Dover Spanish Immersion Completion Rate by Cohort Year

\begin{tabular}{|l|l|l|l|l|l|l|l|l|}
\hline $\begin{array}{l}\text { Cohort } \\
\text { Year }\end{array}$ & $\begin{array}{l}\text { Number } \\
\text { Enrolled } \\
\text { Initially }\end{array}$ & $\begin{array}{l}2007- \\
2008\end{array}$ & $\begin{array}{l}2008- \\
2009\end{array}$ & $\begin{array}{l}2009- \\
2010\end{array}$ & $\begin{array}{l}2010- \\
2011\end{array}$ & $\begin{array}{l}2011- \\
2012\end{array}$ & $\begin{array}{l}2012- \\
2013\end{array}$ & $\begin{array}{l}\text { Cohort } \\
\text { Completion } \\
\text { Rate }\end{array}$ \\
\hline 2011 & 32 & 32 & 22 & 17 & 13 & NA & NA & $41 \%$ \\
\hline 2012 & 21 & NA & 21 & 18 & 15 & 13 & NA & $62 \%$ \\
\hline 2013 & 18 & NA & NA & 18 & 16 & 15 & 14 & $78 \%$ \\
\hline 2014 & 28 & NA & NA & 28 & 17 & 15 & 12 & $43 \%$ \\
\hline
\end{tabular}


The adjustment process was longer for the NES and HSS than for the NSS students, yet there were significant differences between individual students within each group, as has been noted. Over time, students developed language-learning strategies that helped them to be successful in this new experience of communicating in Spanish. The NSS students felt comfortable speaking Spanish from the start of the program, yet felt that their reading and writing skills needed improvement. Unlike their NES and heritage peers, however, these students did not talk about feeling uncomfortable on an emotional level about the inadequacy of these skills.

\section{Mastering Academic Content in Spanish}

Two primary characteristics, one qualitative and one quantitative, distinguish the Spanish Immersion model for L2 acquisition from the traditional FL model. First, the focus of instruction is academic content rather than the target language itself. SW described the ironic by-product of the difference between the two programs: "Spanish class is supposed to be teaching (you) how to speak. You don't really do that [in regular classes] and Immersion does." Second, the amount of time Immersion students spend studying in the TL is the equivalent of almost three courses per semester for four years. The research literature has shown that these factors promote L2 proficiency in all four skills.

Students talked about various aspects of their experience studying academic content in Spanish. One of the $10^{\text {th }}$ graders, RT, who considered Spanish to be her best subject, identified her mindset prior to starting this endeavor: "I knew it would be kind of 
a challenge. 'Oh, math class in Spanish, history in Spanish, just might be something I want to be able to say I did,' so the challenge." She and TC were the only ones in $10^{\text {th }}$ grade to articulate the challenge aspect of the program, but several of the $12^{\text {th }}$ graders spoke of it as well (MM and FF). Additionally, RT captured the essence of the intensity and communicative aspect of the experience: "For me, it's just speaking it all the time. It's not a regular class. You're not sitting down doing exercises in your book. You're talking with people. You're learning more. The more you use it and the more hands-on, the easier it is for someone to understand the language." This comment is representative of a number of students and will be discussed later in conjunction with the academic engagement of students in the SIP.

One $11^{\text {th }}$-grade NES student, RS, made a comment of a general nature about the difficulties that he experienced during his $10^{\text {th }}$-grade year, without identifying a subject matter in particular. "The most difficult part was probably sophomore year, because that's the point where they no longer ease you into it, and it hasn't become routine quite yet, and they want to get you to that point of routine. I was a little scared that I was going to fail for a time. The more I did, the easier it became, and then I realized that that fear was probably too much."

The courses which students described as being the most difficult for them were some of their first- and second-year core courses. Math received the largest number of comments about difficulties. A few students also discussed world history. These classes specifically involved learning and mastering all of the material in English and Spanish because of the state assessment exam (the Standards of Learning, or SOL), in English, at the end of the year. When students talked about their math and world history classes, 
they did not mention any cultural aspects of them. (The "culture free" issue was raised by Dr. Ruth Ferree.)

Mathematics. One of the main difficulties that many students discussed about studying math in a second language involved learning the specialized vocabulary. RT described the experience as it related to all of their Immersion coursework: "You're being thrown out there. You're getting to use all these different words. In history, you learn different words than you learn in math class and than you did in your freshman year gym class. So you can apply these different vocabularies in one classroom.”

Five students (DS, JM, JS, LG, SW of the total group of 27) thought that their main problem with math was that they had to learn new content-specific vocabulary. Three $10^{\text {th }}$ graders (JM, JS, and LG) said that after they mastered this vocabulary, they felt that studying math became routine. JM's statement is probably representative of these peers. She said, "An example is math. It was at first difficult for me, but now Spanish, it really is not difficult at all in math. It has nothing to do with math, really." Senior SW described her experiences with studying math in $9^{\text {th }}$ and $10^{\text {th }}$ grades and her strategy for mastering the material conceptually: "My math classes [were] kind of hard at the beginning because I didn't really know any of the vocabulary in Spanish, and then she started talking about all these different words in Spanish. I was sitting there like 'Oh, my gosh.' So I just kind of learned from the book in English." She found a strategy that worked for her, and this was an essential step in surviving a situation in which she may have been somewhat beyond her comfort zone, and ultimately in successfully completing the program. 
Because of the SOLS, all students faced the problem of switching back and forth between Spanish and English. RT and TC mentioned it specifically as the difficult aspect of math, even though they had identified themselves as strong students in this subject matter. RT said, "Difficult? Not really. It was mostly just that going back and forth for SOLs was kind of challenging because you have learned all these words in Spanish and then 'Uh oh, SOL is in English. So you kind of have to go back and relearn it, which was kind of a challenge at first."

Most of the students took geometry in $9^{\text {th }}$ grade and Algebra II in $10^{\text {th }}$ grade. Eight students, including one HSS and one NSS (out of 27), described their math classes as “difficult” (ES, JP, JM, TS, DS, SW, LG, PG). Within this group, only two students seemed to feel that they had significant problems in this subject matter. JP $\left(10^{\text {th }}\right.$ grade $)$ said that his difficulty with math was on the conceptual level: "I really had trouble with math. I've always had trouble in math, and Mrs. Arnold would stay after school every Tuesday and Thursday with me and help me out." The other student, DS ( $11^{\text {th }}$ grade), described his problem with math in these terms: "The first two years of high school, I took math class. For me, it got a little bit confusing with just trying to learn something as complex as math." This was his suggestion to his teachers: "Maybe if a student really isn't understanding something, maybe start to explain to them in English if it is an absolute must." For Dan, the problem may have been related to both the conceptual and the linguistic aspects. He said that he worked very hard, paid close attention, and received extra help in math from his teacher to overcome this problem.

World history. Only three students (two $10^{\text {th }}$ graders, NSS NJ and NES ES, as well as $11^{\text {th }}$-grade NES AM) specifically mentioned any difficulties with their world 
history class. Conversely, $310^{\text {th }}$-grade NES students (JS, JM, RT) shared $10^{\text {th }}$-grade heritage speaker LG's feeling about this class: "Pretty easy now 'cause my Spanish is getting better, so I understand it more.” These students appear to have adjusted to studying academic content in their L2. For AM, the difficulty was related to vocabulary. She said, "Well, it was kind of hard for me to take history in Spanish—World History II. They say 'Enrique' in Spanish and 'Henry' in English, and I was looking in the book in English, and I couldn't figure out that that was the same person." At the time of her interview, this student spoke about her current proficiency in Spanish: "It's like a second world to me, 'cause it comes out naturally." This second comment is evidence that she found a strategy for learning the academic content, although she did not talk about it.

$10^{\text {th }}$ grader NSS NJ seemed to be having the most significant difficulty of any student in the world history class. She talked of her general experience with the Immersion courses and also about the history class. "I thought it would be like more fun than what it is. And they said that we could do more hands-on things. But we basically just like take notes a lot, especially in history. I've been so lost. In history, all we do is notes 'cause we have to translate from English to Spanish from our textbook. I think it's difficult to do that. When we read, we have to be able to talk about it in Spanish. It gets really hard."

For this student, the difficulty seems related to three aspects of the course. There was a linguistic issue because of the translating back and forth from one language to the other. There may have been a cognitive issue, since the class involved taking a lot of notes and she felt "lost." The third difficult aspect of the course was the magnitude of the task of mastering the material in both languages in the face of the looming assessment 
test (SOL). NJ's comments indicate that she did not feel that she had mastered this academic content, and that she was in a learning environment that was beyond her comfort level. Unlike NJ, who was talking about her lived experience at that moment in time, the 11th grader, AM, had completed and passed this assessment and talked about this experience in her past with the benefit of hindsight, knowing what the outcome had been. On the $11^{\text {th }}$ and $12^{\text {th }}$-grade levels, the Advanced Placement (AP) exams in Spanish (11 ${ }^{\text {th }}$ grade) and in Spanish Literature were the only assessments that students took that were related to their Immersion coursework. No student mentioned anything about them.

Immersion study participants had varying experiences with studying academic content in Spanish. Some of their difficulties were related to the adjustment to studying content in a new language. Other difficulties were undoubtedly not connected to this challenge: individual differences exist between students, who have distinct learning styles, study skills, motivational issues, academic and emotional maturity, and preparation. These additional factors may have affected student performance in the Immersion classes as well as in all of their non-Immersion classes. For example, certain individual differences do not appear to have given an advantage to NJ, the native Spanish speaker. When compared with heritage speaker LG, quoted above, it was NJ who was struggling in world history, while the LG felt more confident in that class. In fact, LG's experience seems to be typical of her NES and NSS peers in $10^{\text {th }}$ grade, as no one else reported difficulties in the world history course. Among $11^{\text {th }}$ and $12^{\text {th }}$ graders, as previously mentioned, only AM discussed any difficulties during the interview.

Discussion. NES, NSS, and HSS do not appear to show significant differences in their responses to questions about studying academic content in Spanish. In math, the two 
students who said they had the most significant difficulties because of the language were NES. One NSS, PG, and one heritage speaker, LG, also found it "difficult" for what may have been language-related reasons. In the world history class, only two NES students (of 20) reported any difficulties. The first, $10^{\text {th }}$ grader ES, simply said she found the course "hard." The second, AM, a junior, has been quoted earlier about her experience with "Enrique" versus "Henry" in that class in $10^{\text {th }}$ grade. This student also expressed her feelings at the time of the interview about studying in two languages: "I feel very comfortable with it, conversing in Spanish, and sometimes I use Spanish in classes I take in English (giggle). So, it's like a second world to me, 'cause it comes out naturally. I asked my teacher could I get an AEP pass in Spanish, by accident. I kind of like it because I can converse in Spanish, and I know it will help me get a job when I get older."

Junior RS had a somewhat comparable experience of being in a situation where he was beyond his comfort zone in $10^{\text {th }}$ grade and feared that he might fail. Comments that he made at the time of the interview, however, were evidence that there had been a significant change in his comfort level as his proficiency in the target language increased: "It's a lot easier than most people would expect. Over time, I've become kind of accustomed to it. It's actually become kind of fun."

Senior EM, who seemed to struggle the most during the initial period, talked about how she felt about studying in Spanish: "Now that I'm a senior this year, it's different because it's almost like everybody does it. I've just gone through it so much and I've been so used to it that now I don't even think about it. Now the light switch goes on in my head, 'Oh, we're in Spanish class. I need to speak Spanish.' You know, when I go out into the hallways, sometimes the Spanish flows over, but most of the time, the light 
switch just goes back on and I'm like 'Oh, yeah, I have to speak English now.' It's an opportunity that not everybody gets, but for me, I've been so accustomed to it, where it is like a second skin to me. I just do it, don't even think about it."

These three students, AM, RS, and EM, were willing to persist in the face of a situation placing them beyond their comfort level in their L2, and through extra effort on their part, they eventually reached a higher level of proficiency. This gave them the wherewithal to be successful in Immersion. Other students in the program very likely had a similar experience but did not discuss it in their interviews.

What does this lack of difference between students of different language groups mean? For NES and HSS, studying academic content in their L2 meant that they had found a new approach to gaining access to the subject matter. They could discuss it in two languages. What did these students say about mastering content in two languages? One of the students (JM) said of her progress, "In math, I was...at first it was very difficult for me, but now Spanish, it really is not difficult at all in math. It has nothing to do with math, really. It was hard to get past that [language barrier], but once you learn Spanish, Immersion is just like any other class, since you understand the language.”

A comparison of students' comments about their initial experience in Immersion in early $9^{\text {th }}$ grade and their experience during their $10^{\text {th }}$ grade or later years shows that they have made significant progress in a relatively short period of time. Few students talked about having difficulties with world history class. Twenty of 27 study participants were native English speakers who had developed enough skills in Spanish to be successful in an academic subject matter. Their experience is an indication that these students were 
able to develop high levels of proficiency in Spanish in the Immersion model for second language acquisition, while also completing some of their academic course work. It also suggests that students can reasonably expect to be successful in this Immersion Program if they have completed Spanish I or the equivalent in the traditional FL setting prior to entry.

\section{Becoming Proficient in Spanish}

Students from all three groups talked about various aspects of developing proficiency in Spanish. NSS students mentioned their progress in reading and writing skills, while NES and HSS generally discussed their progress in listening and speaking skills. Some students in this latter group spoke about the specific strategies they developed to help them with this progress. Their comments about the people with whom they spoke the language and the contexts in which they spoke it provide evidence of their level of comfort with the language.

Students' strategies for developing proficiency. One of the NES students, TC, compared developing proficiency in a language in order to achieve the goals of the Immersion setting to learning a language as the focus of instruction. Her description applies to languages in general rather than to Spanish specifically, of course, and it is an indication that she understood what was involved in learning a language as a tool for communicative purposes and to convey content: "It's been challenging. You have to understand it. You can't just go in and learn vocabulary and learn grammar like you would in a normal Spanish class. You have to learn how to use it and when to use it. 
And you have to understand all of it." This student identified the overarching strategy by which Immersion students learned to be successful in the program: reaching a level of proficiency in the language that enabled them to manipulate it effectively while mastering academic content. Her comment about the "challenging" aspect of the program was a recurring theme from three additional students (RT, MM, FF- including the NSS and HSS $12^{\text {th }}$ graders,), who acknowledged that by definition, it required them to push themselves beyond the norms of the standard curriculum. This particular group of students welcomed this type of opportunity.

As previously mentioned, one factor that contributes to increased proficiency in a second language is the amount of time that students spend listening, speaking, reading, and writing it—an inherent aspect of the program. DS spoke of this: "Constantly applying that language, constantly hearing it will improve your speaking, your vocab(ulary). That's probably one of the most important things I can think of about this program - the continuous application of the language.” Another NES student (RS) concurred: "I was a little scared I was going to fail for a time. The more I did it, the easier it became."

Six NES students (out of a total of 19 interview participants) spoke about specific strategies that they recognized as helping them to move to higher levels of proficiency in the target language, strategies applicable to language learning in general. DS believed that it was important to "pay close attention in class, especially for math." MW suggested another important strategy: "Do all your homework every day or you will be lost." One of the $10^{\text {th }}$-grade students (TS) spoke of a listening strategy: "Some Spanish speakers talk really fast. I repeat what they say in my head." Another $10^{\text {th }}$ grader, JM, 
suggested a two-step speaking strategy: "A lot of the time I'd have what I wanted to say in my head, but I wouldn't know how to say it. And that was difficult, but I got through it. A lot of the time, I'd ask a friend or I'd just try to say it in a different way that I knew how to say it in Spanish."

These comments about strategies that involved finding other ways of expressing an idea or seeking help from a friend represented the experience of a number of other Immersion students as well. Indeed, the strategies of working with another L2 peer and of finding different ways of conveying a message are common approaches to the interactive, developmental process of L2 acquisition across all language-learning settings. The particular effect of student support and of the interaction of Immersion students amongst themselves and with their teacher in the Immersion setting will be discussed later in the chapter.

As an additional strategy, a $12^{\text {th }}$ grader NES, DM, adopted another listening strategy outside the classroom: "I remember sophomore year, I really realized that in order to be able to speak it right, I would have to listen to it more. So that's when I started watching TV, like the Novelas (soap operas), and I just really started watching them. Then I started listening to music, and then I started the guitar because I fell in love with that one song. And I was like 'Oh, that's it.' I started taking Bachata lessons with a guitar teacher." (DM explained this term: “It's a type of dance, but it's also a type of music genre they play mostly in the Caribbean. It's from the Dominican Republic." While the two heritage speakers, LG and FF, talked about their progress, they did not talk about learning strategies for developing L2 proficiency. 


\section{Communicating in Spanish in the Local Community}

$10^{\text {th }}, \mathbf{1 1}^{\text {th }}$, and $12^{\text {th }}$ graders. This study documents the extent to which students in the program used their Spanish both inside and outside of the Immersion setting. It examined the people with whom they chose to interact, the contexts in which they did so, and their responses to these interactions, both in terms of their comfort level in each encounter and of their perceived ability to communicate effectively and appropriately in their L2. A comparison of the $10^{\text {th }}$ graders as a group with the $11^{\text {th }}$ and $12^{\text {th }}$-grade group revealed that 7 of the 9 NES and HSS in the former reported speaking Spanish outside of the Immersion setting. For those in the latter group from the same language backgrounds, the figure was 9 of 12 students. From a purely mathematical standpoint, these two groups approached parity. There were meaningful differences, however, in the number and kind of activities in which they used their Spanish. These favored the $11^{\text {th }}$ and $12^{\text {th }}$ graders, who spoke Spanish in a greater number of activities, in settings which required a higher level of proficiency in environments where they felt less comfortable, at least initially.

Several variables emerged when the study participants were compared across grade levels for linguistic engagement with the local community. The more advanced students generally had a higher level of proficiency in their L2 than those in the $10^{\text {th }}$ grade group, which paralleled and underpinned the natural progression in the types of activities in which students were involved as they went through the program. Differences in the level of proficiency of Spanish of students also existed within a group and across 
groups. For example, some students had more language ability than others, regardless of their grade level. Other factors also contributed to differences in the choices that students made to speak Spanish in particular settings: personality traits, such as shyness, affected the choices students made about activities in which they wished to be involved, and variety in students' interests affected the amount of time they had to commit to activities involving Spanish. Overall, Immersion students evinced different levels of involvement in activities, both formal and informal.

Students in the IP talked about their experiences with members of the Latino community. When these students chose to speak Spanish in real-world, non-academic settings with people whom they did not know, they went a step beyond the more familiar environment of Immersion classroom interaction with their peers and teachers. This represented an important first step for them psychologically in terms of their comfort level with their L2. They seemed willing to take the risk of making mistakes in grammar, vocabulary, and pronunciation even though they were concerned they might be judged by members of the Latino speech community. These interactions not only showed that they had enough confidence in their Spanish-speaking abilities to communicate with strangers outside of their Immersion support system; they also served to validate their abilities in Spanish when these native speakers gave them feedback.

In the $10^{\text {th }}$-grade group, the 7 (of 9) NES and HSS students spoke of using Spanish outside of Immersion in two types of settings: with friends and neighbors or in restaurants and stores. The 9 (of 12) NES and HSS participants in the $11^{\text {th }}$ and $12^{\text {th }}$ grades spoke Spanish with neighbors and friends, in retail stores or restaurants, or where they volunteered or worked — an additional type of setting. These students volunteered to 
serve as translators for local charitable organizations, including churches and medical clinics, and for schools in their school division. The school-related activities included a Service Learning course for Immersion students in which they acted as teaching assistants in ESL classes at local elementary schools during the school year or in the summer (AM, JA). Most of the children in these classes were native Spanish speakers, and so the Immersion students used their L2 with the students and were available when needed to speak with parents or to translate parent communications into Spanish (JA). Immersion students also had the opportunity to babysit for children who were non-native speakers of English while their parents attended ESL classes, as well as to translate for Spanish-speaking parents and family members at school-related events such as field days or back-to-school nights.

Speaking Spanish with neighbors or family friends. Three $10^{\text {th }}$-grade students (AG, RT, JM) reported that they periodically spoke Spanish with a Hispanic neighbor. In addition, JP also talked about speaking his L2 with friends who were NSS. JM spoke about his experience: “My neighbor's Spanish, and whenever I see him, I always talk in Spanish. AG had a similar experience: "My neighbor Verónica speaks Spanish, and so we'll talk, and I'll talk with her family, and we'll watch Novelas and stuff, so that's fun." When asked, "Do you feel comfortable in that situation?" she said, "Yes, a lot more. At first, I was nervous because they were always like 'Come over. Speak Spanish. It will be fun.' I was kinda like: 'uuuh...,' and then actually when I got into it, I understood more than I thought I would, and I've learned a lot, actually." JS seemed proud to tell me that he had been able to communicate with a couple from Cuba, who were pastor friends of his father, when they had visited the family. This same student is also indirectly involved 
in the Spanish-speaking community at his church as he helps his father, who is a pastor, learn simple devotionals.

JP appeared to use Spanish more than all his $10^{\text {th }}$-grade peers. He spoke about speaking Spanish with his NSS friends: "Well, I have a good friend. I'll text him a lot and see what's going on with soccer, stuff like that. I'll text him in Spanish; I'll text him in English for practice and stuff, because I can, so that's cool.” He also talked about speaking Spanish with teammates on the soccer team: “A lot of Hispanics play soccer, so our whole soccer team - maybe half of them-are Hispanic, so I learn their way to play. It's awesome 'cause they don't scream in English because they don't think like that. They think in Spanish first, so they'd be yelling like 'Pass the ball!' in Spanish. I mean, that's cool."

Only one of the $11^{\text {th }}$ and $12^{\text {th }}$-grade study participants, RS, talked about speaking Spanish with neighbors and friends. Rusty spoke confidently about helping a friend to communicate with her grandmother, who spoke only Spanish: "Once at a friend's birthday party, her grandma only spoke Spanish, but her granddaughter didn’t speak any Spanish, and they felt distant. There was a little bit of an experience there where I got to translate between the two of them for a few minutes. That was kind of interesting. She [the grandmother] seemed a little bit uneasy at first, being that I am obviously very white. I was still able to keep up with her in Spanish ability, but after seeing that, I think she felt better." When asked about the changes he had seen in his comfort level in Spanish, he said, 'I'd say I feel fairly comfortable. There's always a little fear that I'm getting something wrong, just because I haven't grown up with the language. I'd say I'm ten 
times as comfortable as I was starting out in regular Spanish classes, not being in Immersion."

When study participants interacted with friends and neighbors, they were in a setting with individuals or with a small group of people in a relatively low-key environment. These situations allowed them to practice their Spanish and to test their ability to communicate with native speakers in a non-academic setting. AG was a good example of a student who pushed herself somewhat beyond her comfort zone in her initial interactions with her neighbor. In doing so, she discovered that her Spanishspeaking abilities were better than she had thought; she gained more confidence in her ability to communicate in her L2. This experience, in turn, could well be the catalyst for her tackling more linguistically and psychologically demanding — and possibly more stressful-situations. This type of experience for $10^{\text {th }}$ graders may give them the confidence to volunteer in subsequent years for some of the activities in which their $11^{\text {th }}$ and $12^{\text {th }}$-grade peers were involved.

Speaking Spanish in restaurants and stores. When students spoke Spanish to members of the Latino community in restaurants and stores, they were speaking with people whom they may not have known. Although the setting may have been somewhat more stressful psychologically for some students than communicating with friends and neighbors, the level of proficiency needed for this type of communication was relatively basic, and students were likely to be familiar with the required vocabulary from their experiences learning about and trying different dishes from countries of the Spanishspeaking world on "Food Days" in their Immersion classes. Nevertheless, some students were comfortable using their Spanish in this setting, while others were not. 
The comments of one NES junior, Dan Smith, suggest that he felt less than comfortable speaking Spanish with restaurant personnel: "There was one trip that we went on to Don Pepe, a Mexican restaurant. I'm just a little bit hesitant. I can understand Spanish and whatnot. I haven't gotten to that point. I'm kind of shy, I guess. I could if I wanted to." When asked whether he spoke Spanish with his Immersion peers in this setting, he replied, "It's kind of a mix, actually. Sometimes we'll apply some English and sometimes we'll apply some Spanish, but we refer to it as Spenglish ." As this student suggested, his choice to speak English with restaurant personnel may have been related to his own personality. His comments contrasted with those of two other students, NES $10^{\text {th }}$ graders RT and JM, who said they do speak Spanish to employees at Latino restaurants.

RT spoke about this experience: "My dad is the area manager for Chipotle, so whenever I go to work with him, they're all like 'Oh, she's in Immersion'. So I do talk to his employees, and it's fun to talk to them. They're from all over, so you kind of learn different words, 'cause a lot of them are Costa Rican, and I don't know many Costa Ricans, so you learn different words." In addition, one of the $11^{\text {th }}$ graders, AM, liked to speak Spanish with native speakers in stores or at the hair dresser's. She reflected on the progress she had made in Spanish: "Before Immersion, if I was in a store I couldn't talk to people in Spanish. Where I get my hair done, they are Hispanic, and I can talk to them in Spanish, which I couldn't do that [sic] before. The major thing is that I can converse and I can understand other Hispanic people, talking outside in public." It is hard to gauge the extent to which these students spoke Spanish with members of the local Hispanic community, since the information is self-reported and there is no way to verify it 
independently. Their comments were, nevertheless, evidence that their proficiency in Spanish had improved, when compared with what these same students said of their Spanish-speaking abilities when they first started the program.

In their interviews, only two NES $10^{\text {th }}$-grade students did not talk about speaking Spanish in the local community. But one of them, (ES), spoke of her plans to use the language in the future: 'I'm about to start volunteering at my church because my church is probably $75 \%$ Hispanics. So we have a food pantry, and there's different groups, so my group hasn't started yet, but I'm gonna help. I'm going to be the bilingual person in my group and help them. They need food, so I would help them fill out forms and get food and everything." The other student, TC, when asked about any future plans she had to be involved in volunteer or other opportunities in Spanish, replied, "Maybe if I have the time, really."

Volunteering in the community. Study participants were a civic-minded group across all three grades, based on what they said about their current and future interests and activities, which involved volunteering to use their abilities in Spanish to help with needs that they had identified in the local Latino community. The only difference between the $10^{\text {th }}$ graders and those in $11^{\text {th }}$ and $12^{\text {th }}$ grades is that the former spoke about volunteer jobs they planned to do in the future, while in the latter group, many of the students were already active in such activities. No $10^{\text {th }}$-grade participant spoke of any current volunteer activities. Eight of $1311^{\text {th }}$ and $12^{\text {th }}$ graders (FF, SW, JA, BS, RB, AM, RS, DM) were involved in various volunteer activities. One of the seniors, DM, was especially active in the Hispanic community: "I guess you realize that there's a lot of need for people who are bilingual and willing to use resources or help out. It's not 
exactly the richest group in America, so you've just got to be willing to help out and stuff like that." Her comments may be representative of the other students as well.

In the Immersion Program, the Director told the students about requests for assistance, from outside non-profit organizations and from their own school division, at events where Spanish speakers would need help with translation. Two students (DM and AM) also accumulated the community service hours required for the Beta Club at school by volunteering for some of these activities. Three other students (FF, MM, and RS) had also volunteered to serve as translators on an individual basis through a parent or their church.

Translating for Spanish-speakers in the school community. One student (DM) served as a translator for adults at events such as a parent-night at a local elementary school and as a baby sitter for young children while their parents are enrolled in ESL classes. DM and a couple of other Seniors (SW and FF) spoke about how they felt about their Spanish speaking abilities when they interacted with adults versus children and the changes they saw in their comfort level as their L2 proficiency improved. DM said, "I knew that they [the ESL kids] were really nervous, 'cause like they didn't know each other themselves. So I felt comfortable because I guess they were kids. It's little kids, so you feel more comfortable to make mistakes and correct yourself. You feel a little freer with your accent. And a lot of them, they're not so focused on your accent, they're just amazed you can speak it and communicate that they're not judging you or anything." As she interacted with children, DM focused on communication. Concerning her experience with Hispanic adults, she said, "I had to translate for parents. I was a little more apprehensive, 'cause they could be judging me. But I think like that kind of wore off as 
that event ...was going on. You'd just be comfortable. First there's meeting people and having to speak to them, what they might think of you. But after a while, you're just translating, you don't really think about it—it just kind of comes out."

SW's comfort level also varied when she spoke Spanish and translated for groups of children versus adults: "The ESL class, I think, was easier than the Christmas Mother (run by a local charitable organization) because I wasn't afraid of the kids judging me on how well I spoke Spanish or not....The Christmas Mother program, you'd have somebody come up, and they don't really speak much English. And you'd have a moment of initial panic, like, 'Gosh, what if they can't understand me?' Or 'What if my accent's too bad?' or 'What if they just look at me in disgust and walk away?' But you just talk and they understand, and you communicate that way." These comments are an indication of the progress that she had made in Spanish, of the risks that she was now willing to take to speak the language with native speakers, and of the confidence that she had gained in her communicative abilities in her L2. Through these experiences, she realized that she had the ability to communicate successfully in another language.

Independent volunteer opportunities. An additional senior, FF, a heritage speaker, seemed to have been as uncomfortable as her NES peers about speaking Spanish with members of the local Hispanic community during her early years in Immersion. She said, "When I first started learning Spanish, my mom would tell me to talk with people at church, to get them to come to our church and stuff. And I didn't want to do it at first, but then after a couple of years of being in the Immersion Program, I realized there's nothing to lose in just talking, and if you make a mistake, I'm pretty sure that they'll understand if you explain to them that you're not native and that you're learning." She talked about the 
confidence she had gained through these experiences as she volunteered for her church: "So I used to go with my church to go on bus ministry around the neighborhoods around our church, and we talked to the Spanish-speaking families, and they all understood where I was coming from when I explained that I'm learning Spanish. And so it kind of, I guess, helped to tell them that I was learning, and I guess the whole thing with the Program, the whole four years, has helped me to become more confident in speaking to people in general in Spanish," Although these students did not explicitly talk about the risks they had taken in stepping outside of their comfort zone to communicate with native speakers, they seemed to recognize the extra effort these interactions required. Participation in the program enabled them to take the leap - to go out into the community — and the positive experience they had in these interactions led them to conclude that these risks had been worth taking. They became more comfortable with such interactions and were likely to seek out further opportunities of this kind.

Rusty, a junior who spoke Spanish outside of school and made connections with local Hispanics, spoke of his volunteer work at the medical clinic: "Well, the clinic's main focus is on kidney failure, and so it's given me a more specific vocabulary. The first few times I did it, it was really uncomfortable and hard to do, but along with the help of Immersion and just doing it more times, it's become a lot easier. At this point, it is more of a conversation than work, so it feels a lot better." Although he was not overly confident in his abilities in Spanish, this was an important accomplishment for him, both in terms of his second language and of the inner strength needed to volunteer to help people in this specialized setting. 
Speaking Spanish at work. Four $11^{\text {th }}$ and $12^{\text {th }}$ graders and one $10^{\text {th }}$ grader talked about their experiences meeting and with talking with Spanish speakers at their place of employment. Daniela worked as a cashier at a grocery store and seemed to embrace the opportunity to communicate with Spanish speakers: "I think like when I see someone that looks different or hear an accent that's different, instead of shying away from that person, or like, 'Oh, they're not going to understand me, I shouldn't talk to them,' you just kind of go up to people and 'Oh, where are you from?' This girl came through my line and her English was horrible or she was trying to explain to me something. I was like, 'Oh, where are you from?' She was from Argentina. So we started having a conversation, so I think it just makes you more open to people. So you're not so like scared of differences, you want to learn more about other people and their cultures."

Another senior, Mina, also worked at a grocery store and talked about her interactions with Hispanics whom she met there: "In the community, at my job I work at Martins (a local grocery store chain) and I run into a lot of Spanish-speaking people. And sometimes I eavesdrop on what they say (giggle). There are actually a few customers that I have who will just come through my line and speak Spanish to me 'cause they know I understand. There's one guy who comes to my job. He cannot speak English, and if I'm there, they ask me to like help him and like translate how much to pay for. It's not like 'Oh, we're going to go here and help these kids.' I've always just run into it, like by accident, and it's like 'Oh, OK you don't' understand, well I kinda can translate for you. I can help you out." A third student, Rosalinda, spoke about her experience with Spanish at her job at TJ Maxx: "I'm pretty much bilingual. I am only a junior, and I already had a pay raise for being bilingual at my job.” 
One of the shyest students, $11^{\text {th }}$-grader Dan (DS), also spoke about a conversation he had with a Spanish-speaking customer in the store where he had worked: "I used to work in a shoe store. There was a lady that was there who told me that she only spoke Spanish, so I started speaking to her a little bit in Spanish. I told her, I was like 'If you need any help, I'll be more than happy to help you out.' That was probably my greatest experience right there was [sic] being able to be probably the only person in the entire store who was able to understand somebody who was of Spanish-speaking descent. I felt pretty comfortable" [with that experience]. This was a student who seemed more reserved and had less confidence in his proficiency in Spanish, as evinced by his prior comment about not speaking Spanish with the servers in the restaurant.

One of the $10^{\text {th }}$-grade boys, John Persie, was notable in the extent to which he interacted with people in the local Spanish-speaking community: "I am with Hispanic people maybe $80 \%$ of the time now." He spoke Spanish with his peers at school and with adults at work. He talked about his job: "My uncle is the owner of a business, and a lot of Hispanics work for him. I [translate] for him. He'd be like 'tell him to do this, this, and this' and I tell him. They know English, but they're just not too great at it. And I can communicate with people. And we would be working." This type of interaction with adult native speakers whom he had not known previously may have been a higher-stress situation for him, at least initially, than talking with his friends at school, as was the case with the 11th and 12th graders discussed earlier. When asked about his comfort level with this task, he replied, "Well, I would start off nervous because I don't want to offend anybody if I say something wrong or if I do the wrong thing. I'd start off just mumbling a few words. Well, then they'd start, they all grow respect for you when you take the time 
to learn their language. And they'll start asking you to talk more and they'll start teaching you words that you didn't know. It grows as the conversation goes on. You start off nervous, and then I wanted to talk with them maybe for a couple of more hours or something like that."

He spoke with apparent pleasure about one conversation he had with two employees from Mexico: “There's two of 'em, and he and his buddy would be like, 'Oh, yeah, remember when I did this and this back in Mexico?' I remember he talked about some festival and, you know, I knew what it was. He was astonished that I knew what it was." This vignette is an indication of his level of conversational Spanish. His knowledge of the culture allowed him to follow a conversation with native speakers and to interact with them in a natural way. The caution that he showed when initiating the conversation was evidence that he understood, on an experiential level, that communicating in another language involves more than putting together a string of words. He seemed to believe that it was important to start slowly and respectfully in order to judge the reactions of his interlocutors, whom he did not know well.

Discussion. When students spoke of the different settings in which they used their Spanish in the local Latino community, they gave evidence that they were moving along the path towards acquiring advanced levels of proficiency in their L2. They became more adventurous in the types of situations in which they chose to interact, and their proficiency increased in tandem with their bravery. Their linguistic and cultural horizons expanded as well. They also gained in confidence through these experiences. No students in this study reported negative experiences in these interactions with native speakers. Such an experience could have adversely affected their confidence level in 
communication in the target language, as well as the subsequent choices they made about interacting with native speakers.

The development of the students' proficiency was, to some degree, related to the choices they made about seeking out interactions with members of the local Latino community. A comparison of a student like DS with DM or SW shows that an element of personal choice affected their comfort level with the L2 and in consequence, the development of higher levels of proficiency. As has been previously discussed, personality characteristics such as shyness could have affected students' decisions to seek out interactions with Spanish speakers. DS spoke Spanish with the one customer in the shoe store but did not seek out further opportunities. Other students across the three grade levels (AG, JP, RS, FF, DM, SW) also experienced some nervousness during their initial interactions in the Latino community but nevertheless demonstrated a willingness to consciously push themselves beyond their comfort level in their L2, continuing to seek out new opportunities. The comments from several of these students indicated that their efforts were rewarded. RS said of speaking Spanish in the medical clinic, "It was really uncomfortable and hard to do, but along with the help of Immersion and just doing it more times, it's become a lot easier." JP's comment was similar in tone: "It grows as the conversation goes on. You start off nervous and then I wanted to talk with them maybe for a couple of more hours." DM's comment indicated that she was able to focus on communication: “After a while, you're just translating, you don't really think about it—it just kind of comes out."

L2 learners' most important experiences for developing proficiency in Spanish were those that involved interactions with native speakers and other members of that 
speech community. These interactions were also an essential component of reaching advanced proficiency. This section has focused on those experiences that were primarily linguistic in nature, although they involved both language and culture since they were "real world situations in a spontaneous interaction and non-rehearsed context and in a manner acceptable and appropriate to native speakers of the language" (ACTFL, 2012, p. 4). When students communicated with L1 Spanish speakers in the community, they moved to a setting that was more demanding linguistically and culturally than the setting inside the Immersion classrooms and that involved interacting with people whom they did not know. For the most part, however, these settings were familiar to the students, since they took place within the broader context of the majority culture and language. This familiarity with the settings probably provided the students with a certain level of comfort in spite of their apprehensions about these interactions. They translated for L1 Spanish-speakers in their own schools, in their places of employment, and in their neighborhoods as L1 representatives of the majority language and culture.

\section{Communicating with People in a Spanish-speaking Country}

A supplemental component of the Immersion Program is an optional summer program in Spain or Mexico that offers students the opportunity to experience the language and culture firsthand. Those students who traveled abroad with Lake County or who made individual trips to visit family members spoke about their experiences with the language and culture. Students who chose to go on such trips knew they would be immersed in a completely Spanish-speaking environment; nevertheless, they underwent 
an adjustment process at the beginning of their stay that caused some of them to be anxious. Many of the study participants in this group (8 of 13) reported such an experience, though HSS and senior FF did not mention anything about her comfort level with the language or an adjustment to speaking it when she went to Mexico. Seven students participated in the study-abroad program with Lake County or traveled on their own to Spain or Mexico to visit relatives, taking their trip after $10^{\text {th }}$ or $11^{\text {th }}$ grades. This section discusses the linguistic aspect of students' experiences abroad. The cultural aspect will be discussed in the following chapter.

Two of the NES students (RB, MW) who traveled abroad reported being comfortable with speaking Spanish, even during the initial adjustment period. One of them (MW), however, spoke about one aspect of her experience with the language: "The type of Spanish that I'm used to is from South America. My best friend, she's Guatemalan and white, so when we went to Spain, I was taught that there were certain words I wasn't allowed to say, because it was a bad word in Spain, but it was OK in another country." RB was confident about her ability to communicate in her L2 when she arrived in Mexico: “I actually speak Spanish really well, so I wasn't too nervous about it." This student was a very poised and confident young lady. It is possible that her personality, combined with her experiences in Immersion prior to going abroad, gave her this comfort level in her L2. This was probably also the case for MW, because she did not say anything about nervousness or difficulties during her interview.

Only three students, NSS María and two NES students (JA and SW), spoke about being somewhat uncomfortable when they first arrived in the country. The first NES, JA, talked about her initial experience with the language on her trip to Spain after her $10^{\text {th }}$ - 
grade year in the program: "I was actually nervous at first because I was younger then. I didn't have that much experience in Spanish, but I actually was able to communicate in Spanish pretty well. Some of the other students weren't from Immersion because it was a Lake County trip. They would ask us to help them talk to some of the people if they wanted something." She also received feedback from her host mother: "My señora that we were staying with said that I was a good speaker (giggle). I was very happy." This student gained confidence in her Spanish-speaking ability through these interactions in this non-academic setting.

SW, the other NES, student reported: "At first it was really intimidating as soon as we got on the plane. We got to the airport, and we got to order lunch and I was like 'Oh my gosh, what am I going to do?' Because that was the first time that I had spoken to somebody whose first language was Spanish and who spoke Spanish all the time. But afterwards, you eventually just got more comfortable with speaking Spanish. I got more comfortable with asking somebody on the street, 'Hey, how do I get to this square over here?' Or just talking to people about things: 'Oh, can you tell me how to get there?" When these NES students interacted with their host families, in their classes, and in the town where they were staying, they gained confidence in their ability to communicate in their L2. They were tested and discovered they could be successful. They seemed to overcome the psychological barrier that had made them hesitant to speak during the initial period of adjustment. This higher comfort level in the language undoubtedly encouraged them to seek more opportunities for interaction.

Although NSS senior María spoke Spanish at home, she experienced some of the same nervousness about speaking the language as her NES peers when she arrived in 
Spain to visit family members: “At first, I was really nervous, and I felt like I couldn't, but then once I got there, I realized that I had learned a lot more from the program than I thought, because I could actually translate pretty much everything they were saying, and I could communicate perfectly fine."

Three other students (EM, BS, AG) traveled abroad with family members. While these trips were short, and for BS and AG did not involve personal interactions with native speakers, the students' exposure to another language and culture was an important step in helping them to understand another language and way of life on an emotional level. AG traveled with her parents to Mexico during elementary school. Although she did not speak Spanish at the time, she spoke of the role that the trip played in her current interest in the language, and for this reason her perspective is included in the discussion: 'I've been to Mexico when I was little, and that's what made me want to speak Spanish, actually. The way they spoke was just really interesting. That's the whole reason why I think I got into Spanish, because that was the first time I was introduced to another language."

The other two students took their trips during their adolescent years. Bridget traveled to El Paso, Texas, and had gone to Mexico for a few day trips with her grandparents and her father since she started Immersion: "The first time I went, it was a complete culture shock for me. Even going down to El Paso, which has a huge Mexican influence in the city, it was a culture shock. My father, I remember distinctly, went to Wal-Mart with me one day. And we went in and he said to the cashier when we went to check out, 'Hello, iHola!', both of them en seguida, in a row, in order to indicate that he knew both, and whatever the speaker was more comfortable with was what he should use. 
It's something I just remember." These trips made an impact on this student, giving her the chance to experience the language and the culture in that naturalistic setting.

NES EM's experience differed from those of the previous two since she was the only person on her trip who spoke any Spanish at all. In addition, unlike the students who had spent several weeks or more abroad, she traveled abroad on a cruise with her mother and had visited Honduras only briefly, on a one-day excursion, during the summer after completing $9^{\text {th }}$ grade in the Immersion Program--a visit that nonetheless made a vivid impression on her both in terms of the culture and of the language. During her interview, she spoke about the cultural differences that she observed and the experience of communicating with native speakers: "It was a little different because I'd only had a year of the actual Immersion Program. And then I'd only had a year before that of regular Spanish-speaking classes. When I spoke, obviously my grammar was a little off, but it was different. A lot of the times, people I spoke to spoke very rapidly, so I would just nod my head and be like 'Yes, yes'. And then my mom was also with me, and she doesn't speak Spanish. She's Irish and English, so that obviously she does speak English, and so every little time someone said something to her, she would ask me, she'd be like 'Hey, Beth, can you tell me what they said?' And it was interesting. I did try to communicate, and I think at my level, I did a pretty good job of doing it." When asked about her comfort level speaking Spanish, she said, "I...honestly, I wasn't really that comfortable. I wanted to speak to them in Spanish, but then I was afraid that they would judge me. You know? I didn't want to be judged, because my Spanish wasn't exactly great, and I wanted to be...still to this day I want to be perfect in Spanish. I don't like having grammatical errors when I speak. And so...comfortable, not really.” A 
comparison of these comments with those describing EM's initial experience with the language were important evidence that her L2 proficiency had increased during her first year in the IP, a significant accomplishment given the difficulties she had had during her first semester. Nevertheless, she did not feel as comfortable during that short trip as her peers did with a three-week home stay after their $10^{\text {th }}$-grade year. As a senior, she had reached a much higher comfort level with her L2: "I've been so accustomed to it, where it is like a second skin to me. I just do it, don't even think about it."

Discussion. During their homestays abroad in a Spanish-speaking country, where they were totally immersed in the language and culture, students reached the highest level of performance in the target language and the culture that they were capable of at the time. The challenge of the setting exceeded that of Spanish-speaking communities in their home country because everything was new and unfamiliar to them. Their comments about their experiences communicating in their L2 during their homestay in Mexico or Spain were positive in terms of their linguistic performance, showing that the Immersion Program had enabled them to reach a sufficient level of proficiency in the language to communicate effectively and appropriately with native speakers.

\section{Social Interaction: The Immersion Family}

The Spanish Immersion Program at Dover High School was a unique community comprised of approximately 75 students and faculty members across the four grade levels. Each grade level was a cohort that created its own identity depending upon the mix of students and their linguistic, cultural, and ethnic backgrounds. For the first two 
years of the program, students attended their Immersion classes only with peers in their grade level. Since this was a specialty center within the school, the class size was relatively small, and the students in each grade bonded. They also bonded across grade levels, forming a cohesive unit they referred to as the Immersion "family". One of the seniors said, "Since the program is so small, it's almost like we're a family. We say 'Somos una familia."” (EM). The Immersion "family" was a recurring theme for the great majority of students on all grade levels and from all backgrounds. A number of students indicated that it referred to their Immersion peers and teachers alike.

There was solid evidence in 7 out of 13 of the $10^{\text {th }}$-grade interviews that these students had formed a unit by the end of that year. TC, a10 ${ }^{\text {th }}$ grader, described the dynamics of the family: "We know how to work with each other. We know how not to work with each other. We know the do's and don'ts of working together, just like a family." This theme was even more frequent with the $11^{\text {th }}$ and $12^{\text {th }}$ graders. JA's remark was representative: "I think the environment of Spanish Immersion, just having this group of people in classes all the time, having this same group of teachers for four years, I think it's a good environment. 'Cause a lot of times we say we are a family, and I think it does kind of create that feeling. Even though there's [sic] people in my Immersion class that I don't always get along with, I still care about them. I still relate to them."

For JA, as for many of the students, the group size appeared to be an advantage. TC was the only student in all three grades who suggested both a downside and an upside: "It's closed off. You live with the same people every day. And after four years, I think you'll get tired of them a little bit. Sometimes you'll just be like, 'I don't want to see you today. Just leave me alone!"' She also spoke of the positive aspect, however: 
"You'll get to know them really well, and you'll make some really good friends." This last comment could well serve as the epigraph of this section, which explores students' perspectives on their relationships with their Immersion peers and faculty members.

\section{The Immersion Community "Family" at Dover High School: Group Cohesion / Support Network of Immersion Peers and Teachers}

Student Friendships. An important aspect of the IP was friendships with their Immersion peers. This theme was common among students from all three grade levels and from all backgrounds. One $10^{\text {th }}$ grader's remark was representative of the group overall: "We have so many classes together that we've become really close friends, 'cause we see each other a lot throughout the day" (LG). The cultural, racial, and ethnic diversity of students' backgrounds was discussed in the introduction to this chapter; it was relevant to student friendships as well and will reappear in later sections on other aspects of students' experiences. María Mancipe offered the perspective of a native Spanish-speaking senior: "Even though we do not have a lot in common, Spanish Immersion brings us together and gives us things in common. We share what we know together. We share the language. We share some beliefs and a lot of things. It makes us come together as a family." Another senior added a further characteristic of their friendships - that of respect: "I think we just understand each other 'cause we did it together and we respect each other. We learn the same stuff. We feel close, so we feel like "I can talk to you"' (DM). Although this student was one of the few to specifically identify the element of respect, it was implicit in the way that many students talked about friendships with Immersion peers. 
A number of students related their friendships to the emotional and academic support they offered. Several students spoke of the emotional and personal aspect (ES, FF, NJ). Tenth-grader ES said, "We are kind of like a family. You knew kids in the school, so if there were other things that you were struggling with, like high school, they could help you out." Another $10^{\text {th }}$ grader added support as a matter of survival in the program: "The kids in the program are awesome. I mean legit. It'd be really difficult to get through this, like I would have quit last year" (JP). Two students spoke of the general atmosphere in the program. NS said, “With everyone, I'm really comfortable here, 'cause we've already had a year together. You really get to know people and how they really open up to you. So we're really open with each other-everybody is (NS)." Sammy echoed the "comfortable" theme and added a further characteristic: "Everybody is so comfortable in Immersion now because we're all friends with each other. And you're not really worried about your friends judging you 'cause you know that they won't." These last themes of openness, judging, and comfort level were discussed previously in the language development section and were common throughout all aspects of the Immersion experience. These three themes were especially significant for some individual students yet were not representative of others.

Several students described the academic support that they offered each other both inside and outside the Immersion classroom. One NES $10^{\text {th }}$ grader described her NSS peers as a resource: “They're always a help if the teacher is helping somebody else and you have a question. You can always ask them" (JM). NS described the relationships in their Immersion classes: "We have the same teachers almost every year. Everybody gets just so close. They like to talk to each other, and they like to help each other out. The 
teachers and the kids and the kids and the kids — they all help each other out (NS)." This statement was consistent with her previous one in terms of the comfort level and the mutual support that students and teachers offered. NSS Pamela, a $10^{\text {th }}$ grader, extended the support theme when speaking about activities outside of Immersion. "You make friends because we're all like one big family. We're always working together. We had a big study session at Barnes and Noble the other day to study for the history test” (PG). Only student in the $10^{\text {th }}$ grade, Nicolasa, spoke about the limits on the extent of her "close" relationships with her Immersion peers, in contrast to her previous statements and also to Pamela's: "When we are outside Immersion, we talk to each other like we don't even know each other. We don't talk to each other for the rest of the day" (NS). Nicolasa's diminished comfort level with American culture and with her peers outside Immersion was a recurring theme for her. It was unclear exactly for what reason(s) her relationships were different in the two settings. Her comments were evidence that not all aspects of student relationships were positive. On balance, however, there was strong evidence of friendships and of supportive relationships amongst Immersion peers across cultural, racial, and ethnic groups.

Teacher support and high expectations. The close relationship that students had with their teachers was a very common theme for many of them. The teacher support theme recurred with a number of NES students when they spoke of their initial experience in the program: "When you're a freshman, it's hard at first, but they really work with you. If you're not understanding, they help you [to] understand better" (ES). Both NES and NSS students alike provided evidence of the way in which teachers supported their students: "They make sure, like Ms. Arnold $\left[9^{\text {th }}\right.$ and $10^{\text {th }}$-grade math 
instructor in Spanish], she stays after. She gives you help [to] redo things to make sure that you learn it and get a good grade" (Bella Swan). Four out of five NSS students also spoke about this support. María's statement is representative: "The teachers are very persistent in making you feel like you are going to succeed at something. They help you want to learn things so that you can do certain things and go on with your life and everything. I feel like the teachers impact our lives. It's completely different from the way other teachers impact their kids' lives” (MM). In this comment, María referred to the personal relationships of students with their teachers, which one senior described: "we can go to any one of our teachers with academic or personal issues because we are a family" (EM).

Respect for their teachers was another common theme for students from all groups, as evinced by statements from an NES. "We just all make friends, and we also bond with our teachers more. So whenever we're together, every teacher tells us to do work. We respect them enough [that] even though we may do some complaining, we'll get it done" (SW). In a representative statement from the NSS perspective, Pamela said, “There's a big respect factor in class [that] they teach you. You can't get up while she's talking. You can't correct her in front of the class. If she happens to say something wrong, that's OK. She's human. You make mistakes. You have to wait till after class to tell her" (PG). This comment was evidence that showing respect to her teacher guided her conduct in class and transcended her status as an L1 Spanish-speaker, in terms of the appropriate setting for correcting the Spanish of her L2 teachers. Overall, teacher support and teacher respect were common themes of students from all groups, and there was very robust evidence of their positive attitudes towards their teachers. 
Another statement about respect was important because it extended the theme; however, it also serves as a prelude to two statements from a second student, offering the opposite perspective. In a $10^{\text {th }}$-grade focus group discussion, one NES student said, "We've talked about the respect we have for the teachers, but the teachers have so much respect for all of us. They really do. They want to make sure that you get the best of your education" (AG). Only one student in the group, NSS NJ, spoke of a conflict with one of her teachers: "I don't think I'm Arnold's favorite." NES BS, who had previously talked about the support that this same teacher had given her, then commented, "She says really nice things about me whenever I see her out of class. She's like 'Oh, Bella.' NS countered, "She says really nice things to you, not to me. I feel she hates me. I've felt that since freshman year. I can't stand math class. It has to do with the teacher and the Spanish part. I feel I don't get as much help as other people get. She was the main reason I was going to drop Immersion. I don't have to see her next year, so that why I stayed." This was the only evidence that there were conflicts between students and their teachers.

NJ's difficult experience with the program went beyond math class. Her name arose in the section on studying world history in Spanish because she was one of only two students who spoke about it, saying "We basically just take notes a lot, especially in history. I've been so lost 'cause we have to translate from English to Spanish from our textbook. I think that's difficult. They said that we could do more hands-on things. I thought it would be more fun than what it is". She ended with, "I'm not in love with the program." Several other students, including seniors María and Francesca (NSS and HSS, respectively), also said they had considered quitting in $9^{\text {th }}$ grade, although their experiences may have been for different reasons than those of Nicole. María's comment 
was representative of their experiences: María said: “At one point I felt like I was going to give up and quit because I couldn't do it, but I made it through. I'm proud that it worked for me [and] proud of what I have learned in Immersion. Now I can actually use my skills here and I can take everything I've learned with me in the future and it is going to better my future". This was evidence that being L1 speakers of Spanish did not necessarily give them an edge over their L2 peers. The evidence further suggests that academically talented and mature students from all backgrounds who were willing to work hard throughout their years in the IP successfully completed it. María's and Francesca's experiences contrast with that of Nicole, who was in the process of completing $10^{\text {th }}$ grade. These two seniors had learned how to do well, but they had struggled at first. Nicole, who was at an earlier stage of her high school career, may have lacked that maturity.

\section{Norms, expectations, and behaviors from the students' perspective. The} academic environment in this program challenged students intellectually. The rigorous curriculum, consisting of Honors and AP level coursework, went beyond the norm because students studied it in Spanish. The Immersion teachers expected them to perform at the same high level as they would have in English. They expected them to be successful yet offered them support when they struggled.

Students shared every aspect of this journey with their Immersion peers, serving as resources for each other and also supporting each other in a classroom setting that many said was non-judgmental. They identified certain learning strategies and study skills as necessary to be successful in the program. Comments from a half dozen students, including NES and NSS $10^{\text {th }}$ graders but only one $11^{\text {th }}$ grader, were representative: 
“There's [sic] higher standards, but it teaches me a good work ethic for the future" (JP). NES Roberta said, "You just have to be disciplined and want to succeed, 'cause if you don't want it, you're not gonna be able to do well or want to go and try to put the effort in." In the NSS group, Nicolasa identified her strategies, which were also representative of other NSS students (Pamela) and a heritage language learner (Lucia): "You have to be focused. I come to class and pay attention to what they're explaining. 'Cause if they go over something new and they give you homework, you're totally lost [if you don't].” Another factor that Pamela and Nicolasa identified was related to responsibility. Nicolasa said, "Some of the teachers don't give you much leeway, but that's just 'cause they want you to grow up a little bit and take responsibility for what you didn't or did do." These strategies and skills involved a general approach to mastering academic content that applied to all high school students who wished to become serious scholars on the university level; they were not specifically related to the Immersion setting. In this setting, however, these students seem to be saying that because of the program, they had to achieve a new level of effort compared to what they may have done prior to high school. Some of the important descriptive words that students cited as characteristics of successful Immersion students were "disciplined, dedicated, responsibility [responsible]," all of which point to a characteristic of successful Immersion students: their internal motivation or perhaps passion as factors enabling them to make that extra effort. John Persie identified this factor: "I think to be in Immersion you have to have a passion for Spanish — the language and the culture." He also said, "If you dedicate yourself, you will learn Spanish.” John's interview revealed that among interview participants, he was one of the most active in terms of using Spanish outside Immersion. He was not the only one, 
however, for whom enthusiasm for the Spanish language and culture was evident. For many study participants, academic engagement in the learning process was clearly evident.

Student engagement and enthusiasm sometimes even spilled over into a feeling of superiority, as two seniors noted. Sammy said, "It's like a certain camaraderie. Yeah, we're Immersion and if you're Mass Com [the other specialty center, located next to theirs], you're not the same. I mean, I'm not trying to be judgmental." María continued the Immersion spirit theme: "Yeah, we take pride in being in Immersion, and you're not, but it's OK. We're still going to accept you."

\section{Parental Support}

In addition to students' support network at school, it is important to acknowledge the role that Immersion parents no doubt also played in their success. Nevertheless, only one student, Francesca, a senior, credited her parents with a supporting role. Francesca said, "Freshman year, I remember I kept telling my mom I wanted to drop out [of Immersion]. There's [sic] people that are dropping out, and that I can't handle this and also my other school work at the same time. Like I would always have to ask my dad what words meant, and I was just getting tired of the workload. I thought it was way too much for me, since it was like an honors level kind of thing. And my mom and my dad both convinced me to stay. They said for me to stay four more weeks before I

complained. I realized that even though it's a harder workload, getting through that and challenging yourself makes you a more well-rounded person, and it helps you, I guess, be 
more understanding of the difficulties in life and that not everything is easy. Being able to push through and tell yourself that it's OK to be challenged. I just felt a sense of accomplishment after I finished $9^{\text {th }}$-grade Immersion. I realized that I might not have understood everything in the beginning, but staying in the program for one year, there's like no point in me going to drop out now. I just felt that if I drop out, I've wasted my whole year. And so I felt kind of relieved that I realized that I can challenge myself and I can succeed when challenging myself. And if it means going through a program like Immersion language or going through honors classes, it's all the same thing. It just helps to push yourself to do the best you can" (FF).

María also spoke about the support that she received from her parents, adding "[I’m] proud because I can do it. And proud of what I have learned in Immersion, and I'm proud that it worked for me because at one point I felt like I was going to give up and quit because I couldn't do it, but I made it through, and now I can actually use my skills here, and I can take everything I've learned with me in the future, and it is going to better my future".

\section{Evidence of Academic Engagement}

Immersion study participants seemed to be particularly engaged in their academic coursework and especially interested in their field of study. The themes that indicated their engagement involved attitudes such as loving the language and the cultures, working harder. A statement from a NES $10^{\text {th }}$ grader was representative of 23 (of 27) participants: "I like learning all these different cultures and a whole new language and 
everything. It's so much fun!" (ES). Evidence for NES students came from their documented use of Spanish in both formal and informal settings: where, how, and with whom they spoke their L2. Many NES (16 of 22) students from the three grades used Spanish at work, in stores and restaurants, in hospitals or medical clinics, and/or at local Latino events. Evidence also came from their involvement in program-related activities inside and outside of Immersion. These experiences have been discussed in an earlier section of this chapter.

Students identified several factors that contributed to their academic engagement; all language groups talked about them. The relationships of students with each other and with their teachers seemed to serve as good sources of motivation. Another was the variety of classroom activities and their interactive, creative nature. One $10^{\text {th }}$ grader's comments were representative of several other students: "The activities are great. They [the teachers] are always thinking of different ways, creative ways to learn. They'll take song lyrics, and we learn verbs [from them]. They don't do boring activities. They think of fun ways and cooking activities and movies and stuff and a way to use our Spanish more interactively" (AG; also JP, MM, RB).

Another factor contributing to students' active engagement was the opportunity to engage in dialogue with each other. Some of the $11^{\text {th }}$ and $12^{\text {th }}$ graders believed that the atmosphere in their Immersion classes promoted the exchange and sharing of ideas. SW spoke about this atmosphere “The classes are open to expression. I don't really feel like I'm being judged. You get to say your opinion and you don't really care if you get it wrong. I mean you care, but it doesn't stop you from saying something" (SW). These students also enjoyed the opportunity to debate issues in their Humanities and Spanish 
Film (Cine) classes (MM, DM, CL, JA). Four $11^{\text {th }}$ and $12^{\text {th }}$ graders (of 13) talked about using Spanish to communicate at lunch and in the hallways in other sections of the school (DM, BS, MM, MW). NS perspective on her academic engagement as a NSS seemed to be related to her comfort level in each language and with each culture: "All the cultures and the different things, especially in Spanish, 'cause I would understand it more. It makes me want to learn it more, rather than in English and me not know what words mean and stuff" (9). This student was the only NSS who addressed this issue.

\section{Discussion}

This chapter explored the experiences of three groups of students with language development in a Spanish immersion setting that involved social interaction and the Immersion family. As they started the Immersion Program, they all shared the same transition of studying exclusively in English to studying three of their content area courses in Spanish. NES students started the Immersion Program with a very basic knowledge of Spanish that they had learned in a traditional first year foreign language course. At that time, there was probably little distinction between them and their peers who started the traditional second year Spanish course in terms of linguistic development. The HSS students spoke some Spanish, yet they did not see themselves as having a measureable advantage in terms of linguistic development over their NES peers. Even the NSS students faced their own challenges in adjusting to using their L1 for academic purposes, although their native-speaker status gave them an advantage over these other two groups in terms of oral communication. Nevertheless, the experiences of two students (of 5) in this group (María and Nicole) were evidence that this advantage alone 
did not guarantee academic success, as both had considered quitting. Additionally, the fact that some native speakers had left the program because of the heavy workload also suggested that their L1 status alone did not guarantee academic success. This was based on second-hand accounts from the program director and several students (JP, NS, ES).

From the moment that students entered their first Immersion class, they embarked upon a novel experience that resembled being in a Spanish-speaking country and having to use only the target language to say everything, regardless of whether or not they felt their skills were adequate. Many of them felt anxious during this initial period, yet the findings from all 27 students showed that each one eventually adjusted to studying courses such as physical education, math, or world history through the medium of Spanish. This process of adjusting to communicating in their L2 in the Immersion Program distinguished itself from that of communicating in a Spanish-speaking country with limited language skills in one very important way. It was related to the focus of the second half of this chapter-the Dover Spanish Immersion Program with the community of students and teachers, and social interaction. The findings showed that these teachers pushed their students just beyond their comfort-level and expected success, yet there was adequate support from them and from their peers. Many students had to learn new skills in order to survive and to thrive academically. Some of these were language-related, such as language learning strategies. Others were related to academic and emotional maturity: a strong work ethic, a love of learning, a belief in the value of hard work and of accepting challenges that require extra ordinary efforts. When students such as Francesca, a HSS, faced challenges early in $9^{\text {th }}$ grade, she stated that Immersion was "way too much for me" and María, a NSS, said that she almost quit. They indicated that they were somewhat 
intimidated by honors and advanced placement level courses, which they had not previously taken. The evidence from the experiences with second language acquisition of these two students as well as of numerous others of struggles but also of successes, such as the statement that studying math and world history in Spanish was routine. These experiences were evidence of a linguistic transformation as well as a transformation in emotional and intellectual maturity. 
V. FINDINGS (PART II)

\section{PERSPECTIVES OF SPANISH IMMERSION HIGH SCHOOL STUDENTS: LEARNING ABOUT AMERICAN CULTURE AND THE CULTURES OF THE SPANISH-SPEAKING WORLD}

This chapter reviews the major findings of the study that are related to students' conceptions of, and experiences with, American culture and of the cultures of the Spanish-speaking world. Their experiences varied, depending upon their status as native English speakers (NES), native Spanish speakers (NSS), or heritage Spanish speakers (HSS), as well as upon individual differences amongst students across all three groups. The chapter starts with students' understanding of culture, then looks at how they described American culture and the cultures of the Spanish-speaking world. Their statements are based on a range of knowledge: from objective knowledge learned in the classroom to the experiential aspects of the cultures acquired in interactions with their Immersion peers and with members of the Spanish-speaking communities both locally and abroad. Student outcomes and future plans related to their immersion experience will also be discussed.

\section{Students' Understanding of Culture}

Students' perspectives on the cultural aspects of their immersion experience were gathered during both the interviews and the four focus groups (two for the $10^{\text {th }}$ graders 
and two for the commingled $11^{\text {th }}$ and $12^{\text {th }}$ graders). As was noted in chapter III, all students were asked the same set of questions during the interviews. For the focus groups, the questions were the same, but the length of the answer to the first question, on the meaning of culture, was not restricted. During those sessions, students were asked to comment on their answers from the interviews, in order to encourage them to explore the issues in more depth. The purpose of interview question 1, "In five words or less, what is culture?" was to start the reflective process.

The most common themes directly discussed or implied by students acknowledged the existence of multiple cultures ( 21 of 27 from all grade levels). Students identified one of two main aspects of culture: "traditions" (8) and "a way of life" (12). They also identified the people in a culture as either "your family"/ "your parents" (7 of 27) or as "a group of people," "people," or "a country" (10 of 27).

Comments from several of the participants are typical. An example of a "way of life" comment was: "People's way of life-it defines how they act and how they live their daily life" (JP). One of the heritage Spanish students (LG) said, "Different people in different parts of the world live differently, and it's just their traditions that each has [the] different life-styles of people." The other heritage Spanish student (FF) thought of the individual: "Culture makes a person who they [sic] are." The senior NSS student (MM) placed the emphasis on the shared aspect of culture: "It's what people live their daily lives by and what makes a group of people connect together and makes them a group, an ethnicity altogether."

A wide range of students identified the role of the family as an aspect of culture. There were two NSS girls (PG and NS), one heritage Spanish-speaker (LG), one African- 
American girl (RB), one girl of mixed race (MW, African-American and unknown), and only two Caucasian NES students (Bella Swan and EM). An example from RB identified culture as being inherited from "your family," saying, "Traditions, race, ethnicity, language, and heritage are brought down from your family." PG, one of the NSS, also talked about the inherited aspect of culture: "Tradition, yeah. 'Cause for me, I'm Dominican, and so it's like I have heritance [sic] from ancient Indians and stuff. In my family, we're taught to embrace where we're from. So culture for me is inherited." Some of the students identified various products of culture that are inherited or that are part of their background: music (2), language (2), food (4), beliefs (1), and religion (5). One student said, "Traditions, language, religion— just all that put together, of a group of people" (JA). The two African-American students and the one student of mixed race did not discuss any conflict or tension related to their racial background. Their experiences as racial minorities in Mexico or Spain will be discussed later in the chapter. For the language minorities, when these students spoke of the culture of their family, the terms did suggest the potential for conflict or tension with mainstream American culture. It was a recurring theme that will also be discussed below.

In another answer to this question, in addition to the role of family in culture, two of these students talked about the role of peers in the development of a person's culture. "Culture is how you were brought up- not only by your parents; it's your whole generation" (PG). Nicolasa made a similar comment: "You're not always gonna follow what your parents give ya". These two comments also suggested a tension or conflict now or in the future between the two cultures. They were meaningful for understanding the experiences of these two students because they had lived in two distinct cultures 
throughout much of their lives- their home culture (Latino) and their school culture (American).

Several students (6 of 27) added the role of experience to the role of family in defining culture. Bridget Saunders, for example, said, "I feel like culture is something that is an indefinable quality in all of us. Because you can't say 'oh, I'm part of this culture and part of the Hip Hop culture and part of the American culture,' you know, because it's such a blended thing. I feel like culture really is how people interact with one another, their upbringing and a conglomeration of everything that's happened to them before. It's hopes for the future also."

\section{Discussion}

The answers to the first question of the interview protocol showed that students in the IP as a whole were aware of the existence, indeed the possible coexistence, of multiple cultures within a given space and even, though this was more intuited than stated, within a given person — not a surprising finding given the students in this type of program. Comments sometimes reflected the ethnic, cultural, or racial background of a particular student. Three students in particular (NS, PG, FF) seemed to be conscious of the cultures that defined them and of themselves as cultural beings; each made comments supporting this notion later in their interviews and focus groups. Other students demonstrated awareness of their cultural identity and of changes that they saw in themselves during their years in the IP. This theme is important for understanding students' Immersion experience and will be discussed further in a later section. 


\section{Students' Perspectives on American Culture}

The major differences between students' views of American culture tended to be determined first by their cultural group (NES, HSS, and NSS) and secondly by their grade level. The analysis of the data proceeded accordingly: first, the perspectives of students within each focus group (and grade level- $10^{\text {th }}$ grade or $11^{\text {th }}-12^{\text {th }}$ graders) were considered; next, all students in the same grade were considered; and finally, a cross-case analysis was done to examine similarities and differences between the $10^{\text {th }}$-grade group and the $11^{\text {th }}$ and $12^{\text {th }}$-grade group. No distinction was made between the $11^{\text {th }}$ and $12^{\text {th }}$ graders because their Immersion courses included both grade levels. Nonetheless, any significant differences were noted and discussed. Evidence from students across all grade levels and all three cultural groups showed that they believed that they had a greater awareness and understanding of American culture than their non-Immersion peers. At times, they evinced a feeling of superiority when they compared their perspectives to those of their non-Immersion peers. (As previously noted, the Immersion Program itself was comparative by nature, and students had many opportunities to compare the two cultures.) Some $10^{\text {th }}$ graders had begun to reflect on the meaning of these differences, and some $11^{\text {th }}$ and $12^{\text {th }}$ graders had given it much more serious thought.

The findings revealed different levels of awareness of American culture. The NES $10^{\text {th }}$ graders tended to define it on a superficial level, while the $11^{\text {th }}$ and $12^{\text {th }}$ graders had reached a deeper understanding of their own culture that permitted them to analyze it more self-critically. In this, they were abetted by the ability to look at it from the 
perspective of another culture. Overall, the combined group of NSS (which included 4 $10^{\text {th }}$ graders and $112^{\text {th }}$ grader $)$ and heritage Spanish-speakers $\left(110^{\text {th }}\right.$ grader and $112^{\text {th }}$ grader) showed a greater level of awareness and understanding of the two cultures than their NES peers-not surprising given the higher level of exposure to both cultures for NSS and heritage speakers. All the NSS had lived in both cultures in the United States since early elementary school at a minimum and had also lived abroad in their native country for varying amounts of time. A further finding concerning these students' perspectives on American culture was that the characteristics they identified and described were almost always direct opposites of counterparts in the cultures of the Spanish-speaking world and were viewed in many cases in a negative light.

\section{$10^{\text {th }}$-Grade Students}

A significant number of students (7/14) from the combined NES and NSS groups identified the diversity of American culture as one of its most salient features, though their other perceptions were more distinct. A representative statement from the NES students gave a surface-level, factual description: "We have a lot of different cultures. There isn't just one American culture here. There's too many types of people and, I mean, we all live in the same place" (TC). Another NES student gave a similar example using her family: "So I'm Italian, so I have [sic] more of an American-Italian... my grandmother makes meatballs, rather than traditional American food, like religion, heritage, stuff like that" (RT). 
The use of short, descriptive adjectives betrayed a surface-level understanding of the culture. Four (of 14) students from all groups made comments similar to this one: “American culture is very modern to me, and it's growing very fast because the technology these days is growing really fast" (JM, NES). One student each from NES, HSS, and NSS concurred with this student. Their descriptions took a comparative stance because they were implicitly judging that culture against the cultures of the Spanishspeaking world.

"The melting pot" or "the tossed salad?" In exploring the theme of America's diverse cultures in their English classes, $10^{\text {th }}$-grade study participants had debated the categorization of American culture as a "melting pot" versus a "tossed salad." A few students mentioned this debate during their interviews and during one $10^{\text {th }}$-grade focus group. Not surprisingly, the native Spanish-speaking and heritage Spanish student as a group had to grapple with living in two cultures more significantly than their NES peers, based on the comments just below and others discussed later in the chapter. It is important to discuss the melting pot/ tossed salad dichotomy briefly because it captures the variations both in students' perspectives on the relationships between the cultures in the U.S. and in how the cultures change and evolve over time.

The term "melting pot" was discussed in both $10^{\text {th }}$-grade focus groups. In one of them, the term was only mentioned by one NES student describing American culture, who added, "We accept other cultures" (AG). The other NES students in this group did not contribute anything of significance to that discussion. Students in the other focus group discussed it at some length, however, and several NES students questioned whether it was possible to define the culture using either metaphor by itself. It was introduced by 
one NES boy: “I guess it's kinda like a melting pot. There's a bunch of different cultures, so it's kind of an outside perspective from other cultures. At first, it was a salad. Now, I think it's a melting pot, in my opinion. People's children learn to grow farther apart from maybe their own culture depending on where they were raised" (TS). The other NES student said of the culture, "It is different in lots of ways because you have people coming from different parts of the world. So all the cultures mix. You have your tomatoes, and that could be like one culture from a different place out of the United States. And you could have like different things, but I don't know, I could go either way there" (JM). This comment was evidence that she might not have thought about it previously or that she was open to considering both concepts or a mixture of them. These two students seemed to acknowledge the influence of one's surroundings on one's home culture, and they believed that cultures evolve and change over time. By contrast, NSS student Pamela said, "I go with a salad. There's so much culture in the U.S., but it's not like they're all melted together." The other NSS in the group responded to this comment. Then the following exchange ensued:

Nicolasa: They're not all accepted

Researcher: In terms of cultures?

Nicolasa: Like society might not agree.

No student responded to Nicolasa's comment, and it was not explored further in focus group three.

The comment was evidence that, as a student of Mexican descent with very close ties to that country, Nicolasa's personal experience in the U.S. may have had some 
unfavorable aspects. (She told me that her mother had American citizenship, so she was in the country legally.) It was unclear whether she was referring to her own personal experiences, to those of family members or friends, or to her observations of the ways in which she had seen fellow Mexican or other immigrants treated. She was the only $10^{\text {th }}$ grade student to address an issue tacitly related to immigration. The issue of immigration was of greater interest to students in the $11^{\text {th }}$ and $12^{\text {th }}$ grade focus groups and is discussed below, along with the related, stereotypical theme of America as the land of opportunity.

Both Nicolasa and Pamela, as NSS immigrants, gave evidence that they were keenly aware of the relationship between their home cultures and the many cultures to which they had been exposed while living in the United States, an awareness shared by one NES student as well. Pamela contributed further to the melting pot debate: "Being in U.S. culture, you get to see a bunch of different cultures, and it's like you can pick and choose what you might like to do when you have your own family, I guess, compared to your home country, which would be your culture and strictly your culture. So I guess it's a good thing" (PG). Nicolasa made a similar comment and then extended it: "You're influenced by everyone - everything you believe in.” On another occasion she said, speaking of the multicultural environment in the United States, "I think it gives you a wider perspective on what it is you want and what you don't want to have, I guess. In your [sic] life, maybe they would follow up with that when they're older." These comments indicated that these students' perspectives on life were evolving and that they acknowledged that their culture would change over time as they adopted different cultural practices from the ambient culture. The comments also showed that they were developing 
their own independent thoughts about their home culture that were separate from those of their parents.

Although the description of American culture as a melting pot may be a trite cliché, the discussion revealed distinct differences in the ways in which the two NSS students understood the relationship between their strong Latino culture at home and the American cultural environment at school. Although the NES, NSS, and HSS lived in an environment that combined the two types of cultures for three of their courses, the NES Immersion peers did not have the same intimate experience with living in two cultures.

American traditions? When students were asked to describe American culture, they acknowledged the existence of multiple cultures within American culture, but they did not identify any unifying characteristics. For example, when students were asked to identify specifically American traditions, two students said there were some but identified only three: the Fourth of July, Easter, and "the tooth fairy" (AG, JP). A couple of students used the word "untraditional," and one student said, "We don't follow our traditions, but I don't know how to explain it" (Bella Swan). A fourth student said, "Those traditions are not American traditions, 'cause we get our traditions from other countries" (ES). No other comments of any significance followed in this particular focus group, nor did students in the other focus group made meaningful comments about American traditions. Given the last comment about the origins of American traditions, it is somewhat ironic, but perhaps also fitting, that the only student in $10^{\text {th }}$ grade to identify Thanksgiving as an American tradition was Pamela, an NSS; from an historical perspective, the concept was created by a group of grateful immigrants and is the original American tradition. Pamela said, "Thanksgiving, that's culture and that's a tradition in my family for ages that we 
have to have. My whole family from the Dominican Republic comes down and we have Thanksgiving together. So we still have turkey, but then with the turkey, we have a pernil. It's pork" (PG). (These types of comments were also common among the $11^{\text {th }}$ and $12^{\text {th }}$ grade participants and will be discussed below.) It is worth repeating that the $10^{\text {th }}-$ grade NES participants, relatively oblivious to their own culture, felt that the traditions of American culture were adopted from other cultures yet identified very few, in contrast to the discussion of the cultures of the Spanish-speaking world, in which all of the participants identified many traditions.

Constitutional rights. Only one NES student mentioned an aspect of American culture related to the constitutional rights of its citizens, an example of a deeper level of understanding of a cultural difference. Two NES students responded very briefly.

BS: Freedom, like freedom of speech. In other countries you do some things that we do, you get...

JP: ...prosecuted.

BS: Prosecuted, yeah.

JP: There we go.

JS: Killed.

BS: Or be shunned or something.

No more was said on this theme by these students, though another NES student in $11^{\text {th }}$ grade developed the theme more fully in her interview.

America: the land of opportunity? This theme was discussed by NES and NSS $10^{\text {th }}$ graders alike. Two NES students identified it, one saying, "In some of the poorer places in Latin America, they kinda need opportunities, and I think that's why we all have 
the illegal immigrants crossing the border. And so I mean they're comin' here for a better life" (JS, BS). Two NSS students also discussed this theme in their interviews. Nicole Jackson described American culture with the words "We have more opportunities than you would somewhere else." She explained her shifting perspective that had come from what she had learned in the Immersion Program about her native Peru: "I thought that life wasn't as bad in Peru. I thought it was just the same, but I see that they had it way worse than I have it now. They didn't have a lot of opportunities that I will.” This student's comparison of the opportunities she believed were available to her in the United States versus those in Peru was an example of a positive aspect of American culture. Only one other NSS student, Nicolasa, made a comment of a similar nature: "I've been trying to do my best in school to have something better than what my parents have." She was not in the $10^{\text {th }}$-grade focus group where the opportunity theme was raised, but rather in the other one. Her comment was somewhat ironic in light of her previous comment about cultures: “They're not all accepted”.

These comments, which singled out the economic and educational opportunities that motivated people to immigrate to the United States, were among the few aspects of the culture that students identified with positive attributes. As will be shown, opportunity was also a recurring theme for some of the $11^{\text {th }}$ and $12^{\text {th }}$ graders, who offered a more nuanced interpretation of the notion that was closer to Nicolasa's.

The $10^{\text {th }}$-grade study participants described American culture using clichés often deployed by people from other cultures. A number of students at this grade level seemed to believe that these characteristics were accurate. Differences and sometimes opposing points of view were noted between the NES students and their NSS peers, but there were 
also marked distinctions within groups, notably within the NES cohort. When these students shared their diverging opinions with each other, it served as a reality check held up to a particular cliché. It emerged in the focus group discussions that such interchanges were a common occurrence for students across all grade levels.

Consumerism: fast food nation. The first cliché that the $10^{\text {th }}$-grade group of students mentioned in one of the focus groups was American "fast food." Two or three NES students felt that this aspect of the culture was prevalent throughout the country and construed it as a negative feature, as the term "brainwashed" suggests: "We incorporate advertising in every aspect of our lives. You can see fast-food restaurants around every corner, and that's the first thing you recognize as a little kid. We're pretty much brainwashed to recognize certain things as a child 'cause they're advertised on TV a lot" (AG). The word "advertising" suggests the theme of consumerism, although no one took the analysis that far. Another student took a comparative stance: "We're too lazy to go home and cook a nice home-cooked meal, like other countries do every day. Like fast food in two seconds" (ES). The reality check came from two or three NES students. John Persie's response was representative: "I usually have dinner with my family every night." Another NES student's comment linked the themes of "fast food" and "the lazy (vs. busy) American": "It's just 'cause we have busy lives.” A Latino perspective came from the only NSS student in that focus group: "My mom would rather cook home meals, 'cause [fast food]'s not healthy, it can get you really fat. Most of my family members, they like to cook too...make a lot of food and sit down at the table (with) the family eating." 
Individualism. One $10^{\text {th }}$ grade NES boy took this cliché to be negative: “Stereotypical American culture, I think, revolves around being self-centered. Like I guess other countries think that America is arrogant." He served as his own reality check when he added: "My experience here, it's not arrogant, but more people care about others more than people realize" (TS). His comment was evidence that he was aware of this stereotype, although he did not believe that it was accurate. The older students discussed this theme at greater length.

The family in American culture. This theme, raised by two of nine NES, by all four NSS, and by the one $10^{\text {th }}$-grade HSS, was an example of a cliché given multiple reality checks. Most of the comments reflected negatively on the culture. Two NSS students and the heritage language student made comments that complemented each other yet did not represent their own personal experiences. MS, for example, said, "In America, it seems that we don't have time for family." The heritage language learner commented, “The average American teenager doesn't really spend much time with their family like they should, because it's important. They're more into technology. They're always like out or on the phone, texting, or using the computers or watching TV" (LG). This student agreed with NSS Nicole's comment: “They (Latino culture) value family way more than we do, getting time with family, not as much with friends."

Several students, including the two NES boys in that focus group, one NSS, and one heritage Spanish speaker, presented a confirming reality check as John Smith (NES) responded to these comments: "We have the most divorce out of any other country. It means we value family a lot less. It should be a lot more important than that." This 
student told me that he was a Christian and was very religious. For him and for his peer John Persie, family values were an integral part of their lives.

In the other $10^{\text {th }}$-grade focus group, NSS Pamela offered a different perspective on the American family, adding a reality check in which she spoke as an American: "I don't agree with the whole thing that America doesn't have time for family. I'm Hispanic, but I'm an Americanized family, I guess. My mom may not be there all the time, but she definitely makes time to have dinner together and stuff." The comments students made about the family in the respective cultures were evidence of differing perspectives between students and of the possibilities they had to engage in dialogue with each other and to learn from each other. Students described their relationship as close and said that they were "open" with each another. Eleventh and $12^{\text {th }}$ graders also discussed these opportunities and believed they constituted a very important aspect of their overall Immersion experience.

\section{Native Spanish-speaking students and a heritage Spanish-speaking student.}

The notions of family, often the crux of different cross-cultural perceptions and judgments, lead us to a consideration of the four $10^{\text {th }}$-grade native Spanish-speaking students. They offered distinct perspectives on American culture because their lives straddled two cultures, and they seemed to be able to look at each as both outsiders and insiders. The answers from these four students at a minimum gave the focus groups a comparative aspect.

Two of them gave a broad, positive description of American culture (MS, NJ). Mary said, "Part of American culture is always being proud of America and where you 
come from." Nicole said, "We have more opportunities here than you would somewhere else." This theme was indicative of an important difference in the level of cross-cultural understanding between this NSS and her NES peers. (Heritage speaker Lucia Guido's initial description of American culture resembled those of her NES peers.) For two of the native Spanish speakers (PG, NS), there was evidence of some kind of interaction with their home culture that produced tension between their minority culture and the dominant American culture. In contrast, the other two NSS students, Mary and Nicole did not seem to experience conflicts between the two cultures.

Philosophical differences existed between the dominant American culture and the way PG's and NS's families had raised their children. PG said, for example, "It's different, 'cause in the Hispanic culture, it's like very family-oriented. And then in American culture, it's not so much. Like for example, me at my house, we have to have dinner together and we actually have to sit down at the table and have dinner. And then I go to my friend's house and it's not that. It's like everybody is eating dinner everywhere else-in front of the T.V. So I mean, it's different, but it's not anything bad." The other NSS student, Nicolasa, said, "Something based, probably on society. Like technically how their parents were raised, they would want to raise them different, but it ends up being more about society, rather than their traditions and stuff." This student had been raised with Mexican traditions and way of life, and she said she did not always feel comfortable with American culture. She was probably trying to say that the culture in which she had received her schooling had exerted pressure on her home culture and conflicted with it. She was critical of American culture: "American culture, it's really different. They talk about friends and popularity and stuff like that and we really don't 
care for that. We don't really talk about the same things they do. We talk about actual meaning things like what are we going to do with our lives and stuff. They talk about like weird things, like life and stuff like that." This was a recurring theme for her during the interview and focus group, providing substantial evidence of the impact of crosscultural friction on her life.

The "simple life." When the tables were turned, the NES students' perspectives on life in Central and South America and Mexico were more simplistic than that of the NSS classmate in one $10^{\text {th }}$-grade focus group. They will be discussed here, rather than in the section on students' perceptions of the Spanish-speaking world, in order to highlight the dynamics between these two groups of students. The following discussion took place in a focus group with 3 NES girls, 2 NES boys and 1 NSS girl, Nicole Jackson. Her perspective served as a contrast to those of her non-Hispanic Immersion peers, who seemed to have more a naïve, idealized perspective of life in that region of the world. None of these NES students had traveled or lived abroad and therefore had no personal experience with life in that region. Although Nicole had left Peru at a young age, this Latina student seemed to have an understanding of the challenges of daily life in poorer nations such as her native country. The conversation indicated the level of cultural analysis of some NES $10^{\text {th }}$ graders compared to that of a NSS $10^{\text {th }}$ grader with personal experience.

When some of the non-Hispanic students described the cultures of the Spanishspeaking world, they characterized them as having a "simpler life-style," "less roads and so people are forced to walk" (JP). Nicole responded, "That's not simple." She understood the reality of living with fewer roads and without any transportation except 
one's feet: "You can't really go too many places. You're limited to what you can do" (implying without a car). As $10^{\text {th }}$ graders, this group of American students was preparing to drive soon and conceived of the "simpler life" as one where they would not have to find money to pay for the expenses associated with car ownership. Through the lens of their idealized perceptions, life in a place where they could "walk everywhere," or ride a bicycle, or take a bus, a train, or a taxi to travel longer distances was their dream. Walking places or riding a bicycle was also good exercise. In the area where they lived, a car was essential; there were few buses, and many had to rely on their parents to transport them where they needed to go.

This Latina student brought the non-idealized perspective of someone who had seen firsthand what it was like to live without motorized transport of one's own. Throughout this conversation, the 5 NES students and Nicole presented their points of view and were polite with each other, yet the NES students did not seem to grasp the concept of what life was really like for some people in some Latin-American countries. They interpreted life there from the perspective of their life in suburban America and seemed incapable of switching out of that perspective to one that was dramatically different. Nicole's perspective came from personal experience and made a valuable contribution to the Immersion experience of NES students because it pushed her peers who lacked such experience to examine their own assumptions about life in another culture.

This conversation was an example of the types of exchanges about culture that were possible between students from different cultural backgrounds within the Immersion classroom: it was evidence of the role of social interaction in culture learning. Nicole 
offered valuable insight and tried to inject a dose of reality about the challenges of life in certain areas of Latin America. The NES students' stereotypical view was not changed during that conversation, yet her comments may have raised their awareness and loosened the hold of their original perspective. The ability to switch perspectives is a process that takes time and exposure in addition to involving the development of awareness and self-reflection. These NES students had not yet reached that stage.

\section{$11^{\text {th }}$ and $12^{\text {th }}-$ Grade Students}

Students in the $11^{\text {th }}$ and $12^{\text {th }}$-grade focus groups described American culture much as their $10^{\text {th }}$ grade Immersion peers had, emphasizing its cultural diversity and using general terms that identified some surface-level aspects. But they went beyond that level, both in their understanding and their ability to put it into words. One of the NES students identified themes representative of many of her peers: "America is a country of immigrants. Everybody's been here for a while, and so it doesn't really matter but since everybody came over from some place. It's just inside the country, they'll be like, 'Oh, I come from this place. I came from that place too.' We don't have a national identity. Outside the country, you identify yourself as an American. And so it's different inside than outside" (SW). Sammy's comment about the inside and outside perspectives was that of a student who had traveled abroad and understood that she had gained insight into her own culture through exposure to contrasting cultures.

For the NES group, one senior's comment captured the general perception of the multiplicity of cultures held by 9 of the 13: "Together we have this one culture, I guess, 
but obviously each group of people, like each ethnicity and nationality, has its own culture within the culture" (JA). This student was the only one to directly mention a unity to the culture. Rosalinda, one of the African-American students, implied it, while the others emphasized only the diversity. She said: "There are many different races and different holidays — like a salad. To me, it's more about sharing. 'Cause we share ideas and a lot of American cultural mixes and a lot of other cultures, like African-American; it's about sharing ideas."). These two comments seemed to suggest that the diverse cultures were related to each other in some way, while those that follow did not.

The consumerism and individualism themes were common to a number of students in their definitions of American culture; they were considered negative attributes. For example, three NES students described the culture by naming common products, most related to material culture: football, food, sports, money, the way you dress, politics, your beliefs, different religions. One student echoed these themes: "I think American culture has a focus on the individual. There's a lot of focus on money and things that one could find important in the American society, but outside of the American society, it's viewed as greedy and malicious and bad" (BS). This student's statement was an ultra-critical cliché. It represented negative stereotypes of American culture to which she had been exposed in reading Brave New World, in watching films in the Cine class, or through other sources. It was unclear whether this perspective represented her personal beliefs as well. These two themes will be discussed at greater length below.

A number of students in this study found it difficult to identify specific features of American culture, often defining it in a negative way by what was lacking rather than by what it had. For example, two NES students described American culture from a 
comparative perspective, judging it negatively. One student said, "Boring. I mean we have our football and our food. I think we just take from everybody else" (DM). The second student felt that the culture was "kind of lazy [because] we have a lot of Spanish, German, Italian and all the other immigrants that come here. There's not a lot that's specifically American" (CL). They seemed to miss the contradiction implicit in their quotes. The words "kind of lazy" and "take from everybody else" launched a negative criticism of the culture rather than emphasizing the diversity of American culture as a positive aspect. The themes that students have suggested here will be discussed at greater length later in the chapter.

This group had only one heritage Spanish speaker and one native Spanish speaker. Their perspectives on American culture were comparative in nature and involved the interaction of the two cultures, like those of their $10^{\text {th }}$-grade peers. HSS Francesca's perspective will be discussed in the next section because it specifically relates to the debate concerning the appropriate metaphor for American culture. NSS María raised a broader question about American culture that will be discussed further below.

The melting pot or the tossed salad? This theme received brief attention during a focus group meeting and was mentioned by several students in their interviews. Overall, these students espoused the "tossed salad" concept, in comments similar to those of NSS $10^{\text {th }}$ graders Nicolasa and Pamela. Four students (MW, FF, CL, RB), the latter two NES, felt that the concept of the tossed salad was appropriate. Francesca, the heritage Spanish-speaker in this group, made a representative statement: "The melting pot is a bad way to put it because of the assimilation kind of thing. Melting pot is saying that different 
cultures come here and they change their culture, their way of living instead of, I guess, staying with their culture, but adding to it, if you know what I am saying." She illustrated her thought, based on her experience: "Culture, it's like a person's background, and it helps mold a person. [For example,] American culture for me, 'cause I come from a different background, so it [sic] is a conflict between my identity [sic] for culture. I consider Mexican and American part of my ethnicity. I usually combine them together and it becomes my culture-a mix".

NES Mina seemed to concur with Francesca on the additive nature of American culture, citing an example from her neighborhood: "You have the Mexican family [which has] a really strong culture, and then the Mexicans [who] live up the street. [They] have the same thing, the American thing. They eat hamburgers and have salsa and dip at the same time." In that focus group, SW, another NES, sought to refine Mina's assertion: "I don't know if that's totally right 'cause I mean everybody changes a little bit based on where they are, so it's like you do change, but it's not this like..." [She did not complete her thought]. These comments represented students' beliefs about the ways in which cultures influence each other. The comments of Francesca, a heritage language learner whose culture combined aspects of Mexican and American culture, were different from those of NES students Mina and Sammy. These two students described their experiences with the cultures on a more intellectual level rather than as differences they grappled with personally to the same extent as their NSS peers. Nevertheless, the comments by $11^{\text {th }}$ and $12^{\text {th }}$-grade NES students were evidence that they had a deeper understanding of the ways in which cultures influenced each other than all but one or two of their $10^{\text {th }}$-grade NES peers. 
American traditions? The answers of some students in this group were similar to those of the $10^{\text {th }}$ graders. Two students (out of 13) believed that the traditions came from other countries, so that only people from those countries (cultures) celebrated particular holidays. Similar holidays were mentioned. Rusty named two: "Fourth of July and Thanksgiving are [the] major American holidays, and the basis of those are barbecue followed by blowing stuff up (fireworks). Really the one unifying thing among American culture is food and blowing stuff up. People get it all on American holidays." Only one student identified religious and cultural holidays: "We don't have celebrations that everybody (emphasis of student) does. We have Fourth of July, but that's pretty much it. For the most part, not everybody celebrates Christmas. Not everybody celebrates Kwanza, Chanukah, everything like that. In other cultures, there are traditions that are huge (student's emphasis) For example, Hispanic cultures, the Week of Saints, Semana Santa, pretty much every body celebrates that" (BS). This student did not delve deeper into the reason that certain American traditions were not shared by everybody by specifically pointing to the religious, cultural, and ethnic diversity of American culture. Nor did students in all grades, in talking about celebrations or festivals in Latin America, mention their religious origins, the role of religion (Roman Catholicism), or the lack of religious diversity in those predominantly Roman Catholic countries. Nevertheless, the role of religion in these countries was a common theme for students, even though they did not link it to these festivals.

When describing American traditions, 4 (of 6) students in one focus group (BS, AM, EM, CL) spoke of those belonging to their own families or of practices that were 
related to special foods or customs; these traditions may have evolved for financial or practical reasons and reflected the personal preferences of individuals. In one example, AM spoke of a family holiday tradition: "Every other Christmas, me [sic] and my family go to Florida to visit my grandfather and his wife. But we don't necessarily do like all the gifts and stuff like that. If someone were to ask me why we do that every other year, I don't know. It's our tradition. We just do that. And that's what I am going to do when I get older".

The Bill of Rights in the U.S. Constitution. Four students mentioned an aspect of American government: The $310^{\text {th }}$ graders mentioned freedom of speech. Only one student, an NES junior (CL), discussed it in her interview. Charlotte explained her thoughts: "We're learning about all the Amendments-especially, like, the First Amendment — which is freedom of speech, religion, all that. We can be whatever religion we really want to be, instead of just Catholic, Catholic, Catholic. For Spain, they had a time where you had to be like Catholic, Catholic, Catholic, before the Spanish Civil War started and the Republicans were like 'We can be whatever religion we want to be. We don't have to be Catholic.'" In their brief mention of freedom of speech, the $10^{\text {th }}$ graders showed some cross-cultural insight into an important aspect of American government that did not exist in some cultures of the Spanish-speaking world. Charlotte's insight about freedom of religion in the U.S. and Spain indicated that in studying the history of the Spanish Civil War, she may have gained a deeper appreciation for the First Amendment rights of Americans. In both cases, the comparative process facilitated this deeper understanding. 
America: the land of opportunity? The theme of America as the land of opportunity is related to perspectives on work and to lifestyle differences between American culture and the cultures of the Spanish-speaking world. Three NES and two NSS $10^{\text {th }}$ graders had discussed it previously. At the $11^{\text {th }}$ and $12^{\text {th }}$-grade levels, only one NES student, Rosalinda, mentioned this theme as reflecting on American culture in a positive way, while two students from the same group looked at it negatively. In one focus group, students discussed the perspectives of people in the cultures of the Spanishspeaking world portrayed in the films in their Cine class. Bridget explained: "I think that they recognize that the land of opportunity doesn't necessarily always want them to come." Rusty responded, "A lot of times, the movies we watched, El Norte, María Llena de Gracias, and others, they'll see themselves as like 'woe is me' and 'I gotta get to America where the place is better. That's where all the money is.' Whereas [sic] in America, politicians almost have a verbal tic at the end of every speech, 'America is the greatest, the best country on earth'... This place sucks." Rusty's comments supported Bridget's view yet had an even more negative message. These two comments suggested a perspective resembling what Nicolasa may have felt as Mexican immigrant: “They [people from different cultures] are not all accepted." Despite this comment, however, she was in school in the United States for the opportunity that it offered her to have a better life than her parents, and she was accomplishing this goal. The comments from Rusty and Bridget provided a reality check to the cliché of the land of opportunity for which the United States is known abroad. They were evidence that the films had prompted these students to think about and respond to the issues that had been addressed. 
Another NES senior spoke about the outside perception of America portrayed in one of the Cine class films: "In El Norte, the girl thought that she had read in a magazine about all the beautiful things about America. She thought that all Americans had wonderful houses and wonderful cars, just because they were Americans. And when she got here, she thought that you could automatically get like a beautiful house and a beautiful car just because you got here" (EM). Bridget identified what she thought was the central message of these films:

"These films were really good examples of the fact that, you know, they recognize that they could not come to America. They were not supposed to do it. It was illegal, but that they're so single-mindedly stuck on the necessity of being an American that they are willing to break every law that they can think of to become American and to immerse themselves in the opportunities in our culture and the difference".

The perspectives of students like Bridget, Elizabeth, and Rusty, who may not have had personal experience with this aspect of American culture, were one-sided. NSS María, like $10^{\text {th }}$ graders Nicole and Nicolasa, understood "America, land of opportunity" not as a cliché, but as a very real and important aspect of their lives. María said: "They come here because their families back in Guatemala need the support because there's [sic] no jobs there. NES Mina and Daniela were in-between: both had come to understand the motivation of certain immigrants to live and work in the United States through their friends. Daniela's statement indicated the empathy that she felt concerning their motivation. "In Humanities, we learn so much about culture. I think a lot of people are very ignorant when it comes to immigration. I think that if they just had to have a day 
where they had to get their water from a barrel or something, they would understand why people wanted to immigrate here".

Consumerism / Individualism. The "land of opportunity" theme and the image of American culture from El Norte are related to the broader theme of consumerism/ individualism. This theme is also related to the cliché of the "lazy" American who eats "fast food," identified by a couple of the $10^{\text {th }}$ graders. Among the $11^{\text {th }}$ and $12^{\text {th }}$ graders, however, it shaded into comparative discussions of lifestyle differences and of beliefs about work and the work ethic in American culture and in the cultures of the Spanishspeaking world.

The older students discussed their perspectives on work from a philosophical standpoint, linking them to the general approach to life in the respective cultures. María, the NSS senior, captured the philosophical difference she had observed during her trip to Spain: "Over there, they would rather work enough to make a living, but here, everybody lives to work, and I guess I like that lifestyle, it's so different. They're just peaceful people and they're just relaxed. It was sooo nice..."... The theme was also identified by Francesca, the heritage learner, and by several NES $11^{\text {th }}$ and $12^{\text {th }}$ graders. The older students identified far-reaching implications of materialism, and their analysis was deeper than that of their $10^{\text {th }}$-grade peers.

There were discussions in both of the $11^{\text {th }}$ and $12^{\text {th }}$ grade focus groups, and students reacted to Hispanic stereotypes of American culture, which they gained through the lens of the films in Cine class. NES Elizabeth pushed back against one such 
perspective. "A lot of times in those movies, people perceive us [in America], you do very little work and you get very much reward, whereas in Hispanic countries, you work for what you get. We do work hard and it's not manual labor, but it is actual work". NES Daniela started a discussion in the other focus group, offering a reality check: "The stereotype 'Americans are lazy'-I hate that stereotype, 'cause it's not true. Like my mom has two jobs, so I don't really think that's true. People think that 'cause we're in America, we don't struggle, like we have all this money. We struggle. There's broke people in America, believe it or not! I mean other countries just think we have it made, and we do to a point. I mean, we have a lot. I mean our country's rich. We have IPods and stuff like that. You go somewhere and everybody has them. It doesn't mean we didn't work for that." Daniela's comments were evidence that she was aware of the cliché about Americans and work and rejected it.

Two other students also offered a reality check to the lazy American cliché. NES Bridget cited a statistic that she had seen: "Americans work more hours than workers in other countries." NES Mina, gave an example from her family: "I guess part of our culture is working hard. My dad's been doing it like forever. They worked as hard as they can. I work two jobs, and I have to get my brother off to school, off the bus. I have to take care of him, then I have got to go home, do my work, clean up the house. We work. We work till we're ready to die. It's too hard. We don't live life." Mina and Daniela gave similar personal examples of the American work ethic, yet Mina's last comments were evidence that she was unhappy with this type of lifestyle as it affected her and her family. In addition, Mina's commented about life in Spain: "The Spanish culture is just gorgeous compared to any other thing. Living over there is beautiful 
compared to the United States, we need to step up our game on the things that we believe in and how strong we feel about what we believe in. You know"? These experiences might lead her to reevaluate the lifestyle she imagines for herself as an adult. The American work ethic was a theme that some $11^{\text {th }}$ and $12^{\text {th }}$-grade students connected to the American consumer-oriented society.

There was evidence of the variation in students' perspectives across cultural groups, but also within the NES group, when it came to consumerism. The most negative description of American culture in an interview had come from Bridget: "Outside of the American society, it's viewed as greedy, malicious, and bad." When this answer was read to her focus group, she developed her idea: "I have been reading this book, Brave New World, and it forces you to recognize that American culture is so thoroughly focused on consumerism." No student directly responded to this comment to contest it or agree with it. Elizabeth contributed the next comment, relating consumerism to individualism: "It's all about the individual. Everything in our culture is 'How can I make progress for myself? How can I be the CEO of this company?' Instead of 'How can I help other people to do things?"' This student introduced another negative cliché that suggested that people were selfish or egotistical. Students did not respond to this theme either. A reality check to Bridget's comment arose in the other $11^{\text {th }}$ and $12^{\text {th }}$ grade focus group. Mina described the individualism theme in a less critical fashion when she said, "[I think it is] more individual, more independent. A lot of people aren't family-based. Some are. Some aren't. Some are religious. Some aren't. They're more about making money instead of being a happy family. I don't think we're all mean and greedy.” Mina's description emphasized the variation of interests and beliefs in American culture. This theme was 
not developed further by students. While the analysis that students gave did not involve the deepest levels of cross-cultural awareness and cross-cultural understanding among the $11^{\text {th }}$ and $12^{\text {th }}$ graders, these students were reflecting on their home culture and considering the differences that they saw with the cultures of the Spanish-speaking world. Deeper insights into one's home culture and other cultures develop through exposure and through these processes.

A native Spanish-speaking student and a heritage student. As was noted with regard to the $10^{\text {th }}$ graders, the perspectives of the NSS and HSS students and their insights into cross-cultural differences were markedly different from those of their peers-Nicole's comment "That's not simple" was evidence of just such insight. The description of American culture and the American family by the only NSS in $11^{\text {th }}$ and $12^{\text {th }}$ grade group, María, in her interview was a further example: "Kind of distant. American culture is really different from the cultures that I grew up knowing and what my family shows me, and really different from what I have experienced personally." She used the expressions “nurturing, loving, very caring. They're a tight-knit group of people." In focus group 2, this researcher read out only the descriptor "distant" to summarize María’s idea.

Students did not completely understand this single term. HSS Francesca interpreted it as describing the American family and the lack of close relationships within it. The researcher then suggested to students that the term may have referred to emotional distance. Jaime (NES) responded, making an insightful comment on American culture, compared to the $10^{\text {th }}$ graders, who had talked about aspects of the culture on the surface level: "It's focused on materialism. And I think for some of us, we think that the 
material things are gonna take the place of having real relationships with people." Jaime appeared to be considering her culture from an outside perspective as she extended María's description. She also analyzed the materialism on a deeper level because she considered the impact on people's lives. Mina's earlier comment, "making money instead of being a happy family," seemed to be a variant of Jaime's because it implied having relationships with people. In comparison to the level of analysis from these two students, senior Elizabeth and junior Bridget's comments ("decadent, greedy, malicious, and bad") considered the culture on the surface level without considering the underlying impact of consumerism or individualism on people. NES Daniela provided a counterpoint and a reality check to Jaime and Mina's analysis of the culture as she described her perspective on her own family: 'I don't think we're distant 'cause we want to be. Like I don't go home every night and not have dinner cooked with my mom 'cause I don't want to. It's 'cause she's working, so you don't always get to choose to be distant. We don't want to be that way, it just kinda happens." The $11^{\text {th }}$ and $12^{\text {th }}$-graders were split overall in the way they described relationships with their family members as "close" or not very close. One student said that her family lived in two different places, without saying anything about the actual relationships. This conversation was yet another example from the $12^{\text {th }}$ graders of social interaction related to sharing perspectives related to cross-cultural differences.

NES Jaime and Mina, and HSS Francesca analyzed the American consumerfocused lifestyle, the American perspective on work, and their impact on the family in the culture from a comparative perspective, based on their firsthand experiences with life in Spain or Mexico when they visited one of these countries. They recognized the contrast 
between the American cultural perspective and the perspective of the cultures of the Spanish-speaking world. The reflections of these three students showed insight into the cultures because they not only examined the issue on the surface level but perceived the less obvious underlying effect on people. Jaime and Mina had identified materialism as a substitute for personal relationships or a happy family.

HSS Francesca's subsequent reflections were also evidence of the experiential aspect of cross-cultural awareness/understanding, and the potential for in-depth analysis, of students who had the benefit of spending time in a Spanish-speaking culture. Her observations and experiences gave her a deeper understanding of the family when she visited her aunt in Mexico, as well as a deeper insight into her own culture: "I feel like they're more, I guess, connected because of their humbleness and their poverty, because that's all they have. That's their family. So it makes their culture more connected than our culture....Working, I guess the lifestyle we have here is totally different from there and it makes us distant. 'Cause we have a lot more stuff that we worry about and stuff that we have to do in order to succeed in life.... And for us to have fun, we feel like we need to go out and spend money and go out and do different things— get away from the house, instead of liv(ing) close to each other and go do fun stuff, like just go to the park or something. I don't know; we get bored really easily.” After her return from her stay abroad, she had the opportunity for further reflection on these experiences and perspectives individually and with her peers.

Francesca's experience and her reflections were typical of the other students from all groups who had studied or lived abroad. They had gained experience with aspects of Mexican or Spanish culture that involved cultural practices and perspectives at a deeper 
level of the culture-differences in the nature of friendship, in cultural space, and in the roles of men and women in society. This aspect of experiential culture learning in the Spanish-speaking world will be discussed in the second half of this chapter.

The "simple life." Anticipating that discussion, this next section recalls the $10^{\text {th }}$ graders'cliché of the "simple life"; the $11^{\text {th }}$ and $12^{\text {th }}$ graders did not use that term, but the subject was the same, involving money, gas (implicitly automobiles), and American consumerism as they contrasted with aspects of life in Latin America. NSS María seemed capable of looking at two contrasting cultural perspectives on happiness and seeing herself as belonging to both, while Daniela and Mina seemed to be poking fun at their perspectives as American consumers. María started the conversation in her focus group, speaking as a Latina about an alternative to this consumerism:

“Well I mean - they're poor, but they're still happy. 'OK, we don't have a TV, but hey, we're gonna still throw a party and get together with their friends and family. We're just happy people." She then switched to speak about her American perspective. "Here, it's like 'I don't have anything. I don't have money and I'm not goin' anywhere. My life is, you know, horrible. Over there, you just get to go with friends and do whatever."

Mina: And that's no fun. (Several people laugh.)

Daniela: (giggle) That's no fun! (giggle)

Several people giggle and say, No fun!

Mina: No money. No gas. No fun. 
These $12^{\text {th }}$ graders were analyzing their lives as American consumers and critiquing themselves from a new perspective, using a touch of humor as well. All were cognizant of the contrast in the definition of happiness: In the United States, it was defined by material goods, whereas in Latin America, people found happiness in their relationships with friends and family. This conversation showed that these students were grappling with this contrast in life styles and in the respective value systems of the two cultures. They may have been considering how these insights might impact their lives in the future. Compared to the $10^{\text {th }}$-grade conversation, the level of analysis of these students was evidence of the continuum of culture learning. The conversation was similar to the $10^{\text {th }}$-grade one as an example of the role of social interaction in the sharing of perspectives about values and lifestyles in American culture and in the cultures of the Spanish-speaking world.

Discussion: looking at American culture from the outside. When NES students described aspects of American culture, they often criticized them in a negative way as lacking comparable features from the cultures of the Spanish-speaking world. For example, they identified American consumerism, the lack of cultural traditions, American individualism, and the lesser role of the family as aspects of the culture that they felt reflected negatively on it. Overall, students in all three grades defined the American family from a comparative perspective, using as a foil the family in the cultures of the Spanish-speaking world.

The NSS, HSS, and NES students who had visited Spain or Mexico had the firsthand experience that enabled them to make more in-depth comparative analyses, and the evidence presented above also showed some clear overall differences in the 
perspectives of the NES, on the one hand, and the NSS and HSS, on the other, especially when one compared their answers during the individual interviews. These persisted in the American culture discussions in the focus groups. Additional evidence from the NES group also showed changing perspectives on their home culture, although it is not clear whether these new perspectives came entirely from participation in the IP. Students clearly moved along a continuum of culture learning as they progressed through the program.

In one of the $10^{\text {th }}$-grade focus groups, the students were asked, "Is there a standard American culture?" One of the NES students, TS, said, "So and then you don't really have a standard unless you have an outside perspective on that." This insight indicates that he was aware that other cultures and points of view existed. In another focus group, a $12^{\text {th }}$ grader who had been to Spain with the Lake County group made a more developed comment about defining a culture from an insider's perspective: "I think it's harder to say what our culture is when we're actually part of it, so it's kinda hard to say what it is when you're in the middle of it. It's easier to describe a certain thing if you're on the outside" (SW). When Immersion students made comparisons between their home culture and their second culture, they gained valuable insights into both, and their ability to shift perspective grew. Comparisons derived from social interactions and academic content were an inherent characteristic of students' experiences in the Dover SIP and no doubt contributed to changes in the breadth and depth of their cultural perspectives. Further comparisons that the participants made between American culture and the cultures of the Spanish-speaking world will be discussed in the next section of this chapter, which explores how students defined these cultures. 


\section{Learning about the Cultures of the Spanish-speaking World within the Immersion Program}

Participants in the Immersion Program learned about the cultures of the Spanish speaking world on a number of different levels. The first, at the surface level, was as objective academic content through the formal curriculum. Second, students learned a more general approach to studying about another culture: respect and open-mindedness. Third, they learned about Hispanic cultures through their interactions and experiences with Immersion peers and teachers and with people outside of the program. Fourth, those who traveled to a Spanish-speaking country deepened and expanded their knowledge about aspects of the culture of a particular country. On a non-verbal level, they began to understand aspects of the culture such as traditional greetings of Hispanic friends and family, which they gained experientially through interactions with their Immersion peers or other members of a Spanish speaking community at home or abroad-an example of moving towards cultural acquisition. In the remainder of this chapter, this progression will be categorized under the broad categories of "knowledge," "experience," and “transformation." ("Experience" subsumes skills as well.) The IP itself provided both knowledge and experience, while local and international Spanish-speaking settings provided knowledge and understanding through experience. The potential end result of 
both kinds of learning is designated "transformation" and is treated at the end of the chapter.

The process of learning about a culture and of acquiring skills in another culture was a gradual one that developed over time. The findings of this study show that students were at different stages along the continuum in their understanding of the cultures of the Spanish-speaking world, depending upon their grade level, their individual experiences, and their cultural background. There were also individual differences between students, not related to these factors. In addition, students in the program matured at various rates over the four years, a normal process for all high school students, except that the Immersion context shaped their experiences differently, as this study has shown. For example, evidence showed that the depth of students' understanding of cultures was facilitated through the debates that took place in their Immersion courses in $11^{\text {th }}$ and $12^{\text {th }}$ grades and in the self-reflection that seemed to occur for a number of these students. In sum, Immersion participants had the opportunity to explore the cultures and to develop their thought processes over time as they matured into adulthood. The recurring themes and the sometimes substantive differences between students' understanding of the cultures of the Spanish-speaking world will be discussed with reference to grade level, language status (NES, HSS, NSS), and individual characteristics.

The Immersion experience itself was a cultural phenomenon. It brought together students who by and large did not know each other, from all of the middle schools of Lake County. Their adjustment involved not only entry into the program but also the start of high school. As previously discussed, the most significant adjustment of the program for all of them involved speaking only Spanish starting on the first day. Evidence 
revealed that the cultural aspect of their Immersion experience was not an issue for the great majority of students, as only mentioned in one focus group (MM, MW, DM, SW, JA). These five seniors may have been reflecting on their years in the program as they prepared to complete it. Another senior, EM, was the only individual student who reported "feeling out of place" with the Latino culture during that initial period. No $10^{\text {th }}$ or $11^{\text {th }}$ graders spoke of any adjustment to the cultural aspect of their initial experience.

When the five seniors talked about their initial experience in Immersion, they talked about two distinct groups of students and how their relationships had evolved over time. María started the discussion: “I think over the years, we've gotten more comfortable with each other. Before, Sammy, Jaime, and Julie (NES students) used to be on one side and we'd (the NSS students) be on the other side. And we'd be like 'Yeah!!' And they were like (she paused to emphasize the silence of the NES students; giggles from many students). María continued, And now we're all like 'Yeah!!'” (again, laughter from many). Daniela added, 'We just understand each other 'cause we're in the class, so we want to get together." This one conversation did not provide enough evidence to completely interpret in what way(s) students may have been uncomfortable-whether it was with the language or with both the language and the culture. Alternatively, their discomfort may have been equally attributable to the Immersion experience along with the new experience of all $9^{\text {th }}$ graders starting high school.

For one senior, however, the initial adjustment to the program involved both the language and the culture (EM). We have already seen Elizabeth's initial language experience, but culture surfaced when she spoke of the groups in her $9^{\text {th }}$-grade Immersion class: "It was pretty much divided into two groups. The Latino-Americans, who knew the 
culture already and were just here to get better in their Spanish. And it was us, which we called the Gringos, which is the Americans and everything." Elizabeth talked about how she had felt: "When I get thrown into here, and half of our class are native LatinoAmericans. . . You know, they're from Puerto Rico, they're from Mexico, they're from Spain, whatever. And I felt really out of place. When I got into my freshman year, this one girl was talking about how she was going to her cousin's Quinceañera, and I'm like 'What is that?' I just didn't understand, and a lot of the times, I just felt like I was in my own little bubble."

Only Elizabeth and Mina (NES) and Nicolasa (NSS) reported difficulty adjusting to a new culture. Nicolasa's low comfort level with American culture was an ongoing issue that has already been discussed, while Mina's experience, which involved her cultural experience in Immersion and her initial experience with Spanish culture when she went abroad, will be treated below.

\section{Knowledge}

Academic content. Spanish Immersion students studied many aspects of the cultures of the Spanish-speaking world throughout their four years in the program, which emphasized the diversity within the cultures of the Spanish-speaking world. (See Appendix D for Dover curriculum and course of study documents.) During their 9th and $10^{\text {th }}$-grade years, they studied Spain and the major countries of Latin America, focusing on traditions, families, and festivals. They gained their knowledge through textbooks and related experiential culture projects, for which they did research on aspects of a particular 
country: a tradition, a holiday, a festival, or its culinary specialties. During their 11 th and $12^{\text {th }}$-grade years, they explored aspects of the cultures in more depth in their Humanities classes, their Spanish Cinema class, their Media in Spanish Culture class, and their AP Spanish Literature class. One of the students (EM) talked about the knowledge they gained from doing the projects: "When we do projects, we kind of simulate what happens there. Like, if we're learning about Cinco de Mayo, in our humanities class we will have like a Cinco de Mayo party and we will look up traditional foods of Cinco de Mayo and traditional things that they do, you know?" The same was true of the more advanced classes. "Humanities [class] is similar. We do a lot of units that we will focus on one country's culture or history. We do projects that are based off of certain cultures and we learn about, like, Spanish, or Hispanic holidays, Hispanic traditions, things that we wouldn't learn otherwise" (EM ).

Of the cultural themes that surfaced in the interviews and focus groups, the importance of religion in the cultures of the Spanish-speaking world was one of the most commonly mentioned (3/ 5 NSS students, 10/20 NES, 2/2 Heritage Spanish speakers, for a total of 15/27). This aspect of the cultures was included in each of the courses having a cultural component. One of the NES students captured this: "[In] Mexico, Catholicism is huge. It's inseparable from the culture, but in Spain, it's less so. It is a big deal there still, but it's not, you know, [that] everybody's Catholic. You have to go to Mass. I'm not a religious person, and when I'm in Mexico and in El Paso with my grandparents, I go to Mass. They [teachers in the Immersion Program] can't teach us Catholicism, even though it's a huge and inseparable part of the ethnicity" (BS). "In Cine," she continued, "we watched a film, María Llena de Gracias. It was about the drug cartel down there 
and drug trafficking and, um, you saw these huge drug lords, and they would wear rosaries, and they would stop and pray in front of churches. And while you may think, 'Oh, that's a bad person. Why are they praying?' you know, 'God doesn't love them.' They are so involved in the Catholic Church, and it's something that they really, honestly care about. That it's an inseparable part of the culture." Spanish films gave students the opportunity to explore important aspects of the cultures in a medium closer to the realworld setting than textbooks, and they provided the springboard for debates and discussions on these issues.

In focus group discussions about important aspects of the cultures of the Spanishspeaking world, the role of the family was a common theme. Students learned about it as part of the academic content and also through their Immersion peers and teachers. Students from all cultural backgrounds discussed it most frequently as it contrasted with the family in American culture, as discussed above.

One $10^{\text {th }}$ grade focus group talked about the central role the family plays. NES JS struck a comparative note in talking of divorce, a family-related topic that has not yet been addressed: "We have the most divorce out of any other country. It means we value family a lot less. It should be a lot more important than that." In a discussion of religion, Bella Swan also spoke of divorce: “A lot of Hispanic people are Catholic 'cause that's part of their culture, and you can't divorce when you're Catholic. It's against their religion." One of the NSS students rejoined, "When they get married, their thought is 'OK, I can never divorce. I want to be with him forever - not just I want to marry this person. Divorce is not an option.' I think when you're more or less committed to make things work, with each other, [when] one thing goes wrong, they'll usually just go 'OK, 
we'll move on.' They actually want to make stuff work, so they might as well make things better for 'em" (NJ). This was the only group of students that talked about divorce, the family, and the role of religion. Students in $11^{\text {th }}$ and $12^{\text {th }}$ grades also had the opportunity to share their individual perspectives on religion in AP Spanish Literature.

Students became aware of the major Latino issues in the U.S. and abroad. HSS Francesca talked about this experience for Immersion students: “[In] Immersion, [we spend time] reading about different cultures and different countries, learning the history about them and combining altogether with how they live their life. We as Immersion kids understand now why the Hispanic people come here as immigrants, come here to support their families, come here to look for jobs and things. We understand that now. And so now all of us, not just the Hispanics, but everybody, now is more defensive towards that kind of thing when people want to stereotype people. We just understand that now. We don't have that ignorance we did before." This student's last comment about their level of cultural awareness and cross-cultural understanding was common to students at all grade levels, though based on the types of comments they made, $11^{\text {th }}$ and $12^{\text {th }}$ graders understood the issues at a deeper level.

Four students identified the history of a country as an important aspect of a culture (JA, CL, RB, SW). The only $10^{\text {th }}$ grader to mention history was Taite, who said, "It really helped give a lot of the history behind it and showed us how it's developed and how the movement of people has changed the cultures, like the influx of Europeans into the Americas changed the Mexican or Aztec cultures at the time. It's just shown how the patterns of history have kind of changed everything and how it used to be, how it is now, and how they still retain some of the traditions that they used to have." Jaime's statement 
about history and colonialism was evidence that students had the opportunity to broaden their horizons and their thinking about the material they had studied in their Englishspeaking classes: "In general, a lot of it is derived from Spanish, from Spain, and from indigenous cultures and from African cultures and from all the different mixing that went on. [In Immersion], we learned a lot about colonialism in Spanish-speaking countries. A lot of times, we learn about it in the English colonies and about thirteen English colonies and all that. We don't learn so much about Mexico or about those countries. I've learned a lot about the Conquista and Mexico, when Cortez took over and he defeated the Aztec emperor. I've learned about the plantations in Cuba and about liberation of countries in Central and South America" (JA). This typified the kind and level of analysis that the four $11^{\text {th }}$ and $12^{\text {th }}$-grade students were able to do. Jaime's link between Central and South American history and American colonial history was an example of a Connection (ACTFL) she came to understand through her Humanities class.

Products and practices. When students learned about common products and practices in the cultures of the Spanish-speaking world as academic content, they gained cognitive knowledge and understanding of these cultural practices on a superficial level. They could talk about them intellectually and compare and contrast them with aspects of American culture. Bargaining in open-air markets in Central and South America, or taking a siesta, became familiar cultural practices to them. Charlotte, an NES student who had not traveled abroad, said of bargaining, "You hear all these examples of markets and stuff where you can go and haggle. You never do that here. You have one price, that's all you get." The knowledge that students gained was valuable to them for several reasons. First, they learned that their own cultural practices were not necessarily common to all 
cultures. Second, they took an initial step in developing open-mindedness and cultural sensitivity, as they learned about practices that would not be considered culturally appropriate or acceptable in American culture. The third potential benefit was to become familiar with these aspects of the cultures if they traveled abroad. This was Elizabeth's case on her one-day visit to Honduras: "In Spain and Mexico, they have some things that are just not appropriate here, like having the siesta. They shut down all business and everything. Whereas here, if someone told you 'Oh, from two to four, you're going to shut down your business so that we can take a nap,' they'd look at you and they'd laugh, you know?" She traded roles with her mother on their trip: "My mom, she's not acclimated to the culture, and she doesn't understand what goes on. I felt like I was the teacher and I had to teach her everything. I felt so proud of myself when we went to Honduras and everything shut down at two o'clock. I knew that it was because it was siesta time. You know, nap time.” Her comments were evidence of her comfort level with the culture on that trip. Knowledge of some basic cultural practices allowed her to function on a minimal level as a tourist. It also gave her the opportunity to learn more about the people and life in that culture since she had already learned these basics.

Students talked about the many festivals in Spanish-speaking countries, another "product" of their cultures. Most $10^{\text {th }}$ graders discussed them because they were a focus of the cultural content during the first two years of the program; few, if any, $11^{\text {th }}$ and $12^{\text {th }}$ graders even mentioned them. One representative comment about the festivals came from John Smith: "We do learn a lot about their cultures and festivals and stuff, but it's usually centered on one country, whatever project you're doing. The Festival of Alasitas, it was a cool festival. I did a project on it. I believe it was [in] Colombia. I might have the 
wrong country there. It might not be Colombia." (Note: It was actually in Bolivia. See (Retrieved from, http://www.boliviabella.com/alasitas-bolivias-festival-ofabundance.html ). "Alasitas are like a small miniature, a trinket, of anything, pretty much anything that you can think of. You buy the things that you want in the coming year. And so you have all these little trinkets, and they are supposed to bring you good luck in that thing. It's about a week festival. It was originally from a worship of a god. I think of Alasitas. It was supposed to bring good harvest, I think." (Note: The website above confirmed that he was the God of the Harvest.) Another example came from Emma Smith: "They have a lot of festivals for their patron saints, like La Festival de San Fermin." These students often noted the contrast with American culture, which they believed did not have any traditions, perhaps because of its lack of festivals for patron saints.

As students studied aspects of these cultures, such as the festivals or the siesta or the practice of bargaining over the price of goods in a market, they gained a surface level understanding of them as academic content. In order to gain an understanding of a particular practice on a deeper level, it is necessary to experience it in person in one of the relevant countries because the affective aspects of culture exist within a community of people who interact with each other and construct that culture together in a specific context, a specific place (geographic location), and time. As a result, when L2 learners such as Francesca and Elizabeth bargained in a market in Mexico or Honduras respectively, their interactions with merchants served to elicit feedback not only from a communicative standpoint but also on the degree to which the actions were culturally appropriate on an affective and non-verbal level. In addition to learning about an aspect 
of the culture related to social interaction, the students also experienced the culture holistically. These other aspects involved as many as all five of their senses, as well as their own emotional reactions to the experience.

Learning about aspects of cultures through the Cine class. The Cine class was a particularly effective part of students' academic culture learning since it also provided vicarious experience of sight, sound, and emotion Eleventh and $12^{\text {th }}$ grade students gained insight into the cultures of the Spanish-speaking world from the perspectives of the people in those cultures. This was a unique and valuable experience for them because the films were not widely disseminated in the American market, but especially because the films gave them access to the authentic culture: they were not an interpretation of the culture by an American film producer drawn to a particular issue in another country. Two of the students talked about the types of movies they watched and the cross-cultural analysis that they did for these movies. Francesca said, "It was kind of cool learning, just seeing where a particular film was from, like different countries. Seeing how they think and what is their entertainment, which is always interesting, 'cause there's [sic] movies of all types, like romantic comedies, and there's also the historical ones. There's Realismo Mágico - it's like the fine line between realism and fantasy, like in the movie, Like Water for Chocolate, Como Agua Para Chocolate. We watched that."

Students in one of the $11^{\text {th }}$ and $12^{\text {th }}$-grade focus groups discussed various aspects of Hispanic cultures that they had observed in these Spanish movies, in particular friendship in Hispanic cultures, cultural practices in the family, and the roles of men and 
women in Hispanic cultures, (This latter was enriched by students' experiences abroad and will be discussed in that section.) NES JA commented on the perspective that students gained from this class: "I think Cine is definitely a class that helps with understanding Spanish culture. I'm watching movies that are in Spanish that are from a Spanish-speaker's perspective, that are filmed in a Spanish-speaking country... we don't get that here. The way that we portray Hispanic people is a lot different than the way that Hispanic people portray themselves, you know. When I watch these movies, a lot of times, I get a taste for whatever country they're filmed in, and I get a taste for that culture. It's kind of like you get a little preview of that country's culture.”

Elizabeth talked about new cultural perspectives they became aware of through the movies: "We do talk about the behavior of other cultures. We're talking about people with disabilities because we're watching a movie about a woman with a disability. The movie's title [is] De eso, no se habla. It's a phrase that we use in Spanish, which means of [sic] this, we do not talk about. In Spain and Mexico and other countries, since many families are more traditional, many people just say, 'De eso, no se habla', and that's just it. Like the issues that we have here, like I said, the social issues that we have here, many times they just don't talk about. It's not, it's inappropriate."

Three NES students (CL, DS, RB) talked about friendships in the movies, comparing them to friendship in American culture. Charlotte's comment was representative: "Well, there's one movie that we're watching now, called La Historia Oficial. And one of the things that a lot of people seem to be having trouble with is just the Hispanic idea that friends are really close. There's a lot of touching, hugging, really close and hugging like this. And here in America, you would never see friends really 
close and hugging like this for more than just two seconds. But they were doing it for minutes at a time, so that's just one of the things. We're not nearly as close and intimate as they are." Spanish movies exposed students to authentic interactions of people in a particular cultural context. Charlotte's comments suggest that they responded to this cultural practice on a non-verbal level in addition to learning about it on an intellectual level. A comment of Dan's illustrated this: “There's a scene where there's two friends. They're just like best friends, you know? There's some people that are not used to that and would see it and be like 'Aw, well they're... ."' Another (unidentified) student interrupted, "They're lesbians." (Note: They were not.) DS finished his thought: “They're more than just friends. I guess I wasn't used to that at first. But I guess you get used to it." These comments were evidence of the efficacy of this type of exposure to new cultural perspectives as a supplement to academic content. Students like Charlotte and Dan, who had not traveled abroad to a Spanish-speaking country, experienced a new dimension of the culture with an immediacy impossible through other media. But although this medium affected students and gave them access to a deeper level of crosscultural awareness, it was still one step removed from experiencing this type of friendship through interactions in a Spanish-speaking country, which would directly impinge on their emotions and their non-verbal comfort level.

Students also talked about differences in cultural practices within the family that they observed in the movies, especially those that differed from American cultural norms. Bridget spoke of one such contrast in family living arrangements, based on her own family: "I feel like there's a lot of differences [sic] in family culture. For example, my stepdad, he doesn't believe that an entire family should live together. Like for example, 
my grandmother on my dad's side, she lives with my aunt, my uncle, you know, the whole family lives in the same house. That's just the way it is. And it's no problem. But my stepdad is very much like: 'Oh, no, no, no! That's uncivilized'. They (Hispanics) view themselves as more family-oriented." Bridget's stepfather had a closed-minded outlook; he interpreted cultural practices according to the cultural norms of his home culture. It could be said that he had an ethnocentric view of the world. Bridget, on the other hand, had an ethno-relative view of culture: she acknowledged that a practice is to be judged within its own cultural context and not by some outside or universal standard.

Rosalinda also spoke of cultural practices in families: "I know here that it's more individual and when we turn 18, you're supposed to be out of the house. We can't wait to go off to college. I watched one of their movies. It was El Norte. [In] Mexico and places like that you're still in the house until you get married. And they're like 30, 40, and they're still living with their parents, and that's normal."

In each of these examples, students gained awareness of cultural practices that challenged their assumptions of accepted cultural norms in their home culture. Their comments were evidence that they were trying to make sense of these practices and to respond to them on an emotional level that went beyond mere intellectual awareness; they appeared to be learning an approach to understanding cultural differences which was not judgmental and involved developing cultural sensitivity and open-mindedness. The Immersion students' opportunity to share their perspectives and to explore cultural differences far exceeded the way that culture has been taught in the traditional FL setting, where the focus is often on the surface-level study of Kramsch's “food, festivals, folklore, and statistical facts" (1991, p. 218) — and where, if a movie is shown, the 
cultural practices involved can remain alien because little time is set aside for discussion, especially discussion with close Hispanic peers. The Immersion students were developing valuable skills that would allow them to deal with other cultures throughout their adult lives. The cultural content the juniors and seniors learned through their Spanish film class differed from content focused on the major products and practices in the cultures of the Spanish-speaking world, presented as traditional academic content. The films offered a more real-life context and involved both cognitive and affective aspects of culture: The topics that were addressed elicited responses from the students, no doubt exchanges of ideas, and possibly shifts in attitude.

\section{Experience}

Learning about culture from Immersion peers and teachers. This section explores the products and practices students learned about experientially through their peers and teachers within the Immersion Program, a distinction made in part to emphasize that they also learned by doing, as briefly noted above, and that the personal experiences of NSS students and others were integrated into discussions of academic cultural content.

The NES students gained awareness of both superficial and deeper aspects of the cultures of the Spanish-speaking world through their NSS Immersion peers and their teachers, and the NSS students also learned from their NES peers. Students varied in their breadth of awareness of the cultures, as well as in their depth of understanding of various aspects of the cultures, but within the Immersion setting, especially after students' initial 
experience in $9^{\text {th }}$ grade, the key elements of the Spanish language and social interaction combined to mediate culture learning.

Aspects of the cultures. An introduction to the typical dishes in the countries of the Spanish-speaking world was an integral component of the Immersion curriculum, one that combined learning about the dishes as cross-cultural knowledge with the sensory experience of preparing and tasting them. Comments showed that students also learned a deeper, culture-general lesson: on Food Days, they learned about respecting cultural differences, and about showing open-mindedness by trying an unfamiliar dish. Food Days also served as preparation for travel to a Spanish-speaking country.

Students were each assigned a particular country to research and were expected to prepare certain dishes for their peers to sample on "Food Days." They were also exposed to typical dishes when they went to local Latino restaurants with their program. The NSS students contributed to the discussions about foods from their home countries. A few NES students found out about new foods or new food combinations from their NSS peers who ate them in their lunches. The Immersion teachers also talked about their own experiences with the foods of the countries they were most familiar with. In the interviews and focus groups, the students did not talk about trying new foods on "Food Days," evidence that they were probably comfortable with this experience.

One notable exception was NES Mina, who was uncomfortable at first. She talked at length about her adjustment process to unfamiliar foods and ways of doing things. "I guess you have to gradually do it. I had to start out with the food. I have never liked flan, but in respect for the person who made it, I ate it and it was actually good compared 
to what I had eaten." She described how she had felt: "It's intimidating, but you have to fight your fear. You just take it one step, one little obstacle." Several other examples of the cultural aspect of Mina's Immersion experience will be discussed below.

Several students spoke of learning about aspects of the cultures of the Spanishspeaking world through Latino music, dance, and television programs. Bridget said, for example, "[We listened] to Spanish music while we were doing busy-work, because that's how we learned Enrique Iglesias's Dímelo, which was our favorite, and that was during our freshman year." Further comments from a number of students indicated that after the initial exposure to the music in class, they also started listening to music of the Spanish-speaking world outside of school, evidence that Latino music had become part of their lives.

Some of the 11 th and $12^{\text {th }}$-grade students learned about cultural space and greetings in cultures of the Spanish-speaking world from their Immersion peers; in particular they appeared to have accustomed themselves to hugging and kissing on the cheeks. Comments from two seniors indicated different responses, at least initially. Daniela, an NES student, explained: "I think they (Immersion students) greet people different because the other day, my mom went to shake this girl's hand and she (the Immersion student) just looked at her. Here, we're like 'Hey!' We hug and kiss on the cheek, and then now you don't even shake hands with people. I mean not all the time." Mina initially responded differently in Immersion: "María can tell you, I'm probably the meanest person. 'Don't come hug me. Like, you don't touch me'. But now, I just walk down the hallway, and I'll just hold everybody's hand." She added, "'Cause we're so lovey-dovey, and we would just hug each other.” The comments from Daniela and Mina 
were evidence that they had begun to assimilate this non-verbal practice related to social distance in the Spanish-speaking world. For Mina, it marked a significant accomplishment (her initial comments were corroborated by María). This group of seniors had adopted a number of non-verbal Hispanic traits as part of their Immersion culture.

Learning about topics such as cultural values and family relationships and immigration in the Spanish-speaking world can be purely academic, but when the insights come from observing and interacting with Hispanic peers, such learning becomes experiential. Jaime spoke of what she had observed about parents and children: "A lot of people would be surprised because they would think it's weird how strict their (my NSS friends') parents are, but I think we learn a lot about Hispanics, in Hispanic countries: the parents are more respected than here. I mean, it's different." The "respect" theme recurred for NES students in all grades. All of the NSS participants also said their parents were strict.

Students learned about the immigration issue in the United States through interactions with their NSS friends, as well as through the movies they watched in Cine class. They also debated the issue in one of their Immersion classes. Some students were more knowledgeable than others, depending on the experiences they had had. Only $11^{\text {th }}$ and $12^{\text {th }}$ graders talked about the issue. María's remarks were based on her family's perspective: "They come here because their families back there need them to be here. They need them to support them back at home because there's no jobs [sic] there." NES Mina introduced the topic of illegal immigrants: "I hang out with a lot of different types of people, and depending on if you hang out with people who are illegal, you understand. 
You have that more intimate concern about it. But if you don't see the circumstances, and you don't see the situations they go through, you're not gonna understand. Just by watching TV, it's not the same. You don't feel it." Mina hit the nail on the head: As students studied about this issue, learned about it through their peers, and developed their thinking through debates, they gained an understanding of it on an emotional level unavailable in traditional culture learning.

\section{Learning about Aspects of Cultures through Experiences in the Local Community}

As the Spanish Immersion students studied about the cultures of the Spanishspeaking world in their American public high school, they did so in an American cultural setting and in comparison to American culture. They learned about and experienced the cultures of the Spanish-speaking world via factual content knowledge and via interaction with their teachers and peers. But non-academic settings also allowed students to learn about and experience the cultures of the Spanish-speaking world: Some of the students had the opportunity to meet people in the local Hispanic community. When students participated in the Lake County study-abroad program or traveled abroad as individuals, they experienced the culture first hand and were immersed in it. Study participants spoke volubly of what they had learned and of their experiences with the cultures in the focus groups and interviews. We will look first at their experience in the local community.

\section{Experience}

Students' experience in the local community was observational and to a somewhat lesser extent interactional. They had less to say about the cultural aspect of 
these kinds of experiences with members of the local community than they did about the language aspect discussed above, and there were fewer of them to provide evidence: Some students used their Spanish infrequently outside the IP, and others not at all. Further, the $10^{\text {th }}$ graders did not do any volunteer work in the community and therefore did not have the breadth of experience of their $11^{\text {th }}$ and $12^{\text {th }}$ grade Immersion peers. The one exception was John Persie, who used his Spanish with native speakers at work. The $11^{\text {th }}$ and $12^{\text {th }}$ graders were much more actively involved in using their Spanish in the local community ( 9 of 13), and 8 of the 13 students had traveled abroad as well. Some of their experiences were only related to the language and to communication; the cultural themes they brought up most frequently tended to be inspired by their experiences interacting with people abroad. These will be treated in the next section.

The most frequently recurring themes inspired by experiences in the local community had to do with the role of family and the role of religion in the cultures of the Spanish-speaking world, also among the most common themes in the previous section on academic content. Religion will only be touched on briefly here.

\section{Learning about family relationships: Aspects of family culture. A NES} student captured the essence of life in the cultures of the Spanish-speaking world: "The biggest part of Hispanic culture is family, and it's the center of the culture. Why you do things you do, who you're with — everything is for the family" (BS). This analysis was supported by all the NSS Immersion students. Nicole commented, "On the holidays, I have to be with my family. For New Year's Eve, most people are out with their friends. I have to be with my family. And Christmas, I can't really party with my friends for those days. I have to be with my family 'cause it's all family." 
Students experienced concrete examples of culture when they spent time with Spanish-speaking friends or neighbors. Elizabeth spoke of what she had learned about the relationships in families from her Latina friend and contrasted this with those in her own family: "With her family, everybody talked to each other every single day. If you didn't see the person in person, you called them on the phone to ask them how their day was." Of her own family she said, “I don't have a good relationship with my mother. If I don't see my mom until 8 o'clock, I don't call her on the phone and say 'Hey how was your day'? She also said that Hispanic family members tended to spend a lot of time together, even when they did not live together, adding, "Food was always like the center of every family get-together. It wasn't a family get-together unless you had some type of meal." Food was the topic of some of her own interactions with her friend's family members: "A lot of the times, when I went over there, they were always like 'Are you hungry? Do you want to eat? I can make you something?' In my family when I have friends come over, they're like 'Watch some TV, eat some chips, there you go.' Whereas [in] her family, they would make these huge meals_-just for like one person." This student had grasped another cultural perspective and gained insight into her own culture through this comparison.

NES Immersion students, observing relationships in families and in the Spanishspeaking community, almost always described them as respectful. Their NSS Immersion peers uniformly confirmed this quality as well. One NES talked about this characteristic: "I feel like family is really respected in most Latino countries more than here. They have holidays - the Day of the Dead and stuff-and they worship family and friends and we don't have anything like that here. I feel like it is more recognized." This student 
understood that a respectful attitude went beyond respecting people as individuals and connoted a respectful attitude towards the family as an institution. Elizabeth's comment on this characteristic, based on her observations of her Latina friend and her family, was representative of a number of Immersion students: "You don't talk back to your parents." In her own family, "if I talk back to my mom, the most I get is grounded for a week." These observations were common to a number of NES and NSS alike. For example, one NSS student talked about her family and contrasted this attitude to her experience with American parents: “It's respect. You don't really talk back to them. If they tell you to do something, you're gonna do it. Like here, you can talk back to a lot of people. You're not as respectful." The comments of students from both cultural backgrounds demarcated a cultural difference in the relationship of parents and children: a parent's word is unequivocal and unquestioned in the cultures of the Spanish-speaking world. Nicolasa, another NSS, confirmed this analysis: "Anything they say is right. Sometimes it isn't, but anything they say should be right." One NES boy commented on what he had observed in his NSS soccer teammates, linking their respectful behavior to their religious background: "They're very religious, and most of them are Catholic. I have a friend as well on the soccer team and he's very religious. A lot of them wear their rosaries, you know, with the Virgin Mary on it, and they try to limit cursing and all the stuff on the field. So they're respectful." 


\section{Experiencing the Cultures of the Spanish-speaking World While Abroad}

When the $11^{\text {th }}$ and $12^{\text {th }}$ graders traveled abroad, they interacted with their host families and with people in the community. Preparation for their new experiences consisted of what they had experienced in the classroom with Immersion peers and teachers, as well as any experiences they had had with people in their local Spanishspeaking community. Both at home and abroad, interactions in the various settings meant learning about new cultural practices that they sometimes had to perform. Some students found a particular practice uncomfortable at first but eventually became more comfortable with it. At this next level, students had their prior experiences to help them but faced an additional element of challenge. In some situations, they reached a level at which they might never be comfortable with every aspect of a particular cultural practice. This continuum of comfort paralleled the continuum of their cultural evolution.

Eight of the $1311^{\text {th }}$ and $12^{\text {th }}$-grade students went abroad (to Honduras, Mexico, or Spain). The travelers consisted of six NES students, the heritage student, and the NSS student, all of them girls. Two of the six NES students took only very brief day trips abroad as tourists and were accompanied by a family member. They gained important insights into certain aspects of the language and culture through this exposure, but their experiences were not equivalent to the others in breadth and depth. In the interviews and focus groups, some of them spoke only of their initial concerns about their level of proficiency in the language, as discussed in an earlier section of this chapter; they did not talk about any aspects of the culture that they did not understand or that they found uncomfortable. Others (4) talked about certain aspects of the culture to which they had 
to adjust (JS, MW, FF, MM). The most common themes included the omnipresent family and religion, which will be treated briefly. Students' also reflected on their experiences with food, bargaining in the market, walking in town in a group of all girls and figuring out how to interact with men who tried to talk with them, exchanging greetings with people they knew and did not know, and dealing with other social-distance differences. Finally, four of these girls (3 NES, JA, RB, BS, and heritage learner FF) also reflected on their observations on role of men and women in the cultures of the Spanishspeaking world and how they felt about what they had observed from their own cultural perspectives as women who had been raised in the American cultural milieu.

Of course, students also talked about previously unfamiliar aspects of culture or history that were of special interest to them, the kind of surface-level observations that one might find in a travel book. These included new foods, new cultural or historic sites, new festivals, and the way people dressed. Rosalinda, for example, noted the practice of naming streets after significant dates in the history of the country or the region, "They had mini celebrations. I didn't know what was going on. They had a street that was called el 10 de junio- June $10^{\text {th }}$ and when that day comes up, they have a big party on that street”. Francesca observed that Mexico had Chinese restaurants, with people in them speaking Spanish! María remarked on the number of languages she heard when traveling on a bus in Barcelona.

\section{Themes}

The family and religion. The students who traveled abroad all lived with a host family or with members of their own family and were expected to adjust to the cultural 
practices and schedules of that family. Although they were aware of the main aspects of the culture from their background in the Immersion Program, they gained a new awareness from the concrete manifestations in a particular family. In their families, three students (BS, MW, RB) noted the role of religion and the overt signs they saw on their visits. They reported that they felt compelled to attend Mass with their "family." Bridget Saunders said, "Mexico, Catholicism is huge. You have to go to Mass, you know. I'm not a religious person, but when I'm in Mexico and in El Paso with my grandparents, I go to Mass. Like that's an inseparable part of the culture." Mina talked about her experience in Spain: "Staying there it's like [I saw] how important religion is. Like I went to church over there, and I don't go to church here. And it was like how strong people can be, how strong their pride can be about who they are and what they believe in. Compared to the United States, we need to step our game up on the things that we believe in and how strong we feel about what we believe in." Their comments about going to church showed some degree of cultural sensitivity and respect towards the families with whom they stayed.

Foods. Meals, mealtime and food were a theme that was common to three students, yet each one responded somewhat differently depending on their cultural adjustment. Rosalinda commented on one mealtime practice: "Everybody eats together as a family there, I noticed, whereas here, you know, sometimes you just want to eat lunch somewhere. Even in schools, they leave school to eat with their families and then come back." Rosalinda and Francesca both noted differences in family mealtimes and in the number of meals they ate each day, but their responses were evidence of two ways to adjust to cultural differences. Rosalinda responded positively to this change: "It's very 
strange, they have like six meals, and we only have three major meals. They have a morning meal and then breakfast and then lunch, and then after lunch they have their set snack time, where everyone eats a snack. And then they have their dinner. It's really cool! (giggle)" Her comments seemed to reflect a comfortable adjustment to the differences in mealtime routines. Francesca, on the other hand, appeared to struggle with mealtimes and the foods that were served at her aunt's house: “There was [sic] no snacks in between [meals], and I would look in the fridge for something to eat and there was nothing in the fridge. 'Cause I guess they get just the certain amount for each meal every time they go to the little grocery store on the corner to get fresh food, which is kind of different 'cause I'm used to having my refrigerator stocked with food. Around 3:00, my aunt would have lunch made, and that was sometimes eggs with ham cut in it. It was kind of like lunch/dinner in a way. And they ate dinner, which is sweet foods, like what we eat for breakfast, around eight or nine. So they had cereal and yogurt and hot chocolate with Mexican bread. I thought it was different, 'cause I would always eat soup for dinner. And like when they had that stuff, I'd be like, 'Oh, I'll eat that later. I'll just have some soup 'cause it's my dinner time, not breakfast. . .So it was a little different for me to adjust to the types of food that they ate at a certain times." Francesca may have been genuinely hungry and therefore felt less comfortable accepting the changes and adjusting to them, but she seemed to have experienced some culture shock regarding this particular aspect of life at her aunt's house. Overall, however, she believed that her stay with her aunt was a very positive experience.

When students talked about their experiences with new foods or with food preparation and other practices related to mealtimes, their responses ranged from 
enjoyment to feelings of culture shock. On the enjoyment end of the spectrum, Francesca said, "The movie theaters were different. I thought it was cool. Their popcorn, they can have like chile-limón on their popcorn. And they can have caramel on their popcorn, and butter. They can have whatever they want on their popcorn, and also they have the regular snacks that we have here. They have candy and stuff, but I kinda liked going for their popcorn 'cause I love chile-limón popcorn. It's just kind of my thing."

Students abroad also had the opportunity to try new ways of doing things, such as learning to prepare a cultural staple. Francesca said, "My aunt and my grandma [taught] me to make homemade tortillas. I never would have imagined me doing them by myself. But a couple of nights ago, I did them by myself and they turned out perfectly, and my dad was happy! So I am happy that I learn different things about culture and other academic things at the same time. It just makes me more aware of where I'm coming from and more open-minded to learn things." In this particular case, her experience resulted in the acquisition of a skill.

Unlike Francesca and Rosalinda, Mina responded to cultural differences in Spain with significant culture shock as she adjusted to living there. She was the only student to talk about such an experience: "I'm not a big change person. I'm picky with my food and stuff. So it took me a long time to warm up. I didn’t unpack my suitcase until the second week we were there. I think that I hated it the first week, because I did not know anyone except for the people I went to school with. I didn't know what to do. I was in a different place. It was different food. I wanted to go home... I missed my bed, so I hated the first week." This reaction was evidence that the new culture was initially beyond her comfort level. 
She also commented on her experience with the food. "In Spain, I didn't like a lot of foods. It's intimidating, but you have to like fight your fear. You just take it one step, one little obstacle... [our] dinners with the Immersion family prepared me for Spain." Her response to her friend Sammy's "Mina, just eat it!" cited below, however, indicated that there was a limit to her open-mindedness about new foods, which she also acknowledged.

MW: Like I'll at least try something. Like in Spain, I was, I didn't like a lot of foods.

SW: You ate bread the whole time (giggle).

MW: I was trying. I tried the food. But if I didn't like it ... She (Sammy) was really mad, 'cause she was like "Mina, just eat it!" "No, I don't want to." But I would take a piece, a little piece, and I'd have my bread on the side ... That's what I ate most of the time I was over there - bread and chocolate. That's the only thing I really liked. (Giggles.) Bread and chocolate. Yeah, I would not eat fruit. Yep, I wouldn't eat the fruit. I would try it, but it was hard.

Mina's experience was unique to her. The fact that the other five students who travelled abroad for homestays did not mention any experiences related to a significant cultural adjustment at all was an indication that overall they were comfortable in the cultures (JA, MM, FF, RB, SW). The aspects of the cultures to which these students had to adjust will be discussed in later sections of this chapter.

Learning to bargain in the market. Two students who knew about the practice of bargaining to purchase merchandise from street vendors spoke of trying out their skill when they were abroad. Francesca said,

Well in Immersion, I think it was freshman year, we were talking about how in Mexico, when they go to markets and stuff, you need to bargain in order to get the right price. So when I was there in Mexico, I remember I visited the pyramids and Tenochtitlán. And there were these bracelets that I told her [my aunt] I really wanted, and I asked my aunt if I could get them, and she said sure, but you have to bargain. I was like "Oh, Oh, I remember!" So I go up to the guy, and I'm like, 
"Can I have those bracelets? Can I try them on?" He was like, "Yes, yes, try them on." And I was like, "Oh, what's the price?" and he said, "They're 300 pesos." And I was like, "Oh, well you can have them back." And he was like, "No, no, no, they look really nice on you." And I was like, "No, I'm fine, it's too much for me." So I kind of started walking away, and he followed me, and he was like "What about 200?" and I was like, "I don't have that much on me right now. Maybe if I come back some other time, I will come and get 'em." And he was like, "Oh, OK, for you, I will give you 150 pesos." Which is kind of like \$15 here. And so I was like, "Alright, I'll do that," 'cause I know it's money for him, and I was just like "OK." So I gave him 150 pesos and I got my bracelets, and it was like my experience bargaining that I remember Ms. Morton (pseudonym) telling us about.

Elizabeth also talked about her experience bargaining:

When we were in Honduras, I felt really good because I did understand the culture better than if I was just an American tourist that knew nothing about it, just going in there. The way that they ran business and everything, it's definitely different than here in the Americas. It's more relaxed. There's little kids that have, you know, bracelets on a stick who are walking around and selling them to you. "OK, you can buy this, you can buy that." And there, you barter a lot too. If you feel that you aren't getting a good price, you can barter. Here, like if you tried to barter, most likely, they'd be like "No. There's somebody else that wants to buy my product. You can go find it somewhere else." But there, like, "If you want it for this price, I guess we could meet in the middle" and go right there.

The comments from these two students were evidence that awareness of this cultural practice and a basic knowledge of how to bargain were valuable to their comfort level as they purchased a trinket in a market.

In bargaining for goods in a market, Elizabeth also learned about life in a different part of the world:

Here, we have a very like middle-class society, and there I got to see the other side of things. I saw what it's like to have six- or seven-year-old kids go out on the street and try and sell bracelets to tourists just to provide food for your family and everything. So I did take back that not all cultures are as privileged as some people can be, and that sometimes you do have to do the hard stuff.

Although her experience of observing life in Honduras was very brief, she gained awareness of the culture on an affective, as well as a cognitive, level. 
Cultural space and greetings. Social distance norms differ from one culture to another, as do greetings. Each involves a non-verbal aspect that is best learned in the realworld setting in interaction with members of that cultural group, in other words via its "performance" by the cultural natives. For the L2 learner, a reciprocal response is involved that includes how he or she feels about this interaction in terms of comfort level. In this group of six seniors (4 NES- JA, MW, DM, SW; 1 HSS- FF and 1NSS- MM), students greeted each other with a kiss on each cheek as part of their Immersion culture. They also talked about how comfortable they felt with these greetings and other aspects of social distance that they encountered abroad in a Spanish-speaking culture. In a nonjudgmental way, they described the Hispanic perspective on these practices and compared them to those in the United States:

DM: ...passionate (giggles)... I think, the culture's more touchy. MW: More intimate

JA: If somebody's talking to you and you don't know them that well, and they're touching you. They have their hand on you. I think in a lot of Hispanic cultures, it's not as weird to touch people you don't know.

MW: Here, if guys hug each other it's like, "Oh, you're gay." Over there, it's like, "Oh, y'all are best friends." Oh, it's OK to hug each other, kiss each other."

Mina was the only student to state that she had initially been uncomfortable with greeting her Immersion friends with a kiss on each cheek, essentially a low-risk practice. Greeting people abroad whom she did not know represented a new level of challenge in terms of her comfort level. She spoke of her experience in Spain:

There, it's like "Oh, you're new, give me a hug, give me a kiss on the cheek." (Hesitation) "I'm not a very touchy person, so it kinda caught me off guard the first week. But after being there for a while, it was like every time I met a new person, it was like "OK, hug." I got used to it. The kissing part I didn't like, but I gave the hugs. . .So here, it's different. It's like, "Oh, OK maybe a hand shake, 
maybe wave, you're new to me, I don't know you, so don't get into my little bubble." Over there, it's like there's no bubble. You just always hug, hug, hug. They're very, I wouldn't say intimate, but more "OK, I know you now. We can be as close together as we need to.

These comments were evidence of how she adjusted to this cultural practice in Spain and also of the significant changes that had occurred in her way of interacting with people since she had started the IP. The "no bubble" metaphor captured the nature of this difference in social distance between the two cultures appropriately. The accounts of these NES students provided evidence of cross-cultural awareness and an understanding of this aspect of the non-verbal culture acquired through interactions, yet neither of them seemed entirely comfortable culturally in these interactions at that level (MW, JA).

\section{The roles of men and women in the cultures of the Spanish-speaking World.}

Men's and women's roles in a culture embody some of the basic premises around which the culture is organized. Their non-verbal aspect in the Spanish-speaking world was a theme discussed by four students (FF (HSS), RB, JA, BS (NES). These American girls

talked about how they were treated by men when they went to Spain or Mexico and about the differences they observed in the ways that men and women interacted in those cultures, comparing them to their own experience in the United States. While they had studied about the more traditional roles of men and women in the cultures of the Spanishspeaking world through academic content (especially in Cine) in the Immersion curriculum, it was through their experiences abroad that they attained a deeper level of cross-cultural awareness and understanding on a non-verbal and emotional level. Their experiences sparked them to reflect on their beliefs as American women. 
Three of them considered how they would feel personally in this type of relationship. Jaime spoke of her observations about men in Spain and of the ways in which men interacted with her and the other girls in the group:

I think in Spain and in a lot of Spanish-speaking countries there's the whole machismo thing. It's definitely, I would say, it's more sexist there. The men were a lot more forward, even men that were a lot older than us. They would approach us and say these weird, awkward things. So, that was difficult to me in terms of, something about the culture that I wasn't really aware of. But, at first we were just kind of like, "Oh, OK" (giggle). We were surprised, kind of taken aback, but then we just got used to it. We learned that [when] we walked with some of the guys in the group, then there was a lot less of that from the Spanish men.

The strategy that Jaime and her friends developed was an example of learning about a non-verbal cultural practice and making adjustments in their actions to reach a higher comfort level.

Jaime spoke about the insight she had gained about cultural roles of men and women in Spain that enabled her to better understand retroactively the films she watched in class:

When we're studying stuff in Humanities and even Cine, I think from an American's perspective, you see these things and you say 'That doesn't make sense,' you know? Why would he treat her like that? Or why doesn't she just leave him? I am referring to those movies, [that we saw] in Cine? But having been to Spain and seeing how they are there and how it's a lot more sexist, I kind of understand more. I think it makes a lot more sense to me.

Three students gave examples of what they observed about the roles of men and women, based on their respective host families; Francesca's observations about the relationship of men and women in the families with whom she stayed in Mexico were corroborated by Rosalinda and Bridget, who had visited Mexico and southern Texas. She said: 
The role of the women in society was kind of a little hard for me to grasp because when I was living with my father's cousin's wife, she just listened to everything he told her to do, and if he told her to go to the market to get groceries, she would take the baby with her and go get groceries. And for me, she expressed her opinions and everything, but she was the shy, quiet type and she just was subordinate to what he was saying. But she just had a different, quiet, nice, softspoken personality to her.

It was through this experience that she gained a greater understanding of gender-related cross-cultural differences between Mexican and American cultures:

I realized that here women have more rights and they're allowed to voice their opinions. And they're allowed to have the higher roles in society, while in Mexico, like a woman in government is not looked down upon, but it's just not right in their eyes, I think. It's not common. So a woman with brains and an attitude, they don't really like over there. And over here, they don't really mind. It's OK for here. So, yeah, it's an eye-opener. . .

[For] me, growing up here, I'm like more independent and I voice my opinions. If I have a problem, I will politely ask. If I have a question, I won't be scared to ask the teacher or anything. When I am in a relationship, I am not the one that wears the pants, but I'm not scared to tell somebody that what they're doing is offending me, or I don't appreciate the things that are going on. If they ask me to do something I don't want to do, I will be like, "No, I'm not going to do it. ... Over there, it seems like you just can't do that 'cause you'd just be out of the role of society.

Francesca's comments were evidence that she had distinguished an aspect of

Mexican culture that she could not accept on personal, professional, and political levels

and that she had gained a heightened understanding of the role of women in American

culture. She also observed that even Mexican cultural roles are not monolithic:

In the country, when I went with my aunt. Her husband had died, so she was raising two children, but she is more of an independent type like me and didn't really need to depend upon the man. There's a lot of things that she had to do since she didn't have a man in the house. So there's two different, I guess, roles, that the women had, depending upon their situation.

In the other $11^{\text {th }}$ and $12^{\text {th }}$-grade focus group, Rosalinda spoke about the way a

Mexican family in her neighborhood conserved its traditions: "They came here for the 
opportunities, but they still follow their same traditions. They don't assimilate, and everything was very kinda strong in their faith." When subsequently asked whether they would keep their American traditions if they were to move to Mexico, the students homed in on gender roles:

Bridget: Oh, no.

Unknown: Nope

BS: Oh, no, no, no, no.

Researcher: Wait, I asked Rosalinda, though.

BS: Sorry.

Rosalinda: I ... (hesitates, mumbles something incomprehensible) I don't know. I kinda liked their culture, 'cause they're so festive. I don't know 'cause I was so used to being American and so individual. If I were to go down there and then take care of a man and clean all his st ... I don't know 'cause ... Not all. . . Unknown: (repeats what Rosalinda said) "Take care of a man."

Researcher: You're not sure you'd like that.

RB: Yeah.

In this brief conversation, Rosalinda's comments indicated that she would not be willing to accept the traditional role of women in Mexico. Although Bridget and the three other girls in the group did not contribute to this particular discussion, all four of them had gained emotional, non-verbal, and intellectual insight into the role of women and men through their firsthand experience in a Spanish-speaking community in Texas, Mexico, or Spain. They had also identified an aspect of American culture they discovered they valued deeply, one that they deemed integral and essential for them personally. The comments of Jaime, Rosalinda, and Francesca, were examples of the deepest level of analysis for students in this study because they reflected upon what this type of relationship would mean to them personally. Although Jaime did not explicitly reject the 
traditional relationships that she had observed in films and in Spain, her comments were evidence that she concurred with the other two.

As students interacted with people abroad and gained cross-cultural awareness and understanding of particular aspects of the host cultures, they noted marked differences in the nature of these interactions when compared to American cultural norms. To some practices, like bargaining, they accommodated themselves almost with glee. To others, like going to Mass, they conformed out of respect. Certain students felt uncomfortable with the physical closeness of the interactions or greetings, and others could not accept personally, either intellectually or emotionally, the relationships they observed between men and women. Even in this last case, however, their comments always showed respect.

\section{Transformation: Changing Cultural Perspectives}

The Immersion family. The Immersion Program offered study participants the opportunity to spend four years developing proficiency in written and spoken Spanish and learning about the cultures of the Spanish-speaking world. The academic curriculum was hugely enriched, giving students an in-depth exposure to these cultures. The Immersion experience also involved the Immersion community, which included NES, HSS, and NSS students and Immersion teachers: The interactions between and among them were essential to the overall experience. Students understood the impact the program had had on them over time in terms of their knowledge of the cultures, but also 
vis-à-vis their own changing cultural perspectives. This was evident in the perspectives of the $10^{\text {th }}$-grade students, but for juniors and seniors the evidence was even greater.

In a focus group discussion, a group of remarkably perceptive juniors and seniors identified the different factors that they felt had contributed to the evolution of their perspectives. Jaime identified the first: "I think a lot of it stems from (1) being a group of people who are all different. Like, who come from different backgrounds and have different religions and all kinds of different things. But we're all learning about Hispanic culture, and we're learning about Spanish.”

Sammy identified the second and third factors in the process of changing cultural perspectives: "I feel it's not exactly the curriculum or anything, but how it's structured. You're (2) with these people through three classes each year. You're kind of forced to interact with people and (3) your stereotypes break down." She described the process further: "I don't tend to judge people as much as before. It's like before; I'd look at 'em and make a snap judgment about 'em." There is support in the research literature in the field of intercultural competence and culture teaching and learning for the processes that students have identified. The process of breaking down stereotypes and changing cultural perspectives involves "suspending judgment" (Fantini, 2000, p. 28), "suspending disbelief" (Byram, 1997, p. 50), or no "prejudgment” (Trifonovitch, 1977, p. 553). Changing cultural perspectives have been described as an example of a cultural shift (Bennett, Bennett, \& Allen, 2003). These terms seem to be descriptive of students' approach to people from diverse backgrounds. María also contributed her experience with stereotypes and judgment: "Before Immersion, I would stick with a certain group of people. 'Oh, that girl's kinda funny. I don't think I'm gonna talk to her. She doesn't look 
like we would have anything in common." These comments, representative of many students in the $11^{\text {th }}$ and $12^{\text {th }}$-grade group, were evidence of the changes that students believed had occurred in their cultural perspectives over their four years in the program. The "snap judgment" described by Sammy and paraphrased by María suggests that stereotyping creates a barrier inhibiting interactions between people who appeared dissimilar on the surface.

Rusty elaborated on the value of the second factor, social interaction, from his perspective: "Group work is especially important to me. It gives us the option to bounce ideas off of each other. We're given time for free expression in class, and one of the girls likes to share the experiences she's had with her Spanish-speaking grandparents. Then we have another girl who occasionally shares her experiences, and it gives us contrasting views."

Several students identified the fourth factor, which also brings in social interaction. Charlotte explained: "There's a lot more focus (4) on the students, and we can actually have debates, 'cause in our other classes it's more structured and you have to get through the SOL. In humanities, we had a large debate about African cultures and a huge debate about immigration." María also talked about the value of these debates and other interactions in AP Spanish Literature: "It's more than just reading and writing about it, because you get an insight on it, and you get a different point of view from different people. We like giving our opinions, and we like talking about it and that's what makes you change (italics added).” 
Developing open-mindedness to other cultures; risk aversion. When students talked about what they had learned about the cultures of the Spanish-speaking world, they believed they had become more open-minded towards other cultures. Daniela spoke of her attitude: "I think you give people a chance more. You're more interested in what you can learn from them and what they can teach you." Three other students in her group concurred. This student seemed to be referring to open-mindedness, suggesting that the Immersion environment had helped to foster its development in students. Mina identified two additional factors that contributed to the Immersion environment. First, students developed layered relationships. She said: "We don't only learn about the Spanish people, we learn about other people as well. Ok, yeah, we're studying in Spanish, but we talk about a lot of stuff. We have conversations in class, and we talk about like each other's lives and the different things we do and stuff. We don't just learn about the class curriculum. We get on a discussion." Mina went on to identify the second factor, the result of the first: "It makes you more comfortable. Like, now, OK, I can go hang out with a different group of people. I can go hang out with those kids who are from a different country. And you just become more comfortable with who you are so that you are able to go and show yourself to somebody else and accept another person as well.” Mina's comment also neatly captured another theme common to the seniors in the program: their own personal growth. Mina appeared to have come to know herself better through her IP experiences, a theme to be further discussed below.

It has already been noted how important comfort-level in a particular cultural context was for this student. The changes that she talked about in her own cultural perspectives were an indication that developing open-mindedness was a gradual process 
of developing awareness and understanding of the cultures of the Spanish-speaking world that began on her first day in the Immersion Program. Her experiences trying new foods on Food Days and learning about traditional greetings from her NSS friend María represented a leap of faith whereby she pushed herself beyond her comfort zone. No other NES student experienced these changes as intensely as she did.

During her home stay in Spain, Mina found herself in situations that were beyond her comfort zone; she reacted differently in the true immersion setting to aspects of the culture she had been familiar with in the IP. Greetings and new foods required another, partial, cultural adjustment from her, but she did her best to be game: "Like in Spain, I was trying. I tried the food. I'll at least try something." Nevertheless, she remained somewhat risk-averse, though self-aware and frank about the limits beyond which she preferred not to go.

Risk aversion was not common among study participants across all grades and language groups, but $10^{\text {th }}$-grader NSS Nicolasa provided another variation on this theme. Immersion classrooms and the IP community represented her comfort zone. Yet although she said she was "close" to her NES Immersion peers and that they all had "open" relationships with each other, she did not interact with them outside of Immersion. She also talked about feeling uncomfortable in some interactions with American peers. These comments were evidence of individual differences between students in encounters with people from other cultures; for Nicolasa it may simply have been a question of personality. Her inhibitions may have been overcome in IP by a supportive learning community and repeated and frequent interactions in which students shared ideas and engaged in dialogue about diverse points of view, yet another indication of the 
importance of the social interaction that students described as so essential to the Immersion experience.

Perspectives of Immersion vs. non-Immersion students. The theme of an Immersion perspective was well developed in students of all grade levels as they talked about the contrasts in cultural perspective that they saw between members of their community and their non-Immersion peers and teachers at school. They also spoke of differences in perspective they had observed outside of school. One student, DM, put the IP philosophy in a nutshell: "[We] embrace differences."

One example, among many, afforded insight into the Immersion perspective. EM and BS, who were White, and RB, an African-American, talked about the cultures at their school and in particular about one incident involving a cultural conflict between White "rednecks" (their term) and Black students. EM began, "They got into a fight just because they didn't like what the other person believed in. I don't know anything about the argument. I don't know what the issues are." RB explained her perspective: "I have no take on it at all. There was [sic] text messages going around ... If you're Black, wear black (chuckle) tomorrow. If you're White, wear white. Yeah, it was a big thing. I think I was wearing a white shirt (chuckle, students laugh). I don't take part in any of that kind of stuff. It's just ridiculous." BS added, "Hispanics and those in Immersion" have no problem.

The terms used by these three students were related to the characteristics they believed defined them as "Immersion" students. Students across all grade levels commonly said, "We no longer have that ignorance." In her comment just above, BS 
seemed to be saying that the non-Immersion Hispanics in the school were also not "ignorant" of other cultures by virtue of living in two different cultures.

The "ignorance" comment conveyed Immersion students' knowledge and awareness of other cultures and of other cultural perspectives, especially their depth of knowledge of the cultures of the Spanish-speaking world. It also conveyed tolerance, respect, sensitivity to other cultures, and open-mindedness towards different ways of doing things. Immersion students understood what it meant to speak another language; Spanish was an integral part of their identity as Immersion students. Many of them also believed in the importance of speaking multiple foreign languages and planned to pursue this goal in college. When Immersion students interacted with peers and teachers in other area of the school, they sometimes shared their Immersion perspective with them.

Developing cultural sensitivity at home and abroad. Some of the older students in the program spoke about respecting people from other cultures. Others mentioned "caring" more or becoming "kinder and more humanitarian" as changes they believed had occurred in their feelings and attitudes towards people from other cultures as they learned about the cultures of the Spanish-speaking world.

Immersion students' trips abroad gave them their first opportunity to live in another culture and to experience all aspects of it. As a by-product, they became sensitive to their identity as Americans and of what that means from the perspective of outsiders. Francesca talked about this experience:

When I went to Mexico without having my family there with me, I was by myself, and I didn't want to be portrayed as being a snotty person, because I'm definitely not a snotty person. It makes me stop and think about how I want myself portrayed before I open my mouth or before I make a gesture with my 
hands or my face or anything, 'cause before I had that kind of attitude like I didn't really care about what people thought of me. I guess I have stopped and thought about what I say before I say it and how I act. And it makes me sit back and realize that I appreciate what I have here and appreciate how far my family has come from where they were before-like my father. And just things like that in general.

When Francesca first visited her cousin's family, she had been stereotyped as a "lazy American." This may have been the impetus for her to evaluate how others viewed her. Here she showed that she was developing not only cultural sensitivity to her hosts and to her own cultural identity, but also independence from her parents and the recognition that she alone was responsible for what she said and did.

Personal experiences and growth. Confidence involves a belief in one's abilities that generally develops over time. One's degree of self-confidence can be a matter of personality as well: shyness is a personality trait, just as boldness is. Even the most confident individuals, however, have a comfort zone within which they feel secure, and a range of options beyond it that they find challenging, and challenge, according to UVA Anthropology and International Comparative Education professor Diane Hoffman, involves “moving outside of one's comfort zone and expanding one's SELF” (personal communication, February 12, 2012).

Students in the IP had developed their proficiency in Spanish and had gained awareness and understanding of the cultures of the Spanish-speaking world, rising to challenges since starting the program in $9^{\text {th }}$ grade. Some of them also recognized that they had made strides in their own personal growth and specifically talked about the changes they had seen in themselves. The aspects of personal growth that students identified centered on self-confidence, and on emotional and intellectual maturity that 
develops during adolescence. Students stated that they had gained knowledge of themselves as individuals. They had seen increases in their overall academic engagement, in their beliefs about their ability to be successful in Honors and AP classes, in their critical thinking skills, and in their capacity for thinking independently.

An example of greater emotional and intellectual maturity was related to the theme of academic engagement, which was a common theme for students and was discussed in some depth in chapter IV. Charlotte's statement is one example that represented a change that took place for a number of her peers: "Spanish Immersion, I've never had experiences like this before. It has changed the way I take to school, 'cause before I was kind of lazy, like I didn't really study at all. But for humanities, I know I have to study or else I'm not going to do very good. That's helped me in my other classes too just to make sure I study more and learn more".

Another facet of personal growth for students involved increased self-confidence, which all Immersion students showed to some extent, when they made the decision to join the SIP. In doing so, they showed a willingness to challenge themselves to go beyond the standard high school curriculum. The extra effort that the SIP required of them and the new challenges that they faced were more than some were accept. As a result, some students did leave the program (Director of the program, April 19, 2011, personal communication). An example of increased self-confidence gained through challenge was described by seniors Francesca and María. Francesca’s statement represented the thoughts of both: "Being able to push through and tell yourself it's OK to be challenged. I realized that even though it's a harder workload, getting through that and challenging yourself makes you a more well-rounded [sic] person. It helps you to be 
more understanding of the difficulties in life and that not everything is easy. I just felt a sense of accomplishment after I finished $9^{\text {th }}$ grade Immersion”. A characteristic of these two students and of all Immersion students was also perseverance.

Another example of personal growth and self-confidence was related to the activities in which students participated. Senior Jaime stated, "In my Spanish Immersion classes, we do a lot of talk, a lot of debating, a lot of discussions, and I wasn't really as comfortable with that as a 9th grader as I am now. So I think I participate more in terms of interacting with people — not just in Spanish, but [in] English too, in other class' discussions, and I am more confident in myself." This student seemed to be related to the interactions themselves in addition to the intellectual aspect that she gained through knowledge and experience. A further contributor to self confidence was identified by junior Rusty: "I think that I am a little bit more confident in Spanish, as opposed to English. The language actually requires a little bit of confidence in the accent to go with the speed and other things". For both of these students, social interaction within a supportive Immersion community played a role in their increased confidence levels.

Two students spoke about how they had become more independent thinkers through the knowledge they had gained about the cultures of the Spanish-speaking world. These were further examples of self-confidence and were similar to the previous discussion about Jaime. NES senior Elizabeth said, for example:

The Immersion Program kind of just made me a bolder person about the way I think of the world and the topics and stuff, because before the Immersion program, I didn't really have thoughts. I went by what my parents said, you know? If I did have thoughts, I didn't, you know, fight for them. I didn't voice my opinion. You have to be bold, you know, to be brave. You can't understand something without knowing about it and learning about it first. So knowing about 
the issues has definitely given me that little extra oomph to go over the top, not just kind of stay where I am, so that I can change as the times change. You know, not just be in my little box.

NSS sophomore Nicolasa had described her parents' role in her thinking: "Anything they say is right. Sometimes, it isn't, but anything they say should be right." In her interview, she identified the changes in her thinking:

It's made me more open to different things, not very judgmental anymore. My dad always told me about South America, and he told me it was just a bad place to be and there was a lot of trafficking and stuff. And we learned about Colombia and places like that. I mean there is [sic] bad things, but there's so much more, like the people, the society, the places to go.

Although these two students came from two different cultures and two different grade levels, they both seemed to be talking about developing more independent thought and critical thinking skills as a benefit of participating in the program.

Overall, the study participants in the Dover SIP, as a group, had confidence in their academic abilities and in their level of proficiency in Spanish. They felt a sense of accomplishment because they had chosen to challenge themselves, to go beyond their comfort level by joining the SIP for their high school trajectory. Virtually all of the students across all three grade levels spoke with some confidence about their experiences. As $10^{\text {th }}$ graders, they made comments such as "Studying math and history in Spanish has become routine" or "I just thought it would be cool to say I studied math and history in Spanish.” These NES students' level of proficiency in their L2 helped prepare them to move to the next level of challenges in the $11^{\text {th }}$ and $12^{\text {th }}$ grades. Overall, the NES juniors and seniors (9 out of 12) spoke with confidence about their proficiency in Spanish and their ability to understand conversations in the outside world. These students considered themselves non-native Spanish-speakers, but since they did not look Hispanic, at times 
they had to explain their proficiency in Spanish and their identity as Spanish-speakers to people in their local community, making their experience all the more transformational.

Some students experienced much more significant personal changes in terms of their cultural perspectives than others. Elizabeth was a notable example, the student quoted on the previous page as saying, "You have to be bold, you know, to be brave. . .

[I want to] change as the times change. You know, not just be in my little box." As a $9^{\text {th }}$ grader, as previously mentioned, she "felt really out of place" and hadn't know what the Quinceañera was. "I was in my own little bubble," she said of that period. The bubble metaphor referred in this case to her own cultural world. The bubble enclosed her, just as stereotyping closes off "the other"; they are two sides of the same barrier that had interposed itself between groups of students in the past.

In the Immersion setting, students from diverse cultural perspectives came together and were exposed to each others' perspectives through the social interaction. Their comments clearly pointed to this interaction as the catalyst for the transformation of their perspectives. Elizabeth articulated this well:

I just had to get out of my little bubble. One day I was just "You know what? I kinda just have to make myself comfortable. There's nothing that I can do that's going to make it easier for me than if I just try. I actually have to be a part of it. I actually have to talk with friends about what they do with their lives and such."

The bubble metaphor recurred with Mina, in her case referring to the social distance in American culture. She has already been quoted reflecting on greetings in the two types of cultures. In the U.S., she was comfortable:

You're new to me; a handshake, maybe a wave, I don't know you, 
so don't get into my bubble. But, she continued, "In Spain there's no bubble. It caught me off-guard the first week. After being there for a while, every time I met a new person it was like, 'Ok, hug'. I got used to it. The kissing part I didn't like, but I gave the hugs.

Her adjustment to this cultural practice marked the culmination of a multi-step process that had occurred over more than two years. It started with interactions with her Immersion peers and their family members to which she eventually adjusted. Mina's and Elizabeth's changes in behavior and comfort level may represent some of the greatest transformations among the students in the study, when considered within the context of their statements about cultural adjustment over the course of their four years in the program.

The common thread in the group of 7 students (out of 26 interviewed) who specifically identified their own personal growth as an important aspect of their Immersion experience was the increase in emotional and intellectual maturity that they had gained during their high school years. The $11^{\text {th }}$ and $12^{\text {th }}$ graders and only one $10^{\text {th }}$ grader, Nicolasa, articulated these changes, which the rest of her peers did not discuss.

\section{Discussion and Conclusion}

It is important to examine the experiences of each group of students and to consider them in their relationship to the Immersion experience as a whole, both in terms of second language acquisition and social interaction in the Immersion Family, which was dealt with in chapter IV, and of culture learning, which has been the focus of this chapter. In order to achieve a complete cultural snapshot of the Dover SIP at the time of 
this study, it was necessary to examine the cumulative effect of each student's cultural experiences over four years. The following overall picture of their culture learning emerges:

As a whole, students' culture learning moved along a continuum from $9^{\text {th }}$ through $12^{\text {th }}$ grades. Each student arrived with his or her individual background and personality traits. The findings from this study showed distinct differences in the breadth and depth of culture learning from surface-level cross-cultural knowledge and awareness to a much deeper level of cross-cultural understanding. The $10^{\text {th }}$-grade NES students overall were notably absent from the discussions of the deeper levels of cross-cultural understanding because the cultural content of their Spanish courses in the first two years was more basic in nature, and they had had very limited experiences with the local Spanish-speaking community outside of the Immersion classroom. The one notable exception was John Persie, who worked with his uncle and helped to translate for the Spanish-speaking employees. Nevertheless, he only talked about the communicative aspect of his interactions. The four $10^{\text {th }}$-grade NSS students lived in two cultural worlds, and their level of cross-cultural understanding was deeper. While the students in this group were able to speak about issues from the Hispanic cultural perspective as well as from the American, the dominant culture in their lives was their home, i.e. Hispanic culture. Although three of the four spoke as insiders in both cultures, the one exception was Nicolasa, whose comments from the interview and the focus group were evidence that she considered herself to be an outsider in American culture.

An examination of the $11^{\text {th }}$ and $12^{\text {th }}$ grade NES students as a whole revealed perceptible differences in their level of culture learning in comparison to their $10^{\text {th }}$ grade 
peers from the same language group. These distinctions were affective and cognitive and were related to a variety of factors. These students in the upper grades had more extensive cross-cultural knowledge than their younger NES peers. The most significant enhancements on the curricular level included the films they watched in their Cine class and the interactive sharing of ideas, as well as the debates. The films gave them a modicum of sensory involvement, as well as exposure to the affective aspect of the cultures. For those students with limited experiences outside the Immersion classroom, these films were their only exposure to the cultures at that level. The value of these courses was evident for all the NES $11^{\text {th }}$ and $12^{\text {th }}$-grade students except one, when compared to their $10^{\text {th }}$ grade peers, based on their comments about the concept of friendship in American culture and in the cultures of the Spanish-speaking world. Also on the affective level, extracurricular activities involving interactions with members of the local Spanish-speaking community afforded students the potential to gain a deeper level of understanding of the cultures.

In the $11^{\text {th }}$ and $12^{\text {th }}$ grade group, the transformational experiences related to the cultures of the Spanish-speaking world were characteristic of the NES students who had been abroad. The distinctions within this group were related to the extent of their experiences outside the Immersion classroom in addition to their experiences abroad in a Spanish-speaking country. NES and NSS status differences were relatively subtle in this group because 7 of the 12 NES students and the one NSS student had had experiences abroad. The noticeable differences within the remaining 5 NES students who had not been abroad were related to the extent of their interactions with people in the local Spanish-speaking community. Thus, for the 3 of them who had had limited experiences, 
there was evidence that most of their understanding of the cultures remained on the surface level as cross-cultural knowledge. The evidence from 2 of these 3 from their comments on the films in Cine class showed some understanding of certain aspects of affective culture on an intellectual level, but they had not experienced them on a personal level since they had not had any of these interactions.

The next step on the continuum of culture learning was embodied by the remaining two students in the group of 5 who had not been abroad. The junior boy and the senior girl distinguished themselves from the other three by the extent of their involvement in the community at their place of employment, as volunteers in schoolrelated and independent activities, and in their own personal lives. Evidence from their interviews and the focus groups showed that they felt more comfortable in a Spanishspeaking environment in terms of language and culture, yet they lacked the level of cultural insight and understanding that came from the experience of study cum homestay abroad. They were thus situated between the other two groups of NES $11^{\text {th }}$ and $12^{\text {th }}$ graders in terms of their level of cross-cultural knowledge and understanding. Finally, when the experiences of these two students were considered in comparison with each other and also with the study abroad group, an additional distinction separated them: Daniela's level of cross-cultural understanding was almost indistinguishable from that of her study-abroad peers, who had had the benefit of additional affective experience conveyed through social interaction, in which they observed cultural differences and reacted to them personally. A notable example of this was the deeper level of perceived understanding the American girls abroad gained concerning the role of men and women in the two cultures. 
As the seniors prepared to complete the program, they seemed well positioned to speak Spanish for personal enjoyment and/ or to continue to study it at the post-secondary level and, for some, to pursue a career that would involve working in the language. The next section explores this theme briefly and marks the end of the findings chapters.

\section{Immersion Students' Plans after High School}

Although the interview protocol did not include a line of questioning about students' future plans, as tangential to the goals of the research, the question nevertheless, arose during the second focus group of $11^{\text {th }}$ and $12^{\text {th }}$ graders, and all of those present answered. At that point, the seniors knew where they would be attending college. In the two $10^{\text {th }}$-grade groups, students were asked about their general post-high school plan but not specifically about plans to attend college. Students' answers involved college plans and possible career interests. Nine of $1311^{\text {th }}$ and $12^{\text {th }}$ graders and 10 of $1310^{\text {th }}$ graders said they had firm or tentative plans to go to college. Eleven out of 26 students said they planned to study Spanish or another modern language, with 4 of them interested in majoring in the language, while 7 planned to study two or more languages. In the NSS group, only María, a senior, talked about plans to study Spanish in college. (The other, younger, NSS students were not specifically asked about college plans.) Four additional students expressed an interest in studying Spanish in college but did not give details. Eighteen out of 26 students said they were interested in a job that involved the use of Spanish. Five out of 18 NES students planned to use their Spanish-speaking skills to 
work in the U.S., while 13 out of 18 planned to work abroad. Several students spoke about their interest in traveling to a Spanish-speaking country to explore places that they had studied in academic content.

A number of students felt motivated to offer their skills to help address the societal challenges faced by members of Spanish-speaking communities in the U.S. Data from the present study, previously discussed, show that in Immersion they had gained awareness of these issues; immigration, poverty, and low levels of proficiency in English were specifically discussed. Some students had also had personal experiences at home or abroad that contributed additional insights.

In the $11^{\text {th }}$ and $12^{\text {th }}$-grade group, a common theme was the genuine desire to help people in need, and a number of them planned to do so as professionals. Twelfth-grader Daniela's earlier comments had conveyed her empathy toward local Latinos as she interacted with them as a volunteer in the schools or at work in a grocery store. She said of her plans and those of her peers, "A lot of us are going into careers.... When you go out into the world, you can really put it to use and do good things with it, volunteer your time or make it a career, whichever you choose." Jaime's career interests echoed Daniela's: "I feel a lot of empathy, I think, with Hispanic issues. I feel like I care more about [issues] like immigration and stuff that really impacts the Hispanic community. I am getting to the point where I'm pretty sure that I want to do something that is in civil rights and stuff like that. And I think it's motivated me. I want to help people who come to this country who may not get their rights that they deserve." She and María both planned to become lawyers. One student planned to become a teacher or a nurse and to use her Spanish when needed. All three planned to work in the United States. 
Four others in this group planned to work abroad. Dan hoped to become a pastor and to do missionary work abroad. Mina, Daniela, and Francesca planned to go into the medical field and to become doctors or nurses. In a representative comment, Francesca said, "I'm actually planning to be a nurse or a doctor. I'm going to River City University, and I am doin' pre-med. I kind of want to go and work during the summers when I'm in college, I guess [to] a different Spanish-speaking country, like help out there. Because I know that third-world countries need as much medical help as they can get, because the medical help they have now is poor."

In the $10^{\text {th }}$-grade group, 11 out of 14 students had made plans to do jobs that involved Spanish, and within this group, four of them specifically stated that they planned to help others using their Spanish-speaking abilities. Of these four (3 NES boys and 1 NSS girl) with goals of a humanitarian nature, two hoped to do missionary work, and two leaned toward engineering. The first of the potential engineers, Trevor, had distinct career plans: "I've already had my mind set before Immersion: structural or electrical engineer. I'd like to probably go and help build houses in poor third-world countries [like] Argentina, maybe Chile or Brazil.... Um not Brazil, um Spain. That would help me interact with other people that don't know English.” The other, Nicole, had spoken about life in her native Peru and her desire to return there to help, and elaborated: “Some people don't really have houses. It's dirty down there. They don't really have roads or anything. I feel like I want to help, like countries in South America, like get stuff that they need when I get older. I want to build roads for them, like have safer conditions to live in." NSS Nicolasa planned to return to her native Mexico to live 
and pursue a college degree and hoped to become a veterinarian, while NSS Mary planned to become a teacher.

Among the students who talked about their post-high school plans, 7 (of 26) were motivated, at least in part, by their religious convictions, which they specifically identified. $11^{\text {th }}$ and $12^{\text {th }}$ graders Daniela, Francesca, and Dan fit into this category. Tenth graders ES, JS, JP, and TS were similarly motivated. JS was no doubt influenced by his father's numerous mission trips to Cuba: "I want to be able to speak with them. My dad, he's a pastor at a church that has a lot of Hispanics, and he speaks some Spanish, like rudimentary Spanish, so I help him with his devotions and stuff, so he can say it in Spanish right." This student's desire to be fluent in Spanish in order to help people in Cuba may also have been motivated by his observations of his dad's limited knowledge of the language. Students across all three grades believed in the importance of communicating in Spanish to show their respect for native Spanish-speakers. 


\section{CONCLUSIONS AND IMPLICATIONS FOR FURTHER RESEARCH}

This study was conceptualized as a response to the research findings of the scholars included in Lange and Paige's Culture as Core (2003), as well as to F. M. Klein's (2004) challenge not only to clarify the various terms that scholars have used to define culture learning, but also, and above all, to put into practice the approaches to culture teaching and learning that have been devised. It is also a response to Kramsch, Galloway, and other scholars in foreign language education who argue for an approach to culture learning that goes beyond the tendency to be mere "cognitive border crossing." It responds as well to the finding that scant research exists in immersion education on the secondary level; prior research alluded to in Wesely's literature review (2009) revealed the consensus that culture in one-way and two-way immersion programs at all levels was not being well taught, if taught at all. Finally, this study has sought to extend the research of Bearse and de Jong (2008; de Jong \& Bearse, 2011) on students in a high school twoway immersion program by examining students' perspectives on culture learning in a one-way immersion program and by providing evidence of what culture learning looks like in this setting from the students' point of view.

When the data collection phase began, it appeared that its central focus would be the cultural aspect of students' experiences. As the initial themes emerged, however, it became clear that second language acquisition and social interaction mediated culture and thus were situated, along with culture, at the heart of the study. As a result, this study 
contributes to the field of second language acquisition by confirming the findings of prior research, it explores and expands the body of knowledge on the role of social interaction in SLA and culture learning in foreign language education and in immersion education, and finally, it breaks new ground in the field of culture learning, contributing to the literature on this topic as well in both educational modalities.

This chapter discusses the main findings in second language acquisition, social interaction, and the teaching and learning of culture and their relationship to the existing research literature. It goes on to discuss the three research questions and the implications of this study. Finally, it proposes suggestions for further research and outlines the researcher's conclusions.

\section{Second Language Acquisition Studies}

\section{The Developing System}

The immersion research literature on second language acquisition for elementary school students has documented that this instructional setting is effective for developing high levels of proficiency in the target language (Genesee \& Lindholm-Leary, 2013; Lyster, 2007; Fortune \& Tedick, 2008). For high school immersion students, this instructional setting provides the optimal set of conditions: "comprehension, speech production, learning, and social interaction” (Van Patten, 2003), for developing high levels of proficiency in the target language, yet only Forrest (2011) had examined this factor and no authoritative studies have been conducted to date. Anecdotal evidence from students in the Dover SIP is discussed later in this section. A central aspect of the 
developing system is input that is meaning-based and contextualized, and the system develops by means of many interactions over a long period of time. The empirical literature in two-way and one-way immersion has provided support for both these aspects of SLA. When native and non-native speakers of the two languages provide models as each group of non-native speakers practices their L2 through their interactions with their L1 peers, L2 proficiency is fostered (Howard \& de Jong, 2009, and others). Since the Dover High School SIP was a one-way immersion program, no classes in English existed exclusively for the benefit of the Immersion students; therefore, the NSS students, along with the teachers, provided the models in Spanish for their NES peers. Student participants gave strong evidence that there was abundant input and output, that it was contextualized, and that they had sufficient time over the four years of the program to develop their L2 proficiency. Students across all three grade levels talked with confidence about their high levels of proficiency in Spanish. The NES students' use of the target language in various settings outside of school and the comparisons they made between themselves and their non-Immersion peers were further evidence of their L2 proficiency. Further, an inherent characteristic of immersion programs, both two-way and one-way, is that students learn their L2 through academic content. Virtually all of the target language input and output was meaning-based and contextualized. Students also indicated that communication in their L2/ L1, not accuracy, was the primary focus. They understood this goal well and said it was emphasized by their teachers. In the supportive atmosphere of the Dover SIP, the study participants felt comfortable communicating in their L2. This was important for the NES and Heritage learners 
because it gave them the comfort-level to speak Spanish without fear of being judged by their peers.

\section{The Nature of the Experience of Acquiring a Second Language}

Speaking a second or other language involves effectively communicating in culturally appropriate ways with members of the target speech community. In the SLA research literature, Hymes (1972) identified this communicative competence as "knowing what to say, to whom, in what circumstances, and how to say it." Some of the participants in this study provided evidence that they were aware of the "appropriateness" component of their L2, although they did not specifically discuss the cultural dimension of communication. For them, it was related to manner, one aspect of the "how," the respect to be shown when communicating with native Spanish-speakers, a common theme for students across all grade levels and from both language groups (BS, DM, JA, FF, SW, JP, AG, RT, NJ, PG, JM, MS etc.). Two of the native Spanish speakers spoke of how they were expected to communicate with members of their own family; one of them said, "Respect is the biggest thing" (PG). Within the native English speakers, only one junior mentioned that she knew not to say anything offensive (BS), thus combining the "what" and the "how" aspects. One NES $10^{\text {th }}$ grader addressed this issue in a more rudimentary way: "When you talk to someone in Spanish, it's kinda how you just talk in English. You'd just be respectful” (JM).

Several study participants mentioned reciprocity of respect. Not only did they believe that speaking Spanish to Hispanics conveyed the message that these native English-speakers valued and respected the language and the culture; $10^{\text {th }}$ grader John 
Persie became aware that "they all grow respect for you when you take the time to learn their language." A few other students (DM, AG etc.) experienced similar feedback, gaining an important insight about the nature of language and culture through social interaction with native speakers.

These Immersion students had gained awareness of at least some aspects of appropriate communication in Spanish that are supported by the theoretical literature in SLA. Yet awareness alone is insufficient for effective and culturally appropriate interactions, as Fetzer (1997) had posited when speaking of the role of "real-life contexts" in providing students with feedback about their L2 performances. Students in the Dover SIP had such opportunities (in widening concentric circles) inside the program, outside the program with friends or neighbors, through service learning, and through their experiences abroad. These opportunities were an important aspect of the program, and a number of students in $11^{\text {th }}$ and $12^{\text {th }}$ grades sought them out. They received positive feedback from these interactions and gained greater confidence in their Spanish-speaking abilities.

\section{Foreign-language (One-way) Immersion}

The SLA benefits of the one-way immersion program for high school should not be overlooked. In the United States, the majority of one-way immersion programs are for Spanish. The curriculum, which combines intensive and accelerated L2 development and content area courses, offers a unique high school experience. It challenges educators to go beyond the traditional medium of instruction and at the same time offers an 
intellectually and culturally rich curriculum with a particular focus on the cultures of the Spanish-speaking world. In addition to these benefits, the non-immersion curriculum offers students all of the other requirements for graduation.

As the courses are conducted exclusively in Spanish, the focus is on communication, and students have many opportunities to use it for different purposes. Their L2 becomes more complex over time as a function of the kind and content of courses. The program brings together native Spanish-speaking students and native English-speaking students, and its benefits extend to both groups in terms of language development in this culturally rich and diverse environment. L1 and L2 speakers of Spanish interact with each other authentically, since the focus is on the message rather than the language. The one-way immersion model offers NES students one of the best options for learning to communicate and thereby for reaching high levels of proficiency in their L2.

For the native Spanish speakers, one-way immersion may be the best model for them on the high school level because they develop their academic language in their L1 and their L2, better preparing them to study in college at an advanced level. NSS students benefit personally from the one-way program as well because it helps to preserve their linguistic heritage and gives them a greater understanding of, and pride in, their own cultural heritage. For heritage language learners, the benefits of this type of program are undeniable for similar reasons.

These benefits highlight the great potential of foreign language immersion in high school. As a stand-alone program, certain communities may find that it is more feasible 
to implement and could be less costly to implement than the K-8 model for one-way immersion. In the long run, such a program at the high school level may be superior to the K-8 model in terms of what students are able to do with their skills after high school. It offers a challenge many high school students would welcome, and when well done, it has the potential to be one of their best options in terms of overall experience, not to mention the outcomes of high levels of proficiency in Spanish, culture learning, and intellectual development that they can achieve.

\section{Social Interaction in Two-way Immersion and Foreign-Language Immersion Programs}

\section{Language Status}

Language status, as a characteristic of students, has been identified in the empirical literature as a factor that can affect student interactions and outcomes in regular K-12 classrooms as well as in immersion classrooms. The seminal research studies for socio-economic status and social interaction of students were conducted by E.G. Cohen and R.A. Lotan (2004, 1997), and others, in regular K-12 classrooms, documenting unequal patterns of interaction. In the two-way immersion literature on elementary school programs, researchers such as de Jong and Howard (2009), Palmer (2004, 2009), and Mora, Wink \& Wink (2001), among others, also identified language minority status and socioeconomic status as negatively affecting social interaction between students and teachers . Additionally, when Howard, Sugarman and Christian (2003) examined studies on academic performance by Lindholm and Fairchild (1988), Lindholm-Leary (2001), and others, they found a differential between language majority and language minority 
students, as language minority students underperformed their native English-speaking peers "even when controlling for students' free and reduced-lunch status."

The role of language status on social interaction in the two-way immersion literature is more complex than the findings of studies in the preceding paragraph, as prominent scholars F. Genesee and K. Lindholm-Leary (2013) have discussed in their recent article on immersion programs for majority language students in Canada and dual language education programs (also called two-way immersion or DBE) for minority language students in the United States. The authors discussed the concept of "contentbased language education" and reviewed 45 years of research related to key issues for each type of program, including those relevant to this discussion of language minority students: L1 and L2 proficiency and academic achievement. The authors contextualized this discussion from the perspective of 40 years of studies and government reports on ELLs, of whom many were low SES, in terms of academic achievement. These data have shown low-levels of academic achievement, high drop-out rates, and low rates of college and university attendance and graduation (Lindholm-Leary \& Genesee, 2010). In terms of English achievement, the findings of Genesee and Lindholm-Leary (2013) review of the research revealed that "given effective programs, ELLs in TWI and DBE acquire high levels of oral and written language proficiency in English that are comparable to those of English mainstream students despite the fact that they have significantly less exposure to English" (p. 15). In addition, data from academic achievement of ELLs showed that "all studies of middle and secondary school students who had been in TWI or DBE in elementary school were as or more successful than comparison group students" (p. 17). Thus, from the perspective of this researcher, TWI/ 
DBE programs are one of the most advantageous models for L2 acquisition for ELLs, especially when there are large numbers of students from the same language concentrated in one location- i.e. for Spanish-speakers in the United States.

Few studies have explored the experiences of native English-speaking and nonnative-English-speaking subjects in secondary school two-way and one-way immersion programs. Those conducted by Bearse and de Jong (2008; de Jong \& Bearse, 2011, 2012) on the perspectives of TWI middle and high school students were the exception. Their findings provided evidence of unequal academic, linguistic, and socio-cultural outcomes based on students' language status as majority English speakers or minority Spanish speakers.

In contrast with these studies, there was no evidence from students in the Dover SIP that language status played any role in student/ peer or student/ teacher relationships within the program. Nor was there evidence of the unequal opportunities or unequal outcomes that were documented in previous studies. In the literature review for this study, the researcher had posited that minority language status might negatively impact NSS students.

Several factors at this study site contributed to this finding. In all Immersion classes, a "Spanish ONLY" policy was strictly enforced by the teachers and understood and respected by the students. Therefore, the issue of language use and language preference did not exist within the Immersion classrooms. Some of the NES students reported speaking very little during the initial adjustment period. There was also strong evidence that some NES and Heritage learners struggled to communicate in Spanish at 
the beginning. This was not a language status issue, however; the native Spanishspeaking students also had to adjust to speaking their L1 all of the time because they had been educated exclusively in English. There was no evidence that this group felt superior to their NES peers, since they had their own challenges: lack of familiarity with reading and writing, with the formal grammar, with vocabulary differences, and with using the academic language instead of the slang they spoke at home. Neither was there evidence of differences in teachers' expectations for either NES or NSS, as comments from both groups of students documented.

Immersion students' input about their language use and language preferences outside the Immersion wing at school was evidence of their level of confidence in Spanish and of their pride in the program. Charlotte, for example, said "So you, like, have just such a focus that you can really switch between either language. 'Cause me and my friends, if I have another friend who's in Spanish Immersion in the same class, sometimes we'll just talk back and forth in Spanish and everyone else will be like 'What are you talking about?' We'll just keep on goin."' Two seniors noted the "Immersion spirit." Sammy Wells said, "It's like a certain camaraderie. Yeah, we're Immersion and if you're Mass Com (the other specialty center, located next to theirs), you're not the same. I mean, I'm not trying to be judgmental." María added, "Yeah, we take pride in being in Immersion, and you're not, but it's OK. We're still going to accept you."

The spirit of Immersion was very characteristic of the $11^{\text {th }}$ and $12^{\text {th }}$ graders and somewhat characteristic of $10^{\text {th }}$ graders. In the school setting, where the majority culture dominated, there was also no evidence of status issues between NES and NSS students, but as we have seen, Immersion students did evince a feeling of superiority vis-à-vis non- 
Immersion peers. (In their comments about speaking Spanish outside the Immersion wing, students felt the power of speaking another language. They were conscious that those around them did not understand what they were saying, and some seemed to relish this experience.) One NSS Immersion student's perspective about the program was indistinguishable from that of her NES peers: "For the most part, it's fun 'cause it's like being that I'm in a Specialty Center and am looked upon. It's like we're the example, so that fact is pretty cool."

Immersion students sometimes encountered non-Immersion students whom they believed were "ignorant" about linguistic and cultural differences. Students said they tried to educate these peers, a theme that most of the seniors mentioned (MM, MW, SW, JA, DM). One example may have been evidence that some non-Immersion students and teachers saw Spanish as a lower-status language. NSS María certainly thought this was the case when she told the story of a non-Immersion native Spanish-speaking classmate who was pregnant and to whom a non-Immersion teacher said in halting Spanish, “¿Tú tienes bébé?" María felt that the teacher had treated her friend as "stupid" or "inferior." (Alternatively, the teacher may in fact have simply been showing concern by mustering her few words of Spanish.) As an Immersion student, María did not hesitate to respond to comments of this sort, informing teachers or fellow student concerning remarks she considered insensitive. This type of response was evidence of the IP students' cultural sensitivity toward persons to whom denigrating comments were made, and a measure of their belief in the high status of the Spanish language and of the cultures of the Spanishspeaking world. The NSS students, who had gained greater awareness of these cultures, 
appeared to profit from the reversal within the program of their minority linguistic and cultural status on the outside.

Nor were the NSS and HSS shortchanged with regard to their curriculum. Research in the TWI Immersion literature on a high school program has shown that learning opportunities for NES and NSS students were not been equally distributed because the number of courses in English in the programs studied was significantly greater than the number in Spanish. Bearse and de Jong (2008; de Jong \& Bearse, 2011) and de Jong and Howard (2009) have shown that this negatively affected the NSS students in their L1, whereas scholars have emphasized the importance of developing a student's L1 academic language in order to transfer these skills to their L2 (see the discussion on academic language and non-native English-speaking students at the beginning of chapter IV.

The curriculum of the Dover HS SIP required all students to take three courses per year in Spanish for four years. This curriculum represented an advantage for this high-school stand-alone foreign language immersion program over the TWI high school site previously mentioned, where students only took one course per year in Spanish. Given the absence of other studies of TWI programs at the high school level, this researcher does not know whether the curriculum of this TWI program is representative. (Students in the program investigated by Bearse and de Jong had had a program that was more intensive in Spanish at the elementary and middle school levels.) Since all the Dover SIP students took more courses in Spanish per year, the opportunities to use the language were greater than those in the TWI study for all students. In addition, since their coursework consisted of honors- and advanced placement-level material, their academic 
language could develop more fully. With roughly the same number of non-Immersion courses in English as those in Spanish, students' opportunities to develop their academic language in English were also equally distributed across both language groups. Although the NSS students reported a significantly higher level of proficiency in their L1 at the start of the program than their NES peers in their L2, almost all students in this latter group also eventually developed high levels of proficiency in Spanish as well by their senior year, according to their own self-assessments. In the early stages of the program, the Immersion teachers served as models for the NSS students in their L1, while the latter served as resources for their NES peers. In the later stages of the program, the level of L2 proficiency of this latter group overall was sufficiently high to provide for challenging exchanges. At the end of four years in the program, all of the seniors reported feeling prepared to enter college-level courses in Spanish, which many of them cited as a goal.

\section{The Role of Social Interaction in L2 Acquisition and Culture Learning}

A second language is acquired through interaction with others-in the case of the Dover IP, initially with one's peers and teachers. L2 development requires input and practice, both of which are dependent on interaction. It also requires constant contact and the time to develop over an extended period. When students interact with each other and their teachers, they receive feedback about whether they have communicated their message effectively and appropriately. Students also give each other mutual support on an emotional level as they learn to communicate in their L2, creating a low-stress environment to the extent possible. NES and HSS students also have the opportunity to 
interact with their NSS peers, who offer them challenge and support in their L2 development. As L2 learners develop skills in the target language, activities such as skits and group work sessions involve interaction and challenge students to reach higher levels of proficiency in the language. When students have the opportunity to share ideas with their peers, they develop their thoughts on specific topics; it is through interaction that their thoughts become more sophisticated. Debates are another opportunity for interaction, with a focus on expression at a higher level. Students have to synthesize their thoughts on one perspective of a topic in a more organized way. Through interaction in a debate, students have the opportunity to challenge each other, to refine their thinking, and to gain further insights into an issue from multiple perspectives.

L2 development benefits from interaction with speakers of a local L1 community in informal, unrehearsed communication, a different type of communicative task in terms of stress and vocabulary needed. These L1 speakers provide input at a different level than one's peers and implicitly challenge the L2 speaker linguistically, as well as culturally, in addition to expanding his repertoire of experiences in the target language. It is through interaction that the student receives feedback about the level of effective and appropriate communication, which in turn facilitates higher levels of proficiency in the L2. When students travel abroad to a country where the linguistic and cultural context is authentic, they experience similar opportunities to interact with L1 speakers and similar benefits as well, along with the greatest challenge and the highest level of stress in a communicative task. It is again through interaction that students receive feedback on their ability to communicate effectively and appropriately. When they receive positive feedback, they 
also may gain greater confidence in their L2 speaking abilities, thus raising their comfort level with these interactions.

Social interaction plays an essential role in culture learning in combination with the target language. When L2 learners talk with their L1 peers, they learn about the culture from that person's perspective in a supportive environment. As they venture out into communities of L1 speakers of the target language, they face greater cultural challenges when they interact, but they also observe their interlocutors and receive feedback about the cultural appropriateness of their own language and of the non-verbal aspects of their speech.

\section{Student Friendships}

The present study examined and documented how the close relationships of students and teachers in the Dover Spanish Immersion Program created a family environment in which emotional support raised their comfort level and gave them the confidence to accomplish tasks such as communicating in their L2 and eventually debating in the target language. The findings showed robust evidence of the value of the Immersion Family in shaping many aspects of students' experiences with language and culture learning, from survival in $9^{\text {th }}$ grade through graduation.

The two studies in the research literature, which mention these relationships briefly, did not focus on social interaction and therefore underreport it. The two-way immersion high school students in Bearse and de Jong (2008; de Jong \& Bearse, 2011), valued their friendships with their immersion peers and the "comfort it provided them in 
school." These findings implicitly suggest the existence of positive student interactions between the NES and NSS students in the program, although the study does not specifically examine them. The close relationships of students from both language and cultural groups also extended to their immersion teachers. In the other study, Wesely's (2009) $6^{\text {th }}$-grade foreign language immersion students also spoke of the importance of "meaningful relationships" and a "sense of belonging and ease" in their programs. These students, however, consisted solely of native English-speakers; thus the cross-cultural dynamic of the relationships between students was not a relevant issue. Thus, a threeway comparison with the TWI high school students and the Dover SIP participants would not be possible.

\section{The Teaching and Learning of Culture}

Students' accounts of their experiences with culture learning in their SIP yielded evidence of a process that was developmental and ongoing in nature and in which students were actively engaged. Mina's experience with appropriate greetings, to give a small example, touched all the cognitive, affective, and behavioral bases distinguished by Paige et al. (2003), as she progressed from initial discomfort when María’s mom first greeted her, eventual comfort greeting friends and their family members, discomfort when greeting new people in Spain with hugs and kisses, and eventual "split the difference" accommodation. This one cultural practice involved prior knowledge and experience as well as an experiential component blending a new cultural behavior and an emotional reaction. The contribution of Immersion peers to Mina's culture learning 
process in this example was undeniable as she progressed from discomfort to greater comfort and moved into a more challenging environment abroad, where she again felt discomfort and eventual cultural adjustment.

Scholars and educators in the field of culture teaching and learning have identified various factors that they believe are involved in the processes of achieving cross-cultural understanding, four of which can be provisionally deployed in a classroom setting: developing awareness of one's home culture and the target culture (Kramsch, 2013, 2009, 2003, 1993b), cross-cultural knowledge (Kwintessential,2013, retrieved from http://www.kwintessential.co.uk/cultural-services/articles/cross-culturalunderstanding.html), cross-cultural dialogue and debate (Kramsch, 1993b,2003, 2013) self-reflection (Fantini, 2000; Kramsch, 1993a), and finally exposure and interaction in the "field" in real-life contexts (Fetzer, 1997). All of these factors emerged from the interview and focus group study data as contributing to the impressive degree of cultural awareness and understanding that students were acquiring.

Robinson-Stuart and Nocon (1996) also posited that an essential process for developing deeper levels of cross-cultural understanding for L2 learners is interaction with L1 speakers of the target culture, because of the non-verbal aspects of communication (see also Morain, 1986) and of feedback. In the Immersion setting, NES, HSS, and NSS students and their teachers were constantly involved in these processes as they interacted with each other. Teachers also served as the cultural facilitators (Klein, 2004; Kramsch, 2003, 1993a; Crawford-Lange and Lange, 1984), setting up such opportunities for student interaction as "idea sharing" and debates. Bennett, Bennett, and Allen (2003) and Fantini (2000) went a step beyond interaction, positing that the cross- 
cultural dialogue and self-reflection may lead to the "ability to shift cultural perspectives," a process they believe is at the core of culture learning for students. A number of advanced students in the SIP appeared to have developed this ability to look at important current cultural issues through different cultural lenses.

\section{Culture Terms Revisited}

The findings of this study have shown that students in the Dover SIP developed a breadth and a depth of knowledge of the cultures of the Spanish-speaking world far exceeding that of students in previous research in the one-way and two-way immersion literature. Scholars such as Met and Lorenz (1997) and Genesee (2008) had long asserted that the cultural objectives of immersion programs were difficult to meet, as Wesely (2009) affirmed in the literature review for her study. An additional note concerning this is necessary for clarification. These scholars based their analysis almost completely on research studies on elementary or middle school (K-8) programs, where there is not as much flexibility in the curriculum to incorporate cultural content, due to required coursework for all students, including those in immersion programs. In contrast, since elective courses are incorporated into the high school-level curriculum, this additional flexibility in coursework may be used by the immersion programs for some of their own requirements (see Appendix D for the Dover High School Course of Study). Nonetheless, very little, if anything, is known in the empirical research on the cultural content of programs at this level. This present study addresses that gap. The evidence suggests that the cultural objectives are attainable. Students' depth of knowledge and 
understanding of the cultures of the Spanish-speaking world developed over the course of their four years in the program through academic content and firsthand experiences with their immersion peers, and with members of the local or international communities. While the findings did show great gains in cultural knowledge and understanding for students, there were also noticeable differences by language group, in addition to individual differences.

An examination of the definitions of culture that were proposed in chapter II and their relationship to students' experiences with culture learning revealed that virtually all students from $10^{\text {th }}$ had gained cross-cultural knowledge. Kwintessential (http://www.kwintessential.co.uk/cultural-services/articles/cross-culturalunderstanding.html), accessed 3/3/2014) defined the term as "surface level of familiarization with cultural characteristics, values, beliefs, and behaviors" of a culture. Students had no hesitation describing cultural phenomena on the surface level. Observable increases in the level of cross-cultural knowledge were evident in $11^{\text {th }}$ and $12^{\text {th }}$ graders, which they had gained from a curriculum rich in cultural content, with classes such as Humanities I, Humanities II, Spanish cinema, and Spanish media, all of which included students from both grades. Most juniors gave evidence developing crosscultural awareness when they discussed and compared the cultural perspectives of Americans and Hispanics. Those who interacted with native speakers locally or internationally were developing a degree of cross-cultural understanding as well. All but one of those who had participated in the study abroad program, or had traveled abroad individually for more than a few days, were seniors. (The remaining student, a NES, was a junior.) Among the seniors, one was a native Spanish speaker, one heritage speaker, 
and the other 4 were NES. This group, including the junior, evinced the deepest levels of cross-cultural awareness and cross-cultural understanding.

\section{Students' Awareness of Basic Culture Notions}

Students seemed to understand the concept that gaining an understanding of a culture, even one's home culture, involved comparing it to another one. A $10^{\text {th }}$-grade boy articulated this thought: "You don't really have a standard unless you have an outside perspective on that." This implies as well that they acknowledged the existence of multiple cultures, each with its respective cultural perspective, a concept that almost all of them identified.

In the research literature, Damen (2003) emphasized the existence of cultural variation within a culture and the evolution of cultures over time. Virtually all study participants were very aware of the cultural variation that existed in the cultures of the Spanish-speaking world, given the number of countries about which they had studied formally or informally, but their beliefs were mixed about the notions of change and evolution within a particular culture. A number of students pointed to "traditions" involving festivals and holidays with religious origins and significance as evidence that some cultures do not change. This perspective was represented by an $11^{\text {th }}$-grade NES student, “Their cultures, they don't change much. They’ve had their cultures for many, many years, like back to the Aztecs" (RB). Another statement represented the opposite perspective: "traditions are changing," (10 $10^{\text {th }}$-grade NES student). RB's comment was somewhat of an inconsistency for this junior in comparison with deeper insights that she 
had gained about other aspects of the cultures of the Spanish speaking world (for example, see the discussion of the roles of men and women in chapter 5). Study participants were adolescents whose level of intellectual development may explain, at least in part, these variations in the level of their insights. The take-home messages that students learned about the immutability of a culture represented a shallow understanding of culture and suggest the need to emphasize a more nuanced view in the curriculum.

Scholars and educators have also stressed that culture involves behaviors, beliefs and values (Byram, 2003 and others), in addition to the traditional food, facts, festivals, and fairs (Andrawiss, 2004, and numerous others). While food and festivals were very common themes, especially for the $10^{\text {th }}$ graders, students overall were well aware of the importance of religion and of the strong family values in the cultures of the Spanishspeaking world, evidence that they saw the relationship of cultural practices to cultural beliefs and values.

Finally, the process of culture learning develops along a continuum (Paige et al., 2003; Kramsch, 1993a; Fantini, 2000, and others). Immersion students—especially the $12^{\text {th }}$ graders - almost uniformly recognized the breadth of cross-cultural knowledge, awareness, and/or understanding they had gained during their years in Immersion. Ever comparative, they saw this in particularly sharp relief as they compared themselves (and by implication their Immersion "culture") to their non-Immersion peers. Common to many students was the statement "We're not ignorant" or "We don't have that ignorance.” Their cultural experience has been discussed extensively in chapter V. 


\section{What Culture is "Taught" at Dover?}

In the Dover SIP, students studied traditional academic content from high school and college courses, reading short stories, poetry, plays, news etc. and watching films (v. the curriculum for Immersion in Appendix D). For some courses, such as $10^{\text {th }}$-grade world history, the material involved lectures and note taking. Elsewhere, a number of students emphasized the interactive activities through which the material in the curriculum was presented, including mini skits, presentations, and use of other media such as radio, the Internet, films, and television programs in Spanish. They also completed a variety of individual projects related to aspects of the cultures such as food and authentic cultural artifacts. Overall, the knowledge they acquired was not inert. Along with frequent informal interchanges among students, teachers made certain that there were opportunities for discussions and debates and other moments at which students could share information. Extra-curricular activities involved, among others, field trips to a traditional dance performance, to a soccer game between a local team and the Mexican national team, and to restaurants where Spanish was spoken. In other words, their learning was highly experiential as well as academic.

After four years in the IP, students had gained an in-depth understanding of the most important aspects of the cultures of the Spanish-speaking world that were common to all or most of them. They had also gained knowledge about the major countries of that world (Spain, Mexico, Venezuela, etc) and had some knowledge of the smaller countries in Central and South America. Added to the knowledge base provided by their SIP course offerings, the supplemental extra-curricular activities and the opportunities for interaction with native speakers in school, in the local and/or international communities 
were sufficient to propel them beyond the established goals for immersion programs: "increased cultural awareness" (Lenker and Rhodes, 2007 and others) or, more ambitiously, "to learn about and understand the cultures of the people who speak the Immersion language" (Met and Lorenz, 1997). The level of cross-cultural knowledge, awareness, and understanding that many students gained in this program were evidence that their "received messages" (Wesely, 2009) about the cultures of the Spanish-speaking world were rich and complex.

\section{The Extracurricular Experiences in Culture Learning in the Community and Abroad}

Cultural experiences can be observational or interactional. When students interacted with members of the local Latino community, they mainly gained experience and confidence in communicating in Spanish, but they also had the opportunity to observe the culture as well as to experience firsthand a number of the aspects about which they had learned as academic content.

When students traveled abroad, principally to Mexico and Spain, their observations increased dramatically, and their understanding of aspects of the cultures reached deeper behavioral and affective levels as they interacted with native speakers. When they bargained in a market, talked with someone standing very close to them, or greeted new people by kissing them on both cheeks and hugging them, they performed cultural behaviors which in turn engaged their emotions. Their task was to adjust to the experience of being completely immersed in the language and culture. For some, this entailed the validation of their speaking abilities. This was the case for Jaime, whose 
Señora (host mother) told her she spoke well. One student, Mina, experienced significant culture shock for the first week of her stay before beginning to adjust to the new culture. Students learned about cultural adjustment by undergoing it, and some, like Mina, discovered that there was a limit to their comfort level with certain practices. These experiences gave students a deeper level of cross-cultural understanding because it involved the affective aspect of the cultural practice. An analysis of this culture learning process for Dover students and of their development of cross-cultural knowledge, awareness, and understanding will lead us shortly to confirm the relevance of the definition of culture from Paige et al. (2003) introduced in Chapter II.

\section{The Role of Service Learning}

One of the experiential components in the Dover SIP curriculum was a servicelearning course that brought students together with native Spanish speakers, offering them the chance to practice their L2 and to gain additional insight into the cultures of the Spanish-speaking world using their linguistic and cultural skills at the moment. These experiences in service learning and the independent volunteer opportunities that students undertook were described in some detail in chapter IV because they were mainly related to L2 proficiency. A second option in the service-learning course was to serve as a teaching assistant in Dover's traditional non-Immersion Spanish classes. Seniors Mina and María served as in-class tutors and were language role models for this group of students. The findings of this study showed that the value of the service learning activities and of the experiences in the local community indeed lay primarily in practice 
communicating with native speakers of Spanish. Students became more confident and comfortable doing so. The researcher had posited that a cross-cultural experience would be an inherent feature of the service-learning course, but this was not the case in the tutoring option, and cultural opportunities were uneven in the others.

\section{The Culture Learning Process: Culture-general and Culture-specific Content}

Paige et al. (2003) have defined culture learning as

The process of acquiring the culture-specific and culture-general knowledge, skills, and attitudes required for effective communication and interaction with individuals from other cultures. It is a dynamic, developmental, and ongoing process which engages the learner cognitively, behaviorally, and affectively.

To what extent did Dover Immersion students grasp the culture-general and culture-specific aspects of culture learning? They gave evidence of both. Although they may not have identified them as such, examples of culture-general knowledge, skills, and attitudes were evident. Their awareness of "culture-bound behaviors" (Mantle-Bromley, 1992) or other cultural differences was an example of culture-general knowledge.

Elizabeth McLean's comment “One day I was just 'You know what? I kinda just have to make myself comfortable" was an example of a culture-general insight and behavior related to cultural adjustment. The comment expressed by a number of students from all grade levels, "We don't have that ignorance [anymore]," was an indication of a culturegeneral attitude. Students consciously expressed the thought that they had developed an understanding not specific to any one culture, but rather to cultural difference in general. 
All Dover students identified examples of culture-specific knowledge such as the Aztec origins in Mexican culture. Jaime learned a culture-specific skill in Spain when she and her friends discovered that walking with the boys in their group would deter men in the street from making inappropriate comments to them. Culture-specific skills and behaviors could potentially be developed by students through experience as they interacted with native speakers at home or abroad, but only those students who had traveled abroad spoke about their experiences with this type of interaction. They did not say whether they had heard about the "invite the boys" strategy prior to departure but appeared to have developed it on their own, and they verified its effectiveness through feedback derived from the interactions themselves. An example of a culture-specific attitude was the importance of family and religion in the cultures of the Spanish-speaking world and the cultural practices that demonstrated it. This attitude was recognized and understood at a deep level by virtually all Dover students.

\section{Review of Research Questions}

\section{Question One: Are There Benefits of the Immersion Program and the Immersion Experience for Students?}

The Dover Spanish Immersion Program was a fast-track approach to second language acquisition; participants had the opportunity to learn Spanish at an accelerated pace and to reach high levels of proficiency in the four years that they spent in high school. The number and kind of courses in Spanish afforded intensive content, as well as practice and communication in Spanish. In addition, the supportive context created by the Immersion family encouraged students to go beyond their comfort level to learn more 
of their L2 and its associated cultures. In an environment that students identified as "nonjudgmental," they were willing to take the risk of communicating in their L2 knowing that they might make mistakes, because they always kept in mind that their goal was to communicate. This family environment also prepared students to move to the more challenging linguistic and cultural context of the local Spanish-speaking community.

Language development. When L2 acquisition takes place through academic content, virtually all input and output are contextualized, providing the optimal conditions for developing high levels of L2 proficiency, thus supporting VanPatten's (2003) theoretical and research findings. This was the case for students in the Dover SIP, whose linguistic progress was also fostered by the emotional security they felt despite transitory fears.

Native English speakers developed high levels of proficiency in Spanish and some even became bilingual, based on their own self-assessments. NES students had the benefit of L1 Spanish-speaking peers in their classrooms to serve as models and resources for them; they reported that NSS peers were available to help them when they had trouble expressing themselves. In the process, much comprehensible input and meaning-based output were generated. The advanced NES students had the potential to study the language in college in connection with other areas of interest, which included teaching, nursing, medicine, engineering, construction, and law. In addition, their proficiency in Spanish also may have expanded their opportunities for interpersonal relationships with members of the Spanish-speaking communities at home and abroad. 
The HSS and NSS students were at crossroads, in terms of linguistic proficiency and the cultural heritage of their families, when they made choice to start the SIP and then to remain in it to completion. The two HSS students were similar to their NES peers in terms of their proficiency in Spanish, prior to starting the program. The NSS students were bilingual in their oral communication skills, yet lacked writing skills in their L1. Their decisions opened doors for them to greater academic opportunities (for example, honors-level and advanced placement courses) which might have been closed had they chosen to spend their high school careers studying in English only, in the standard mainstream high school curriculum. This was especially crucial for those who were considered to be Generation 1.5 students. As Harklau, Losey, \& Siegal (1999) have noted, many of these students are placed in low-ability classes where they do not develop the same level of writing skills. These researchers compared low-track vs. college-track writing classes in high schools and found that the focus of instruction differed in the former classes as compared to the latter ones. The lower-track classes do not teach the writing skills that are the prerequisite for college-level coursework.

Francesca, the senior HSS, identified the professional goal of becoming a physician and of working in Spanish-speaking countries in Central and South America. When she graduated from high school, she was on track for realizing this goal or for exploring other options at a later date.

One of the most powerful linguistic and cultural benefits of the program for HSS and NSS students alike involved the way in which they were positioned at its completion. The rigorous academic curriculum in high school, in addition to the culturally-enriched Immersion curriculum, prepared them for the highly challenging college coursework. It 
raised the level of their academic language in two languages, instilled them with confidence, maintained their connections to their cultural and linguistic heritage, and gave them the flexibility to take advantage of opportunities to study in both languages at home or abroad. Students like senior Francesca (HSS), who had identified the goal of becoming a physician and of working in Spanish-speaking countries in Central and South America, and María, who planned to become an immigration lawyer, were thus poised to realize whatever professional and personal goals they might have and to function as educated members of both language communities.

Given linguistic and cultural benefits of the program, the demographics of Dover High School Spanish Immersion Program were crucial to its success and should be taken into account by any school contemplating a one-way program. Nevertheless, this should not be viewed as a deterrent to communities with less diversity. Suggestions are offered in the section on future research and implications sections for those contemplating establishing programs in their school division. The value of the model for L2 proficiency on the high school level is very strong and offers students many opportunities after high school even in the absence of a local native speaking population. The combination of racial, ethnic, and cultural diversity of the students had been identified as one of the strengths of two-way immersion programs. This was also a characteristic in the Dover SIP.

In $9^{\text {th }}$ grade, all students, NES, HSS, NSS, adjusted with varying difficulty to speaking exclusively Spanish in all Immersion classes and to interacting with students from two different cultural backgrounds (the latter mostly an issue for NES). They talked about the process of discovering one another's cultures, a theme especially well 
developed by the seniors, perhaps because their experiences were more numerous. Elizabeth Mclean, who spoke about the distinctly separate groups of students in her cohort in $9^{\text {th }}$ grade, was the one NES student who experienced a significant cross-cultural adjustment process. Yet her trajectory converged with that of NSS senior María, who had also talked about the NES and NSS students as distinctly separate groups at the beginning. These groups would eventually become one: they were "Immersion."

A Culturally Rich and Deep Experience in High School. One of the important benefits of the SIP was the role that social interaction and language played in mediating culture. For this reason, in the discussion of this research question, the aspects related to culture learning and social interaction have been merged. It has been shown that opportunities to share ideas with peers were integrated into the course work; discussions for students were also possible inside and outside the classroom, as the seniors especially mentioned. Students debated important issues within the cultures of the Spanishspeaking world that were concerns in the countries themselves. Tackling issues that affected the Spanish-speaking community as it interfaced with American culture contributed to the depth of their cross-cultural awareness and understanding. NES students learned about the cultures of the Spanish-speaking world. NSS students learned about their native country and culture in addition to learning about the other countries and cultures of the Spanish-speaking world. In the Immersion wing, they learned from the academic curriculum, from their teachers, and from one another.

As they reflected on their IP experience, students themselves identified the value of the prevailing interactional dynamic. Their awareness of diverse cultural perspectives was not faceless and abstract because they spent their entire high school phase together 
and had many opportunities to interact. They also evaluated their own cultural beliefs and values, gaining insights into their home culture through the exploration of their second culture via study, experience, and interaction. Their thinking developed as they matured from adolescence to adulthood and could venture out into the world more, making for a deeper and broader cultural experience overall; in terms of their intellectual maturity, students were ready to reap the benefits of this high school-level immersion program. The richness of their experiences was an indication of the potential of this type of cultural interaction as a model for other high school foreign-language immersion programs, and as an objective to at least orient the thinking of teachers in regular language classes.

The presence of a Spanish-speaking population in Lake County as well as in the nearby city facilitated additional, relatively frequent opportunities for students in the program to meet formally or informally with members of the local community. Social interaction played an integral role in these as well, from chance encounters at a grocery store or restaurant to regular stints at volunteer or work sites and visits to friends in their homes. As students in an Immersion program on the high school level, the Dover students were able to work for pay or to do volunteer jobs, improving their chances for interaction with native Spanish speakers. The local community offered a more challenging context linguistically and culturally for the NES students, because they had to interact with native Spanish-speakers independently, outside of their Immersion Family support system. Conversely, local Spanish speakers may have been pleased to find people who spoke their L1 and may have been accepting of mistakes or cultural faux-pas. 
The most challenging experiences for students, both linguistically and culturally, involved communicating with native Spanish speakers in Mexico or Spain. Three (of 5) students experienced an initial nervous moment as they anticipated speaking the language. One of them expressed fears that also represented the other two (SW): "At first it was really intimidating as soon as we got on the plane. We got to the airport and we got to order lunch and I was like 'Oh my gosh, what am I going to do?' After the nervousness of being in this new environment subsided, almost all found that they were ready for this next level of linguistic demands, based on feedback from their host families or on selfassessments of their own performance in comparison with that of non-Immersion peers in the Lake County study-abroad group. For example, JA stated: "Some of the other students weren't from Immersion because it was a Lake County trip. They would ask us to help them talk to people if they wanted something." When students went through this program, their process of adjustment to the linguistic and cultural demands of each succeeding concentric circle, from inside Immersion to the local community to the international stage, followed a similar pattern as they doubted, then tried out, then trusted their linguistic ability and cultural competence to succeed at the tasks required of them. Within the Immersion Family, students shared an immersion culture that was made up of linguistic and cultural components. The language became part of their identity and was a unique characteristic of their program within the school. The evidence has also shown that the cultural aspect of the Immersion Family was also an integral part of their identity, combining as it did American culture and the cultures of the Spanish-speaking world.

For most students, adjusting to speaking Spanish exclusively in class represented their greatest challenge during the initial stages of the program; only Elizabeth Mclean 
spoke of a significant adjustment experience involving both language and culture. Her experience was not unlike that of being in a Spanish-speaking country and probably helped her to function in the culture when she was in Honduras for a day trip with her mother. For the great majority of study participants, however, the cross-cultural adjustment did not appear to have been difficult. Mina was the exception, the only student for whom the adjustment to the cultural aspect of Immersion involved some culture shock and the only one to experience significant culture shock in Spain, during the first week of her homestay.

\section{Question Two: Does the Setting Enhance Culture Learning?}

Several characteristics of the Spanish Immersion Program at Dover High School enhanced students' culture learning; all are to some degree applicable to foreign-language immersion programs in general as models for successful foreign-language learning.

- The setting was separate and well defined (like a foreign country), enhancing its identity and making it easier to enforce its particular rules and behavioral norms.

- The students were ethnically and culturally diverse, with adequate representation of the target language and culture(s). Students gained firsthand exposure to cultures other than their own home culture and to novel perspectives and new ways of doing things. The long-term and repeated nature of these opportunities, which spanned four years, allowed students to develop their thinking and to reflect on what these different perspectives meant to them personally. Evidence in this program suggested that the diversity of the students enhanced the exchange 
of ideas and perspectives and further contributed to the maturing of the adolescent mind that normally takes place during the high school years.

- The teachers were experienced, and cognizant of the potential of immersion education and the particular needs of immersion students, although there were no native Spanish speakers at the time the study was conducted.

- The curriculum was organized and developmental and spanned the four years of the program. The evidence from students showed that they gained in-depth academic knowledge of the cultures of the Spanish-speaking world. Experiential learning within classrooms began the outward spiral of experiences that constituted the non-academic curriculum: field trips, service-learning activities with local Hispanic children and adults, and a study-abroad program that introduced students to the wider world.

- Emphasis was placed on social interaction and communication (which are by definition experiential), contributing to an atmosphere that was relaxed and supportive in nature, in spite of the rigorous nature of the program. Social interaction took place between and among students and between faculty members and students in the Immersion community and then gradually spiraled beyond it. In this particular program, the organized, developmental curriculum + the appropriate ethnic diversity of the students + the abundant social interaction constituted the necessary conditions for a deeper level of culture learning. 
How did students integrate American culture and the cultures of the Spanishspeaking world? As they learned about the target cultures in Immersion, they responded to them and compared them to their perspective on American culture.

Among $10^{\text {th }}$ graders, the NSS students sometimes felt a conflict between the culture at school and the culture at home with their families. They evaluated American culture from the perspective of their home culture, which for them was the dominant one. This was especially true because it was the culture of their parents, whom they respected, under whose rules they lived, and by whom they were guided. Nonetheless, their knowledge of American culture, gained through their lives at school, influenced them to a certain extent in conceptualizing the features that they might adopt in their lives as adults. This was less true for NSS Nicolasa, who planned to return to Mexico. The others, PG, MS, and NJ, were clear that their Hispanic values and beliefs were part of their identity as Americans.

While some of the $10^{\text {th }}$-grade NES students had thought about how Spanish might be integrated into their adult lives as a major or minor in college, or in their profession, the evidence showed that they had not thought about their involvement with their own culture to the same degree as their NSS peers. Most of them did not evaluate deeper aspects of it: what it truly consisted of, what it meant to them on an emotional level, how it shaped their values and those of their family. A number of $10^{\text {th }}$-grade NES students did believe that overall, Americans were not as family-oriented as those in the countries of the Spanish-speaking world. They identified religion and Roman Catholicism as guiding the beliefs and values in these cultures. Only a few (JS and JP) who spoke of their strong 
religious and family values lamented the lack of strong religious faith and family values in American culture. John Smith said America "should" value them more.

In the $11^{\text {th }}$ and $12^{\text {th }}$-grade group, María, the sole NSS participant, had a good understanding of both her American and Guatemalan/Spanish cultures and felt that the traditional values in her family sometimes set up a conflict between the two. The NES students and the heritage learner, who had traveled abroad, were able to perceive aspects of the behaviors and corresponding values and attitudes within cultures of the Spanishspeaking world on an affective level, especially those involving social distance and the roles of men and women. JA, FF, and RB reflected on how they felt when someone they did not know stood close to them and touched them during a conversation. What they observed of the traditional, more paternalistic, relationships between men and women in Spain or Mexico threw their own beliefs as American young women into sharper relief. They wondered whether they would be willing to accept this type of relationship if they were to live in either of those countries.

In considering the NES Immersion students as a group, they all seemed to be aware of their identity as Americans, though less so than their NSS peers, yet they were also aware that their perspective on what that meant was different from that their nonImmersion peers in school. Some of the older group of NES students, juniors Rosalinda, Bridget, and Rusty and all of the seniors, were conscious of a second, more recently fledged identity as L2 speakers of Spanish. The language was an integral part of their lives, to the extent that they had to explain to non-Immersion students and to people in the wider community how it was that they spoke Spanish so well. 


\section{Question Three: What Was Learned from the Students That Has Not Been Addressed in the Research Literature?}

The research literature to date has not examined the significant roles played by social interaction and the immersion community (Dover's Immersion Family) on students' second language development and culture learning. In prior studies by Bearse and de Jong, Amato, and Wesely, close relationships or friendships between students and teachers were mentioned, but they were not the main focus. The present study explores in depth the Dover Immersion Family and its role in both language acquisition and culture learning, addressing this gap by extending a topic the other studies had discussed only peripherally.

Concerning language acquisition, research has shown that developing L2 proficiency requires, in the words of VanPatten (2003), “comprehension, speech production, learning, and social interaction" (p. 44), and that this developing system consists of a great deal of meaning-based, comprehensible input, output, and feedback. As previously stated, all of these elements are present in abundance in immersion programs, which represent one of the most favorable models for SLA. Nevertheless, these factors were insufficient by themselves to fully understand the L2 acquisition process for the Dover Spanish Immersion students. This study contributes to the empirical literature an elucidation of the human element, which necessarily involves people: their interpersonal relationships and their emotional side. It appears to this researcher that the emotional and linguistic support of peers and teachers played a decisive role for these students in terms of their comfort level and L2 proficiency. 
During the first weeks and months of the program, the emotional and linguistic support that was crucial for students' survival in Immersion undoubtedly came from their teachers. A non-judgmental environment existed that encouraged students to take the risk of speaking in their L2, thus promoting communication. As $12^{\text {th }}$-grader Sammy (SW) said, "When I took Spanish I, I did terrible at speaking. One of my fears of Spanish before was just standing up before a class and having everybody say, 'Oh, wow, she's a terrible speaker of this.' In Immersion, they don't want that. [You] just speak and get it out."

Peer support played a complementary and equally important role for students on an emotional level and promoted their L2 development. Sammy said it well: "During class, it's like a support-network. Like, if you forget a word when you're talking, somebody will help you with your presentation, to pronounce something." As the Dover SIP students faced highly challenging tasks, they were pushed to cooperate with each other in order to survive. They were very aware of facing these challenges together and of developing strong bonds in the process. As their comfort level with the language increased, so did their interactions with their Immersion peers and teachers. Over time, their L2 proficiency skills developed, and they gained experience communicating in the target language within the program. They were then ready to take the risk of interacting with members of the Spanish-speaking community at home and abroad.

Concerning culture learning, this study breaks new ground by examining immersion students' experiences, a topic the empirical literature appears to have neglected or not considered at all. The findings show that the process of culture learning was not dissimilar to that of L2 learning, involving social interaction and communication 
in Spanish within the Immersion family. The ethnic, racial, and cultural diversity of students from native English-speaking and native Spanish-speaking backgrounds provided differing cultural perspectives as the fodder for student interactions such as idea-sharing, discussions, and debates. The interpersonal relationships that existed between students grew into friendships built on respect and openness; students shared an experiential bond and an emotional connection. Thus the diversity of the students, combined with their close interpersonal relationships, yielded deeper levels of crosscultural insight and understanding, as evinced in particular by the juniors and seniors, whose knowledge and experiences were far broader than those of their $10^{\text {th }}$-grade peers. The statements from students about their relationships with each other and with their teachers provided solid evidence that within this community of practice, the Immersion Family, their accomplishments exceeded that which they would have been able to do without this emotional support to buttress them.

\section{Implications for Further Research.}

This study was exploratory in nature; therefore a myriad of suggestions for further research have emerged, in fields ranging from immersion education, to traditional foreign language education, to second-language learning for English-language learners (ELL) in the context of American public education.

In the area of L2 proficiency levels for students in high school foreign language immersion programs, there appears to be virtually no authoritative research studies, as this researcher encountered only L. B. Forrest (2011) results that were presented at an 
ACTFL conference. A study comparing proficiency levels of students in high school oneway immersion and two-way immersion programs. Since research on high school foreign language immersion programs is very scarce, more studies on what students learn about the target culture in other programs would broaden what little is known about this experience. A longitudinal study that followed students over the course of their four years in the program would yield a more in-depth picture of their linguistic and cultural evolution. A variant of such a study would follow students after completion of the program; its goal would be to explore the trajectories of students during their post-high school years. What they do in the initial years after completion? Where are they five to ten years later? In what ways did participation in the program affect their decisions about their professional and personal lives?

Although the findings from this research were very positive overall, further research would do well to study other sites to confirm or disconfirm these findings. Different student demographics, the absence of a local population of native speakers of the target language, and variations in other factors could no doubt yield different experiences and different outcomes. In addition, studies that focus on perspectives of the immersion teachers would also contribute to a broader understanding of the immersion experience. Observational studies would be useful. Student-peer or student-teacher interactions in the classroom could be observed during debates or discussions in the humanities or Cine classes and combined with subsequent individual interviews of teachers and students representative of the different racial, cultural, and ethnic groups in the program. Another observational study could focus on culture learning or second language development during the initial days and weeks of the program to examine the 
interactions between native speakers of the target language and their native Englishspeaking (or Heritage-language) peers at that time and at appropriate intervals thereafter.

The present study examined the perspectives of second-semester $10^{\text {th }}$ graders through graduating seniors; capturing students' initial experiences could be valuable in a number of different ways and could include the experiences of those who dropped out, as Wesely (2009) did. The experiences of this latter group of students would better delineate deterrents to success as well as factors motivating those who remained in the program. It could yield a clearer picture, of the overall immersion experience, throwing into sharper relief the challenges that students faced and the factors that contributed to their perseverance and success. A better understanding of the high bar set by a good foreignlanguage immersion program would assist teachers and administrators contemplating such a program in their schools.

\section{Implications for Teachers, School Districts, and the Foreign Language Curriculum.}

This study about language and culture learning and teaching and social interaction has insights for other language-learning settings. In immersion education, the findings suggest possible modifications at the high school level curriculum in two-way immersion programs. Researchers Bearse and de Jong criticized the immersion curriculum in the TWI high school program in their study for its limited scope (one Spanish course per year in high school) and the resulting unequal opportunities for L1 academic language development for the native Spanish speakers compared to native English speakers. School districts and individual school administrators in these programs might consider 
the Dover High School curriculum as a model from which to learn about what is feasible at that level. NSS, HSS, and NES students' academic language in English and Spanish benefited in equal measure and was very likely enhanced by comparisons between the two for all language groups - another topic that could be investigated. What's more, no independent English classes for Immersion students needed to be put in place. Evidence from the present study suggests that the Dover curriculum significantly enhanced students' experiences without compromising their ability to complete their required course work in English.

The program thus gave students from both language backgrounds the tools to be better positioned to use both their L1 and their L2 at an advanced level in their postsecondary trajectories. Their level of academic language and their learning in general also improved because their cognitive abilities became significantly more sophisticated over the course of the four years: Students were developmentally more ready to think deeply in high school than when they finished middle school. The students in the TWI middle-school program studied by Bearse and de Jong, who took only a few more courses at the high school level, are unlikely to have experienced this to the same degree- yet another topic inviting study.

On the all-important question of outcomes, the findings of this study suggest that students were in fact learning about the target cultures and developing high levels of proficiency in Spanish in this foreign language immersion program. The language benefits and the academic and cross-cultural knowledge, awareness, and understanding students gained, and the experiences they had, greatly enriched their high school years. The vast majority of the NES students began the SIP having taken only Spanish I in 
middle school. The robust evidence of their level of language development suggests that this type of stand-alone high-school program is an attractive and viable option for FL education. From the perspective of the school district, it is more feasible economically than a full K-12 TWI program, and study findings suggest the likelihood for significantly better outcomes, overall, than in traditional FL courses. The implementation of this type of high school program may also be a viable option for school districts with existing K-8 TWI programs that encounter significant logistical, organizational, and economic barriers when envisioning a program at the high-school level.

On the topic of culture learning, the Immersion students spoke frequently about the cross-cultural knowledge and awareness they had gained through their experiences in the program and contrasted them with the "ignorance" they saw in their non-Immersion peers. (Along with examples of cultural intolerance, they cited as evidence examples of comments from their non-Immersion peers: "You speak Mexican" or "What part of Mexico is the Dominican Republic?") The Dover SIP was a cultural incubator within the broader context of the high school in which it is housed and could potentially be used as a valuable resource for the school as a whole. School-level administrators and teachers as well as the Immersion team of teachers might consider finding opportunities for dialogue about cultural diversity between Immersion students and their non-Immersion peers whereby each group might gain valuable insights into the respective cultures.

Although scholars and researchers in the literature review criticized the teaching of culture as "food, fairs, and festivals," the findings from this study revealed that a surface- level awareness of these aspects of the culture was valuable for Immersion students because they were not all that was taught and because they served as "advance 
organizers" for students, helping them to better understand their experiences when they interacted with native Spanish-speakers in the local community or abroad. Armed with this background knowledge, students felt more comfortable with the target language and culture. Senior Elizabeth Mclean's prior knowledge about the siesta and the practice of bartering for goods in the marketplace, for example, facilitated her willingness to take the risk of bartering when she traveled with her mother on a cruise and stopped in Honduras. John Persie's background knowledge of festivals celebrated in Mexico facilitated the conversation when he talked with his Mexican co-workers during their lunch breaks and may have raised his comfort level in the language.

The Spanish Cine class was a valuable component that provided cross-cultural knowledge and exposure to the affective level of cultural learning. Teachers in traditional foreign language courses should consider incorporating target language films into their curricula and providing sufficient opportunity for students, preferably including some from the target culture, to talk with each other about the issues raised in the films.

The findings from this study also suggest the need to expand in other ways how culture is taught in traditional foreign language courses, so that students can encounter and respond to other cultures at a deeper level. Suggestions include integrating experiential activities outside the classroom that involve interactions with native speakers at the school, ELL students of the target language where possible. FL and ELL teachers could collaborate on activities in English and the target language that would benefit both groups of students. Native speakers of the target language in the local community could also serve as a valuable resource for L2 learners. Additionally, especially in schools having a graduation requirement of community service hours, volunteer opportunities 
could be arranged for students to use their target language skills to translate for parents at school activities. Other organizations might offer volunteer opportunities in the community. It goes without saying that school district administrators and teachers should also actively encourage students to participate in a study-abroad program with a homestay, creating their own where possible.

In communities and schools without access to native speakers of a target language, another strategy for district-level FL administrators would be to identify virtual "pen pals" in a country where the language is spoken. This type of activity is appropriate even in schools where students have access to native-speaking locals. There is some evidence in the research literature documenting the benefit of communicating via email or Skype with native-speakers in an online community, both for L2 practice and culture learning. Some of the same opportunities for students to interact with native speakers of the target language would also be appropriate for college students, which has implications for professional development seminars and teacher preparation programs for FL and ELL teachers on the university and college level.

In conjunction with Paige et al.'s (2003) definition of the nature of the culturelearning process, the findings suggest implications regarding the acquisition of deep levels of cross-cultural awareness and understanding. It is a long-term process that involves exposure over time combined with individual reflection on the meaning of cultural phenomena. Language and social interaction play an essential role. The example of Jaime, Francesca, and Rosalinda and their experiences with the sexual roles of men and women in the United States and Mexico or Spain were evidence of the different levels of understanding of this aspect of the culture and of its developmental 
nature. On the cognitive level, students had learned about the roles of men and women in the cultures of the Spanish-speaking world and talked about the perspectives of each group. On the affective level, Jaime's comment was evidence that she had gained some understanding from watching Spanish films in the Cine class. All three of the students gained further understanding of the phenomenon on the affective level when they were abroad, through a combination of observations and interactions that they then compared with their own experiences as American women. These three students evaluated this aspect of the culture in terms of what it meant to each one of them personally and how it fit into their belief system. Their deeper level of cross-cultural understanding about this particular aspect did not obligate them to accept it, however. In fact, these three students rejected the notion that they could adopt this type of role were they to live in either country. Their conclusion marks another level of the culture-learning process. There is support for this process in the literature; Klein (2004) has stated that understanding an aspect of a culture at a deeper level does not mean acceptance of the practice for oneself. In the traditional foreign language classroom, gaining this type of understanding of an aspect of the culture on an affective level may be out of reach.

\section{Conclusion: The Dover Spanish Immersion Program and the Five Cs from the ACTFL National Standards}

The role of the ACTFL National Standards in culture teaching and learning in U.S. foreign language education since the late 1990s was discussed in chapter II. This framework identified goals comprising five aspects: Communication, Cultures, Connections, Comparisons, and Communities. In the absence of studies of traditional or 
immersion programs that examine the perspectives of students on their experiences with language and culture learning, the role that each of these components of foreign language education plays in students' experiences has remained unexplored, to the best of the researcher's knowledge. What follows is an attempt to break this ground.

In this study, an examination of the importance of the five Cs in the Dover curriculum for 9th and 10th grades, based on an analysis of students' responses in interviews and focus groups, led to the following rankings:

\section{The Dover Curriculum and the 9th and $10^{\text {th }}$-Grade Experience.}

1. Communication, Connections, Communities

2. Cultures

- Comparisons

Communication, Community, and Connections were categories inherent in the Dover Spanish Immersion Program, and therefore all three are ranked in first place. Connections standard 3.1 speaks of the need to "reinforce and further [students'] knowledge of other disciplines through the foreign language" (National Standards, 1999, n.p.). All Immersion course work involved making connections to other disciplines though the medium of the target language, which they used exclusively for oral and written communication.

This study showed that Communities had two meanings for students: first and foremost it denoted the Immersion Family; secondly, it referred to the (non-Immersion) communities in which students spoke Spanish outside of school. The Immersion Family may be considered an extension of the idea of community envisioned in the ACTFL 
framework, but it could quite possibly be considered the epitome of the concept, given the solid evidence from the $10^{\text {th }}$ graders. Study findings also showed that the second Communities standard (5.2), which concerns "evidence of becoming life-long learners by using the language for personal enjoyment and enrichment” (National Standards, 1999, n.p.) described Immersion students' involvement in activities in the target language. Sixteen (of 22) students across all grade levels gave evidence that they enjoyed speaking the target language outside of school. Their plans for the future also frequently included using it with friends, studying the language in college, and/or using it in a current or future job. In sum, based on evidence from the $10^{\text {th }}$ graders, the cultural content of their Spanish language courses played an introductory role during the first two years of the program, and much of the Cultures content involved Comparisons, making the latter a subcategory of Cultures.

\section{The Dover Curriculum and the 11 th and $12^{\text {th }}$-Grade Experience}

\section{Communication, Communities $>$ Culture, Connections}

- Comparisons

The curriculum for $11^{\text {th }}$ and $12^{\text {th }}$ graders was primarily focused on culture, but language (Communication) and social interaction (Communities) mediated Culture in the Immersion Family and within other communities of Spanish speakers at home or abroad. In addition, students had sufficient academic and experiential input not only to make Comparisons but also Connections. Therefore Communication, Communities, Cultures, and Connections are all ranked first. 
Comparisons remains a subcategory of Cultures because much, though not all, in Cultures remained comparative for the students. When they identified aspects of American culture or of the cultures of the Spanish-speaking world, study participants from both language groups very frequently did so comparatively. But it was by examining cultural differences that they experienced that the older students learned about cultural perspectives and grappled with their meaning for each of them personally.

In this study, the second Connections standard, "Students acquire information and recognize the distinctive viewpoints that are only available through the foreign language and its cultures" (National Standards, 1999, n.p.), was primarily applicable to the $11^{\text {th }}$ and $12^{\text {th }}$ graders, who took courses such as Cine, the media course, and the AP Spanish literature course. Students developed an understanding of the perspectives of the Spanishspeaking world that were available to them only through Spanish. A few students who participated in the SIP gave evidence that their L2 proficiency had opened doors to other aspects of the target cultures only accessible through the target language. Eleventh grader Rusty, for example, watched authentic television programs in Spanish on Univisión and talked about the cross-cultural insights that he had gained: "A lot of their commercials (from Central and South America) and game shows are very sex driven. I think it's a big part of their culture that I don't think we would have learned from Immersion.” This student's high level of proficiency in his L2 gave him access to both verbal and nonverbal aspects of the culture as he observed interactions between people that involved sight, sound, and emotion. The Spanish Cine course provided other examples as well. Ten (of 13) juniors and seniors considered the language and the culture to be an integral part of their identity, which incorporates the goals of the ACTFL framework. 
An examination of the ACTFL framework in light of the findings of this study reveals that it was a helpful tool for organizing and categorizing the interview and focus group data, just as it is helpful to educators in classrooms. The progression from products to practices, and then to perspectives reflects the experiences of students in the Dover IP. Yet the ACTFL 5 Cs have no hierarchy; they are a map without roads. For this reason, they did not help this researcher to focus on and to understand the central message of this study. All the standards and guidelines discriminated by educators and interculturalists are top-down, whence the challenge of "operationalizing" them articulated by Klein (2004, p.2).

The present study followed a "bottom-up" process that traced individual students' experiences and perspectives and the paths they took from one stage to the next. The categories proposed are fewer and more organic, beginning and ending with the individual: the role of social interaction in language development and culture learning within the Immersion family. Students progressed over time from the Immersion family to ever-widening concentric circles as their experiences grew and they reflected on them. The Dover IP students' road map has the potential for showing educators a new way forward, with appreciation for these students now forging their own cultural pathways in the 21 st century. 


\section{BIBLIOGRAPHY}

Abarbanel, J. (2009). Moving with emotional resilience between and within cultures. Intercultural Education, 20(S1-2), S133-S141. doi:10.1080/14675980903371035

ACTFL, AATF, AATG, AATI, AATSP, ACL, . . NCJLT-ATJ (2013). National standards for foreign language education. Retrieved from https://www.actfl.org/advocacy/discover-languages/advocacy/discoverlanguages/advocacy/discover-languages/resources-1 ?pageid=3392

Agar, M. (1994). Language shock: Understanding the culture of conversation. New York, NY: William Morrow.

Alanís, I. (2000). A Texas two-way bilingual program: Its effects on linguistic and academic achievement. Bilingual Research Journal, 24(3), 225-248. doi:10.1080/15235882.2000.10162763

Alanís, I., \& Rodríguez, M. A. (2008). Sustaining a dual language immersion program: Features of success. Journal of Latinos and Education, 7(4), 305-319. doi:10.1080/15348430802143378

Allez, viens! (2006). Austin, TX: Holt, Rinehart \& Winston.

Allez, viens! Annotated teacher's edition (2006). Austin, TX: Holt, Rinehart \& Winston.

Alred, G., Byram, M., \& Fleming, M. (2006). Education for intercultural citizenship: Concepts and comparisons. Clevedon, England: Multilingual Matters.

Amrein, A., \& Peña, R. A. (2000). Asymmetry in dual language practice: Assessing imbalance in a program promoting equality. Education Policy Analysis Archives, $8(8)$. Retrieved from http//epaa.asu.edu/epaa/v8n8.html

Andrawiss, H. (2004). Cultural dimensions of foreign language learning: A sociocultural perspective (Doctoral dissertation). Retrieved from https://etda.libraries.psu.edu/paper/6479/ (UMI No. 3242214).

Angus, D. L., \& Mirel, J. E. (1999). The failed promise of the American high school, 1890-1995. New York: Teachers College Press, Columbia University.

Asher, C. (2011). The progressive past. Reference \& User Services Quarterly, 51(1), 4348. doi:10.5860/rusq.51n1.43 
Askildson, V. (2008). What do teachers and students want from a foreign language textbook? (Doctoral dissertation). Retrieved from University Microfilms International (3297985).

Aud, S., Fox, M. A., \& Kewalramani, A. (2010). Status and trends in the education of racial and ethnic minorities (NCES 2010-015). Washington, DC: U.S. Department of Education. Retrieved from http://nces.ed.gov/pubs2010/2010015.pdf

August, D., \& Hakuta, K. (1997). Improving schooling for language-minority children: A research agenda. Washington, DC: National Academy Press.

Barnlund, D. C. (1988). Communication in a global village. In L. A. Samovar \& R. E. Porter (Eds.), Intercultural communication: A reader. (6th ed., pp. 22-32). Belmont, CA: Wadsworth.

Barr-Harrison, P. (1998). A study to identify program standards, goals, objectives and projects in existing high school foreign language immersion programs in the United States (Doctoral dissertation). Retrieved from University Microfilms International (9926729).

Bateman, B. E. (2002). Ethnographic interviews as a tool for culture learning in a university Spanish classroom (Doctoral dissertation). Retrieved from University Microfilms International (3066366).

Bateman, B. E. (2004). Achieving affective and behavioral outcomes in culture learning: The case for ethnographic interviews. Foreign Language Annals, 37(2), 240-253. doi:10.1111/j.1944-9720.2004.tb02197.x

Baumgratz-Gangl, G. (1991). Relating experience, culture and language: A French video project for language teaching. In D. Buttjes \& M. Byram (Eds.), Mediating languages and cultures (pp. 228-239). Clevedon, England: Multilingual Matters.

Bearse, C., \& de Jong, E. J. (2008). Cultural and linguistic investment: Adolescents in a secondary two-way immersion program. Equity \& Excellence in Education, 41(3), 325-340. doi: 10.1080/10665680802174817

Bennett, J. M., Bennett, M. J., \& Allen, W. (2003). The development of intercultural sensitivity in the language classroom. In D. L. Lange \& R. M. Paige (Eds.), Culture as the core: Perspectives on culture in second language learning (pp. 237-270). Greenwich, CT: Information Age.

Bennett, M. J. (2009). Defining, measuring, and facilitating intercultural learning: A conceptual introduction to the Intercultural Education double supplement. Intercultural Education, 20, S1-S13. doi:10.1080/14675980903370763 
Berg, D. N., \& Smith, K. K. (1988). The self in social inquiry: Researching methods. Newbury Park, CA: Sage.

Berger, J., Cohen, B. P., \& Zelditch, M., Jr. (1972). Status characteristics and social interaction. American Sociological Review, 37(3), 241-255. Retrieved from http://www.jstor.org/stable/2093465

Berger, J. B., Cohen, B. P., \& Zelditch, M., Jr. (1966). Status characteristics and expectation states. In J. Berger \& M. Zelditch, Jr. (Eds.), Sociological theories in progress, Vol. 1 (pp. 9-46). Boston, MA: Houghton Mifflin.

Bikle, K., Billings, E. S., \& Hakuta, K. (2004). Trends in two-way immersion research. In J. A. Banks \& C. A. M. Banks (Eds.), Handbook of research on multicultural education (2nd ed., pp. 589-604). San Francisco, CA: Jossey-Bass.

Bloom, B. (1964). Stability and change in human characteristics. New York, NY: John Wiley.

Bok, D. (2009). Foreword. In D. K. Deardorff (Ed.), Sage handbook of intercultural competence (pp. ix-x). Thousand Oaks, CA: Sage.

Borjian, H. (2001). Teacher content knowledge and the role of technology for teaching foreign languages in elementary schools (Doctoral dissertation). Retrieved from University Microfilms International (3026777).

Brody, J. (2003). A linguistic anthropological perspective on language and culture in the second language curriculum. In D. L. Lange \& R. M. Paige (Eds.), Culture as the core: Perspectives on culture in second language learning (pp. 37-51). Greenwich, CT: Information Age.

Byram, M. (1989). Cultural studies in foreign language education. Clevedon, England: Multilingual Matters.

Byram, M. (1997). Teaching and assessing intercultural communicative competence. Clevedon, England: Multilingual Matters.

Byram, M. (2003). On being 'bicultural' and 'intercultural'. In G. Alred, M. Byram, \& M. Flemming (Eds.), Intercultural experience and education (pp. 50-66). Clevedon, England: Multilingual Matters.

Byram, M. (2013). Intercultural competence. In L.L.S. Lim (Ed.), The encyclopedia of applied linguistics. Blackwell Publishing Ltd. doi:10.1002/9781405198431.wbeal0554 
Byram, M., \& Feng, A. (2004). Culture and language learning: Teaching, research and scholarship. Language Teaching, 37(03), 149-168.

doi:10.1017/S0261444804002289

Byram, M., Zarate, G. \& Neuner, G. (1997). Sociocultural Competence in Language Learning and Teaching. Strasbourg, France: Council of Europe.

Carr, M. (2003). Continuing Spanish Immersion at Lawrence North High School. ACIE Newsletter, 6, 6-8, 19. Retrieved from http://www.carla.umn.edu/immersion/acie/vol6/May2003_LawrenceN.html

Carrigo, D. (2000). Just how much English are they using?: Teacher and student language distribution patterns, between Spanish and English, in upper-grade, twoway immersion Spanish classes (Unpublished doctoral dissertation). Harvard University, Cambridge, MA.

Cazabon, M., Nicoladis, E., \& Lambert, W. E. (1998). Becoming bilingual in the Amigos two-way immersion program [Research Rpt No. 3]. Berkeley, CA: Center for Research on Education, Diversity \& Excellence. Retrieved from http://repositories.cdlib.org/crede/rsrchrpts/rr03

Center for Applied Linguistics. (2011). Directory of foreign language immersion programs in U.S. schools. Retrieved from http://www.cal.org/resources/immersion/

Center for Applied Linguistics. (2012). Directory of two-way bilingual immersion programs in the U.S. Retrieved from http://www.cal.org/twi/directory

Center for World Languages. (2013). Courses and descriptions. Retrieved from http://www.henrico.k12.va.us/curriculum/immersion.html

Chambless, K. S. (2003). The impact of foreign language exploratory programs upon the attitudes of elementary school students towards foreign languages and cultures (Doctoral dissertation). Retrieved from University Microfilms International (3092343).

Christian, D. (1996). Two-way immersion education: Students learning through two languages. The Modern Language Journal, 80(1), 66-76.

Christian, D. (2008). Foreword. In T. Fortune \& D. J. Tedick (Eds.), Pathways to multilingualism: Evolving perspectives on immersion education (pp. xiv-xvii). Clevedon, England: Multilingual Matters.

Cohen, E. G. (1972). Sociology and the classroom: Setting the conditions for teacherstudent interaction. Review of Educational Research, 42, 441-452. 
Cohen, E. G. (1982). Expectation states and interracial interaction in school settings. Annual Review of Sociology, 8, 209-235.

Cohen, E. G. (1984). Talking and working together: Status, interaction, and learning. In P. L. Peterson, L. C. Wilkinson, \& M. T. Hallinan (Eds.), The social context of instruction (pp. 171-187). New York, NY: Academic Press.

Cohen, E. G., \& Lotan, R. A. (1997). Raising expectations for competence: The effectiveness of status interventions. In E. G. Cohen \& R. A. Lotan (Eds.), Working for equity in heterogeneous classrooms: Sociological theory in practice (pp. 77-91). New York, NY: Teachers College Press.

Cohen, E. G., \& Lotan, R. A. (2004). Equity in heterogeneous classrooms. In J. A. Banks \& C. A. M. Banks (Eds.), Handbook of research on multicultural education (pp. 736-750). San Francisco, CA: Jossey-Bass.

Cohen, E. G., \& Lotan, R. A. (Eds.). (1997). Working for equity in heterogeneous classrooms: Sociological theory in practice. New York, NY: Teachers College Press.

Collier, V. P., \& Thomas, W. P. (2004). The astounding effectiveness of dual language education for all. NABE Journal of Research and Practice, 2(1), 1-20.

Crawford-Lange, L. M., \& Lange, D. L. (1984). Doing the unthinkable in the secondlanguage classroom: A process for the integration of language and culture. In T. V. Higgs (Ed.), Proficiency: The organizing principle (pp. 139-177). Lincolnwood, IL: National Textbook Company.

Crawford-Lange, L. M., \& Lange, D. L. (1987). Integrating language and culture: How to do it. Theory into Practice, 26(4), 258-266.

Creswell, J. W. (2005). Educational research: Planning, conducting, and evaluating quantitative and qualitative research. Upper Saddle River, NJ: Pearson/Merrill Prentice Hall.

Crossman, K., \& Pinchbeck, G. (2012). An intensive academic English course for Generation1. 5 ELLs bound for postsecondary studies: Curriculum design, development, and implementation. TESL Canada Journal, 29(Special Issue 6), 231245.

Cummins, J., \& Yee-Fun, E. M. (2007). Academic language: What is it and how do we acquire it? International handbook of English language teaching (pp. 797-810) Springer. doi:10.1007/978-0-387-46301-8_53

Damen, L. (1987). Culture learning: The fifth dimension in the language classroom. Reading, MA: Addison-Wesley. 
Damen, L. (2003). Closing the language and culture gap. In D. L. Lange \& R. M. Paige (Eds.), Culture as the core: Perspectives in second language learning (pp. 71-88). Greenwich, CT.: Information Age.

de Bot, K., Ginsberg, K. R., \& Kramsch, C. (Eds.). (1991). Foreign language research in cross-cultural perspective. Philadelphia, PA: John Benjamins North America.

de Jong, E. J. (2006). Integrated bilingual education: An alternative approach. Bilingual Research Journal, 30(1), 23-44.

de Jong, E. J. (2011). Foundations of multilingualism in education: From principles to practice. Philadelphia, PA: Caslon.

de Jong, E. J., \& Bearse, C. I. (2011). The same outcomes for all? High-school students reflect on their two-way immersion program. In D. Tedick, D. Christian, \& T. Fortune (Eds.), Immersion education: Practices, policies, possibilities (pp. 104-122). Clevedon, England: Multilingual Matters.

de Jong, E. J., \& Bearse, C. I. (2014). Dual language programs as a strand within a secondary school: Dilemmas of school organization and the TWI mission. International Journal of Bilingual Education and Bilingualism, 17, 15-31. doi:10.1080/13670050.2012.725709

de Jong, E. J., \& Howard, E. R. (2009). Integration in two-way immersion education: Equalizing linguistic benefits for all students. International Journal of Bilingual Education and Bilingualism, 12(1), 81-99. doi:10.1080/13670050802149531

de Jong, E. (2013). Sharon A. Reyes \& James Crawford, Diary of a bilingual school: How a constructivist curriculum, a multicultural perspective, and a commitment to dual immersion education combined to foster fluent bilingualism in Spanish-and English-speaking children [Review]. Journal of Immersion and Content-Based Language, 1(1), 163-165. doi: 10.1075/jicb.1.1.10dej

Deardorff, D. K. (Ed.). (2009). The SAGE handbook of intercultural competence. Thousand Oaks, CA: Sage.

DeKeyser, R. (1995). Learning second language grammar rules: An experiment with a miniature linguistic system. Studies in Second Language Acquisition, 17(3), 379410. doi:10.1017/S027226310001425X

DeKeyser, R. (2007). Practice in a second language: Perspectives from applied linguistics and cognitive psychology. New York, NY: Cambridge University Press. 
DeKeyser, R., Salaberry, R., Robinson, P., \& Harrington, M. (2002). What gets processed in processing instruction? A commentary on Bill VanPatten's "Processing instruction: An update." Language Learning, 52(4), 805-823. doi:10.1111/14679922.00204

Delgado-Larocco, E. L. (1998). Classroom processes in a two-way immersion kindergarten classroom. (Doctoral dissertation). Retrieved from University Microfilms International (9920255).

Denzin, N. K., \& Lincoln, Y. S. (Eds.). (2000). Handbook of qualitative research (2nd ed.). Thousand Oaks, CA: Sage.

Dewaele, J. (2008). "Appropriateness" in foreign language acquisition and use: Some theoretical, methodological and ethical considerations. IRAL: International Review of Applied Linguistics in Language Teaching, 46(3), 245-265. doi:10.1515/IRAL.2008.011

di Gennaro, K. (2013). How different are they? A comparison of generation 1.5 and international L2 learners' writing ability. Assessing Writing, 18(2), 154-172. doi:http://dx.doi.org/10.1016/j.asw.2013.01.003

Dörnyei, Z. (2003). Questionnaires in second language research: Construction, administration, and processing. Mahwah, NJ: Lawrence Erlbaum Associates.

Doughty, C. J., \& Long, M. H. (Eds.). (2003). The handbook of second language acquisition. Oxford, England: Blackwell.

Draper, J. B., \& Hicks, J. H. (2002). Foreign language enrollments in public secondary schools, fall 2000. Alexandria, VA: American Council on the Teaching of Foreign Languages.

Dweck, C. S. (2006). Mindset: The new psychology of success. New York, NY: Random House.

Ellis, R. (1992). The classroom context: An acquisition-rich or an acquisition-poor environment? In C. Kramsch \& S. McConnell-Ginet (Eds.), Text and context (pp. 171-186). Lexington, MA: D.C. Heath.

Ellis, R. (2005). Measuring implicit and explicit knowledge of a second language: A psychometric study. Studies in Second Language Acquisition, 27(02), 141-172. doi:10.1017/S0272263105050096

Ellis, R. (2006). Current issues in the teaching of grammar: An SLA perspective. TESOL Quarterly, 40(1), 83-107. doi: 10.2307/40264512 
Ellis, R., \& Loewen, S. (2007). Confirming the operational definitions of explicit and implicit knowledge in Ellis (2005): Responding to Isemonger. Studies in Second Language Acquisition, 29(1), 119-126. doi:10.1017/S0272263107070052

Espínola Mesa, C. (2007). The kids of the other side of the hallway: Teachers' perspectives of the academic achievement of Latino English language learners (Doctoral dissertation). Retrieved from University Microfilms International (3263941).

Experiment in International Living. (2013). Retrieved from http://www.experimentinternational.org/

Fantini, A. E. (2000). A central concern: Developing intercultural competence. In A. Fantini (Ed.), Our Institution. SIT Occasional Papers Series (pp. 25-33). Brattleboro, VT: School for International Training. Retrieved from http://www.sit.edu/SITOccasionalPapers/sitops01.pdf

Fantini, A. E. (2009). Assessing intercultural competence. In D.K. Deardorff (Ed.), The SAGE handbook of intercultural competence (pp. 456-476). Thousand Oaks, CA: SAGE Publications, Inc.

Fetzer, A. (1997). Negative contextualization: A socio-semiotic approach to language teaching. In M. Putz (Ed.), The cultural context in foreign language teaching (pp. 85-109). Frankfurt, Germany: Peter Lang.

Fitts, S. (2006). Reconstructing the status quo: Linguistic interaction in a dual-language school. Bilingual Research Journal, 30(2), 337-365. doi:10.1080/15235882.2006.10162880

Forrest, L. B. (2011). Comparing program models and student proficiency outcomes. American Council on the Teaching of Foreign Languages (ACTFL) Conference in Denver, CO.

Forrest, S. N. (2006). Three foci of an effective high school generation 1.5 literacy program. Journal of Adolescent \& Adult Literacy, 50(2), 106-112. doi:10.1598

Fortune, T. (2013). What the research says about immersion. Retrieved from http://www.carla.umn.edu/immersion/documents/ImmersionResearch_TaraFortune.h $\underline{\mathrm{tml}}$

Fortune, T., \& Jorstad, H. L. (1996). U.S. immersion programs: A national survey. Foreign Language Annals, 29(2), 163-178. doi: 10.1111/j.19449720.1996.tb02325.x 
Fortune, T., \& Tedick, D. J. (2003). What parents want to know about foreign language immersion programs. (ERIC Digest No. EDO-FL-03-04). Washington, DC: Center for Applied Linguistics. Retrieved from http://www.cal.org/resources/digest/digest_pdfs/0304fortune.pdf

Fortune, T., \& Tedick, D. (Eds.). (2008). Pathways to multilingualism: Evolving perspectives on immersion education. Clevedon, England: Multilingual Matters.

Freeman, R. D. (1996). Dual-language planning at Oyster Bilingual School: "It's much more than language." TESOL Quarterly, 30(3), 557-582. Retrieved from http://www.jstor.org/discover/10.2307/3587698?uid=3739936\&uid=2129\&uid=213 4\&uid=2\&uid=70\&uid=4\&uid=3739256\&sid=21103893037337

Galloway, V. (1999). Bridges and boundaries: Growing the cross-cultural mind. In M.A. Kassen, (Ed.). Language Learners of Tomorrow: Process and Promise (pp. 151-188) Lincolnwood, IL: National Textbook Company.

Garnett, B. (2012). A critical review of the Canadian empirical literature: Documenting generation 1.5's K-16 trajectories. TESL Canada Journal, 29(Special 6), 1-24.

Genesee, F. (1987). Learning through two languages: Studies of immersion and bilingual education. Rowley, MA: Newbury.

Genesee, F. (1985). Second language learning through immersion: A review of U.S. programs. Review of Educational Research, 55(4), 541-561.

Genesee, F. (2008). Dual language in the global village. In T. Fortune \& D. J. Tedick (Eds.), Pathways to multilingualism (pp. 22-45). Clevedon, England: Multilingual Matters.

Genesee, F., Holobow, N. E., Lambert, W. E., \& Chartrand, L. (1993). Bilingual education for majority English-speaking children. European Journal of Psychology of Education, 8, 3-22.

Genesee, F., \& Lindholm-Leary, K. (2013). Two case studies of content-based language education. Journal of Immersion and Content-Based Language, 1(1), 3-33.

Golafshani, N. (2003). Understanding reliability and validity in qualitative research. The Qualitative Report, 8(4), 597-607. Retrieved from http://www.nova.edu/ssss/QR/QR8-4/golafshani.pdf

Grittner, F. (1990). Bandwagons revisited: A perspective on movements in foreign language education. In D. W. Birckbichler \& American Council on the Teaching of Foreign Languages (Eds.), New perspectives and new directions in foreign language education (pp. 9-43). Lincolnwood, IL: National Textbook Company. 
Hadi-Tabassum, S. (2002). Language, space, and power: A critical ethnography of a dual-language classroom (Doctoral dissertation). Retrieved from University Microfilms International (3057011).

Hadley, A. O. (2001). Teaching language in context. Boston, MA: Heinle \& Heinle.

Hancock, C. R., \& Scebold, C. E. (2000). Defining moments in foreign- and secondlanguage education during the last half of the twentieth century. In D. W. Birckbichler \& R. M. Terry (Eds.), Reflecting on the past to shape the future (pp. 118). Lincolnwood, IL: National Textbook Company.

Harklau, L. (2003). Generation 1.5 students and college writing. ( No. EDO-FL-03-05). Washington, DC: Center for Applied Linguistics.

Harklau, L. (2003). Representational practices and multi-modal communication in US high schools: Implications for adolescent immigrants. In R. Bayley \& S. Schecter (Ed.), Language socialization in bilingual and multilingual societies (pp. 83-97). Clevedon, England : Multilingual Matters.

Harklau, L., Losey, K. M., Siegal, M., \& NetLibrary, I. (1999). Generation 1.5 meets college composition. Mahwah, N.J.: L. Erlbaum Associates.

Hinkel, E. (2011). Handbook of research in second language teaching and learning. New York, NY: Routledge.

Hobbs, F., \& Stoops, N. (2002). Demographic trends in the 20th century. Census 2000 Special Reports (No. CENSR-4). Washington, DC: U. S. Government Printing Office. Retrieved from http://www.census.gov/prod/2002pubs/censr-4.pdf

Holme, R. (2002). Carrying a baby in the back: Teaching with an awareness of the cultural construction of language. Language, Culture \& Curriculum, 15(3), 210-223. doi: 10.1080/07908310208666645

Howard, E. R., \& Sugarman, J. (2007). Realizing the vision of two-way immersion: Fostering effective programs and classrooms. Washington DC: Center for Applied Linguistics.

Howard, E. R., Sugarman, J., \& Christian, D. (2003). Trends in two-way immersion education: A review of the research. (Report No. 63). Baltimore, MD.: Center for Research on the Education of Students Placed At Risk. Retrieved from http://www.csos.jhu.edu/crespar/techreports/report63.pdf

Jansen, G., \& Peshkin, A. (1992). Subjectivity in qualitative research. In M. D. LeCompte, W. L. Millroy, \& J. Preissle (Eds.), The handbook of qualitative research in education (pp. 681-725). San Diego, CA: Academic Press. 
Johnson, M. (2003). Parent activism: A critical component for secondary immersion. ACIE Newsletter, 6 (3), 1, 3-5, 19. Retrieved from http://www.carla.umn.edu/immersion/acie/vol6/May2003_ParentAct.html

Johnson, R. K., \& Swain, M. (1997). Immersion education: International perspectives. New York, NY: Cambridge University Press.

Jonas, D. (1987). An exploratory study of an innovative high school language program (Spanish, California). (Doctoral dissertation). Retrieved from University Microfilms International (8719914).

Jurasek, R. (1995). Using ethnography to bridge the gap between study abroad and the on-campus language and culture curriculum. In C. Kramsch (Ed.), Redefining the boundaries of language study (pp. 221-251). Boston, MA: Heinle and Heinle.

Kibler, A., Salerno, A., \& Hardigree, C. (2014). 'More than being in a class': Adolescents' ethnolinguistic insights in a two-way dual-language program. Language and Education, 28 (3), 251-275. doi:10.1080/09500782.2013.822880

Klein, F. M. (2004). Culture in the foreign language classroom: Teachers' beliefs, opportunities and practice. (Doctoral dissertation). Retrieved from University Microfilms International (3129227).

Kleinjans, E. (1975). A question of ethics. International Educational and Cultural Exchange, 10(4), 20-25.

Kramsch, C. (1991). Culture in language learning: A view from the United States. In K. de Boot, R. Ginsberg, C. Kramsch (Eds.), Foreign Language Research in CrossCultural Perspective (pp. 217-240). Utrecht, The Netherlands: Benjamin, 1991.

Kramsch , C. (1993a). Context and culture in language teaching. Oxford, England: Oxford University Press.

Kramsch, C. (1993b). Language study as border study: Experiencing difference. European Journal of Education, 28(3), 349-358.

Kramsch, C. (2003). Teaching along the cultural faultline. In D. L. Lange \& R. M. Paige (Eds.), Culture as the core: Perspectives on culture in second language learning (pp. 19-35). Greenwich, CT: Information Age.

Kramsch, C. J. (2009). The multilingual subject: What foreign language learners say about their experience and why it matters. Oxford, England: Oxford University Press. 
Kramsch, C. (2009). Third culture and language education. In V. Cook \& W. Li, (Eds.), Contemporary Applied Linguistics: Vol. 1: V. Cook (Ed.), Language Teaching and Learning (pp.233-254). London, England: Continuum.

Kramsch, C. (2010) Theorizing translingual/transcultural competence. In G. S. Levine \& A. Phipps (Eds.), Critical and intercultural theory and language of pedagogy. AAUSC Issues in Language Program (pp. 15-31). Boston, MA: Heinle Cengage.

Kramsch, C. (2011). The symbolic dimensions of the intercultural. Language Teaching, 44(3), 354-367. doi: 10.1017/S0261444810000431

Kramsch, C. (2013). Culture in foreign language teaching. Iranian Journal of Language Teaching Research, 1(1), 57-78.

Kramsch, C., \& McConnell-Ginet, S. (Eds.). (1992). Text and context. Lexington, MA: D.C. Heath.

Krashen, S. D. (1982). Principles and practice in second language acquisition. New York, NY: Pergamon Press.

Krashen, S. D. (1995). Principles and practice in second language acquisition. New York, NY: Phoenix ELT.

Krashen, S. (2005). Second language "standards for success": Out of touch with language acquisition research. The International Journal of Foreign Language Testing, 1(2), 12-16. Retrieved from http://www.tprstories.com/ijflt/IJFLTSpring05.pdf

Krashen, S. (2008). Language education: Past, present and future. RELC Journal, 39(2), 178-187. doi:10.1177/0033688208092183

Krashen, S. D., \& Terrell, T. D. (1983). The natural approach: Language acquisition in the classroom. San Francisco, CA: Alemany Press.

Krueger, R. A., \& Casey, M. A. (2009). Focus groups: A practical guide for applied research (4th ed.). Thousand Oaks, CA: Sage.

Kvale, S. (1996). Interviews: An introduction to qualitative research interviewing. London, England : Sage.

Kwintessential Ltd. (2013). Cross cultural understanding. Retrieved from http://www.kwintessential.co.uk/cultural-services/articles/cross-culturalunderstanding.html

Lado, R. (1964). Language teaching, a scientific approach. New York, NY: McGrawHill. 
Lafayette, R. C. (1988). Integrating the teaching of culture into the foreign language classroom. In A. J. Singerman (Ed.), Toward a new integration of language and culture (pp. 47-61). Middlebury, VT: Northeast Conference on the Teaching of Foreign Languages.

Lafayette, R. C. (2003). Culture in second language learning and teaching: Anthropology revisited. In D. L. Lange, \& R. M. Paige (Eds.), Culture as the core: Perspectives on culture in second language learning (pp. 53-69). Greenwich, CT: Information Age.

Lambert, W. E., \& Cazabon, M. T. (1994). Students' views of the Amigos program. (Research Rpt. No. 11). Santa Cruz, CA: National Center for Research on Cultural Diversity and Second Language Learning.

Lambert, W. E., \& Tucker, G. R. (1972). Bilingual education of children: The St. Lambert experiment. Rowley, MA: Newbury House.

Lange, D. L. (1999). Planning for and using the new national culture standards. In J. K. Phillips, R. M. Terry, American Council on the Teaching of Foreign Languages, (Eds.). Foreign language standards: Linking research, theories, and practices (pp. 57-135). Lincolnwood, IL: National Textbook Company in conjunction with the American Council on the Teaching of Foreign Languages.

Lange, D. L., \& Paige, R. M. (2003). Culture as the core: Perspectives on culture in second language learning. Greenwich, CT: Information Age.

Lantolf, J. P. (1999). Second culture acquisition: Cognitive considerations. In E. Hinkel (Ed.), Culture in second language teaching and learning (pp. 28-46). Cambridge, England: Cambridge University Press.

Lenker, A., \& Rhodes, N. C. (2007, February). Foreign language immersion programs: Features and trends over 35 years. CAL Digest, 1-4. Retrieved from http://www.cal.org/resources/digest/digest_pdfs/flimmersion.pdf

Levine, T. R., Park, H. S., \& Kim, R. K. (2007). Some conceptual and theoretical challenges for cross-cultural communication research in the 21st century. Journal of Intercultural Communication Research, 36(3), 205-221. doi:10.1080/17475750701737140

Lightbrown, P. M., \& Spada, N. (2000). How languages are learned. Oxford, England: Oxford University Press.

Lincoln, Y. S., \& Guba, E. G. (1985). Naturalistic inquiry. Beverly Hills, CA: Sage.

Lindholm-Leary, K. J. (2001). Dual language education. Clevedon, England: Multilingual Matters. 
Lindholm-Leary, K. (2011). Student outcomes in Chinese two-way immersion programs: Language proficiency, academic achievement, and student attitudes. In D. Tedick, D. Christian, \& T. Fortune (Eds.), Immersion education: Practices, policies, possibilities (pp. 81-103). Avon, England: Multilingual Matters.

Lindholm-Leary, K., \& Borsato, G. (2001). Impact of two-way bilingual elementary programs on students' attitudes toward school and college. (Research Rpt. No. 10). Santa Cruz, CA: Center for Research on Education, Diversity \& Excellence.

Lindholm-Leary, K., \& Genesee, F. (2010). Alternative educational programs for English language learners. In Research on English language learners (p. 323-382). Sacramento, CA: California Department of Education Press.

Lindholm-Leary, K., \& Hernández, A. (2011). Achievement and language proficiency of Latino students in dual language programmes: Native English speakers, fluent English/previous ELLs, and current ELLs. Journal of Multilingual and Multicultural Development, 32(6), 531-545. doi:10.1080/01434632.2011.611596

Long, M. (Ed.). (2007). Problems in SLA. New York, NY: Lawrence Erlbaum Associates.

Lyster, R. (2007). Learning and teaching languages through content: A counterbalanced approach. Amsterdam, The Netherlands: John Benjamins.

Mantle-Bromley, C. (1992). Preparing students for meaningful culture learning. Foreign Language Annals, 25(2), 117-127. doi: 10.1111/j.1944-9720.1992.tb00519.x

Maxwell, J. A. (2005). Qualitative research design: An interactive approach (2nd ed.). Thousand Oaks, CA: Sage.

McCollum, P. (1994). Language use in two-way bilingual programs. IDRA Newsletter, 21, 9-11.

McCollum, P. (1999). Learning to value English: Cultural capital in a two-way bilingual program. Bilingual Research Journal, 23(2-3), 113-134.

doi:10.1080/15235882.1999.10668682

Met, M., \& Lorenz, E. (1997). Lessons from U.S. immersion programs: Two decades of experience. In R. K. Johnson \& M. Swain (Eds.), Immersion education: International perspectives (pp. 243-264). Cambridge, England: Cambridge University Press.

Met, M. (1993, November). Foreign language immersion programs. CAL Digest. Retrieved from http://www.cal.org/resources/digest/met00001.html

Met, M. (2001). Why language learning matters. Educational Leadership, 59(2), 36-40. 
Met, M., \& Galloway, V. (1992). Research in foreign language curriculum. In P. W. Jackson (Ed.), Handbook of research on curriculum (pp. 852-890). New York, NY: Macmillan.

Miles, M. B., \& Huberman, A. M. (1994). Qualitative data analysis: An expanded sourcebook (2nd ed.). Thousand Oaks, CA: Sage.

Mitchell, R. (1988). Communicative language teaching in practice. London, England: Center for Information on Language Teaching.

Montone, C., \& Loeb, M. (2000). Implementing two-way immersion programs in secondary schools. (Educational Practice Rpt. No.5). Santa Cruz, CA: Center for Research on Education, Diversity \& Excellence. Retrieved from http://www.cal.org/crede/pdfs/epr5.pdf

Mora, J. K., Wink, J., \& Wink, D. (2001). Dueling models of dual language instruction: A critical review of the literature and program implementation guide. Bilingual Research Journal, 25(4), 435-460.

Mougeon, R., Nadasdi, T., \& Rehner, K. (2010). Second language acquisition: Sociolinguistic competence of immersion students. Clevedon, England: Multilingual Matters.

Nostrand, H. L. (1991). Basic intercultural education needs breadth and depth: The role of a second culture. In E. S. Silber (Ed.), Critical issues in foreign language instruction (pp. 131-159). New York, NY: Garland.

O'Connell, M. E., \& Norwood, J. L., Eds. (2007). International education and foreign languages: Keys to securing America's future. Washington, DC: National Academies Press. Retrieved from http://www.nap.edu/openbook.php?record_id=11841\&page=1

O'Malley, J. M., Chamot, A. U., Stewner-Manzanares, G., Russo, R. P., \& Küpper, L. (1985). Learning strategy applications with students of English as a second language. TESOL Quarterly, 19(3), 557-584. Retrieved from http://www.jstor.org/stable/3586278

Ortega, L. (2007). Second language learning explained? SLA across nine contemporary theories. In B. VanPatten \& J. Williams (Eds.), Theories in second language acquisition: An introduction (pp. 225-250). Mahwah, NJ: Lawrence Erlbaum Associates.

Paige, R. M., Jorstad, H. L., Siaya, L., Klein, F. M., \& Colby, J. (2003). Culture learning in language education: A review of the literature. In D. L. Lange \& R. M. Paige (Eds.), Culture as the core: Perspectives on culture in second language learning (pp. 173-236). Greenwich, CT: Information Age. 
Palmer, D. K. (2004). Educating for equity in a dual immersion classroom: ";no interrumpas!". (Doctoral dissertation). Retrieved from University Microfilms International. (3183853).

Palmer, D. K. (2008). Building and destroying students' 'academic identities': The power of discourse in a two-way immersion classroom. International Journal of Qualitative Studies in Education, 21(6), 647-667. doi:10.1080/09518390701470537

Palmer, D. K. (2009). Middle-class English speakers in a two-way immersion bilingual classroom: "Everybody should be listening to Jonathan right now ..."TESOL Quarterly, 43(2), 177-202. doi: 10.1002/j.1545-7249.2009.tb00164.x

Patton, M. Q. (1990). Qualitative evaluation and research methods (2nd ed.). Newbury Park, CA: Sage.

Paulston, C. B. (1992). Biculturalism: Some reflections and speculations. In C. B. Paulston (Ed.), Sociolinguistic perspectives on bilingual education (pp. 116-130). Clevedon, England: Multilingual Matters.

Potowski, K. J. (2002). Language use in a Spanish-English dual immersion classroom: A sociolinguistic perspective. (Doctoral dissertation). Retrieved from University Microfilms International. (3044203).

Potowski, K. J. (2004). Student Spanish use and investment in a dual immersion classroom: Implications for second language acquisition and heritage language maintenance. Modern Language Journal, 88(1), 75-101. doi:10.1111/j.00267902.2004.00219.x

Pufahl, I., \& Rhodes, N. C. (2011). Foreign language instruction in US schools: Results of a national survey of elementary and secondary schools. Foreign Language Annals, 44(2), 258-288. doi: 10.1111/j.1944-9720.2011.01130.x

Rhodes, N. C., \& Pufahl, I. (2010). Foreign language teaching in U.S. schools: Results of a national survey. Washington, DC: Center for Applied Linguistics. Available at http://www.cal.org/resources/pubs/fl_teaching.html

Robinson, G. L. (1991). Second culture acquisition. In J. E. Alatis (Ed.), Georgetown University round table on languages and linguistics (pp. 114-122). Washington, DC: Georgetown University Press.

Robinson-Stuart, G., \& Nocon, H. (1996). Second culture acquisition: Ethnography in the foreign language classroom. The Modern Language Journal, 80(4), 431-449. doi: 10.1111/j.1540-4781.1996.tb05463.x 
Sacks, H., Schegloff, E., \& Jefferson, G. (1974). A simplest systematics for the organization of turntaking for conversation. Language, 50, 696-735. Retrieved from http://anthroweb.ucsd.edu/ jhaviland/AudVid/AudVidReadings/Simplest_Systemati cs_for_Turn-Taking_(Language).pdf

Sanz, C. (Ed.). (2005). Mind and context in adult second language acquisition: Methods, theory, and practice. Washington, DC: Georgetown University Press.

Saville-Troike, M. (2003). Extending communicative concepts in the second language curriculum: A sociolinguistic perspective. In D. L. Lange \& R. M. Paige (Eds.), Culture as the core: Perspectives on culture in second language learning (pp. 3-18). Greenwich, CT: Information Age.

Seelye, H. N. (1993). Teaching culture: Strategies for intercultural communication (3rd ed.) Lincolnwood, IL: National Textbook Company.

Silva, E., Warde, A., \& Wright, D. (2009). Using mixed methods for analysing culture: The cultural capital and social exclusion project. Cultural Sociology, 3(2), 299-316. doi: $10.1177 / 1749975509105536$

Singerman, A. J. (Ed.). (1996). Acquiring cross-cultural competence: Four stages for students of French . Lincolnwood, IL: National Textbook Company.

Strickler, U., \& Emke, M. (2011). Literalia: Towards developing intercultural maturity online. Language Learning and Technology, 15(1), 147-168. Retrieved from http://llt.msu.edu/issues/february2011/stickleremke.pdf

Swain, M. (1985). Communicative competence: Some roles of comprehensible input and comprehensible output in its development. In S. Gass \& C. Madden (Eds.), Input in second language acquisition (pp. 235-253). Rowley, MA: Newbury House.

Swain, M. (1997). The output hypothesis, focus on form and second language learning. In V. Berry, B. Adamson, \& W. Littlewood (Eds.), Applying linguistics: Insights into language in education (pp. 1-21). Hong Kong, China: University of Hong Kong.

Swain, M., Brooks, L., \& Tocalli-Beller, A. (2002). Peer-peer dialogue as a means of second language learning. Annual Review of Applied Linguistics, 22, 171-185. doi:10.1017/S0267190502000090

Tedick, D., Christian, D., \& Fortune, T. (Eds.). (2011). Immersion education: Practices, policies, possibilities. Buffalo, NY: Multilingual Matters.

Thomas, M. (2009). Ethical issues in the study of second language acquisition: Resources for researchers. Second Language Research, 25(4), 493-511. doi: $10.1177 / 0267658309349676$ 
Thomas, W. P., \& Collier, V. P. (2002). National study of school effectiveness for language minority students' long-term academic achievement. Santa Cruz, CA: Center for Research on Education, Diversity \& Excellence. Retrieved from http://files.eric.ed.gov/fulltext/ED475048.pdf

Trifonovitch, G. (1977). Culture learning/culture teaching. Educational Perspectives, 16(4), 8-22.

Trilling, B., \& Fadel, C. (2009). 21 st century skills: Learning for life in our times. San Francisco, CA: Wiley.

Trompenaars, F. (1994). Riding the waves of culture: Understanding diversity in global business. New York, NY: Irwin.

Urban, W. J., \& Wagoner, J. L. (2004). American education: A history (3rd ed.). New York, NY: McGraw-Hill.

Valdés, G. (1997). Dual-language immersion programs: A cautionary note concerning the education of language-minority students. Harvard Educational Review, 67(3), 391429.

Valdés, G. (2001). Heritage language students: Profiles and possibilities. In J.K. Peyton, D.A. Ranard, \& S. McGinnis (Eds.), Heritage languages in America: Preserving a national resource. Language in education: Theory and practice. (pp. 37-77). Washington, DC: The Center for Applied Linguistics.

Valdes, J. M. (Ed.). (1986). Culture bound: Bridging the cultural gap in language teaching. New York, NY: Cambridge University Press.

Van der Keilen, M. (1995). Use of French, attitudes and motivations of French immersion students. Canadian Modern Language Review, 51(2), 287-304.

van Lier, L. (1989). Reeling, writhing, drawling, stretching, and fainting in coils: Oral proficiency interviews as conversation. TESOL Quarterly, 23, 489-508.

VanPatten, B. (2003). From input to output: A teacher's guide to second language acquisition. Boston, MA: McGraw-Hill.

VanPatten, B., \& Williams, J. (Eds.). (2007). Theories in second language acquisition. Mahwah, NJ: Lawrence Erlbaum Associates.

VanPatten, B. (2002). Processing instruction: An update. Language Learning, 52(4), 755 803. doi:10.1111/1467-9922.00203 
VanPatten, B., \& Cadierno, T. (1993). Input processing and second language acquisition: A role for instruction. Modern Language Journal, 77(1), 45-57. doi:10.1111/j.1540-4781.1993.tb01944.x

Wesely, P. M. (2009). The language learning motivation of early adolescent French and Spanish elementary immersion program graduates. (Doctoral dissertation). Retrieved from University Microfilms International (3360409).

Wesely, P. M. (2010). Student attrition from traditional and immersion foreign language programs. Language and Linguistics Compass, 4(9), 804-817. doi:10.1111/j.1749818X.2010.00241.X

Wesely, P. M. (2012). Learner attitudes, perceptions, and beliefs in language learning. Foreign Language Annals, 45(s1), s98-s117. doi:10.1111/j.1944-9720.2012.01181.x

Wesely, P. M. (2013). The nature of foreign language anxiety in elementary immersion program graduates. Journal of Immersion and Content-Based Language Education, 1(2), 226-250. doi:10.1075/jicb.1.2.04wes

Wilson, R., \& Dewaele, J. (2010). The use of web questionnaires in second language acquisition and bilingualism research. Second Language Research, 26(1), 103-123. doi: $10.1177 / 0267658309337640$ 


\section{APPENDICES}

Page

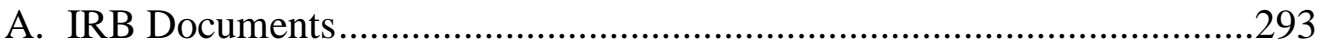

1. Cover Letter Parent and Student ...............................................293

2. Cover Letter Student over 18 ................................................296

3. Parent Consent-Interview .......................................................299

4. Child Assent-Interview ........................................................302

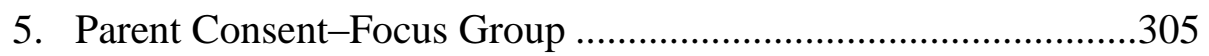

6. Child Assent-Focus Group .......................................................308

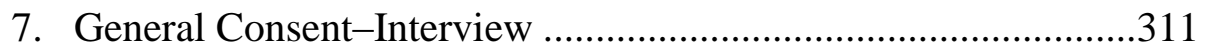

8. General Consent-Focus Group .................................................314

9. Informational Meeting Announcement ....................................317

B. Interview and Focus Group Questions...............................................318

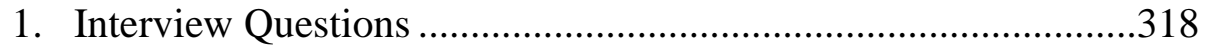

2. Focus Group Questions-10th Grade..........................................319

3. Focus Group Questions-11th and 12th Grades .........................329

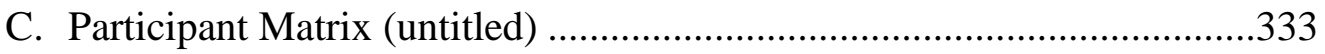

D. Dover High School Spanish Immersion Program Goals and Content.....334

1. Dover High School Spanish Immersion Goals ...........................334

2. Dover High School Spanish Immersion Course of Study ............334

3. Dover High School Spanish Immersion Curriculum ...................335

4. Lake County Goals and Vision ..............................................339 


\section{APPENDIX A: IRB DOCUMENTS}

\section{Cover Letter}

Dear Spanish Immersion Center Parent and Student,

My name is Lucy Johnson and I am a PhD. student in Social Foundations of Education in the Department of Leadership, Foundations, and Policy at the Curry School of Education at the University of Virginia. I am conducting a research study in the Spanish Immersion Center at Dover High School. I am interested in finding out about your child's experience with Latino and American cultures as participants in this program.

The results of this study will be used to help us understand the experience of these students in the Spanish Immersion Center. The results will also be used to help us to improve the Immersion Program. They will also help us to understand what students learn about culture in this program.

I have enclosed a packet which includes a description of my study and the consent forms that you and your child will need to fill out giving him or her permission to participate. Your son or daughter's participation in this project would be greatly appreciated. I hope that you seriously consider his or her participation.

If you have any questions or concerns about the study, or if you would like to withdraw your child from the study, please contact me at:

Lucy Welbourn Johnson

Leadership, Foundations and Policy Studies

Curry School of Education

Ruffner Hall 280

P.O. Box 400265

University of Virginia

Charlottesville, VA 22903

Telephone:

Email: 1wj2k@virginia.edu

\section{Your son or daughter has two options for participating:}

\section{Option one: Focus Groups only}

- Your child will participate in one focus group with Center classmates about his or her experience with Latino and American cultures as a student in the immersion program.

Time required: The study will require about 1 hour of his or her time. Your child will not miss any instructional time while participating in this activity. 


\section{How to enroll in option one:}

- Parent and child sign their individual consent forms saying focus group participant.

- Return these documents in the envelope enclosed to school.

- I will contact your child to schedule one hour-long focus group.

- Thank you for agreeing to participate!

\section{Option two: Focus Group + An Individual Interview}

- Your child will participate in one focus group with Center classmates about his or her experience with Latino and American cultures as a student in the immersion program.

- In addition to this focus group, your child will also participate in a more in-depth individual interview with this researcher about these same experiences. Individual interviews will allow for more discussion of topics raised during the focus groups.

Time required: The study will require about 1 hour of his or her time for the focus group and 1 hour for the interview, for a total of approximately 2 hours. Your child will not miss any instructional time while participating in this activity.

\section{How to enroll in option two:}

- Parent and child sign their individual consent forms saying focus group participant

- Parent and child ALSO sign their individual consent forms saying interview participant

- NOTE- If you choose option two- PLEASE RETURN BOTH the Focus Group participant consent AND the interview participant consent.

- Return these documents in the envelope enclosed to school.

- First Activity-I will contact you to schedule one hour- long interview.

- Second Activity-I will contact you to schedule one hour- long focus group.

- Thank you for agreeing to participate! 


\section{Eligibility:}

Students who have completed one year of the Spanish Immersion Center Program at Dover High School are eligible to participate.

\section{Researcher:}

Lucy Welbourn Johnson

Leadership, Foundations and Policy Studies

Curry School of Education

Ruffner Hall 280

P.O. Box 400265

University of Virginia

Charlottesville, VA 22903

Telephone:

Email: lwj2k@virginia.edu

\section{Advisor:}

Robert W. Covert

Leadership, Foundations and Policy Studies

Curry School of Education

Ruffner Hall 280

P.O. Box 400265

University of Virginia

Charlottesville, VA 22903

Telephone: (434) 924-0833

Email: rwc3q@virginia.edu

If you have questions about your rights as a research participant, please contact: Tonya R. Moon, Ph.D.,

Chair, Institutional Review Board for the Social and Behavioral Sciences

One Morton Dr Suite 500

University of Virginia, P.O. Box 800392

Charlottesville, VA 22908-0392

Telephone: (434) 924-5999

Email: irbsbshelp@virginia.edu

Website: www.virginia.edu/vprgs/irb

Sincerely,

Lucy Welbourn Johnson 


\section{Cover Letter}

Dear Spanish Immersion Center Student,

My name is Lucy Johnson and I am a PhD. student in Social Foundations of Education in the Department of Leadership, Foundations, and Policy at the Curry School of Education at the University of Virginia. I am conducting a research study in the Spanish Immersion Center at Dover High School. I am interested in finding out about your experience with Latino and American cultures as a participant in this program.

The results of this study will be used to help us understand the experience of students in the Spanish Immersion Center. The results will also be used to help us to improve the Immersion Program. They will also help us to understand what students learn about culture in this program.

I have enclosed a packet which includes a description of my study and the consent forms that you will need to fill out if you choose to participate. Your participation in this project would be greatly appreciated. I hope that you seriously consider participating.

If you have any questions or concerns about the study, or if you would like to withdraw from the study, please contact me at:

Lucy Welbourn Johnson

Leadership, Foundations and Policy Studies

Curry School of Education

Ruffner Hall 280

P.O. Box 400265

University of Virginia

Charlottesville, VA 22903

Telephone:

Email: 1wj2k@virginia.edu

\section{You have two options for participating:}

\section{Option one: Focus Groups only}

- You will participate in one focus group with Center classmates about your experience with Latino and American cultures as a student in the immersion program.

Time required: The study will require about 1 hour of your time. You will not miss any instructional time while participating in this activity. 


\section{How to enroll in option one:}

- Sign the individual consent form saying focus group participant.

- Return this document in the envelope enclosed to school.

- I will contact you to schedule one hour-long focus group.

- Thank you for agreeing to participate!

\section{Option two: Focus Group + An Individual Interview}

- You will participate in one focus group with Center classmates about your experience with Latino and American cultures as a student in the immersion program.

- In addition to this focus group, you will also participate in a more in depth individual interview with this researcher about these same experiences. Individual interviews will allow for more discussion of topics raised during the focus groups.

Time required: The study will require about 1 hour of your time for the focus group and 1 hour for the interview, for a total of approximately 2 hours. You will not miss any instructional time while participating in this activity.

\section{How to enroll in option two:}

- Sign the individual consent form saying focus group participant, indicating your grade level.

- Sign the individual consent form saying interview participant.

- NOTE- PLEASE RETURN BOTH the Focus Group participant consent AND the interview participant consent.

- Return these documents in the envelope enclosed to school.

- First Activity-I will contact you to schedule one hour long interview.

- Second Activity-I will contact you to schedule one hour long focus group.

- Thank you for agreeing to participate!

Eligibility:

Students who have completed one year of the Spanish Immersion Center Program at Dover High School are eligible to participate. 


\section{Researcher:}

Lucy Welbourn Johnson

Leadership, Foundations and Policy Studies

Curry School of Education

Ruffner Hall 280

P.O. Box 400265

University of Virginia

Charlottesville, VA 22903

Telephone:

Email: 1wj2k@virginia.edu

\section{Advisor:}

Robert W. Covert

Leadership, Foundations and Policy Studies

Curry School of Education

Ruffner Hall 280

P.O. Box 400265

University of Virginia

Charlottesville, VA 22903

Telephone: (434) 924-0833

Email: rwc3q@virginia.edu

If you have questions about your rights as a research participant, please contact:

Tonya R. Moon, Ph.D.,

Chair, Institutional Review Board for the Social and Behavioral Sciences

One Morton Dr Suite 500

University of Virginia, P.O. Box 800392

Charlottesville, VA 22908-0392

Telephone: (434) 924-5999

Email: irbsbshelp@virginia.edu

Website: http://www.virginia.edu/vpr/irb/

Sincerely,

Lucy Welbourn Johnson 


\section{Parent/Guardian Informed Consent Agreement Please read this consent agreement carefully before you decide to participate in the study. Your child will also receive an assent form; please review the assent form with your child.}

\section{Informed Consent Agreement: Interview Participants}

Purpose of the research study: The purpose of this study is to understand immersion students' experience with Latino and American cultures in the Spanish Immersion Center.

What your child will do in the study: Your child will participate in one individual interview about his or her experience with Latino and American cultures in the Spanish Immersion Center for this study. This activity has been described in the parent/ student contact letter.

Time required: The study will require one hour of his or her time. Your child will not miss any instructional time while participating in this activity.

The interview will be recorded on an audio tape recorder. Your child may ask the researcher to turn off the recorder at any time during the interview. Your child may also skip any question that makes him or her uncomfortable. He or she can also stop the interview at any time. Once all of the data are analyzed, these tapes will be destroyed.

Risk: There are no anticipated risks in this interview.

Benefits: There are no direct benefits to you or your child for participating in this research study. The study may help us to understand the experience of immersion students with Latino and American cultures.

\section{Confidentiality:}

The information that your child gives the study will be handled confidentially. Your information will be assigned a code number. The list connecting your child's name to this code will be kept in a locked file. When the study is completed and the data have been analyzed, this list will be destroyed. Your child's name will not be used in any report. The audio tape from your child's interview will be destroyed two months after the study is published.

Voluntary participation: Your child's participation in the study is completely voluntary.

\section{Right to withdraw from the study:}

You have the right to withdraw your child from the study at any time without penalty Your child's audio tape will be destroyed should he or she decide to withdraw from the study. 


\section{How to withdraw from the study:}

If your child wants to withdraw from the study, tell Lucy Johnson. There is no penalty for withdrawing. If you would like to withdraw after your materials have been submitted, please contact: Lucy Johnson

Payment: You will receive no payment for participating in the study.

\section{If you have questions about the study, contact:}

Lucy Welbourn Johnson

Leadership, Foundations and Policy,

Ruffner Hall 280

P. O. Box 400265

University of Virginia, Charlottesville, VA 22903.

Telephone:

Email:1wj2k@virginia.edu

Robert W. Covert

Leadership, Foundations and Policy,

Ruffner Hall 280

P. O. Box 400265

University of Virginia, Charlottesville, VA 22903.

Telephone: (434) 924-0833

\section{If you have questions about your rights in the study, contact:}

Tonya R. Moon, Ph.D.,

Chair, Institutional Review Board for the Social and Behavioral Sciences

One Morton Dr Suite 500

University of Virginia, P.O. Box 800392

Charlottesville, VA 22908-0392

Telephone: (434) 924-5999

Email: irbsbshelp@virginia.edu

Website: www.virginia.edu/vprgs/irb/ 


\section{Agreement:}

I agree to allow my child to participate in an interview for the research study described above. Please include your child's email and telephone number as the contact information for the researcher.

(NOTE- please return both interview AND focus group permissions.)

\section{Signature:}

Date:

Email address:

Phone number:

You will receive a copy of this form for your records 


\section{Minor Informed Assent Agreement 13-17 \\ Please read this assent agreement with your parent(s) or guardian(s) before you decide to participate in the study. Your parent or guardian will also give permission to let you participate in the study. \\ Interview Participant Assent}

We want to learn about how being in the Spanish immersion program has helped you to understand Latino and American cultures.

\section{What you will do:}

This activity has been described in the parent/ student contact letter.

As part of our study, we would like to ask you to participate in an interview about your experience with Latino and American cultures in the Spanish Immersion Center for this study. I will ask you some questions and you will talk with me about what you think about these topics. The conversation will be recorded on an audio tape player. If I ask you a question that makes you uncomfortable, you do not have to answer it. You can also stop participating in the interview at any time during the session. You will not miss any instructional time while participating in this activity.

Time required: The study will require one hour of your time. You will not miss any instructional time while participating in this activity.

Risk: We don't think that there are any risks to you in this study.

\section{Benefit:}

If you participate in this study, there won't be any benefit to you. This study may help us to understand the experience of immersion students with Latino and American cultures.

\section{Confidentiality:}

The information that you give to us during this study will be kept private. Your name will not be used, and the list linking the code name assigned to your real name will be destroyed. The audio tape from interview will be destroyed once the data have been analyzed and the dissertation has been submitted to the university. No one who reads about our study will know it was you. We keep things locked up so that only our researchers see them.

You don't have to participate in this study. 
You can stop doing the study at any time. The audio tape of your conversation will be destroyed, should you decide to withdraw.

If you want to stop doing the study, tell Lucy Johnson. If you choose to stop before we are finished, any answers you already gave will be destroyed. There is no penalty for stopping. If you decide that you don't want your materials in the study but we have already completed the interview, contact Lucy Johnson.

You won't receive any money if you do the study.

If you have questions about the study, contact:

Lucy Welbourn Johnson

Leadership, Foundations and Policy,

Ruffner Hall 280

P. O. Box 400265

University of Virginia, Charlottesville, VA 22903.

Telephone:

Email:1wj2k@virginia.edu

\section{Advisor:}

Robert W. Covert

Leadership, Foundations and Policy,

Ruffner Hall 280

P. O. Box 400265

University of Virginia, Charlottesville, VA 22903.

Telephone: (434)924-0833

Email: rwc3q@ virginia.edu

\section{If you have questions about your rights in the study, contact:}

Tonya R. Moon, Ph.D.,

Chair, Institutional Review Board for the Social and Behavioral Sciences

One Morton Dr Suite 500

University of Virginia, P.O. Box 800392

Charlottesville, VA 22908-0392

Telephone: (434) 924-5999

Email: irbsbshelp@ virginia.edu

Website: http://www.virginia.edu/vprgs/irb/ 


\section{Agreement:}

I agree to participate in an interview for the research study described above. Please include your email address and telephone number as your contact information for the researcher.

(NOTE- please return both Focus group AND interview permissions.)

\section{Signature:}

Date:

Email address:

Phone number:

You will receive a copy of this form for your records. 


\section{Parent/Guardian Informed Consent Agreement \\ Please read this consent agreement carefully before you give permission for your child to participate in the study. Your child will also receive an assent form; please review the assent form with your child.}

\section{Focus Group Consent Agreement}

Purpose of the research study: The purpose of this study is to understand immersion students' experience with Latino and American cultures in the Spanish Immersion Center.

What your child will do in the study: Your child will participate in one focus group with peers about their experiences with Latino and American cultures in the Spanish Immersion Center for this study. This activity has been described in the parent/ student contact letter.

Note: Students will be grouped by grade level, with 10th grade students in one group and 11 th -12 th grade students in a second group.

Time required: The study will require about 1 hour of his or her time. Your child will not miss any instructional time while participating in this activity.

The focus group will be recorded on an audio tape recorder. Your child may ask the researcher to turn off the recorder at any time during the focus group. Your child may also skip any question that makes him or her uncomfortable. He or she can also stop the focus group session at any time. When all of the data are analyzed and the dissertation is submitted to the university, these tapes will be destroyed.

Risks: As the data are not anonymous, there may be a risk of loss of confidentiality from the focus group. There is inherently a higher level of risk of loss of confidentiality associated with focus groups. The researcher will discuss the importance of keeping the conversations confidential at the beginning of each group and also at the end of each session.

Benefits: There are no direct benefits to you or your child for participating in this research study. The study may help us understand the experience of immersion students with Latino and American cultures.

\section{Confidentiality:}

Because of the nature of the data from the focus group, I cannot guarantee that your child's data will be kept confidential and it may be possible that others will know what your child has reported.

However, your child's name will not be used in any report.

Voluntary participation: Your child's participation in the study is completely voluntary. 


\title{
Right to withdraw from the study:
}

You have the right to withdraw your child from the study at any time without penalty Your child's answers on the audio tape will not be used; however, it is not possible to withdraw them after they have been recorded.

\section{How to withdraw from the study:}

If your child wants to withdraw from the study, tell Lucy Johnson. There is no penalty for withdrawing. If you would like to withdraw after your materials have been submitted, please contact: Lucy Johnson

Payment: You will receive no payment for participating in the study.

\section{If you have questions about the study, contact:}

Lucy Welbourn Johnson

Leadership, Foundations and Policy,

Ruffner Hall 280

P. O. Box 400265

University of Virginia, Charlottesville, VA 22903.

Telephone:

Email: 1wj2k@virginia.edu

\author{
Advisor: \\ Robert W. Covert \\ Leadership, Foundations and Policy, \\ Ruffner Hall 280 \\ P. O. Box 400265 \\ University of Virginia, Charlottesville, VA 22903. \\ Telephone: (434) 924-0833 \\ Email: rwc3q@virginia.edu
}

\section{If you have questions about your rights in the study, contact:}

Tonya R. Moon, Ph.D.,

Chair, Institutional Review Board for the Social and Behavioral Sciences

One Morton Dr Suite 500

University of Virginia, P.O. Box 800392

Charlottesville, VA 22908-0392

Telephone: (434) 924-5999

Email: irbsbshelp@virginia.edu

Website: www.virginia.edu/vprgs/irb/ 


\section{Agreement:}

I agree to allow my child to participate in the research study described above. Please indicate the grade level and include your child's email and telephone number as the contact information for the researcher.

(NOTE: If your child wishes to participate in a focus group AND an individual interview, please return BOTH focus group AND interview permissions.)

Grade level:

Signature:

Date:

Email address:

Phone number:

You will receive a copy of this form for your record. 


\section{Minor Informed Assent Agreement 13-17 \\ Please read this assent agreement with your parent(s) or guardian(s) before you decide to participate in the study. Your parent or guardian will also give permission to let you participate in the study.}

\section{Focus Group}

We want to learn about how being in the Spanish immersion program has helped you to understand Latino and American cultures.

\section{What you will do:}

Information about this study is described in the parent/ student cover letter.

As part of our study, we would like to ask you to participate in a focus group with your Spanish immersion classmates about your experiences with Latino and American cultures. I will ask each of you some questions and you will talk with your peers about these topics. The conversation will be recorded on an audio tape player. If I ask you a question that makes you uncomfortable, you do not have to answer it. You can also stop participating in the focus group at any time during the session. You will not miss any instructional time while participating in this activity.

Note: Students will be grouped by grade level, with 10th grade students in one group and 11 th -12 th grade students in a second group.

Time required: The study will require about 1 hour of your time. You will not miss any instructional time while participating in this activity.

\section{Risk:}

If you participate in the study, there is a risk of loss of confidentiality because the discussion will involve a group of people. Once the conversation is taped, it will not be possible to delete the recording of what you have said and this could make you uncomfortable. For example, it is also possible that someone in the group might tell other people about what you or others said. Also, someone may misunderstand what you have said and tell others about it.

\section{Benefits:}

If you participate in this study, there won't be any benefit to you. The study may help us understand the experience of immersion students with Latino and American cultures.

\section{Confidentiality:}

The audio tape from your focus group will be destroyed once the data have been analyzed and the dissertation has been submitted to the university. However, it may be possible for us to figure out who you are because of your answers, but we won't try to do so. 
Because you are in a focus group, we can't guarantee that your information will be kept private. It may be possible that others will know what you said. Confidentiality cannot be guaranteed; it may be a risk to you.

You don't have to participate in this study. You can also stop doing the study at any time.

If you want to stop doing the study, tell Lucy Johnson. If you choose to stop before we are finished, any answers you already gave will be not be used in the study, but it will not be possible to withdraw the audio tape. There is no penalty for stopping. If you decide that you don't want your materials in the study but you already turned them in, contact Lucy Johnson.

You won't receive any money if you do the study.

\section{If you have questions about the study, contact:}

Lucy Johnson

Leadership, Foundations and Policy Studies

P,O, Box 400265, Ruffner Hall 280

University of Virginia, Charlottesville, VA 22903.

Telephone:

Email:1wj2k@virginia.edu

\section{Advisor:}

Robert W. Covert

Curry School Of Education

Leadership, Foundations and Policy Studies

Ruffner Hall 2820

P.O. Box 400265

University of Virginia, Charlottesville, VA 22903.

Telephone: (434) 924-0833

Email: rwc3q@ virginia.edu

\section{If you have questions about your rights in the study, contact:}

Tonya R. Moon, Ph.D.,

Chair, Institutional Review Board for the Social and Behavioral Sciences

One Morton Dr Suite 500

University of Virginia, P.O. Box 800392

Charlottesville, VA 22908-0392

Telephone: (434) 924-5999

Email: irbsbshelp@ virginia.edu

Website: www.virginia.edu/vprgs/irb/ 


\section{Agreement:}

I agree to participate in the research study described above. Please indicate your grade level and include your email address and telephone number as your contact information for the researcher.

(NOTE: If you wish to participate in a focus group AND an individual interview, please return BOTH focus group AND interview permissions.)

Grade level

Signature:

Date:

Email address:

Phone number:

You will receive a copy of this form for your record. 


\section{Informed Consent Agreement: Interview Participant}

\section{Please read this consent agreement carefully before you decide to participate in the study.}

Purpose of the research study: The purpose of this study is to understand immersion students' experience with Latino and American cultures in the Spanish Immersion Center.

\section{What you will do in the study:}

As part of our study, we would like to ask you to participate in an interview about your experience with Latino and American cultures in the Spanish Immersion Center. I will ask you some questions and you will talk with me about what you think about these topics. The conversation will be recorded on an audio tape player. If I ask you a question that makes you uncomfortable, you do not have to answer it. You can also stop participating in the interview at any time during the session. Information about this study is also described in the student cover letter.

Time required: The study will require one hour of your time. You will not miss any instructional time while participating in this activity.

Risk: We don't think that there are any risks to you in this interview.

\section{Benefits:}

There are no direct benefits to you for participating in this research study. This study may help us to understand the experience of immersion students with Latino and American cultures.

\section{Confidentiality:}

The information that you give to us during this study will be kept private. Your name will not be used, and the list linking the code name assigned to your real name will be destroyed. The audio tape from interview will be destroyed once the data have been analyzed and the dissertation has been submitted to the university. No one who reads about our study will know it was you. We keep things locked up so that only our researchers see them.

Voluntary participation: Your participation in the study is completely voluntary.

Right to withdraw from the study: You have the right to withdraw from the study at any time without penalty. The audio tape of your conversation will be destroyed, should you decide to withdraw.

How to withdraw from the study: There is no penalty for withdrawing. If you want to withdraw from the study, tell Lucy Johnson to stop the interview. If you choose to stop before we are finished, any answers you already gave will be destroyed. If you decide 
that you don't want your materials in the study but we have already completed the interview, contact Lucy Johnson.

Payment: You will receive no payment for participating in the study.

\section{If you have questions about the study, contact:}

Lucy Welbourn Johnson

Leadership, Foundations and Policy,

Ruffner Hall 280

P. O. Box 400265

University of Virginia, Charlottesville, VA 22903.

Telephone:

Email: 1wj2k@virginia.edu

\section{Advisor:}

Robert W. Covert

Leadership, Foundations and Policy,

Ruffner Hall 280

P. O. Box 400265

University of Virginia, Charlottesville, VA 22903.

Telephone: (434)924-0833

Email: rwc3q@virginia.edu

If you have questions about your rights in the study, contact:

Tonya R. Moon, Ph.D.,

Chair, Institutional Review Board for the Social and Behavioral Sciences

One Morton Dr Suite 500

University of Virginia, P.O. Box 800392

Charlottesville, VA 22908-0392

Telephone: (434) 924-5999

Email: irbsbshelp@virginia.edu

Website: http://www.virginia.edu/vpr/irb/ 


\section{Agreement:}

I agree to participate in an interview for the research study described above. Please include your email address and telephone number as your contact information for the researcher.

(NOTE-Please return both focus group AND interview permissions.)

\section{Agreement:}

Signature:

Date:

Email address:

Phone number:

You will receive a copy of this form for your record. 


\section{Informed Consent Agreement: Focus Group Participant}

\section{Please read this consent agreement carefully before you decide to participate in the study.}

Purpose of the research study: The purpose of this study is to understand immersion students' experience with Latino and American cultures in the Spanish Immersion Center.

\section{What you will do in the study:}

As part of our study, we would like to ask you to participate in a focus group with your Spanish immersion classmates about your experiences with Latino and American cultures. I will ask each of you some questions and you will talk with your peers about these topics. The conversation will be recorded on an audio tape player. If I ask you a question that makes you uncomfortable, you do not have to answer it. You can also stop participating in the focus group at any time during the session. Information about this study is described in the student cover letter.

Note: Students will be grouped by grade level, with 10th grade students in one group and 11 th and 12th grade students in a second group.

Time required: The study will require about 1 hour of your time. You will not miss any instructional time while participating in this activity.

\section{Risks:}

If you participate in the study, there is a risk of loss of confidentiality because the discussion will involve a group of people. Once the conversation is taped, it will not be possible to delete the recording of what you have said and this could make you uncomfortable. For example, it is also possible that someone in the group might tell other people about what you or others said. Also, someone may misunderstand what you have said and tell others about it.

\section{Benefits:}

If you participate in this study, there won't be any benefit to you. The study may help us understand the experience of immersion students with Latino and American cultures.

\section{Confidentiality:}

The audio tape from your focus group will be destroyed once the data have been analyzed and the dissertation has been submitted to the university. However, it may be possible for us to figure out who you are because of your answers, but we won't try to do so.

Because you are in a focus group, we can't guarantee that your information will be kept private. It may be possible that others will know what you said. Confidentiality cannot be guaranteed, it may be a risk to you.

Voluntary participation: Your participation in this study is completely voluntary. 
Right to withdraw from the study: You have the right to withdraw from the study at any time without penalty. If you choose to stop before we are finished, any answers you already gave will be not be used in the study, but it will not be possible to withdraw the audio tape.

Right to withdraw from the study: There is no penalty for withdrawing. If you want to withdraw from the study, tell the researcher and leave the room. If you decide that you don't want your materials in the study but you already turned them in, contact Lucy Johnson.

Payment: You will receive no payment for participating in the study.

If you have questions about the study, contact:

Lucy Johnson

Leadership, Foundations and Policy Studies

P,O, Box 400265, Ruffner Hall 280

University of Virginia, Charlottesville, VA 22903.

Telephone:

Email: lwj2k@virginia.edu

\section{Advisor:}

Robert W. Covert

Curry school Of Education

Leadership, Foundations and Policy Studies

Ruffner Hall 2820

P.O. Box 400265

University of Virginia, Charlottesville, VA 22903.

Telephone: (434) 924-0833

Email: rwc3q@virginia.edu

If you have questions about your rights in the study, contact:

Tonya R. Moon, Ph.D.,

Chair, Institutional Review Board for the Social and Behavioral Sciences

One Morton Dr Suite 500

University of Virginia, P.O. Box 800392

Charlottesville, VA 22908-0392

Telephone: (434) 924-5999

Email: irbsbshelp@ virginia.edu

Website: http://www.virginia.edu/vpr/irb/ 


\section{Agreement:}

I agree to participate in the research study described above. Please indicate your grade level and include your email address and telephone number as your contact information for the researcher.

\section{Grade level}

Signature:

Date:

Email address:

Phone number: (__

You will receive a copy of this form for your record. 


\section{Informational Meeting}

\section{Spanish Immersion Research Study}

What: A meeting with UVA graduate student researcher Lucy Johnson

For Whom: Prospective study participants and their parents

When: January 18, 2011 6:30-7:15p.m.

Where: Room S102

Why: To answer any questions that you might have about your participation in the study

Have questions but can't make the meeting?

Email me:

Contact Information: Lucy W. Johnson Iwj2k@virginia.edu 


\section{APPENDIX B: INTERVIEW AND FOCUS GROUP QUESTIONS}

\section{Interview Questions}

Question: How do high school students in a Spanish Immersion Program describe their experience with the cultures in which they are schooled?

Introduction of topic:

1. In five words or less, what does culture mean to you?

2. How would you describe American culture?

3. When you think of cultures in the Spanish-speaking/ Latino world, how do you describe their cultures? Please think of concrete examples.

Experience abroad: to travel/ study/ live:

4. Tell us about any experiences you have had traveling or living in a Spanish-speaking country.

5. How knowledgeable did you feel about the culture?

6. How comfortable were you during this experience in another culture? What did you find difficult? How did the experience help you to understand the culture?

Main Questions:

7. What is it like going to school in two languages in the Spanish immersion program? In what way(s) has learning Spanish helped you to understand Spanish-speaking/ Latino cultures?

How has it been helpful? What have you found difficult?

8. Tell us about your experience with the local Spanish-speaking/ Latino community in Immersion Service Learning. How have these experiences helped you to understand Spanish-speaking/ Latino cultures? How comfortable have you felt with this experience? (interactions with members of this community/ communicating in Spanish with them?)

9. How has learning about Spanish-speaking cultures affected the way you do things? 
10. How has this experience changed the way you think?

11. How might this program be improved in terms of learning about Spanishspeaking/Latino cultures? Please give specific examples.

12. Would you recommend this program to someone who wants to know more about Spanish-speaking/ Latino cultures? Why or why not?

Wrap-up Question:

13. We are almost at the end of this interview. Are there other questions that you would like to talk about that we did not mentioned?

\section{Focus Group Questions-10th Grade}

The questions were the same as for the interviews. Groups of interview answers were read to participants to stimulate their thinking.

Introduction of Topic:

1. In five words or less, what does culture mean to you?

- The way people act around themselves (TS)

- The way people live (JS) (NJ), their way of life (ES) (LG) (MS) what they grow up around (RT)

- Tradition: embrace where you're from- it's inherited (PG)

- Tradition, meaning, family and love history ('cause I love it!- AG)

- Worldly, different (ES)

- People, traditions of a group of people [(JM) traditions of a country] (LG), (TC)

- Perspective on someone's family (NS)

2. How would you describe American culture?

- Is it possible to describe Southern Culture?

- The traditions are different from a lot of other countries." A lot of stuff here is acceptable that's not in other countries." (AG) 
- "Based on society" (NS) [EX: parents may want to raise their children according to their own traditions, but society may have a larger influence than parents (societal pressure) (NS)

- Societal pressure: Dating, career interests - popular career vs. what one wants to do

- Acceptable: the way we dress, things we say, the types of foods we eat (AG); "the slang here is kind of vulgar sometimes." (AG)

- We accept different cultures. There's not really just one. (AG)

- A lot more diverse than others. (AG)

- Very modern, fast-paced. (ES) Like food and everything is just fast. (ES) There's not a lot of American traditions. (ES) Growing very fast because the technology these days is growing really fast (JM)

- Music these days, it's very, I'm not sure how to describe it, but I don't know. We're coming up with new things and so it's not really based off of old things." (JM)

- Traditions...are changing (JM)

- Everything's pretty like revolving around music and like Hollywood." (LG)

- "We have a lot of different cultures. There isn't just one American culture here (TC, JS) .... We all live in the same place." (TC)

- "We are the melting-pot of the world." (MS) ..."Our culture has a little bit of influence from other places in the world...from like Hispanic countries, Asian countries, from Europe, everywhere." (MS)

- Part of American culture is always being proud of America and where you come from. We also have baseball, apple pie, barbecue, everything like that." (AM)

- It's different (LG), not as family-oriented as compared to Hispanic culture (PG)

- "American culture isn't necessarily like...I wouldn't describe it as American. I would more describe it like from other countries, 'cause you're not necessarily considered American, so like I'm Italian, so I have more of like an AmericanItalian." (RT)

- "We have more opportunities here than you would somewhere else." (NJ)

- Different languages, food, customs- we don't drink wine with dinner (NJ)

- there are a lot of people that care about more than like stereotypical American culture, I think, revolves around being self-centered, but I think that people care more than people realize Me..Can you explain what you mean by that ? I guess other countries think that America is arrogant. (TS)

- Me: Um hm.

- TS: But my experience here, it's not arrogant, but more people care about others more than you think.

- Me: Um hm. Could you give me any concrete examples of that?

- TS: um, well the other day, I saw someone helping some, an older person cross the street. Um I have seen people pick up trash around the school... 
Do you have further ideas to add?

3. When you think of cultures in the Spanish-speaking/ Latino world, how do you describe their cultures?

- "Like in Spain, it's a lot more formal. The teachers are formally addressed." (AG) Spanish culture is like it's more deep and vivid than ours." (AG) .."there's more into art. The language is beautiful. And the food,..they take to heart how they make their food." (AG)

- "Oh, I love those cultures, they're so rich and so full of life and the music is amazing, the stories they tell are amazing, their culture is just so...oh, I just love it so much." (MS)

- "Very unique..and I don't think a lot of other places are like them. And they're not even that similar to each other." (JS)

- Family-centered (RT) (MS) (ES) (NS) (TS)

- The big Aztec pyramids (PG), the Aztecs (TC),

- Traditions- (JM- Las Fallas, Dia de los Muertos), (PG- Thanksgiving with pernil) ( Quinceañera- (AG)(TS), festivals (JM) (ES) (TC) (PG) (MS), music (MS) (PG), dance, colorful clothing (JS), (RT), food (TS) (MS),

- Food, festivals, holidays (LG) (JS), fairs (LG),

- History (TC)

- I lived in Puerto Rico, so I guess like where I lived, it was less modernized than here...like a town near the mountains." (LG) (there's not as much technology- LG)

- "In America it seems we don't have time for family." (MS)

- ..different languages, 'cause there's more than just one. (NJ)

- ..lifestyle is way different than ours. (NJ)

- Some people don't have houses...they don't really have roads or anythingPeru (NJ)

- Crime is a problem (robberies- $\mathrm{NJ}$ )

- Family is respected (AG); family comes before anything else- (NS)

- Religion: "God is a lot more recognized in Latino culture too." (AG) (RT) (LG) (ES) (TS)

- Monuments, beautiful destinations, history (NJ)

- Poverty- Peru doesn't have many roads, some people don't have houses (NJ)

- Parents: very strict on culture and family traditions- family doesn't want to lose it's traditions (NS)

- Respect is a very big factor. (NS)

- Parental values are important- education is your job- get a better education than your parents. (NS) 
Experience abroad: travel/ study/ live:

4. Tell us about any experiences you have had traveling or living in a Spanishspeaking country?

- Would like to travel to Spain in 12th grade. (JM)

- Learned about life in an Hispanic country- Colombia- from 8th grade Spanish teacher [entire families live together]; people who live in small towns walk everywhere; (RT)

- Walk everywhere: "sense of freedom" since you know everyone, like a family atmosphere- as child, this student went to corner store to buy milk (PG)

- Foods are different and packaged differently (PG)

- Hispanic cultures- there are many (RT)

- Remembers festivals, celebrations of early childhood in Peru. Also styles of houses (NJ)

- Remembers poor quality of roads - cut self one time (NJ)

- Remembers street vendors (NJ)

- As an Hispanic teenager living in the U.S., she feels that her parents are stricter than American parents about bed time and time spent with family vs. going out with friends to spend the night, hang out during holidays (Christmas, New Years) (NJ)

- Patriotism is very important (PG) [ex: students line up in front of flag to sing national anthem]

- School in DR has greater work load than in U.S. (PG)

- TV is different- types of programs and looking at American programs translated into Spanish - some jokes etc are lost in translation (PG) (ex: Sponge Bob)

- Doesn't feel that knowledgeable about Hispanic cultures other than Peru (NJ)

- Feels part of Latino (Puerto Rican) and American cultures, since born in PR, but has grown up in U.S. for most of school career, still has traditions from PR (LG)

- I I feel like I fit in to both cultures because I just kind of live a double-life sometimes because there's times when I'm like doing these Hispanic traditions and then there's times when I'm doing American traditions as well, like the Fourth of July. (LG)

- Celebrates Puerto Rico Day (coquí) (LG)

- Grew up in Puerto Rican neighborhood in NYC (MS) - remembers Puerto Rican food and music; family spoke Spanish at home. (MS)

- Traveled for vacation with family to Mexico as young child and became aware of existence of other languages, of other ways of communicating (AG)

- Remembers : colorful clothing, handmade things (jewelry)- take a lot of pride in what they make; style of houses different; (AG)

- Remembers: "I felt at home there. I was definitely comfortable. It was a good place to be. " (AG) 
- "There's a lot of poor down there, but I guess that's with everywhere." (AG) Sometimes they had to go to find fresh water. (AG)

- Hispanic soccer players seem to be more emotional in their play (JS)

- As a native Spanish speaker, sometimes I don't understand what kids are talking about culturally because their family is different than mine. When they come over to my house, they don't understand why my parents are so strict on me, but I don't think it's strict, I think it's just normal for me. When I go to their house, I think it's really sloppy how their parents are raising them. (NS)

- Topics of conversation are different in Latino culture: Music, dancing, politics, slang (NS)

- Conflict between American and Hispanic culture from Hispanic view point: certain ways of talking would not be acceptable to my parents (NS)

Main Questions:

5. What is it like going to school in two languages in the Spanish immersion program?

- Transition to all Spanish was difficult at first (JM), (ES), (JS), (LG) - teachers helped us a lot to make the transition ; (LG- somewhat weak Spanish skills, even with one Spanish-speaking parent); (NJ- even as a native speaker who has spent a long time in the U.S. education system)

- Transition: Not used to studying Math \& Gym in Spanish (vocab) ("you kinda start out you're rocky 'cause it's like different." (RT) ... but once you get into it, it's really rewarding and enriching to be able to say that "oh, well I can go from an English class to a Spanish class, no problem, no difference. It's fine. And I think you learn more of the language being kind of thrown into it and having to use it so much." (RT)

- Transition to Spanish was "a bit different" b/c "my Spanish is a slang version from New York" and her accent is different (she is learning "proper Spanish") (MS.)

- Transition: I had taken 3 years of Spanish in middle school, so I was pretty much there. So it was pretty easy. (TC)

- It hasn't been difficult. It's just been challenging. You have to understand and you have to know how to figure out how to understand things. (TC)

- Difficult parts: Math in Spanish "a little challenging" (PG), (TS); writing in Spanish = "hard"; Spanish and History- "not hard" (PG) Math- (ES, JM)- "it was very difficult for me", BUT- "once you learn Spanish, Immersion is like any other class, since you understand the language. (LG) (JM) History- hard (ES)

- History in Spanish: I mean it's not the most fun class. It's a lot of work- the translating and the translating back and having to understand it both ways. (TC) 
- Difficult part: speaking English is not permitted at all. (NJ) (JS)

- Difficult part: articulating what you want to say in Spanish. (L2) (JM) (NS)

- Difficult- "more work"/ more homework, than other non-Immersion classes. (JS) (NJ) (TC)

- Difficult- "going back and forth for SOLs was kind of challenging, because you have learned all these words in Spanish and then, "Uh, oh, SOL is in English, so you kind of have to go back and re-learn it, which is kind of a challenge at first..." (RT)

- Difficult? - It's not really that the Spanish is difficult, it's that you have to understand it. You can't just go in and learn vocabulary and learn grammar like you would in a normal Spanish class. You have to learn how to use it and when to use it. And you have to understand all of it. "(TC)

- Difficult: accents, spelling, conjugating verbs, developing skills in writing in Spanish (MS)

- Difficult: Spanish Literature- "it's a little hard because .. a lot of us have to go in the dictionary and look up words..there's a lot of words that we don't know. ...like even the native speakers. (LG)

- Love speaking Spanish and English (MS)

- Learned about geography (NJ)

- Transition was easy (AG), thanks in part to teachers' help (AG)

- Immersion teachers have higher expectations for their students (JS)

- Language: " I like having to memorize verbs in Spanish and then I can review them in English with other people, outside of Immersion, so it helps me practice my Spanish." (TS)

- Language: problems recognizing tenses, knowing where to put accents (NJ)

- Language: "Some Spanish-speakers talk really fast... I've learned to better depict what they say." (TS)

- It's very almost family environment... and everybody is trying to help each other learn. Like they're pushing each other on to do better. And I think that's wonderful. (AG)

- Switching between Spanish and English is difficult at times. You forget what language you're speaking/ using (MS, PG, NJ, NS ) "my brain wants to speak Spanish in English class...." (PG)

- Going to school in 2 languages has become routine. (JS) (LG)

6. In what way(s) has participation in Spanish Immersion helped you to understand Spanish-speaking/ Latino cultures?

- Learn about different countries, festivals, (JS), (AG) (ex: Mexican weddings, Aztecs, Bolivia produces bananas "I love learning about different countries, but that like fascinates me." (PG); festivals (Tomatina, coffee production in Colombia (LG) 
- Put myself in the place of people who would live in Spanish-speaking countries and study more in-depth their lives and...their religion...their faith (TS)

- Learn about Spanish thoughts on death - they celebrate it.(JS)

- "You're surrounded by it. There are a lot of Hispanics in Immersion and so it's like you kind of have a taste of everybody's different culture. And it's not just, like what the book wants you to know. It's like everything. It's like real life, these real people, not just like "Oh Flamenco dancers in Spain... it's real life." (RT)

- Understand the culture through study of its history, customs, traditions, foods, economy.

- Understand variations in the cultures of the Hispanic world (JM. multiple?) :

Ex: Venezuela is kinda like America how they are modern... pop music, malls and stuff, like one of the biggest malls in the world.

- History: "It really helped give a lot of the history behind it and showed us how it's developed and how the movement of people has changed the cultures... like the influx of Europeans into the Americas changed the Mexican or Aztec cultures at that time. It's just shown how the patterns of history have kind of changed everything and how it used to be and how it is now. And how they still retain some of the traditions that they used to have. (TC)

- Traditions: Whole families live together. (TC)

- Family oriented, festivals, foods are different, schools are different (ES)

- Understand Spanish cultures better (JS)

- Greater understanding of world religions and world cultures (TS) from World History class in Spanish

- Learned about cultures other than home culture in Central/South America (NS)

7. Tell us about your experience with the local Spanish-speaking/ Latino community in other community activities

- Spent time with friends who are Hispanic (and their families) (JS)

- Talked with Latino employees at restaurants that father oversees in business

- Helped tutor father in Spanish for his volunteer work with a local church (JS)

8. How have your experiences in the Latino community helped you to understand Latino cultures?

- Religion, food, family is important, working with your hands is more meaningful (AG)

- Different places have different foods. (NJ)

- Language varies from one Hispanic culture to another (RT) 
- Learned about life in Cuba from father who has gone on missions trips to that island (JS): not a lot of food, buildings are old, cars are old

9. What have you learned about appropriate ways of behaving when you interact with Latinos or other Spanish speakers?

- Language: You should address them formally, because you don't know them. (AG)

- How to respect the cultures and differences because there's foods that Hispanic countries that we just think would be weird, but we learn to not be offensive and say like "Eeww.. that's weird." (LG)

- Respect is very important in Hispanic/ Latino cultures: you have to be more polite. (NJ) (JM) (PG) "Respect is the biggest thing." (PG)

- "When you talk to someone in Spanish it's not how, it's kinda how you just talk in English....you'd just be respectful."(JM)

- We have not talked about appropriate ways of acting or doing things with speakers of Spanish. (TC) (JS) (RT) (TS) ; BUT "it's kind of understood...that you treat everyone with respect. (RT)

10. How has participating in Immersion cultures affected the way you do things?

The snow-ball effect in culture-learning- open-mindedness to doing new things, eating new foods

- I cook a lot differently, I like the food better. I definitely go over to my friends house a lot more to speak Spanish. (AG)

- I speak more Spanish (MS), (LG) (TC) (RT); "I'm trying to learn Spanish the proper way. I'm always polite to everybody. " I'm starting to get more into the Hispanic TV. (MS)

- More open-minded (ES) : I'm willing to try new things. (LG), (ES) I'm more interested in traveling now than I was before. (LG)

- I'm not as dependent upon technology as I was before. I'm trying new sports and stuff. (LG)

- Communicate better with family. (NJ)

- Talks with friends about Hispanic cultures: "Just because they live differently doesn't make them weird. I think it's really cool and interesting how people live so differently." (ES)

- Have not changed the way I do things (JM) (TC) (JS) (RT)

11. How has this experience changed the way you think?

- I think in Spanish sometimes (JS) (RT) and dream in Spanish now. (AG)

- Speak in Spanish when mean to speak in English in non-Immersion classes (TS) and others 
- Awareness of important issues in Hispanic countries and in the world in general (TC)

- I'm more accepting of different people, of different cultures., different religions. (LG)

- Awareness of conditions in Hispanic countries and realization of opportunities one has in the U.S. (NJ)

- More respect of Hispanic cultures and their traditions (JM)

- Greater interest in other cultures: "I just love different cultures now and I love learning about it." (ES)

12. In what way(s) has participation in Immersion affected your post-high school plans?

- Desire to help countries in South America: "I want to build roads for them." (NJ)

- Desire to learn about other cultures in college. (ES)

- Major in Modern Languages (ES)

- Interest in Major in Spanish (LG) or minor (JM)

- Want to be a photographer/ may want to be a translator or interpreter or teach ESL (ES)

- Interest in teaching Spanish (LG)

- Continue to speak Spanish through college (TS)

- Want to study other languages (TS)

13. What motivated you to start Immersion?

- Looks good on college applications to say you have earned a bilingual certificate in H.S. (LG)

- $\quad$ Fluency in Spanish (JM) (ES) (JS)

- Communicate with Hispanic friends (JM)

- Spanish language is becoming very strong in our world and lots of people need to know it- may give me an advantage (JM) (ES)

- Curiosity, it will be useful in the future (TC)

- Travel to Spanish-speaking countries (ES)

- Travel to Cuba to do Missions work (JS)

14. Native-Speakers World View from the perspective of American and Hispanic cultures

- "I have two different views on life." (PG) EX: "My family wants me to learn the value of the money." (They will not just give me a car as is the case for some of my American friends.) My view is you're getting stuff just given to you and you haven't earned it." (PG)

- Would like to have a job to help mom and reduce her stress. VS. Friends don't want a job. (PG)

- My family comes first. (PG)

- Guided by parents' rules and values (NS) 
Wrap-up Question:

15. We are almost at the end of this interview, are there other questions that you would like to talk about that we have not mentioned that are important to your Immersion experience?

- Immersion Family- (JM), (TC), (ES) / build bonds ( bonds with teachers and students) (ES)

- Immersion- speaking and learning in Spanish makes H.S. interesting (JM) (ES)

- Interactive class makes it interesting and helps us to understand cultural issues (AG,

- Taking some core courses in Spanish (Math, History) makes you learn Spanish better (RT)

- Learn to exchange ideas, opinions with a group of people whom you know very well.

- Confidence in language proficiency ()

- Feeling of accomplishment in doing big job (AG,

- Teachers are committed to helping students whenever needed

- Like teachers a lot (MS)

- Enjoyed Immersion, made some good friends (MS) (LG)

- We know how to work together and help each other out (TC)

- Connects me with my family (Hispanic) (MS)

- Chance to travel abroad to Mexico or Spain is a great experience in H.S. (LG)

- A lot of people are leaving the program or have already left because they don't enjoy it- has to do with courses in Spanish and particular teacher (NJ)

- Being in Spanish Immersion means our course schedule is rigid/ not many/ or any electives (TC) (not much flexibility) (JS)

- "It's closed off", since you see the same people every day for 4 years (TC) 


\section{Focus Group Questions_-11th and 12th Grades}

Introduction of Topic:

1. In five words or less, what does culture mean to you?

- Beliefs: religious, where you're from, your nationality

- Standard activities of a people

- An experience like any other

- People, music, literature, language

- The heart of the people

- Family, music, what is around you, who you are

- Traditions, language, religion combined of a particular society and a group of people

- Family, traditions, food, religion, lifestyle

- Different traits of a society that define it

- Traditions, race, ethnicity, language heritage

- Very diverse, independent, everyone has their own culture

- Culture makes a person who they are

- What people live their daily lives by... and it's what makes a group of people connect together and makes them a group, like an ethnicity altogether

2. How would you describe American culture? Is it possible to describe Southern Culture?

- "Big mix of everything, like a salad"

- Sharing: we share ideas/ a lot of cultural mixes

- "a melting pot"

- Diverse

- Distant

- Fast-paced

- Individual is the focus

- Sports, politics, Money, family, religion

- Way you dress, what you believe in, religion

- Viewed as "greedy, malicious, bad" by those from the outside

Do you have further ideas to add?

3. When you think of cultures in the Spanish-speaking/ Latino world, how do you describe their cultures?

- Traditions (Siesta, Quinceañera), festivals, fairs, music, dance, colorful, food,

- Cultures don't change as much for many generations

- Family is important, it is the center of life 
- Religion is important

- Poverty is a fact of life in Central, South America, Mexico

- Some appreciate US and opportunities offered here, especially compared to the above

- Different types of Commerce ( open-air markets, bargaining for price)

- Latinos/ Hispanics seem to celebrate life, to be passionate about it, and to relax

Experience abroad: travel/ study/ live:

4. Tell us about any experiences you have had traveling or living in a Spanish-speaking country?

- Politeness, respect for elders observed

- Way men interact with women in public (walking on street)

○ "raw sexuality" - men whistle at women, talk to them about their beauty, follow them

○ "machismo" - girls abroad on trip learn strategies for dealing with men (JA)

- Women are less modest sexually

- Role of women in home- "subordinate to men" (JA)

- Religion and its importance in the lives of Hispanics generally

- "walking everywhere" (RB, MW, MM, SW)

- Easy lifestyle, more relaxed cultures (multiple people)

- Family-centered culture (RB, MW)

- Become more open-minded (MW and others)

- Greeting, phone etiquette are different (R B)

- Gained a greater appreciation for what one has in life, for life in general, for where one comes from

Main Questions:

5. What is it like going to school in two languages in the Spanish immersion program?

- Transition to all Spanish was difficult at first

- Most students adjusted well after a month or two

- Speaking Spanish has become routine

- Switching between Spanish and English is difficult at times. You forget what language you're speaking/ using

- "It's like a second skin to me."

6. In what way(s) has participation in Spanish Immersion helped you to understand Spanish-speaking/ Latino cultures?

- Awareness of differences in holiday celebrations (A.M.) 
- Understand the culture through study of its history, customs, traditions, foods, economy

- Understand culture through CINE you learn about the Hispanic perspective on the world, on life (BS, JA, FF)

- Understand Hispanic issues in depth (ex: immigration in U.S.) (develop empathy)

- Understand variations in the cultures of the Hispanic world

7. Tell us about your experience with the local Spanish-speaking/ Latino community in Immersion Service Learning and other community activities.

- Students helped teachers of regular Spanish classes

- Class activities

○ In-class tutor

- Taught culture lessons

- Went to Hispanic community events (JA)

- Spent time with friends who are Hispanic (and their families) (EM)

- Volunteer for community activities

- Christmas Mother (multiple students)

- Parent-night at elementary schools served as translators

- Worked in ESL summer school classes

- Babysat Spanish-speaking children while parents took English classes

- Helped translate for Spanish-speaking visitors

- Helped translate for Spanish-speaking customers at pay or volunteer job

○ Hospital

○ Medical clinic (RS)

- Church (FF)

- Grocery store, retail store (MW, RB, RS, DM)

8. How has participating in Immersion cultures affected the way you do things?

$>$ The snow-ball effect in culture-learning- open-mindedness to doing new things, eating new foods

$\circ$ respect for the person who made a new dish squid, snails, flan

- You try the new food and discover you actually like it, or it's not too bad

- One small step leads to another one...(MW) these steps may be greater as time goes on..

- Have not changed the way I do things (SW, others?)

- Listen to Spanish music

- Watch TV in Spanish to relax

- Shed stereotypes, open-minded about other cultures (MW) and embrace people who are from different cultures (DM)

- Respect cultural and racial differences (RB, BS) 
- Respect ways of acting in other cultures (EM)

- Realize importance of family (BS) and spend more time with them

- Increased awareness of other cultures and of the importance of speaking FLs

- Awareness of cultures of Hispanic world - have a more humanitarian approach to the world and want to help with problems in Hispanic countries (BS) ( Chile and earthquake, mine disaster)

- Knowledge about Hispanic world- voice one's own opinion, independent of parents

- Change way think about certain issues

- Dress nicely

- Involved in Hispanic community events (JA)

- Careful when interact with people in Spanish to avoid offending them (being snobby)

- Confidence to participate in class discussions, even in English-speaking classes

- Study harder (CL)

- Learning Spanish has improved English vocabulary

- Studying issues in Humanities and other Immersion classes- make Comparisons with U.S. (Government class) (ex: 1st Amendment Rightfreedom of speech and religion) VS. Spanish Civil War (issue of religion)

9. How has this experience changed the way you think? (see above)

Wrap-up Question:

10. We are almost at the end of this interview, are there other questions that you would like to talk about that we have not mentioned that are important to your Immersion experience?

- Immersion Family/ build bonds (JA, EM, BS, DM,MM, RB, SW (bonds with teachers and students)

- Interactive class makes it interesting

- Learn to exchange ideas, opinions with a group of people whom you know very well.

- Confidence in language proficiency (MM)

- Feeling of accomplishment in doing big job

- Teachers are committed to helping students whenever needed

- Time to explore issues and share opinions is a plus in program

- Learn about culture through group work and interaction with Hispanic classmates 


\begin{tabular}{|c|c|c|c|c|c|c|c|}
\hline Pseudonym & Initials & Sex & N.E.S. & N.S.S. & H.S.S. & $\begin{array}{l}\text { Grade } \\
\text { Level }\end{array}$ & $\begin{array}{l}\text { Experience } \\
\text { Abroad }\end{array}$ \\
\hline $\begin{array}{l}\text { Jaime } \\
\text { Anderson }\end{array}$ & JA & $\mathrm{F}$ & $X$ & & & 12 & $\mathrm{X}$ \\
\hline $\begin{array}{l}\text { Rosalinda } \\
\text { Benitez }\end{array}$ & $\mathrm{RB}$ & $\mathrm{F}$ & $\mathrm{X}$ & & & 11 & $\mathrm{X}$ \\
\hline $\begin{array}{l}\text { Taite } \\
\text { Courington }\end{array}$ & TC & $\mathrm{F}$ & $X$ & & & 10 & \\
\hline $\begin{array}{l}\text { Francesca } \\
\text { Flores }\end{array}$ & FF & $\mathrm{F}$ & & & $X$ & 12 & $\mathrm{X}$ \\
\hline $\begin{array}{l}\text { Pamela } \\
\text { George }\end{array}$ & $P G$ & $\mathrm{~F}$ & & $X$ & & 10 & $\mathrm{X}$ \\
\hline Ana Gomez & $\mathrm{AG}$ & $\mathrm{F}$ & $X$ & & & 10 & $X$ \\
\hline $\begin{array}{l}\text { Lucia } \\
\text { Guido }\end{array}$ & $\mathrm{LG}$ & $\mathrm{F}$ & & & $X$ & 10 & $X$ \\
\hline $\begin{array}{l}\text { Nicole } \\
\text { Jackson }\end{array}$ & $\mathrm{NJ}$ & $\mathrm{F}$ & & $X$ & & 10 & $X$ \\
\hline $\begin{array}{l}\text { Charlotte } \\
\text { Lee }\end{array}$ & $\mathrm{CL}$ & $\mathrm{F}$ & $\mathrm{X}$ & & & 11 & \\
\hline $\begin{array}{l}\text { María } \\
\text { Mancipe }\end{array}$ & MM & $\mathrm{F}$ & & $X$ & & 12 & $\mathrm{X}$ \\
\hline $\begin{array}{l}\text { Daniela } \\
\text { Martinez }\end{array}$ & $\mathrm{DM}$ & $\mathrm{F}$ & $X$ & & & 12 & \\
\hline $\begin{array}{l}\text { Jennifer } \\
\text { Mason }\end{array}$ & $\mathrm{JM}$ & $\mathrm{F}$ & $\mathrm{X}$ & & & 10 & \\
\hline $\begin{array}{l}\text { Elizabeth } \\
\text { Mclean }\end{array}$ & EM & $\mathrm{F}$ & $\mathrm{X}$ & & & 12 & $X$ \\
\hline $\begin{array}{l}\text { Aubrey } \\
\text { Mercedes }\end{array}$ & $\mathrm{AM}$ & $\mathrm{F}$ & $\mathrm{X}$ & & & 11 & \\
\hline John Persie & JP & $\mathrm{M}$ & $X$ & & & 10 & \\
\hline $\begin{array}{l}\text { Bridget } \\
\text { Saunders }\end{array}$ & BS & $\mathrm{F}$ & $X$ & & & 11 & $X$ \\
\hline $\begin{array}{l}\text { Nicolasa } \\
\text { Salinas }\end{array}$ & NS & $\mathrm{F}$ & & $X$ & & 10 & $\mathrm{X}$ \\
\hline Mary Scott & MS & $\mathrm{F}$ & & $X$ & & 10 & \\
\hline $\begin{array}{l}\text { Rusty } \\
\text { Shaklford }\end{array}$ & RS & $\mathrm{M}$ & $\mathrm{X}$ & & & 11 & \\
\hline $\begin{array}{l}\text { Emma } \\
\text { Smith }\end{array}$ & ES & $\mathrm{F}$ & $X$ & & & 10 & \\
\hline Dan Smith & $\mathrm{DS}$ & $\mathrm{M}$ & $X$ & & & 11 & \\
\hline John Smith & JS & $M$ & $X$ & & & 10 & \\
\hline $\begin{array}{l}\text { Trevor } \\
\text { Smith }\end{array}$ & TS & $\mathrm{M}$ & $X$ & & & 10 & \\
\hline Bella Swan & BS- 10 & $\mathrm{~F}$ & $X$ & & & 10 & \\
\hline $\begin{array}{l}\text { Roberta } \\
\text { Totti }\end{array}$ & RT & $\mathrm{F}$ & $\mathrm{X}$ & & & 10 & \\
\hline $\begin{array}{l}\text { Mina } \\
\text { Washington }\end{array}$ & MW & F & $\mathrm{X}$ & & & 12 & $\mathrm{X}$ \\
\hline $\begin{array}{l}\text { Sammy } \\
\text { Wells }\end{array}$ & SW & $\mathrm{F}$ & $\mathrm{X}$ & & & 12 & $\mathrm{X}$ \\
\hline
\end{tabular}




\section{APPENDIX D: DOVER SPANISH IMMERSION PROGRAM GOALS AND CONTENT}

\section{Dover High School Spanish Immersion Goals:}

Our goal is to open the eyes and minds of the students to other important cultures. We want our students to learn Spanish well and use it in the community.

\section{Dover High School Spanish Immersion Course of Study}

\begin{tabular}{|c|c|c|c|}
\hline $\begin{array}{l}\text { NINTH } \\
\text { GRADE }\end{array}$ & $\begin{array}{l}\text { TENTH } \\
\text { GRADE }\end{array}$ & $\begin{array}{l}\text { ELEVENTH } \\
\text { GRADE }\end{array}$ & TWELFTH GRADE \\
\hline $\begin{array}{l}\text { Immersion I } \\
\text { (Spanish II) } \\
\text { Immersion Math } \\
\text { Immersion P.E. }\end{array}$ & $\begin{array}{l}\text { Immersion II } \\
\text { (Spanish III) } \\
\text { Immersion } \\
\text { Math } \\
\text { Immersion } \\
\text { World History }\end{array}$ & $\begin{array}{l}\text { Immersion III (AP } \\
\text { Spanish Language) } \\
\text { Immersion Service } \\
\text { Learning } \\
\text { Immersion Humanities } \\
\text { I or II }\end{array}$ & $\begin{array}{l}\text { Immersion IV (AP Spanish Literature } \\
\text { Immersion Media (Spanish through the } \\
\text { Media)/ } \\
\text { (Immersion through the Web) } \\
\text { Humanities I or II }\end{array}$ \\
\hline
\end{tabular}

\begin{tabular}{|l|l|}
\hline SUMMER CREDIT EXPERIENCES & IMMERSION ELECTIVES \\
\hline Immersion Field Experience & Immersion Service Learning \\
Immersion Spain & Immersion Field Experience \\
Immersion Mexico & Spanish Through the Web \\
& Spanish Through the Media \\
& Humanities I \\
& Humanities II \\
& Spanish Cinema \\
\hline
\end{tabular}




\section{Dover High School Spanish Immersion Curriculum}

\section{Spanish Imm1ersion $9^{\text {th }}$ grade}

Spanish Immersion I (Spanish language)

Cultural Content $=$ countries of Central and South America and Mexico

\section{Spanish Immersion $10^{\text {th }}$ grade}

Spanish Immersion II (Spanish Language)

¡Buen Viaje! Glencoe, McGraw-Hill, Schmitt, Conrad J.; Woodford, Protase E. (2000) (Spanish III High School text book)]

Cultural Content= focus is traditions, festivals, Quincañera, family events

Focus- topics

1. Los Viajes (travel- tourism)

2. Rutinas (daily life)

3. Pasatiempos (free time)

4. Pasajes (family events, birth, marriage)

5. Sucesos y Acontecimientos (history)

6. Los Valores (cultural values)

7. La Salud y el Bienestar (health, student health, well-being)

8. Raíces (ethnocultural origins) (Mayas, etc)

10th Grade Literature :

Spanish Literature (readings) Abriendo Paso Lectura; Díaz, Jose M. and Collins, Stephen J. Prentice Hall, Needham Massachusetts (2000)

Focus: includes short stories, poetry, theatre, from the print media 


\section{$11^{\text {th }}$ and $12^{\text {th }}$ Grade Courses}

Humanities I: No text books for this course

Humanities II

Civilización y Cultura (2003) Thomson/ Heinle, $8^{\text {th }}$ edition (college text book)

Focus- topics

1. Origins

a. Europe (Roman, Visigoth, Mayas, Arab)

b. Americas (Aztecs, Incas, Mayas)

2. Religion
a. Religion and society
b. Religion in your personal life
c. Religion in Hispano America

3. The family in the Hispanic world
a. Relationships
b. Family and politics
c. Family and society
d. Importance of family

4. Men and Women in Hispanic Society
a. Names
b. Patriarchal society
c. Women in Spanish literature
d. Women in politics

5. Customs and Beliefs
a. Schedule and social life
b. Talks about siestas, café life
c. Attitudes of Hispanics towards death
d. Attitudes of indigenous peoples towards death
e. Funeral practices

6. Economics in the Hispanic World

7. Revolutions
a. Revolución vs. Golpe de Estado
b. Revolución Mexicana de 1910
c. Bolivia 1952, Cuba 1959, Nicaragua 1979
d. Los Guerrilleros 
8. Famous Spanish Cities
a. Physical aspects
b. Urban life
c. Importance of the city in the Spanish-speaking world

9. USA and Hispanics
a. USA vs. Spain
b. USA vs. New Nations of the Americas

10. Spanish Presence in the US

Tradición y Cambio: Lecturas sobre la Cultura Latinoamericana Contemporánea (1997) Heyck, Denis, and Pagani, María, Boston: McGraw Hill.

Focus- topics

1. Introduction

Geography and Climate

Indigenous Civilizations

History from the Colonial Era $-20^{\text {th }}$ Century

Select Readings from Famous Authors

2. The Social Classes

Spanish Origins

Changes in Society

Select Readings from Famous Authors

3. Ethnic Origins

Ethnic Groups

Select Readings from Famous Authors

4. Contemporary Cities

The Growth of Cities

The City in Latin American History

Select Readings from Famous Authors

5. The Family

The Traditional Family

Changes in the Contemporary Family

Select Readings from Famous Authors 
6. Education

The Traditional System

Reform in Universities

Technical Education

Adult Literacy

Contemporary Challenges (ex: Bolivia, El Salvador)

Select Readings from Famous Authors

7. Religion

Historical Context

The Church as the Defender of the Poor

Heroes and Martyrs

Liberation Theology

Select Readings from Famous Authors

8. Cultural Criticism

The Intellectual and the State

National Identity

Machismo

The Military

Economic Development and the Environment

Select Readings from Famous Authors 


\section{Lake County World Languages}

Vision Statement

We envision that every Lake County school will integrate World Language studies to enhance learning in all subject areas and to help students to develop the desire and skills to become lifelong learners and responsible members of the global community.

\section{World Languages Mission Statement}

The mission of Lake County World Languages is to work in partnership with students, parents and the community to increase intercultural communications. We strive to motivate students who (are)

Able to communicate proficiently in two or more languages

Receptive to other cultures

Realize connections between their communities and others around the world World Languages in Lake County

Why begin learning a second language in elementary level?

Our children today will be

Communicating in languages other than English

Working in global or cross-cultural environments, and

Working with others to solve global challenges.

Elementary school children are at the most developmentally appropriate age to develop proficiency in a second language. Our content-integrated curriculum makes learning a second language and culture fun while providing students opportunities to make connections to other disciplines.

How often will this class be offered?

Initially, elementary students will receive instruction forty five minutes a week. What will my child be able to do with the language?

Benchmark checklists and fridge lists will come home periodically to help you know what your student is learning as well as what you can do at home to help enhance their second language experience. 